\title{
Functional Analysis and Post-Transcriptional Regulation of Oocyte-Specific Transcription Factors During Early Embryogenesis in Cattle
}

Swamy Krishna Tripurani

West Virginia University

Follow this and additional works at: https://researchrepository.wvu.edu/etd

\section{Recommended Citation}

Tripurani, Swamy Krishna, "Functional Analysis and Post-Transcriptional Regulation of Oocyte-Specific Transcription Factors During Early Embryogenesis in Cattle" (2011). Graduate Theses, Dissertations, and Problem Reports. 3381.

https://researchrepository.wvu.edu/etd/3381

This Dissertation is protected by copyright and/or related rights. It has been brought to you by the The Research Repository @ WVU with permission from the rights-holder(s). You are free to use this Dissertation in any way that is permitted by the copyright and related rights legislation that applies to your use. For other uses you must obtain permission from the rights-holder(s) directly, unless additional rights are indicated by a Creative Commons license in the record and/ or on the work itself. This Dissertation has been accepted for inclusion in WVU Graduate Theses, Dissertations, and Problem Reports collection by an authorized administrator of The Research Repository @ WVU.

For more information, please contact researchrepository@mail.wvu.edu. 


\title{
Functional Analysis and Post-Transcriptional Regulation of Oocyte-Specific Transcription Factors During Early Embryogenesis in Cattle
}

\author{
Swamy Krishna Tripurani
}

Dissertation submitted to the Davis College of Agriculture, Natural Resources and Design at West Virginia University in partial fulfillment of the requirements for the degree of

\author{
Doctor of Philosophy \\ in \\ Genetics and Developmental Biology \\ Jianbo Yao, Ph.D., Chair \\ Daniel G. Panaccione, Ph.D. \\ Matthew E. Wilson, Ph.D. \\ Jed H. Doelling, Ph.D. \\ Jorge A. Flores, Ph.D.
}

Division of Animal and Nutritional Sciences

Morgantown, WV

2011

KEYWORDS: Cattle, oocyte, early embryogenesis, NOBOX, FIGLA, Ubc9, microRNA and SUMOylation. 


\title{
ABSTRACT
}

\section{Functional Analysis and Post-Transcriptional Regulation of Oocyte-Specific Transcription Factors During Early Embryogenesis in Cattle}

\author{
Swamy Krishna Tripurani
}

Early embryonic loss is a major contributing factor to infertility in livestock species. A growing body of evidence implicates that oocyte-expressed genes especially the transcription factors are crucial functional mediators of oocyte and early embryonic development. Furthermore, small non-coding RNAs called microRNAs have been demonstrated to be important in regulating numerous biological processes. However, the identities and functions of oocyte-specific transcription factors and microRNAs during early embryogenesis are relatively unknown. Therefore, using bovine as a model the role of oocyte-specific transcription factors and microRNAs were investigated during early embryonic development.

Newborn ovary homeobox (NOBOX) is an oocyte-specific transcription factor essential for folliculogenesis and expression of many germ-cell specific genes in mice. However, the temporal and cell specific expression of NOBOX in bovine oocytes and potential function and regulation of NOBOX in early embryogenesis have not been described previously. Messenger RNA for bovine NOBOX is preferentially expressed in ovaries and undetectable by RT-PCR in somatic tissues examined. NOBOX protein is present in oocytes throughout folliculogenesis and is stage-specifically expressed during oocyte maturation and early embryonic development. Depletion of NOBOX in early embryos demonstrated that NOBOX is an essential maternal derived transcription factor during bovine early embryogenesis, which functions in regulation of embryonic genome activation, pluripotency gene expression and blastocyst cell allocation. Furthermore, a potential microRNA recognition element (MRE) for miR-196a was identified in the 3' UTR of the bovine NOBOX mRNA. miR-196a is expressed both in oocytes and embryos and tends to increase at the four-cell and eight-cell stage. Transient transfection and reporter assays revealed that miR-196a represses the expression of NOBOX in a MRE dependent manner. Ectopic expression of miR-196a mimic in bovine early embryos significantly reduced the NOBOX expression at the both mRNA and protein levels. Collectively, our results establish a novel functional role for NOBOX during early embryonic development. Results also provide evidence that miR-196a is a bona fide negative regulator of NOBOX during bovine early embryogenesis.

Factor In the GermLine Alpha (FIGLA), a basic helix-loop-helix transcription factor, is essential for primordial follicle formation and expression of many oocyte specific genes that are required for fertilization and early embryonic survival. Here we report the characterization of bovine FIGLA gene and its regulation during early embryogenesis. Expression of bovine FIGLA mRNA is restricted to gonads and is abundant in germinal vesicle and metaphase II stage oocytes, as well as in embryos from pronuclear to eight-cell stage, but barely detectable in embryos collected at morula and blastocyst stages, suggesting that FIGLA might be a maternal effect gene. Computational predictions identified a potential microRNA recognition element (MRE) for miR-212 in the 3' UTR of the bovine FIGLA mRNA. Bovine miR-212 is expressed in 
oocytes and tends to increase at the four-cell and eight-cell stage embryos followed by a decline at morula and blastocyst stages. Transient transfection and reporter assays revealed that miR212 represses the expression of FIGLA in a MRE dependent manner. Furthermore, ectopic expression of miR-212 mimic in bovine early embryos dramatically reduced the expression of FIGLA mRNA and protein. Collectively, our results demonstrate that FIGLA is spatio-temporally regulated during bovine early embryogenesis and miR-212 is an important negative regulator of FIGLA during the maternal to zygotic transition in bovine embryos.

Small endogenous RNA molecules, termed microRNAs (miRNAs), are evidenced for their involvement in the regulation of gene expression during folliculogenesis and early embryonic development. To identify miRNAs expressed in bovine oocytes/ovaries, we constructed a bovine fetal ovary miRNA library. Sequence analysis of random clones from the library identified 679 miRNA sequences, which represent 58 distinct bovine miRNAs. Of these distinct miRNAs, 42 are known bovine miRNAs and the remaining 16 miRNAs include 15 new bovine miRNAs that are homologous to miRNAs identified in other species, and one novel miRNA, which does not match any miRNAs in the database. Expression analysis of the 58 miRNAs in fetal ovaries in comparison to somatic tissue pools identified 8 miRNAs predominantly expressed in fetal ovaries, of these eight miRNAs, two miRNAs (bta-mir424 and bta-mir-10b) are highly abundant in germinal vesicle (GV)-stage oocytes and are differently expressed during oocyte maturation and early embryonic development. Expression of the novel miRNA is relatively low in oocytes and early cleavage embryos but high in blastocysts, suggesting a role of this miRNA in blastocyst cell differentiation. This study reports the cloning of 58 miRNAs from bovine fetal ovaries, discovery of new bovine miRNAs including one that is completely novel, and identification of two miRNAs that are highly abundant in oocytes and early cleavage embryos.

Sumoylation is a post-translational modification in which a SUMO (small-ubiquitin-related modifier) moiety is conjugated to specific proteins involved in transcriptional regulation, protein transport, chromosome segregation and signal transduction via an enzymatic cascade. SUMOconjugating enzyme Ubc9, which is highly conserved across species, is essential for several developmental processes. As the first step towards understanding the physiological role of bovine Ubc9, we analyzed the expression of Ubc9 mRNA in bovine tissues including fetal ovaries of different developmental stages, and characterized the temporal expression patterns of Ubc9 mRNA and protein during oocyte maturation and early embryogenesis. Bovine Ubc9 is ubiquitously expressed in all tissues and is highly abundant in fetal ovaries of late gestation. Real time PCR analysis and immunocytochemical analysis demonstrated that expression of Ubc9 mRNA and protein is abundant in germinal vesicle (GV) and metaphase II (MII) stage oocytes, as well as in early embryos, but decreases between eight-cell and blastocyst stage, suggesting that Ubc9 might be a maternal effect gene. We performed yeast two-hybrid assay to identify putative SUMO substrates from a bovine fetal ovary library using Ubc9 as bait. A total of nine interacting clones were identified including three clones encoding activating transcription factor 7 interacting protein 2 (ATF7IP2). Inspection of the ATF7IP2 sequence using SUMOsp 2.0 software program predicted two high probability putative SUMO attachment sites, indicating that ATF7IP2 is a potential SUMO substrate. ATFIP2 is gonad specific and is expressed in fetal ovaries harvested as early as 90 days of gestation and tends to increase with increased gestational age. ATF7IP2 is stage-specifically expressed during oocyte maturation and early embryonic development. Collectively, our results suggest that Ubc9 is developmentally regulated in cattle and it interacts with ATF7IP2, a gonad-specific protein, which might play an important role during folliculogenesis and early embryonic development. 


\section{DEDICATION}

I would like to dedicate my research study to my advisor Dr. Jianbo Yao. Without his vision and guidance, this work would not have been possible, and I certainly wouldn't be here. I truly grew both as a researcher and a person while working with him and I cannot find enough words to express my gratitude. 


\section{ACKNOWLEDGEMENTS}

Foremost, I would like to express my sincere gratitude to my advisor Dr. Jianbo Yao for giving me the opportunity to work in his lab, and for his patience, motivation, enthusiasm, and immense knowledge during my graduate career. I could not have imagined having a better advisor and mentor for my Ph.D study.

I gratefully acknowledge Dr. Daniel G. Panaccione, Dr. Matthew E.Wilson, Dr. Jed H. Doelling and Dr. Jorge A. Flores for serving on my graduate committee and for their assistance in contributing to my research. I specially want to thank Dr. Dale Karlson and Dr. Barton Baker for giving me the opportunity to start my career at West Virginia University. I am grateful to Dr. Paul Lewis, Dr. Keith Inskeep and Dr. Robert Dailey for their insight and wisdom as well as passing along their knowledge and enthusiasm for science.

I wish to express my warm and sincere thanks to Dr. George W. Smith at Michigan State University for his support and guidance during my research. His extensive discussions around my work and interesting explorations in operations have been very helpful for this study. My warm thanks to Dr. Kyung-Bon Lee and Dr. Gabbine Wee at Michigan State University. Their kind support and guidance have been of great value in this study.

I wish to thank my best friend Prashanthi Mulinti and her family for helping me get through the difficult times, and for all the emotional support, camaraderie, entertainment, and caring they provided.

I would like to thank my labmates Dr. Ma, Dr. Salem, Lei Wang, Nan Qi, Dr. Zhang and Nina for their constant support and laboratory assistance.

Lastly, and most importantly, I would like to thank my family especially my parents for their love, encouragement and un-wavering support. Having such a wonderful family support system has always been one of the keys to my success and I thank them from the bottom of my heart. 
I owe my deepest gratitude to my grandmother, who was a woman of great courage and integrity. Even though she passed away, she continues to be a source of inspiration that has given me the strength to get through every challenge that I have faced.

The financial support of Division of Animal and Nutritional Sciences and Division of Plant and Soil sciences at West Virginia University is gratefully acknowledged. 


\section{LIST OF PUBLICATIONS}

\section{Publication-1}

Swamy K. Tripurani, K B. Lee, L. Wang, G. Wee, G W. Smith Y.S. Lee, K E. Latham, and J. Yao. 2011. A novel functional role for the oocyte-specific transcriptional factor newborn ovary homeobox (NOBOX) during early embryonic development in cattle. Endocrinology, 152(3): 1013-1023.

\section{Publication-2}

Swamy K. Tripurani, K. Nakaminami, K B. Thompson, S V. Crowell, C L. Guy and D T. Karlson. 2011. Spatial and temporal expression of cold-responsive DEAD-box RNA helicases reveals their functional roles during embryogenesis in Arabidopsis thaliana. Plant molecular biology reporter, (DOI: 10.1007/s11105-010-0282-1).

\section{Publication-3}

B M. Lingenfelter, Swamy K. Tripurani, J. Tejomurtula, G W. Smith and J. Yao. 2011 Molecular cloning and expression of bovine nucleoplasmin 2 (NPM2): a maternal effect gene regulated by miR-181a. Reproductive biology and Endocrinology, (DOI: 10.1186/1477-7827-9-40).

\section{Publication-4}

Swamy K. Tripurani, Xiao.C, M.Salem, and J. Yao. 2010. Cloning and analysis of fetal ovary- microRNAs in cattle. Animal Reproduction Science, 120: 16-22.

\section{Publication-5}

J. Tejomurtula, K B. Lee, Swamy K. Tripurani, G W. Smith, and J. Yao. 2009. Role of importin alpha8, a new member of the importin alpha family of nuclear transport proteins, in early embryonic development in cattle. Biology of Reproduction, 81 (2): 333-342. 


\section{Publication-6}

Swamy K. Tripurani, G. Wee, K B. Lee, G W. Smith and J. Yao. MicroRNA-196a regulates bovine newborn ovary homeobox gene (NOBOX) expression during early embryogenesis. (Submitted to BMC Developmental Biology). 


\section{TABLE OF CONTENTS}

ABSTRACT

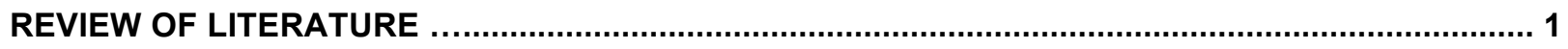

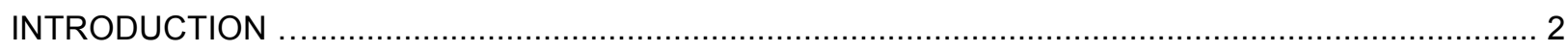

POTENTIAL CONTRIBUTION OF OOCYTE SPECIFIC TRANSCRIPTIONAL AND POSTTRANSCRIPTIONAL REGULATORS TO BOVINE OOCYTE COMPETENCE: AVAILABLE EVIDENCE AND GAPS IN KNOWLEDGE 3

MATERNAL-OOCYTE DERIVED FACTORS REQUIRED SPECIFICALLY FOR EARLY

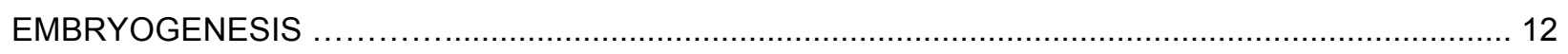

FUNCTIONAL GENOMICS STUDIES OF BOVINE OOCYTE COMPETENCE: IDENTIFICATION OF

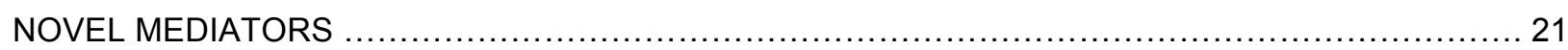

MICRORNAs: SMALL NON-CODING RNA REGULATORS OF DEVELOPMENT $\ldots \ldots \ldots \ldots \ldots \ldots \ldots \ldots . \ldots \ldots$ SUMOYLATION: A NOVEL POST-TRANSLATIONAL MODIFICATION IN REGULATING MAMMALIAN

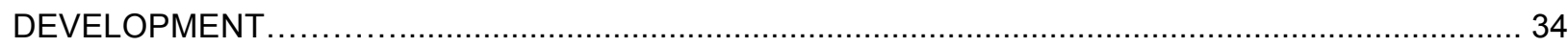

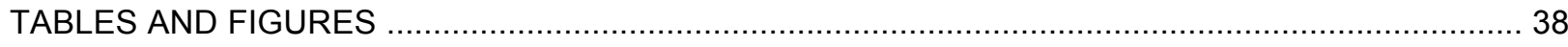

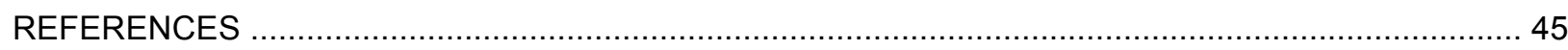

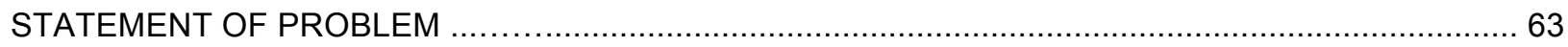

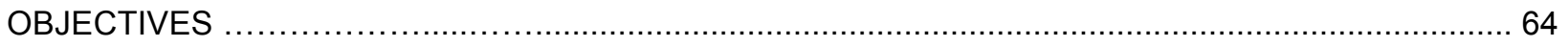


CHAPTER 1: A novel functional role for the oocyte-specific transcription factor newborn ovary homeobox (NOBOX) during early embryonic development in cattle ......................................... 66

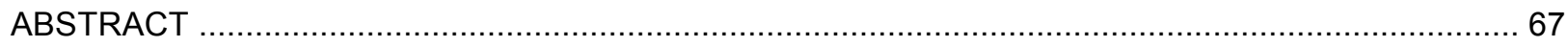

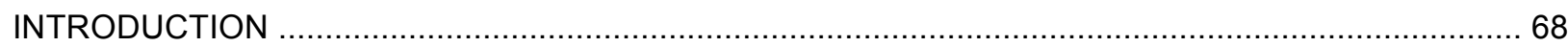

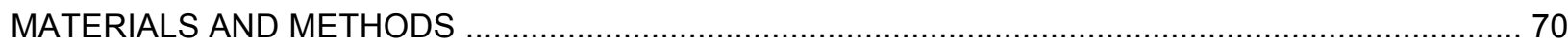

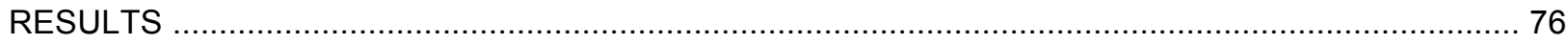

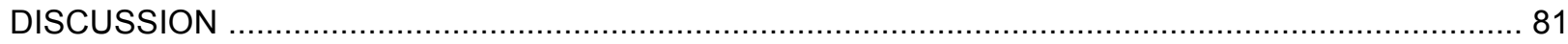

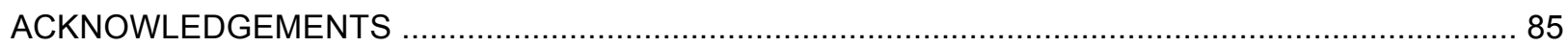

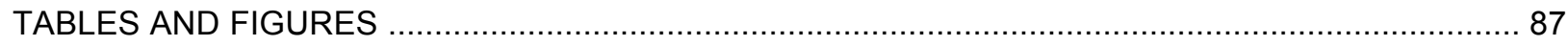

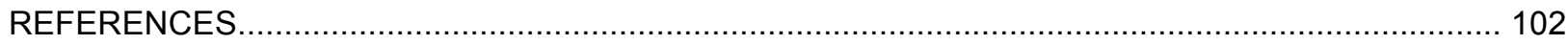

CHAPTER 2: MicroRNA-196a regulates bovine newborn ovary homeobox gene (NOBOX)

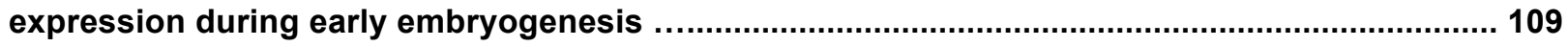

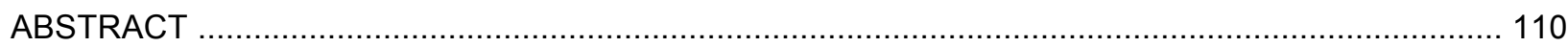

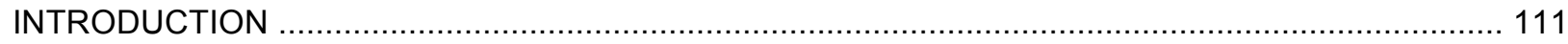

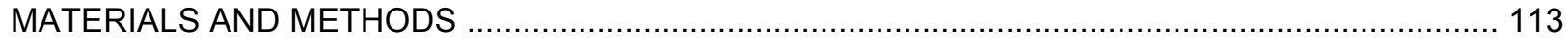

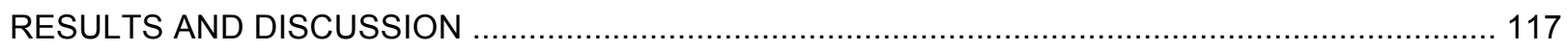

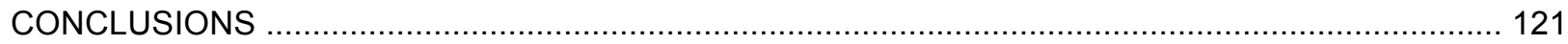

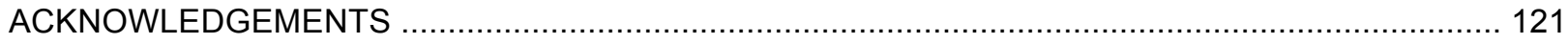

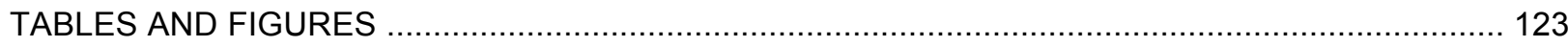

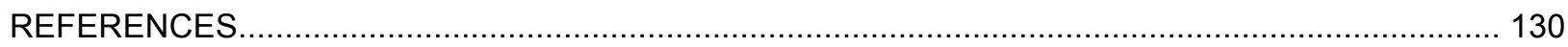

CHAPTER 3: Cloning and analysis of fetal ovary microRNAs in cattle .................................... 137

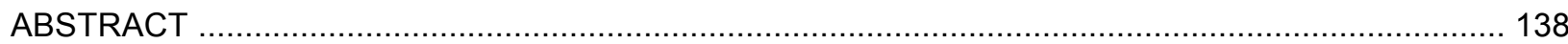

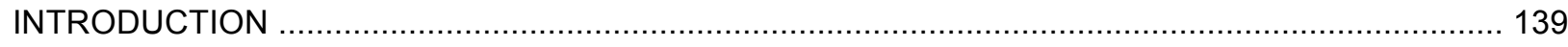

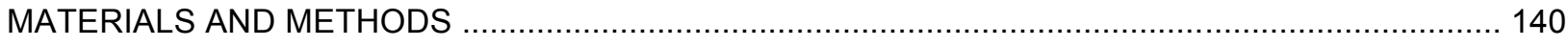

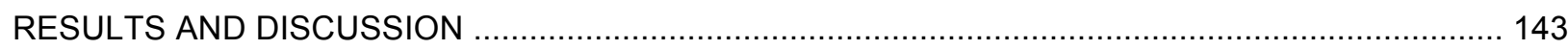

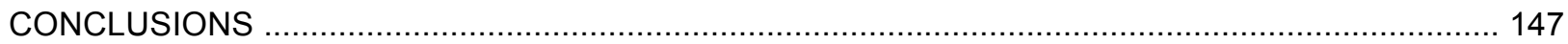




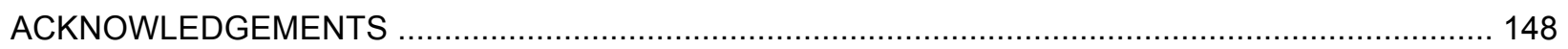

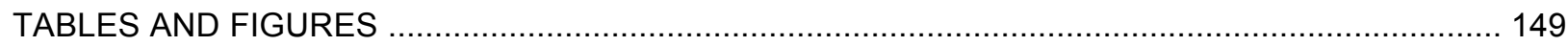

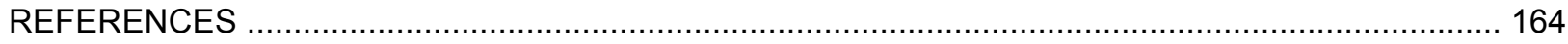

APPENDIX 1: Cloning and expression of bovine factor in the germline alpha (FIGLA) in oocytes

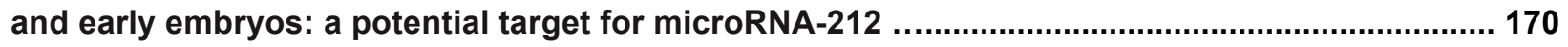

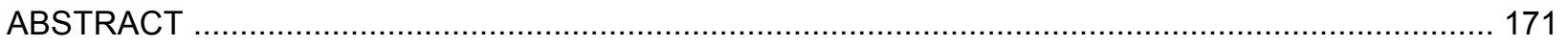

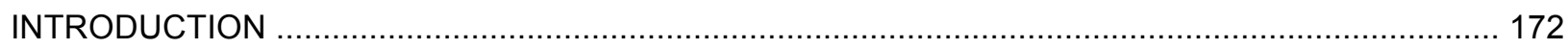

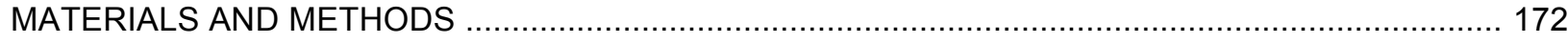

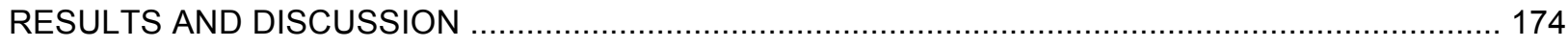

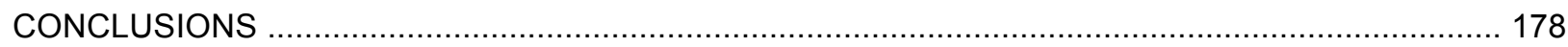

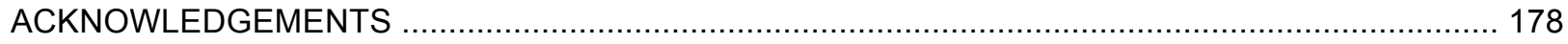

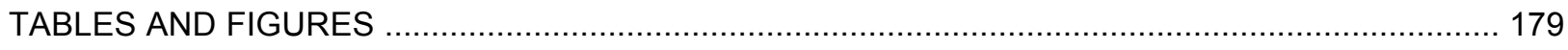

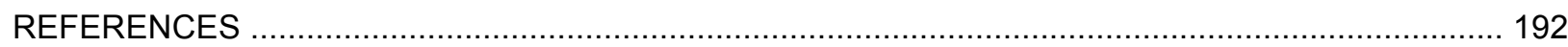

APPENDIX 2: The SUMO-conjugating enzyme Ubc9 is developmentally regulated and interacts with activating transcription factor 7 interacting protein 2 (ATF7IP2) in cattle............................. 195

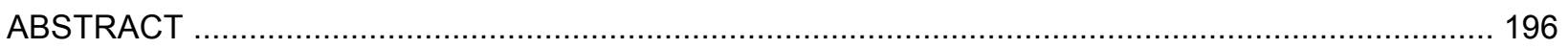

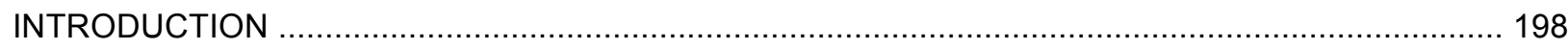

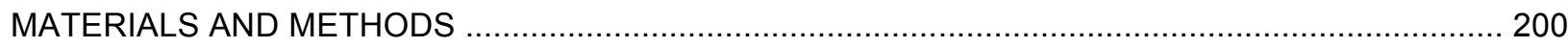

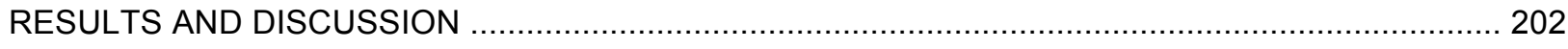

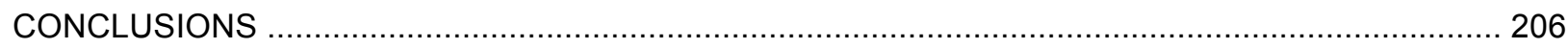

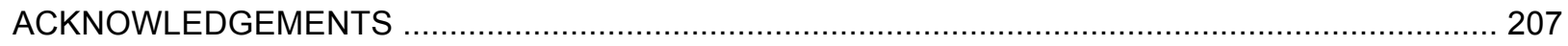

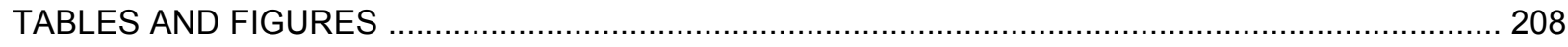

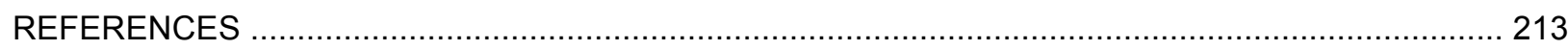

Curriculum Vitae 


\section{LIST OF TABLES}

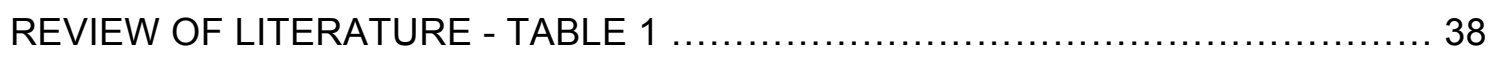

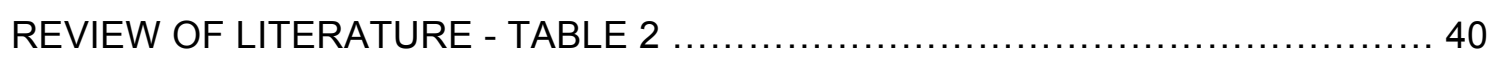

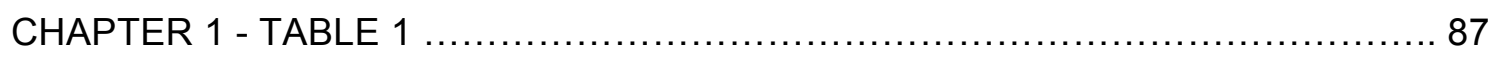

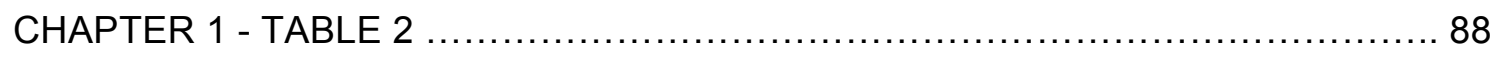

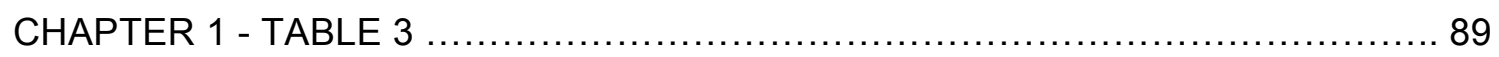

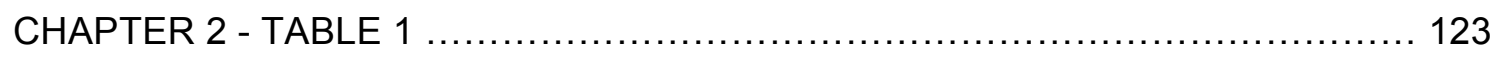

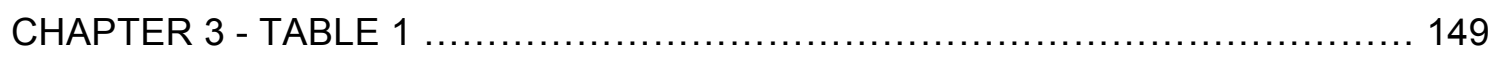

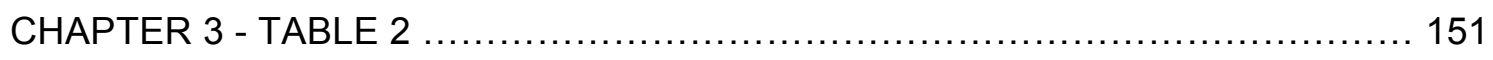

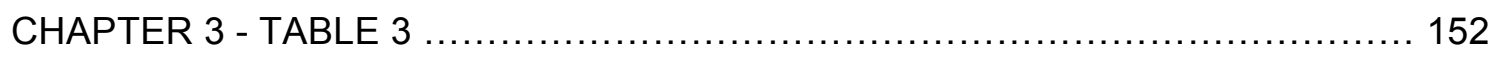

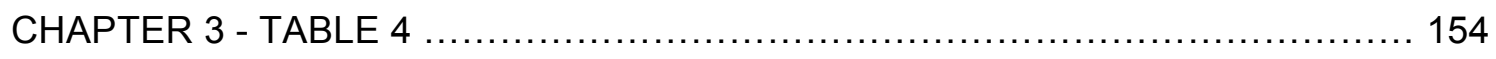

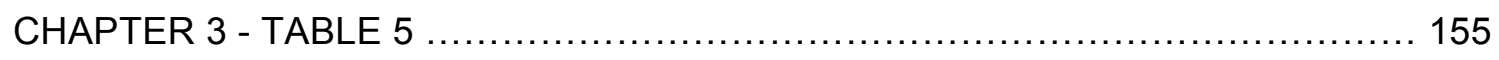

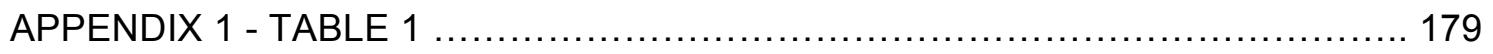

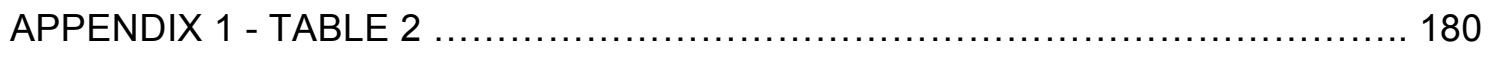

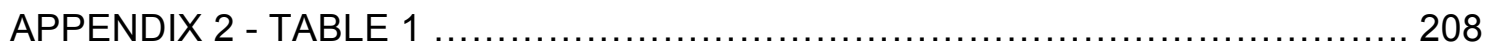

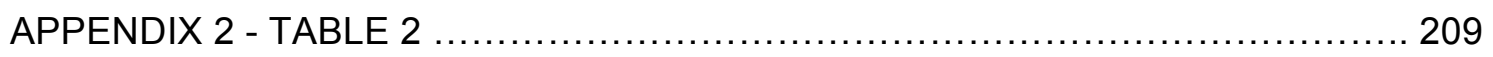




\section{LIST OF FIGURES}

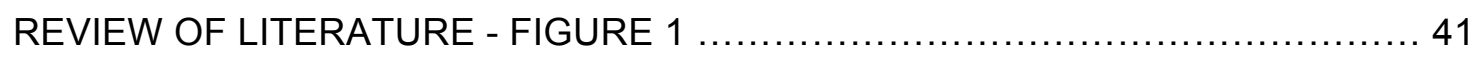

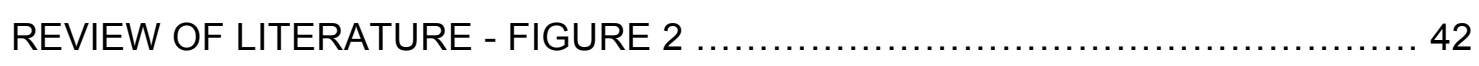

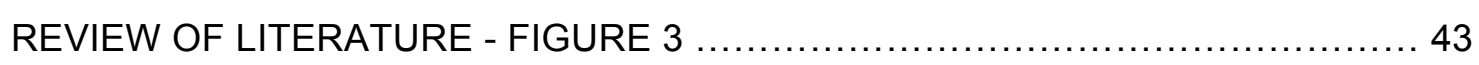

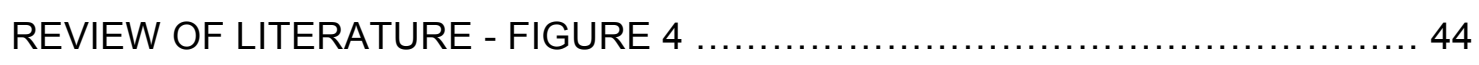

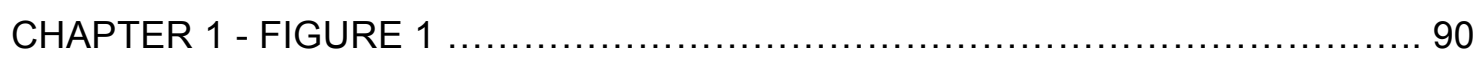

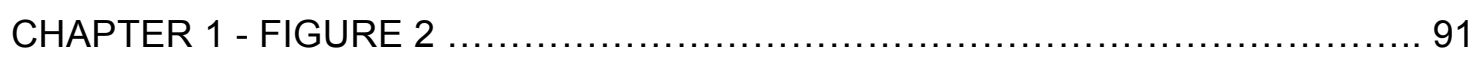

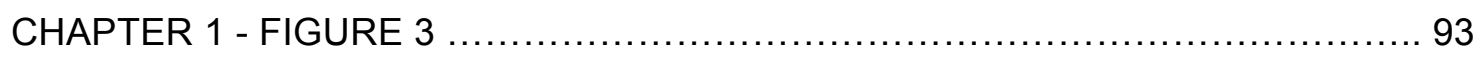

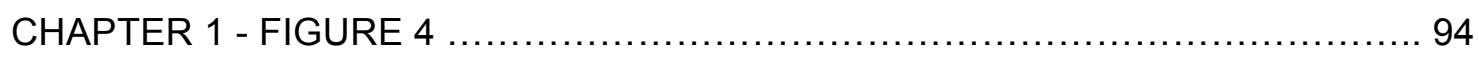

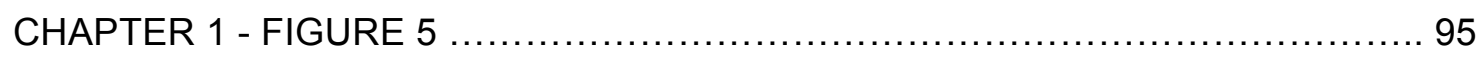

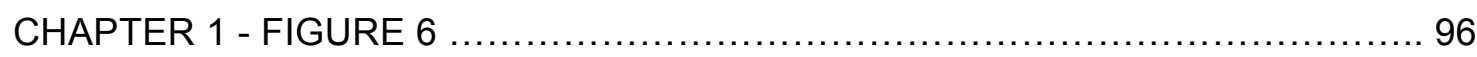

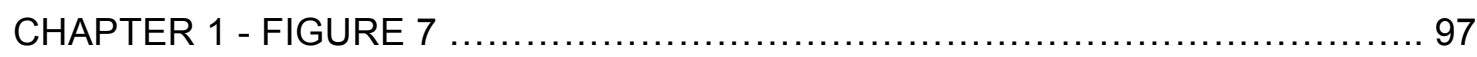

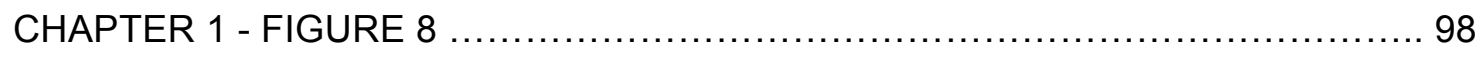

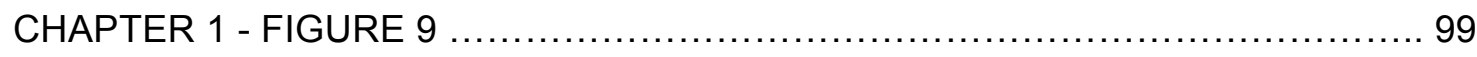

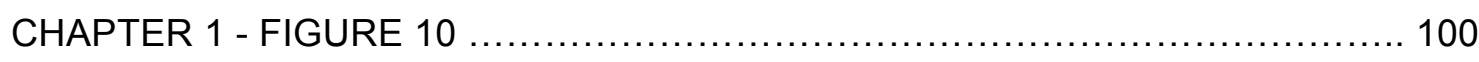

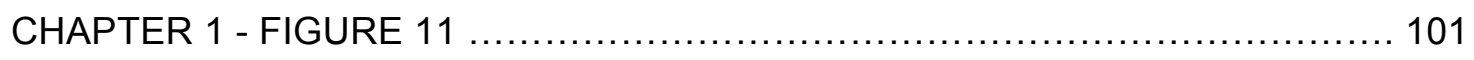

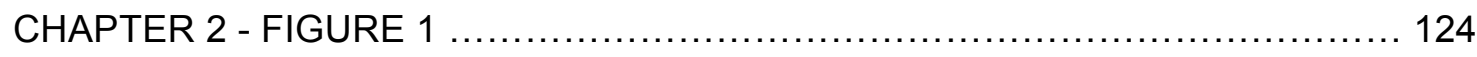

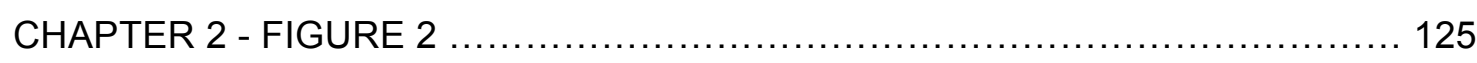

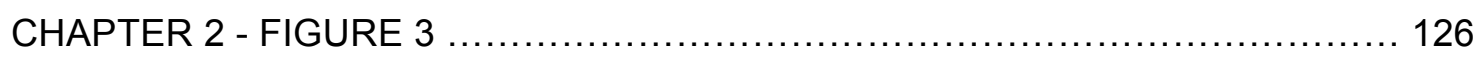

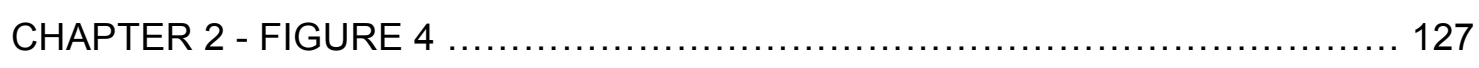

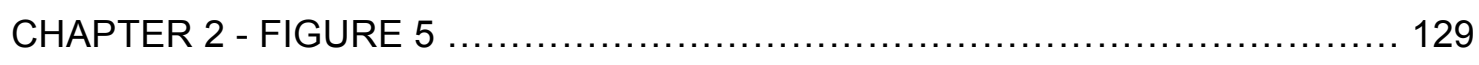

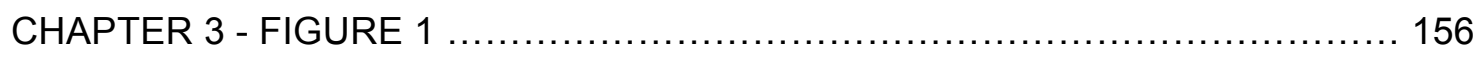




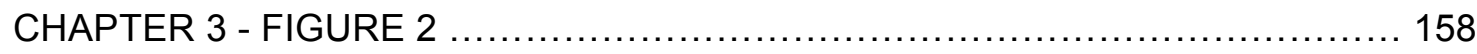

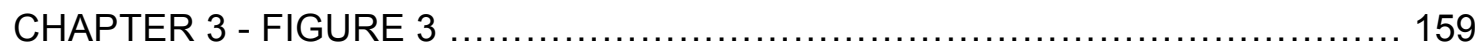

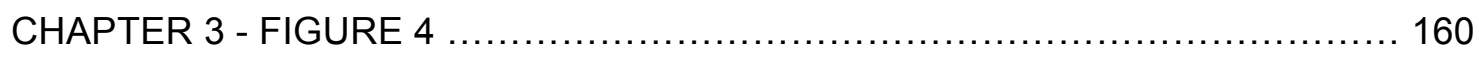

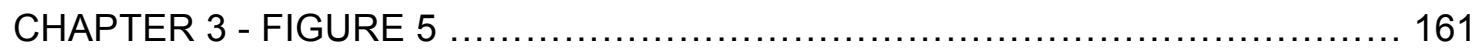

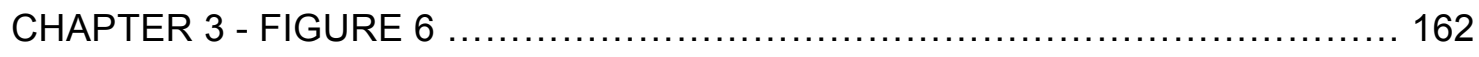

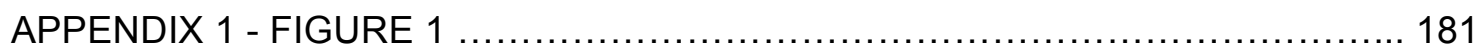

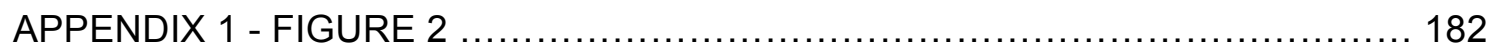

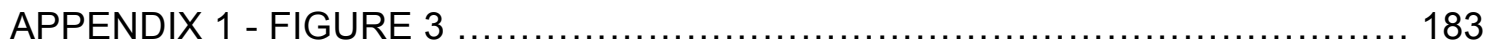

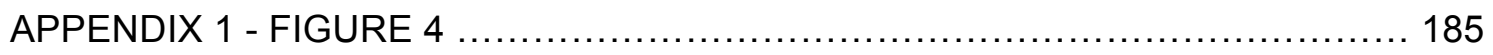

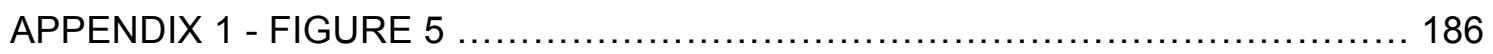

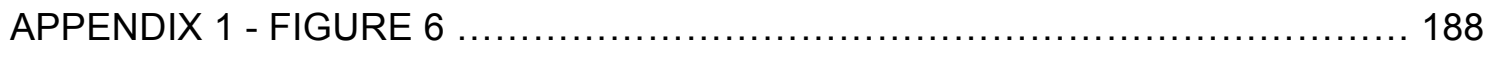

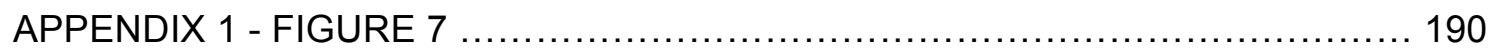

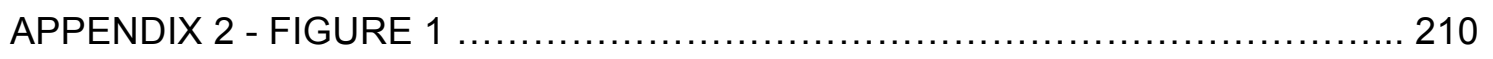

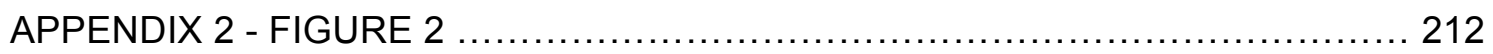




\section{LIST OF ABREVIATIONS}

Ago2 (Eif2c2)

ATG5

ATP

Bax

$\mathrm{Bcl} 2$

$\mathrm{Bcl} 2 \mathrm{I} 2$

bHLH

BMP15

Bnc1

bp

Brwd1

C

$\mathrm{Ca}^{+2}$

Casp2

cDNA

CCNE1

CKS1B

Cpeb1

Ctcf

Cx43

D

DAPI

Dazla
Eukaryotic Translation Initiation Factor 2C, 2

Autophagy-Related 5

Adenosine Triphosphate

Bcl2-associated $X$ protein

B-cell Lymphoma 2

B-cell Lymphoma 2 like Protein 2

Basic Helix-Loop-Helix

Bone Morphogenetic Protein15

Basonuclin1

Base pairs

Bromodomain and WD repeat domain containing 1

Centigrade

Calcium

Caspase 2

Complementary DNA

Cyclin E1

Cyclin Kinase Subunit $1 \mathrm{~B}$

Cytoplasmic Polyadenylation Element Binding protein 1

Connective Tissue Growth Factor

Connexin 43

Days

4', 6-diamidino-2-phenylindole

Deleted in Azoospermia-like Autosomal 


\begin{tabular}{|c|c|}
\hline Dnmt1 & DNA Methyltransferease 1 \\
\hline dsRNA & double stranded RNA \\
\hline$E$ & Embryonic day \\
\hline EGA & Embryonic Genome Activation \\
\hline EGF & Epidermal Growth Factor \\
\hline EST & Expressed Sequence Tags \\
\hline $\mathrm{F}$ & Forward \\
\hline Fgf8 & Fibroblast Growth Factor 8 \\
\hline Figla & Factor In the Germline Alpha \\
\hline Floped & Factor Located in the Oocyte Permitting Development \\
\hline $\mathrm{FSH}$ & Follicle Stimulating Hormone \\
\hline FST & Follistatin \\
\hline FOXD3 & Forkhead Box D3 \\
\hline FZD8 & Frizzled homolog 8 \\
\hline GDF9 & Growth Differentiation Factor 9 \\
\hline GDNF & Glial cell line-Derived Neurotrophic Factor \\
\hline GST & Glutathione S-Transferase \\
\hline GV & Germinal Vesicle \\
\hline $\mathrm{H}$ & Hours \\
\hline $\mathrm{H} 100$ & Oocyte-specific Histone H1 \\
\hline hpi & Hours Post Insemination \\
\hline Hsf1 & Heat Shock Transcription Factor 1 \\
\hline ICM & Inner cell mass \\
\hline JAG1 & Jagged 1 \\
\hline $\mathrm{kb}$ & Kilobase \\
\hline KLF5 & Kruppel-like Factor 5 \\
\hline
\end{tabular}




\begin{tabular}{|c|c|}
\hline Kpna7 & Importin alpha 8 \\
\hline Lhx8 & LIM homeobox 8 \\
\hline LH & Luteinizing Hormone \\
\hline M II & Metaphase II \\
\hline MATER & Maternal Antigen That Embryos Require \\
\hline MET & Maternal-to-Embryonic transition \\
\hline $\mathrm{MeV}$ & Multiexperiment Viewer \\
\hline MHS 5 & MutS protein Homolog 5 \\
\hline Min & Minutes \\
\hline miRNA & microRNA \\
\hline MLH1 & mutL Homolog 1 \\
\hline $\mathrm{mM}$ & Millimolar \\
\hline MOS & Proto-oncogene serine/threonine-protein kinase \\
\hline mRNA & Messenger RNA \\
\hline $\mathrm{nM}$ & Nanomolar \\
\hline $\mathrm{NaN}_{3}$ & Sodium Azide \\
\hline NBE & NOBOX Binding Elements \\
\hline Neg & Negative \\
\hline NIrp 14 & NLR family, Pyrin domain containing 14 \\
\hline NOBOX & Newbornovary Homeobox \\
\hline NPM2 & Nucleoplasmin 2 \\
\hline Oosp1 & Oocyte-secreted Protein 1 homolog \\
\hline Obox & Oocyte-specific homeobox \\
\hline PADI6 & Peptidyl Arginine Deiminase, type VI \\
\hline PBS & Phosphate Buffered Saline \\
\hline
\end{tabular}




\begin{tabular}{|c|c|}
\hline PHD & Plant Homeo-Domain \\
\hline PITX2 & Paired-Like Homeodomain 2 \\
\hline $\mathrm{pl}$ & Pico liter \\
\hline POU & Pit, Oct, Unc \\
\hline $\mathrm{R}$ & Reverse \\
\hline RACE & Rapid Amplification of cDNA Ends \\
\hline Rfpl4 & Ret Finger Protein-Like 4 Gene \\
\hline RNA & Ribonucleic acid \\
\hline RNAi & RNA inteference \\
\hline RPL 15 & Ribosomal Protein L15 \\
\hline RPL 19 & Ribosomal Protein L19 \\
\hline RRM & RNA-Recognition Motif \\
\hline RT-PCR & Reverse Transcription Polymerase Chain Reaction \\
\hline SAC & Spindle Assembly Checkpoint \\
\hline SAGE & Serial Analysis of Gene Expression \\
\hline Sall4 & Sal-like 4 \\
\hline SCMC & Sub Cortical Maternal Complex \\
\hline SCP1 and SCP2 & Sarcoplasmic Calcium-binding Protein 1 \\
\hline $\mathrm{Sec}$ & Seconds \\
\hline SENP1 & Sentrin-specific Protease 1 \\
\hline Sohlh1 and Sohlh2 & $\begin{array}{l}\text { Spermatogenesis and Oogenesis Specific Basic Helix- } \\
\text { Loop-Helix } 1 \text { and } 2\end{array}$ \\
\hline shRNA & Short-hairpin RNA \\
\hline SiRNA & Small interfering RNA \\
\hline Smarca4 & $\begin{array}{l}\text { SWI/SNF related, matrix associated, actin dependent } \\
\text { regulator of chromatin }\end{array}$ \\
\hline
\end{tabular}




\begin{tabular}{ll} 
SNBP & Sperm Nuclear Binding Proteins \\
SOX2 & SRY (sex determining region Y)-box 2 \\
SSH & Suppressive Subtractive Hybridization \\
SUMO & Small Ubiquitin-related Modifier \\
TE & Trophectoderm \\
TGF- $\beta$ & Transforming Growth Factor- $\beta$ \\
tRNA & Transfer RNA \\
Trim24 & Tripartite Motif-containing 24 \\
Ube2a & Ubiquitin-conjugating Enzyme E2A \\
Ubls & Ubiquitin-like proteins \\
UTR & Untranslated Region \\
WEE1 & WEE1 homolog \\
Ybx2 & Y box protein 2 \\
Zar1 & Zygote Arrest 1 \\
Zp2 & Zona Pellucida 2 \\
Zp3 & Zona Pellucida 3 \\
$\mu$ I & Microgram \\
$\mu l$ & Microliter \\
\hline
\end{tabular}


REVIEW OF LITERATURE 


\section{INTRODUCTION}

Oocyte developmental competence is defined as the capacity of the oocyte to resume meiosis, cleave after fertilization, help promote embryonic development and implantation, and bring a pregnancy to term in good health (Krisher, 2004, Picton et al., 1998, Sirard et al., 2006). Oocytes gradually and sequentially acquire developmental competence during the course of folliculogenesis, by synthesizing and accumulating transcripts and proteins that are of importance for successful folliculogenesis, germ cell maturation, fertilization, and early embryogenesis, and are the functional mediators of oocyte competence (Eppig, 2001, Eppig et al., 2002, Hussein et al., 2006). The development of transgenic mouse models and availability of vast arrays of DNA sequence information in the forms of complete genome, expressed sequence tags libraries and suppressive subtractive hybridization (SSH) and microarray data has been critical in identifying and revealing how oocyte-specific transcripts are essential to above oocyte developmental milestones and how they could be functionally associated with poor oocyte competence (Andreu-Vieyra et al., 2006). Our lab has placed considerable emphasis in recent years to understand the functional role of oocyte-derived gene products in promoting early embryogenesis and determination of oocyte competence in cattle. We have utilized a combination of functional studies of candidate genes of interest selected based on published reports in the mouse and functional studies of genes identified using genomic tools in the bovine model system hypothesized to be important for oocyte competence and early embryogenesis. Given the relative lack of data in other mammalian species, this chapter summarizes current knowledge obtained from studies in the mouse regarding the functional role of select candidate oocyte-specific genes (transcriptional and post transcriptional regulators) potentially relevant to oocyte competence in cattle. Available information and gaps in knowledge in the bovine model system (Table 1), where much of the published data is descriptive, are emphasized. In the second part of this chapter, major emphasis is placed on recent insights 
gained (using functional genomics approaches) into novel oocyte expressed genes that confer oocyte competence and are critical for early embryogenesis in cattle.

\section{Potential contribution of oocyte-specific transcriptional and post-transcriptional regulators to bovine oocyte competence: Available evidence and gaps in knowledge}

The ovarian follicle is the functional unit of the ovary, and consists of the oocyte and its associated somatic cells (granulosa, theca and cumulus cells). Folliculogenesis involves a series of highly regulated sequential steps in which a growing follicle either develops to the ovulatory stage or dies by apoptosis. Progression through follicular development is a prerequisite for acquisition of oocyte competence, as $>99 \%$ of bovine follicles become arrested in development at various stages of folliculogenesis, die via atresia and never have the opportunity to release an oocyte to be fertilized. The major steps in folliculogenesis include the primordial/primary transition, the primary/secondary transition, selection, and atresia. The delicate interplay of developing oocytes and somatic cells is controlled and orchestrated through several endocrine factors [follicle stimulating hormone ( $\mathrm{FSH}$ ) and luteinizing hormone (LH) (Danforth, 1995, Moley and Schreiber, 1995), autocrine and paracrine regulators such as TGF- $\beta$ family members (Elvin et al., 2000), the insulin-like growth factor system (Schams et al., 1999), inhibins/activins (Knight and Glister, 2001) and gap junctional communication (connexins) (Kidder and Mhawi, 2002). With the advent of genomics and gene knockout studies, several oocyte specific transcription factors, RNA binding proteins and growth factors were identified and are proved to play essential role in mammalian folliculogenesis (Andreu-Vieyra et al., 2006, Choi and Rajkovic, 2006b, Epifano and Dean, 2002, Pangas, 2007). The list of known oocytespecific genes required for normal development of germ cells and surrounding somatic cells during folliculogenesis continues to expand and currently includes Figla (Factor in the germline 
alpha) (Soyal et al., 2000), Nobox (Newborn ovary homeobox) (Rajkovic et al., 2004), Sohlh1 and Sohlh2 (spermatogenesis and oogenesis specific basic helix-loop-helix 1 and 2) (Ballow et al., 2006, Pangas et al., 2006), Obox (Oocyte-specific homeobox) (Rajkovic et al., 2002), Dazla (deleted in azoospermia-like autosomal) (Ruggiu et al., 1997), Ybx2 (Y box protein 2) (Gu et al., 1998), Cpeb1 (cytoplasmic polyadenylation element binding protein 1) (Racki and Richter, 2006), Gdf9 (Growth differentiation factor 9) (Dong et al., 1996) and Bmp15 (Bone morphogenetic protein15) (Dube et al., 1998) (Fig. 1). These genes encode for a compilation of transcription factors, mRNA binding proteins and secreted proteins expressed in the oocyte and surrounding somatic cells in some instances. Such genes play important regulatory roles in control of follicle formation and germ cell development, regulation of granulosa cell proliferation and steroidogenesis and in some instances also impact early embryonic development (Fig. 1). To date, the functional role of above oocyte/germ cell specific transcription factors and post transcriptional regulators (RNA binding proteins, translational regulators) during the initial stages of early embryogenesis has largely been overlooked, often times due to defects in folliculogenesis in gene targeting models. However, this potential functional role may be of significance particularly to species such as cattle with a longer interval between fertilization to transfer of developmental control to the products of the embryonic genome (maternal-toembryonic transition). The known functional role of such transcriptional and post-transcriptional regulators in the mouse and potential significance to early embryonic development in the bovine species is outlined below.

\section{A. Factor in the germline alpha (Figla)}

Factor in the germline alpha (Figla) encodes a germ-cell specific basic-helix-loop-helix (bHLH) transcription factor (Liang et al., 1997). Figla is a major regulator of the zona pellucida protein genes (Zp2 and Zp3) (Liang et al., 1997). Mouse Figla transcript is expressed as early as embryonic day (E) E13.5 in the female gonad and persists throughout folliculogenesis (Soyal 
et al., 2000). Female Figla knockout mice are infertile (Soyal et al., 2000). Germ cell migration and proliferation and development of embryonic gonads appear normal in female Figla knockout mice (Soyal et al., 2000). However, the formation of primordial follicles is blocked and oocytes are rapidly lost in a matter of a few days (Soyal et al., 2000). As expected Zp1, Zp2, and Zp3 transcripts are not detectable in the ovaries of the Figla knockout mice (Soyal et al., 2000), but important genes such as Gdf9, Bmp15, Kit, Kitl, Cx43 (connexin 43) and Fgf8 (fibroblast growth factor 8) are present in ovaries of both knockout and wild type animals. These observations indicate that Figla plays a key regulatory role in at least two independent oocyte- specific pathways, those that initiate folliculogenesis and those that regulate expression of the zona pellucida protein genes (Soyal et al., 2000) (Fig. 1). A comparison of normal and Figla knockout mice ovaries by microarray and serial analysis of gene expression (SAGE) identified several oocyte specific genes, including maternal effect genes, that are directly or indirectly regulated by Figla (Joshi et al., 2007). Recently, it was shown that expression of Figla is a critical not only for activation of oocyte-associated genes but also for repression of sperm-associated genes during postnatal oogenesis (Hu et al., 2010).

In humans, Figla is expressed as early as 14 weeks gestational age with a dramatic increase in the midgestation (time of primordial follicle formation) (Bayne et al., 2004). Electrophoretic mobility shift assays with in vitro-expressed human Figla protein showed that, as in the mouse, Figla can heterodimerize with E12 protein and bind to the E-box of the human ZP2 promoter, suggesting a similar conserved function of the human and mouse Figla protein. Furthermore, mutations in the Figla gene are associated with premature ovarian failure in humans (Zhao et al., 2008). All these findings suggest that Figla is a critical transcriptional regulator that is required to sustain transcription of its target genes that may be critical both in folliculogenesis and early embryonic development. However, the functional role and regulation of Figla during early embryogenesis is lacking. 


\section{B. Newborn ovary homeobox-encoding gene (Nobox)}

Nobox was identified by in silico subtraction of expressed sequence tags (ESTs) derived from the newborn ovaries of mice (Suzumori et al., 2002). Nobox mRNA is preferentially expressed in germ cells, is detectable in embryonic ovaries as early as E15.5 and is present in oocytes throughout all stages of folliculogenesis (Rajkovic et al., 2004, Suzumori et al., 2002). Female mice lacking Nobox have apparently normal embryonic ovarian development, germ cell migration and form primordial follicles perinatally (Rajkovic et al., 2004). However, growth of primordial follicles and development from the primordial to primary follicle stage is severely compromised (Rajkovic et al., 2004). Nobox deletion also accelerates the loss of oocytes, such that by 14 days post-partum only a few remain in ovaries of mutant mice (Rajkovic et al., 2004). Gene expression analysis in newborn ovaries (before pronounced germ cell depletion) revealed abundance of mRNA for numerous genes preferentially expressed in oocytes, such as Mos, Oct4, Rfp/4, Fgf8, Zar1, Dnmt1o, Gdf9, Bmp15, and H10o is reduced in ovaries of Nobox knockout mice whereas transcripts for genes important in germ cell migration (Kitl and Kit), apoptosis (Bc/2, Bcl2/2, Casp2, and Bax) and meiosis (Mlh1 and Msh5) display similar expression levels in ovaries of wild type and Nobox knockout mice (Rajkovic et al., 2004). Furthermore, Nobox has been shown to bind to putative Nobox binding elements with high affinity and regulate transcriptional activity of mouse Gdf9 and Oct4 genes (Choi and Rajkovic, 2006a) (Fig. 1). In humans, Nobox is oocyte-specific, with expression observed from the primordial stage ovarian follicle through to the metaphase II (MII) oocyte (Huntriss et al., 2006). Furthermore, mutations in the Nobox gene associated with premature ovarian failure have been described in humans (Qin et al., 2009; Zhao et al., 2005). These findings suggest that Nobox is an important transcriptional regulator that either directly or indirectly regulates a subset of genes preferentially expressed in postnatal oocytes, some of which have been shown to play essential roles in oogenesis. However, the temporal and cell specific expression of NOBOX in bovine oocytes and potential function of NOBOX in early embryogenesis is unknown. 


\section{Spermatogenesis and Oogenesis specific basic helix-loop-helix $1 / 2$ and LIM homeodomain transcription factor 8 (Sohlh1, Sohlh2 and Lhx8)}

Sohlh1 and Sohlh2 encode germ cell specific basic helix-loop-helix transcription factors. These genes were discovered using an in silico subtraction strategy to identify genes that are preferentially expressed during early folliculogenesis in mice (Ballow et al., 2006, Pangas et al., 2006). Sohlh1 and Sohlh2 transcripts are expressed in E15.5 and E13.5 embryonic ovaries (Ballow et al., 2006, Pangas et al., 2006). Sohlh1 and Sohlh2 proteins are detectable in germ cell cysts, primordial follicles, and primary follicles but undetectable by the secondary follicle stage, suggesting that regulation of Sohlh1 and Sohlh2 may be important for early folliculogenesis (Ballow et al., 2006, Pangas et al., 2006) (Fig. 1).

Female mice lacking Sohlh1 appears to have normal germ cell migration and embryonic gonadogenesis, but form imperfect primordial follicles that do not progress to primary follicle stage (Pangas et al., 2006). Ovaries of Sohlh1 knockout mice contain significantly lower amounts of Figla transcripts and transcripts for the Figla target genes Zp1 and Zp2 (Pangas et al., 2006). Nobox transcripts are also reduced approximately 4-fold in Sohlh1 knockout ovaries. In addition, oocyte specific genes that were down regulated in ovaries of Nobox knockout mice were also down regulated in Sohlh1 knockout ovaries, confirming that the Nobox pathway is compromised in Sohlh1 mutant mice and that Nobox functions downstream of Sohlh1 (Pangas et al., 2006) (Fig. 1).

Microarray analysis of ovaries of Sohlh1 knockout mice also revealed that the LIM homeodomain transcription factor, $L h x 8$, is down regulated in the absence Sohlh1 (Pangas et al., 2006). Lhx8 is preferentially expressed in testes and ovaries and localizes to oocytes of germ cell cysts and primordial, primary, and antral follicles (Pangas et al., 2006). Lhx8 mRNA expression is detectable as early as E13.5 and mimics embryonic ovary expression of Sohlh1 (Pangas et al., 2006). Ovaries of $L h x 8$ knockout mice fail to maintain primordial follicles, and the transition from primordial to growing follicles does not occur (Choi et al., 2008a). Oocyte-specific 
genes, such as Nobox, Gdf9, Oct4, and Zp3 also show abnormal expression in the ovaries of Lhx8 knockout mice (Choi et al., 2008a). Furthermore chromatin immunoprecipitation and luciferase reporter assay revealed that Sohlh1 binds to the conserved E box element found in the proximal promoter region of Lhx8, Nobox, Zp1 and Zp3 (Pangas et al., 2006). Collectively, results indicate that Sohlh1 and $L h x 8$ are master oocyte transcription factors functionally linked to folliculogenesis and Sohlh1 acts upstream of Lhx8, Figla, and Nobox.

Sohlh2 deficiency in female mice accelerates postnatal oocyte loss in the ovary and causes infertility (Choi et al., 2008b). Sohlh2 knockout mice form primordial follicles and, despite limited oocyte growth, do not differentiate surrounding granulosa cells into cuboidal and multilayered structures (Choi et al., 2008b). In addition, Sohlh2 deficiency affects the expression of numerous genes in oocytes (Nobox, Figla, Gdf9, Pou5f1, Zp1, Zp3, Oosp1, NIrp14, H1foo, Stra8) including Sohlh1 (Choi et al., 2008b). These findings show that Sohlh1 and Sohlh2 are critical for early follicle formation and development and oocyte survival and that Sohlh1 and Sohlh2 play distinct yet important roles (Choi et al., 2008b).

To our knowledge, there have been no published studies on Sohlh1, Sohlh2 and Lhx8 expression in bovine oocytes and early embryos. It would be interesting to know whether these transcription factors are also linked to normal early embryonic development in cattle and help mediate gene expression changes coincident with embryonic genome activation.

\section{Oocyte-specific homeobox gene family (Obox)}

Obox (oocyte-specific homeobox) genes have been referred to as the first homeobox gene family preferentially expressed in mouse adult germ cells (Cheng et al., 2007, Rajkovic et al., 2002). Obox1 and Obox2 were identified in adult mouse germ cells using in silico subtraction strategies (Rajkovic et al., 2002). Obox1 and Obox2 transcripts encode homeodomain proteins and share $97 \%$ identity with each other (Rajkovic et al., 2002). Nucleotide sequence analysis of BACs encoding Obox1 and Obox2 and BLAST searches 
against the publicly available mouse genome database identified Obox3, Obox4, Obox5, and Obox6, which share significant homology to Obox1 and Obox2. Northern blot and RT-PCR analysis revealed that five of six Obox genes are preferentially expressed in gonads (ovary) (Rajkovic et al., 2002). In situ hybridization analysis of Obox1 and Obox6 revealed their transcripts are exclusively expressed in oocytes throughout folliculogenesis (Rajkovic et al., 2002). Mice lacking Obox6 undergo normal embryonic development and are fertile indicating a functional Obox6 gene is not obligatory for fertility (Cheng et al., 2007). However the roles of other Obox gene family members are currently unknown in mice and to our knowledge, no information is available on expression of Obox genes in bovine oocytes and early embryos. Lack of phenotype in Obox6 knockout mice suggests potential functional redundancy amongst Obox gene family members, but studies are needed to understand their expression and potential contribution to early embryogenesis in cattle.

\section{E. Deleted in Azoospermia Like gene (Dazl)}

The Deleted in Azoospermia Like (Dazl) gene is a member of the Deleted in Azoospermia (DAZ) family, expressed exclusively in germ cells. Protein products for Dazl gene family members contain a highly conserved RNA-binding motif and a unique DAZ repeat (Yen, 2004). In humans and mouse the Dazl gene is expressed in both the testis and the ovary (Brekhman et al., 2000, Cooke et al., 1996, Ruggiu et al., 1997), Dazl knockout mice ovaries contain steroidogenically active cells capable of producing estradiol and inhibin, despite a total loss of oocytes during fetal life (McNeilly et al., 2000) and absence of follicular structures. The Dazl protein in mice functions in regulating protein translation in germ cells by interacting with PABP-binding protein (Collier et al., 2005, Padmanabhan and Richter, 2006) and also in maintaining pluripotency and genetic and epigenetic modifications during germ cell development (Haston et al., 2009). 
There is limited information on Dazl expression and function in oocytes of other species relevant to a potential functional role in the bovine species. In cattle, the Dazl gene is expressed exclusively in testis and ovary and thought to play an important role in spermatogenesis (Liu et al., 2007, Zhang et al., 2008). In pigs, Dazl mRNA and protein is localized to the oocyte throughout folliculogenesis and oocyte maturation (Liu et al., 2009). Furthermore, addition of factors such as glial cell line-derived neurotrophic factor (GDNF), epidermal growth factor (EGF), and follicle-stimulating hormone (FSH) that are known to enhance oocyte maturation and developmental competence, increased the expression of Dazl in oocytes derived from the small and large antral follicles during in vitro maturation, Such results indicate that that these factors play a potential role in promoting Dazl expression, which may subsequently affect translational regulation of key proteins associated with oocyte maturation and subsequent embryonic development (Liu et al., 2009). Interestingly, in human blastocysts, the presence of Dazl transcripts was only detectable in blastocysts of good quality (Cauffman et al., 2005). Therefore, results from other species indicate Dazl functions in germ cell differentiation, folliculogenesis and oocyte maturation. Given the importance of translational regulatory mechanisms in the maternal-to embryonic transition (Bettegowda and Smith, 2007), investigation of the link between Dazl expression and bovine oocyte competence holds merit.

\section{F. Y box protein 2 (Msy2)}

Y-Box proteins are multifunctional proteins that are implicated in translational regulation via their ability to stabilize and or prevent translation of specific mRNAs. In addition, some members are also involved in the sub cellular localization or transport of mRNAs by interacting with cytoskeletal proteins (Matsumoto et al., 1996, Ruzanov et al., 1999, Sommerville and Ladomery, 1996). The Y-box protein 2 (synonym, Msy2) is a germ-cell specific DNA/RNA binding protein and a member of a cold-shock domain protein super family that is conserved from bacteria to humans (Wolffe et al., 1992). Msy2 contains the cold shock domain that is 
highly conserved among all $\mathrm{Y}$ box proteins and four basic/aromatic islands that are closely related to the other known germline $\mathrm{Y}$ box proteins from Xenopus (Frgy2), (Tafuri and Wolffe, 1990) and gold fish (Gfyp2) (Katsu et al., 1997). In the ovary, Msy2 is present exclusively in diplotene-stage and mature oocytes ( $\mathrm{Gu}$ et al., 1998). Msy2 constitutes about $2 \%$ of the total protein in the fully-grown oocyte, but after fertilization, it is totally degraded by the late two-cell stage in mice. Female mice lacking Msy2 are infertile due to increased oocyte loss, anovulation and multiple follicular defects (Yang et al., 2005). Furthermore transgenic RNAi mediated reduction of Msy2 results in abnormal intracellular $\mathrm{Ca}^{2+}$ oscillations, chromatin morphology, meiotic spindle formation and protein synthesis during maturation (Yu et al., 2004). Collectively, evidence in mice supports a requirement of Msy2 for oocyte survival, follicular development and fertility, presumably by stabilization and translational regulation of mRNAs critical to oocyte development and survival.

A similar Msy2 expression pattern as observed in mouse is characteristic of bovine embryos (Vigneault et al., 2004b) where expression is low to undetectable after embryonic genome activation (8-cell stage). Observed temporal expression patterns suggest Msy2 may also play a functional role during initial stages of early embryonic development (Vigneault et al., 2004a, Yu et al., 2001, Yu et al., 2002), particularly in cattle. However, direct evidence of such a requirement for Msy2 during early embryogenesis is lacking.

\section{G. Cytoplasmic polyadenylation element-binding protein1 (Cpeb1)}

Cpeb is an RNA-recognition motif (RRM) and zinc-finger-containing sequence-specific RNA-binding protein that is found in a wide range of vertebrates and invertebrates (Richter, 2007). Cpeb proteins are often referred to as Cpeb1. Cpeb1 regulates mRNA translation and, through this activity, influences gametogenesis and early development (Mendez and Richter, 2001, Racki and Richter, 2006, Tay et al., 2003). Adult female Cpeb1 knockout mice contain vestigial ovaries that are devoid of oocytes, but ovaries from mid-gestation embryos contain 
oocytes that are arrested at the pachytene stage due to the absence of protein components (SCP1 and SCP2) which are targets of Cpeb1 and critical for formation of synaptonemal complexes (Tay and Richter, 2001). Further, to assess the function of Cpeb1 later during oocyte development, transgenic mice were generated in which short-hairpin RNA (shRNA) against Cpeb1 was placed under the control of the zona pellucida $3(Z p 3)$ promoter which is transcribed after the pachytene stage (Racki and Richter, 2006). Oocytes from the ZP3-Cpeb1 shRNA transgenic mice do not develop normally. Such oocytes undergo parthenogenetic cell division in the ovary, exhibit abnormal polar bodies, are detached from the cumulus granulosa cell layer and display spindle and nuclear anomalies. Follicular development is also impacted as follicles containing such oocytes exhibit apoptotic granulosa cells (Racki and Richter, 2006). In addition, Cpeb1 has been shown to bind RNA transcripts for several key oocyte expressed genes (Racki and Richter, 2006) and Cpeb1 knockdown oocytes displayed reduced expression of Gdf9, which is important determinant of follicular development.

Some information is available on Cpeb1 expression in bovine oocytes. Cpeb1is localized in oocyte cytoplasm and is hyperphosphorylated during the prophase/metaphase-I transition. Most Cpeb1 is degraded in metaphase-II bovine oocytes and Cpeb1 degradation is prevented in the presence of meiotic inhibitors such as roscovitine (Uzbekova et al., 2008). Like data for Msy2 and Daz1 knockout animals, evidence from Cpeb1 knockout/knockdown studies illustrates the importance of translational regulatory mechanisms and specific molecular mediators to oocyte development and acquisition of competence. To our knowledge, Cpeb1 expression in early bovine embryos has not been examined. However, a role for maternally derived Cpeb1 in translational regulation during the maternal-to-embryonic transition post fertilization in cattle seem unlikely given the massive degradation of Cpeb1 that accompanies progression of bovine oocytes to metaphase II.

\section{Maternal-oocyte derived factors required specifically for early embryogenesis:}


In numerous species, early embryonic development is characterized by important developmental transitions that occur following fertilization (Schultz et al., 1999), including the replacement of maternal with zygotic RNAs, compaction, the first lineage differentiation into inner cell mass and trophectoderm and implantation. First chronologically and hence most important to the focus of this review is the maternal to embryonic transition defined as the time period during embryonic development beginning at fertilization until control of early embryogenesis changes from regulation by oocyte-derived factors to regulation by products of the embryonic genome (embryonic genome activation) (Bettegowda et al., 2008a). In mice, embryonic genome activation occurs during the two-cell stage, but it begins during the four-cell stage in humans, rats and pigs, and during the eight-cell to 16-cell stage in cattle and sheep (Telford et al., 1990) (Fig. 2). In bovine embryos, minor genome activation is initiated as early as the one-cell stage and referred to as minor genome activation (Memili and First, 1999), but the significance of minor genome activation to development is not clear. Progression to the eightcell stage is not dependent on new transcription as development can occur when embryos are cultured in the presence of inhibitors of transcription. Several studies using techniques like microarray, gene-knockout and RNAi have proved that products of numerous maternal effect genes transcribed and stored during oogenesis mediate the maternal-to-embryonic transition (Cui et al., 2007, Paradis et al., 2005, Sun et al., 2008, Wianny and Zernicka-Goetz, 2000). Maternal factors have several prominent functions during the maternal-to-embryonic transition (Li et al., 2010, Schultz, 2002). The first function is the removal of maternal RNA and protein. A second role is to promote dramatic reprogramming of both male and female genomes from a repressed chromatin state to one favoring transcription and a third function of maternal factors is robust activation of the embryonic genome. Such factors also help mediate initial cleavage divisions post fertilization.

In the mouse, above described developmental transitions are accompanied by orchestrated expression of transcription factors (Hsf1, Bnc1, Ctcf, Oct4 and Sox2), chromatin 
remodeling factors (Ube2a, Npm2, Trim24, Smarca4 and Brwd1), DNA methylation machinery (Dntm1, Dppa3 and Zfp57), genes involved in degradation of maternal factors (Dicer1, Ago2 and Atg5) and genes involved in the preimplantation development (Zar1, Mater (NIrp5), Floped, Padi6 and Filia). However, only those that are uniquely expressed in oocytes and functionally linked to early embryonic development (Mater, Floped, Zar1, Npm2, Dppa3 and Oct4) (Table 1) will be discussed below.

\section{A. Maternal antigen that embryos require (Mater)}

Maternal antigen that embryos require (Mater) was identified as an antigen associated autoimmune oophoritis in the mouse and thought to play a role in autoimmune premature ovarian failure (Tong and Nelson, 1999). Subsequent studies demonstrated an important functional role for Mater in early embryonic development. Mater is a single copy gene exclusively expressed by germ cells during oogenesis and is present in early cleavage stage embryos, but barely detectable at the blastocyst stage in several species (Ma et al., 2009, Pennetier et al., 2006b, Pennetier et al., 2004, Tong et al., 2002, Tong et al., 2004). Mater knockout mice have normal folliculogenesis and ovulate oocytes that can be fertilized (Tong et al., 2000). Although resulting zygotes can progress through the first cleavage division, subsequent development is arrested at the two-cell stage leading to a sterile phenotype in homozygous null females (Tong et al., 2000). De novo RNA transcription is decreased in the one- and two-cell embryos lacking Mater. Nevertheless, two-cell embryos lacking Mater were able to synthesize the transcription-requiring complex, indicating that Mater is not critical for initiation of embryonic genome activation (Tong et al., 2000).

Li et al. recently identified a subcortical maternal complex (SCMC) that assembles during oocyte growth and is essential for zygotes to progress beyond the first embryonic cell division ( $\mathrm{Li}$ et al., 2008). The SCMC, located in the subcortex of oocytes, is excluded from regions of cell-cell contact in the cleavage-stage embryo and segregates to the outer cells of 
the morula and blastocyst. At least four maternally encoded proteins contribute to this complex: Floped, Mater and Tle6 interact with each other, and Filia binds independently to Mater (Li et al., 2008). Filia was originally identified as a Mater binding partner preferentially expressed in growing oocytes (Ohsugi et al., 2008). Both Filia and Mater co-localize to the cytocortex of ovulated oocytes, where the stability of Filia is dependent on presence of Mater (Ohsugi et al., 2008). Additionally, depletion of maternal stores of Filia impairs preimplantation embryo development with a high incidence of aneuploidy that results from abnormal spindle assembly, chromosome misalignment, and spindle assembly checkpoint (SAC) inactivation (Zheng and Dean, 2009).

Available evidence also indicates Mater may also function as an oocyte specific maternal effect gene in cattle. Mater mRNA and protein are present in bovine oocyte from the primary follicle stage onwards (Pennetier et al., 2006a). Mater mRNA is decreased during meiotic maturation and through initial cleavage divisions and is low to undetectable in morula and blastocyst stage bovine embryos, whereas Mater protein persists through the blastocyst stage (Pennetier et al., 2006a). To our knowledge, a potential functional role of Mater and it binding partner Filia during bovine oocyte and early embryonic development has not been investigated. However, no relationship between Mater transcript abundance and oocyte quality was observed in two established models (prepubertal calf and brilliant cresyl blue staining) used to identify oocytes of reduced developmental competence in cattle (Mota et al., 2010, Romar et al., 2011). Investigation of potential existence of a SCMC and a functional role for Mater and Filia in early bovine embryos merits further investigation.

\section{B. Factor located in oocytes permitting embryonic development (Floped)}

Floped was identified by screening SAGE libraries derived from ovaries of normal and Figla null mice. Floped is exclusively expressed in the ovary, and within the ovary, expression is restricted to growing oocytes (Li et al., 2008). During early embryonic development Floped 
transcripts are present in one-cell stage embryos, but barely detectable from 2-cell to blastocyst stage. Female Floped null mice are infertile, but have normal ovarian histology, folliculogenesis and oogenesis (Li et al., 2008). Oocytes from Floped mutant mice can be fertilized and normalappearing 1-cell zygotes recovered. However, progression from one-cell to two-cell stage is delayed and blastomeres within embryos from Floped mutant mice often appear unequal in size with attenuated contact regions (Li et al., 2008).

As stated above, Mater, Tle6 and Filia were identified as potential binding partners of Floped and components of the SCMC ( $\mathrm{Li}$ et al., 2008). Tle6, a mammalian homolog of the Groucho gene from drosophila, belongs to the Groucho/Tle super family of transcriptional corepressors known to play a critical role in a range of developmental processes (Bajoghli, 2007). Tle6 is predominantly expressed in ovaries similar to Floped and Mater (Li et al., 2008). There is no SCMC and sub cortical localization of Mater, Tle6 and Filia is absent in the oocytes from Floped null mutant animals and sub cortical localization of Tle6, Filia and Floped is absent in oocytes from Mater null mutant animals indicating that existence of the SCMC depends upon the presence of Floped and Mater (Li et al., 2008). The similar expression pattern of the four genes, the physical interactions of the four cognate proteins, and their colocalization in conjunction with the sterile phenotype of Floped and Mater mutant female mice has established existence of the SCMC potentially required for progression through early cleavage stages of preimplantation development. Comparative studies of the functional role of above genes, and the existence and function of the SCMC in early embryogenesis in cattle both merit further investigation to determine potential species specificity in function of maternal effect genes during early embryogenesis.

\section{Zygote arrest 1 (Zar1)}

Zar1 was identified in mice by subtractive hybridization and cDNA library screening $(\mathrm{Wu}$ et al., 2003a). Zar1 mRNA and protein are preferentially expressed in oocytes throughout 
folliculogenesis, persist in one-cell embryos, but are markedly diminished by the two-cell stage and absent in embryos from four-cell through blastocyst stages (Wu et al., 2003a). Orthologs of Zar1 have been identified and characterized for human, rat, frog, zebrafish, bovine, ovine and chicken (Bebbere et al., 2008, Brevini et al., 2004, Michailidis et al., 2010, Wu et al., 2003b). Zar1 knockout mice have normal ovarian development and folliculogenesis, and ovulated eggs lacking Zar1 can be fertilized (Wu et al., 2003a). However, in contrast to the Mater null embryos, Zar1 null embryos block predominantly at the one-cell stage (Wu et al., 2003a). Additional analysis of the arrest in development showed that the maternal and paternal genomes remain separate in discrete pronuclei in Zar1 null zygotes, and the two haploid genomes do not unite, resulting in incomplete fertilization (Wu et al., 2003a). Despite containing a PHD (plant homeodomain) motif, the cytoplasmic localization of Zar1 does not support a role in gene regulation and its absence in embryos do not affect the synthesis of the transcription requiring complex associated with embryonic genome activation. However the precise mechanisms and potential interacting proteins associated with Zar1 modulation of fertilization and early embryogenesis have yet to be determined (Wu et al., 2003a).

RT-PCR studies in cattle indicate expression of ZAR1 is gonad specific and that Zar1 is present in early embryos (Uzbekova et al., 2006). To our knowledge, evidence supporting a functional requirement of Zar1 for normal early embryogenesis in cattle has not been reported. However, abundance of Zar1 mRNA is lower in oocytes harvested from prepubertal animals (model of poor oocyte quality) compared to oocytes harvested from adults (Romar et al., 2011). The potential functional contribution of Zar1 to progression through early embryonic development in cattle merits further investigation.

\section{Nucleoplasmin 2 (Npm2)}

The nucleoplasmin (NPM) family of nuclear chaperones has three members: Npm1, Npm2 and Npm3 (Frehlick et al., 2007). These proteins have a conserved N-terminal protease- 
resistant core region domain, a classical bipartite nuclear localization signal and a C-terminal tail domain, containing up to two additional amino acid tracts of variable length between the family members (Frehlick et al., 2007). Npm1 and Npm3 are ubiquitously expressed in various tissues (Frehlick et al., 2007). Npm2 is an oocyte-specific nuclear protein that binds to histones and mediates the assembly of nucleosomes from DNA and histone proteins (Laskey et al., 1978). It also binds sperm nuclear binding proteins (SNBPs) in order to facilitate decondensation and remodeling of paternal chromatin following fertilization (Philpott and Leno, 1992, Philpott et al., 1991). Within the mouse ovary, Npm2 transcripts are present exclusively in oocytes throughout folliculogenesis, as well as early embryos, but barely detectable in embryos at morula and blastocyst stages (Burns et al., 2003). Female Npm2 knockout mice are sub fertile or infertile (Burns et al., 2003). Oogenesis and folliculogenesis are normal, except the DNA in the Npm2 null oocytes is amorphous and diffuse with no condensation around the nucleolus, but this defect does not interfere with progression of oocytes to metaphase II and ovulation (Burns et al., 2003). However, Npm2 deficient embryos display arrested development. Although sperm DNA decondensation proceeds without Npm2, abnormalities are evident in oocyte and early embryonic nuclei (Burns et al., 2003). These defects include an absence of coalesced nucleolar structures and loss of heterochromatin and deacetylated histone $\mathrm{H} 3$ that normally circumscribe nucleoli in oocytes and early embryos, respectively (Burns et al., 2003). The mechanisms whereby failure of heterochromatin organization eventually leads to the mitotic failure in Npm2deficient embryos are not known.

In cattle, Npm2 expression is restricted to ovaries and is abundant in germinal vesicle and metaphase II stage oocytes. Npm2 transcript abundance decreases in early cleavage stage embryos, and is barely detectable in morula and blastocysts (Lingenfelter et al., unpublished). While the functional requirement of $N p m 2$ for early embryogenesis in the bovine to our knowledge has not been investigated, expression of bovine Npm2 mRNA is significantly lower in oocytes from the persistent dominant follicles (model for poor oocyte quality) compared to 
oocytes from growing dominant follicles suggesting that Npm2 transcript abundance is associated with oocyte competence. Furthermore, a conserved microRNA (miRNA-181a) binding site was identified in the 3' UTR of the bovine Npm2 transcript. Transfection experiments showed that expression of $\mathrm{Npm} 2$ protein is reduced dramatically in HeLa cells expressing bovine miR-181a compared to the control cells without miR-181a, indicating that translation of $N p m 2$ is repressed by miR-181a. Elucidation of the role of maternal Npm2 in bovine early embryogenesis and as a functional determinant of oocyte competence merits further investigation

\section{E. Developmental pluripotency associated 3 (Dppa3)}

Dppa3 (also known as Stella and Pgc7) was identified while analyzing gene expression patterns in mouse primordial germ cells and embryonic stem cells using a modified serial analysis of gene expression protocol (Sato et al., 2002). It is specifically expressed in primordial germ cells, oocytes, preimplantation embryos and pluripotent stem cells (Sato et al., 2002). During early embryonic development, soon after the formation of the zygote, Dppa3 accumulates in the pronuclei, although it is also detected in the cytoplasm (Payer et al., 2003). Both cytoplasmic and nuclear staining continues during cleavage stages until the blastocyst stage, at which time Dppa3 is down regulated until its reappearance in primordial germ cells (Payer et al., 2003, Sato et al., 2002). Dppa3 protein has a conserved SAP-like domain known to be involved in chromosomal organization (Aravind and Koonin, 2000) and a splicing factor motif like structure. Female mice lacking Dppa3 display severely reduced fertility. Embryos without maternally derived Dppa3 are compromised in preimplantation development and rarely reach the blastocyst stage (Payer et al., 2003). Taken together, these observations implicate Dppa3 as an important regulator of early embryogenesis in the mouse.

In cattle, two variants of Dppa3 have been identified. Variant 1 is present in testis, ovary and oocyte, while variant 2 is present only in oocytes (Thélie et al., 2007). Expression analysis 
during pre-implantation stages indicates that bovine Dppa3 present in early embryos is likely of maternal origin (Thélie et al., 2007) but the functional role of Dpp3a in early embryogenesis in cattle has not been determined.

\section{F. Octamer binding transcription factor 4 (Oct4)}

Oct4 is a member of the POU (Pit, Oct, Unc) domain transcription factor family and can activate or repress the expression of target genes through binding to cis-acting elements which contain an octameric DNA sequence motif (Ovitt and Scholer, 1998). Oct4 is well studied for its role in maintenance of embryonic stem cell self-renewal and pluripotency (Boyer et al., 2006, Lengner et al., 2008, Pei, 2009). The POU domain transcription factor Oct4 shows a dynamic expression pattern in mouse oocytes and embryos. It is expressed during oogenesis and folliculogenesis (Ovitt and Scholer, 1998). Maternal Oct4 RNA and protein are present in fertilized oocytes until the two-cell stage, and zygotic Oct4 gene expression starts at the four- to eight-cell stage (Ovitt and Scholer, 1998). Oct4-deficient mouse embryos develop to the blastocyst stage, but the inner cell mass cells in such embryos are not pluripotent leading to peri-implantation lethality (Nichols et al., 1998). Furthermore, in the absence of a true inner cell mass, trophoblast proliferation is not maintained in Oct4-deficient embryos (Nichols et al., 1998). Oct4-directed expression of Fgf4 provides a paracrine signal that couples expansion of the extra embryonic trophoblast lineage with development of the embryonic primordium.

Collectively, above results indicate embryonic Oct4 expression plays a pivotal role in promoting formation of pluripotent inner cell mass layer in the mammalian embryo and expansion of the trophectoderm layer (Nichols et al., 1998). However, microinjection of Oct4 antisense morpholino oligonucleotides into one-cell mouse embryos revealed a key role for maternal Oct4 in early events during embryogenesis. Results of such studies suggest that maternal Oct4 is required for early embryonic development and plays a critical role in embryonic genome activation (by regulating genes that encode transcriptional and post-transcriptional 
regulators as early as the two-cell stage (Foygel et al., 2008). Therefore, the transcription factor Oct4 is a master regulator of multiple aspects of early embryonic development in the mouse.

Temporal expression of bovine Oct4 during oocyte and early embryonic development is similar to its human and murine orthologues. Bovine Oct4 transcript is present at low levels in the bovine oocyte, increases soon after zygotic genome activation, followed by a sharp increase subsequent to compaction (Kurosaka et al., 2004, van Eijk et al., 1999). Furthermore selective degradation of Oct4 in bovine embryos by injection of double stranded RNA (RNAi) resulted in a significant reduction in numbers of inner cell mass cells in bovine blastocysts (Nganvongpanit et al., 2006). Collectively, results support an important functional role for Oct4 in bovine early embryogenesis, but specific Oct4 target genes critical to early embryogenesis and the functional role of Oct4 of maternal versus embryonic origin remain to be elucidated.

\section{Functional genomics studies of bovine oocyte competence: Identification of novel mediators}

Evidence described above documents the clear contribution of gene targeting studies in mice to enhanced understanding of the functional contribution of oocyte-derived transcriptional and post transcriptional regulators to early embryogenesis and many areas where complementary comparative studies in the bovine model system are warranted. However, inherent species-specific differences in the duration and number of cell cycles required for embryonic genome activation and completion of the maternal-to-embryonic transition in mice versus cattle may suggest potential for species specificity in the regulatory mechanisms and genes mediating this transition (Bettegowda et al., 2008a). Thus, comparative genomics approaches coupled to functional studies in the bovine model system are needed to address dissimilarities in transcriptome composition between model organisms and provide information on existence of genes or gene families that may play important regulatory roles in early 
embryogenesis and contribute to oocyte competence. In recent years, our lab have utilized expressed sequence tag sequencing and microarray approaches as tools to identify potential novel mediators of oocyte competence and the maternal-to-embryonic transition in cattle, coupled with pharmacological and gene knockdown strategies to determine the functional contribution of such genes to early embryogenesis (Fig. 3). The discovery of such novel mediators is described below.

\section{A. JY-1}

To gain a better understanding of the bovine oocyte transcriptome, a cDNA library was generated from a pool of 200 immature, germinal vesicle and metaphase II stage oocytes. While only a limited number of ESTs were sequenced (Yao et al., 2004) from this library, important novel information on oocyte gene expression was obtained. The initial 230 ESTs represented 102 unique sequences. Forty-six of such sequences displayed significant similarity to sequences for known genes present in the Genbank database. Several ESTs represented housekeeping genes (e.g. RPL15). Some represented genes with previously documented expression both in oocytes and other tissues (e.g. CKS1B). However, most of the ESTs encoded either for genes whose expression in mammalian oocytes was previously unknown or for genes of unknown function (Yao et al., 2004). Among the oocyte ESTs (Yao et al., 2004) encoding for genes of unknown function, one sequence (represented by 14 fully sequenced clones of 2 different sizes) was selected for further investigation because it was completely novel and showed no significant homology to sequences of any known genes or ESTs in Genbank. The name $J Y-1$ was assigned to the putative novel gene encoding for this transcript. This novelty of this sequence was considered significant because at the time there were approximately 4.9 million human, 3.7 million murine and approximately 228,000 bovine EST sequences available in Genbank. 
Published studies (Bettegowda et al., 2007) established that the JY-1 gene encodes for a species specific secreted protein belonging to a novel protein family and support an important functional role for oocyte derived $J Y-1$ in promoting early embryogenesis. JY-1 mRNA and protein are expressed in an ovary-specific fashion, present throughout follicular development in primordial through antral follicles and expression within ovarian tissues is restricted exclusively to the oocyte. Within early embryos, abundance of $J Y-1$ transcripts is maximal at the GV stage and declines thereafter to nearly undetectable levels in 16-cell embryos. Results of embryo culture experiments in the presence of the transcription inhibitor $\alpha$-amanitin indicate the $J Y-1$ gene is not transcribed during the $1^{\text {st }}$ and $2^{\text {nd }}$ embryonic cell cycles and thus $J Y-1$ mRNA detected in early bovine embryos is oocyte-derived (Bettegowda et al., 2007).

To test the functional requirement of $J Y-1$ for bovine early embryogenesis, siRNA mediated gene silencing was performed. Microinjection of siRNA targeting JY-1 into zygote stage embryos results in reduced $J Y-1$ mRNA and protein in resulting embryos and a dramatic reduction in proportion of embryos developing to the eight-cell to 16-cell and blastocyst stages relative to uninjected, sham injected and negative control siRNA injected embryos (Bettegowda et al., 2007). Furthermore, addition of recombinant JY-1 protein during initial $72 \mathrm{~h}$ of embryo culture rescues development of $J Y-1$ siRNA injected embryos to the blastocyst stage (Lee et al., unpublished). Results indicate that the novel oocyte-specific protein JY-1 is obligatory for bovine early embryonic development.

Given the fact that $J Y-1$ sequences identified in the bovine oocyte cDNA library were totally novel, the presence of $J Y-1$ orthologues in other species was previously investigated (Bettegowda et al., 2007) using available genome sequence resources. JY-1-like sequences are present at chromosomal locations in other vertebrate species e.g. mice, rats, humans) that are syntenic to the JY-1 locus on bovine chromosome 29. However, putative JY-1 loci in other species lack exons 1 and 2 and do not encode for a functional protein (Bettegowda et al., 2007). Thus, results to date indicate pronounced species specificity in evolution and functional 
requirement of the novel oocyte-specific JY-1 gene for early embryonic development in cattle versus other species noted above.

\section{B. Importin alpha 8 (Kpna7)}

Further analysis of initial EST sequences obtained from above bovine oocyte cDNA library resulted in identification of a novel transcript with similarity to genes of the importin $\alpha$ family. Kpna7 (importin alpha 8) is a new member of the importin alpha family (Tejomurtula et al., 2009). Members of this family are well studied for their role in nuclear transport in several species (Goldfarb et al., 2004). Kpna7 mRNA is specifically expressed in bovine ovaries and it is abundant in germinal vesicle and metaphase II oocytes as well as in early cleavage stage bovine embryos collected before embryonic genome activation, but is barely detectable in morula and blastocyst stage embryos (Tejomurtula et al., 2009). RNAi mediated knockdown of Kpna7 in early embryos resulted in a decreased proportion of embryos reaching the blastocyst stage, indicating a functional requirement of Kpna7 for early embryonic development (Tejomurtula et al., 2009). Furthermore, GST pull-down assays revealed that Kpna7 has a stronger binding affinity for the nuclear protein nucleoplasmin 2 relative to that of other importin alpha protein family members, suggesting that Kpna7 may have an important role in the transport of key oocyte-specific nuclear proteins (e.g., chromatin remodeling and transcription factors) during early development (Tejomurtula et al., 2009). Elucidation of Kpna7 binding partners critical to early embryogenesis and their specific functional role merits further investigation.

\section{Follistatin}

Functional genomics approaches were utilized to identify differences in RNA transcript profiles of both the oocyte and adjacent cumulus cells associated with poor oocyte competence (Bettegowda et al., 2008b, Patel et al., 2007) using the prepubertal calf model of poor oocyte 
quality (Damiani et al., 1996, Revel et al., 1995). A total of 193 genes encoding for transcripts displaying higher mRNA abundance in oocytes collected from adult animals and 223 genes encoding for transcripts displaying greater mRNA abundance in compromised oocytes from prepubertal calves were detected. Such results formed the foundation for a series of subsequent studies designed to elucidate the diagnostic and functional significance of putative markers identified. Of particular interest from the differentially expressed genes revealed from oocyte microarray studies were genes in the regulation of hormone secretion ontology category which were overrepresented in the good quality oocytes harvested from adult (control) versus prepubertal animals. Messenger RNA for one such gene from this ontology category (follistatin; FST) was also greater in two-cell bovine embryos that cleaved early and developed to the blastocyst stage at a rate four-fold greater than their late cleaving counterparts, which displayed reduced follistatin mRNA. Given embryos were collected prior to completion of the maternal-toembryonic transition and initiation of robust transcription from the embryonic genome (Bettegowda et al., 2008a), such differences likely reflect inherent differences in maternal (oocyte-derived) follistatin mRNA content post fertilization and suggest a potential functional role for oocyte-derived follistatin in early embryogenesis.

Based on above results, it was hypothesized that maternal (oocyte-derived) follistatin abundance is a key determinant of early embryonic development in vitro and conducted studies to test this hypothesis (Lee et al., 2009). Exogenous follistatin addition to bovine embryo culture (during the first $72 \mathrm{~h}$; until time of embryonic genome activation) enhanced proportion of embryos that cleaved early (within $30 \mathrm{~h}$ post insemination; indicator of embryo developmental capacity) and proportion of embryos developing to the blastocyst stage in a dose dependent fashion. Furthermore, follistatin supplementation increased blastocyst total cell numbers specifically through an increase in trophectoderm cells, as no effect on numbers of ICM cells was observed. An increase in mRNA for the trophectoderm specific transcription factor $\mathrm{Cdx}-2$ was also observed in response to follistatin treatment. Collectively, results indicate that 
exogenous follistatin treatment of early bovine embryos can enhance multiple indices of embryo developmental capacity (Lee et al., 2009). Follistatin is best known for its ability to bind the growth factor activin at a high affinity and inhibit its activity (Nakamura et al., 1990). However, multiple lines of evidence indicate stimulatory effects of follistatin on embryo developmental capacity are non classical and not mediated by inhibition of activity of endogenous activin (Lee et al., 2009).

Loss of function experiments were also done (Lee et al., 2009) to determine the requirement of endogenous follistatin for bovine early embryonic development. Microinjection of follistatin siRNA into bovine zygotes reduced follistatin mRNA abundance in at four-cell stage by $>80 \%$ relative to uninjected, sham injected and negative control siRNA injected embryos and resulted in lower follistatin protein in eight-cell embryos. Furthermore, follistatin siRNA microinjection caused a $>50 \%$ reduction in blastocyst development which can be rescued with exogenous follistatin treatment. Follistatin treatment of siRNA injected embryos also restored blastocyst Cdx-2 mRNA abundance to control levels. Collectively, results (Lee et al., 2009) strongly support a functional role for follistatin in control of time to first cleavage, blastocyst development and blastocyst cell allocation in bovine embryos and suggest that follistatin may be an important functional determinant of bovine oocyte competence. However, the molecular mechanisms whereby follistatin can enhance early embryonic development remain to be elucidated.

\section{Cumulus cell cathepsins and oocyte competence}

A similar microarray approach was utilized to identify cumulus markers associated with poor quality oocytes in the same prepubertal model system (Bettegowda et al., 2008b). Microarray experiments revealed 110 genes encoding for transcripts displaying greater mRNA abundance in cumulus cells surrounding germinal vesicle stage oocytes collected from adult animals and 45 genes encoding for transcripts displaying greater mRNA abundance in cumulus cells 
surrounding compromised prepubertal oocytes. Genes in the cysteine type endopeptidase activity category (cathepsins B, K, S and Z) were overrepresented in cumulus cell samples harvested from oocytes of prepubertal animals and thus tentatively associated with poor oocyte competence based on microarray studies. Real-time PCR analysis confirmed that greater amounts of mRNA for cathepsins $\mathrm{B}, \mathrm{K}, \mathrm{S}$ and $\mathrm{Z}$ are present in cumulus cells surrounding poor quality oocytes harvested from ovaries of prepubertal animals (Bettegowda et al., 2008b). It was hypothesized that cumulus cell cathepsin $B, K, S$ and $Z$ expression may also be relevant to oocyte quality in adult animals. To test this hypothesis, parthenogenesis was used as an experimental tool to measure the quality of an oocyte as assessed by its potential to develop into a blastocyst following activation and the relationship between oocyte quality and cathepsin mRNA abundance determined retrospectively. Parthenogenesis was used since presence of cumulus cells during IVF is required for subsequent bovine embryonic development (Luciano et al., 2005, Zhang et al., 1995). As hypothesized, the relative abundance of mRNAs for cathepsins $B, S$ and $Z$ is $\sim 1.5-6$ fold higher in cumulus cells collected from oocytes with low developmental competence versus those collected from oocytes of high developmental competence (Bettegowda et al., 2008b) providing further evidence that cumulus cell cathepsin expression is potentially predictive of an oocyte's embryo development potential.

Functional studies were also conducted to test the influence of cumulus cell cathepsin activity on oocyte competence. Given the observed association of cathepsin B, S and Z transcript abundance with oocyte competence, we investigated the effects of treatment with an irreversible, cell permeable and highly selective cysteine proteinase inhibitor (E-64: inhibits cathepsin B) on oocyte meiotic maturation and early embryonic development. E-64 treatment during in vitro maturation does not affect progression to metaphase II, but results in a 40 to $50 \%$ increase in development to the blastocyst stage (d 7) after parthenogenetic activation or in vitro fertilization (Bettegowda et al., 2008b). 
Given the negative association of cumulus cell cathepsin expression with oocyte competence, stimulatory effects of cathepsin inhibitor (E-64) treatment during meiotic maturation on oocyte competence and reported proapoptotic role of cathepsins (Broker et al., 2005, Stoka et al., 2005), we hypothesized that stimulatory effects of E-64 on oocyte competence may be mediated via promoting cumulus cell survival. Meiotic maturation of bovine oocytes in the presence of a cathepsin inhibitor (E-64) results in a pronounced reduction in numbers of apoptotic cumulus cells (Bettegowda et al., 2008b). Results suggest that cumulus cell cathepsin expression is functionally linked to poor oocyte competence by a negative effect on cumulus cell survival and that a threshold number of viable cumulus cells may be necessary during in vitro maturation to maximize acquisition of oocyte developmental competence and success of subsequent early embryogenesis. The mechanisms whereby cumulus cells directly impact developmental competence during meiotic maturation in cattle are directly relevant to a greater understanding of oocyte gene expression and developmental capacity following fertilization.

From a practical standpoint, oocyte competence is a key limiting factor in the efficiency of in vitro embryo production in cattle (Lonergan, 2007). Thus, a greater understanding of the oocyte-expressed genes critical to various milestones in acquisition of developmental competence in general and specifically to progression through early embryogenesis is warranted. Discoveries made possible through functional genomics, and gene-targeting technologies in mice have greatly increased understanding of genes/gene products obligatory to maternal control of early embryogenesis and completion of the maternal-to-embryonic transition in the mouse. However, comparative data establishing a functional role of such genes, particularly the transcriptional and post-transcriptional regulators described in previous section, is lacking in most instances for the bovine model system (Fig. 3).

It is conceivable that disruptions in the maternal-to-embryonic transition attributed to deficiencies in abundance or activity of key regulatory molecules contribute at least in part to the 
less than desirable efficiency of in vitro embryo production, even for those embryos that proceed in development beyond the eight-cell stage and embryonic genome activation. Such perturbations may also be relevant to the high rates of embryonic loss in vivo experienced in bovine species, particularly dairy cattle (Inskeep and Dailey, 2005, Sreenan and Diskin, 1983). Information obtained from mouse models described is a relevant foundation for comparative studies. However, because of inherent species-specific differences in the duration and number of cell cycles required for embryonic genome activation and completion of the maternal-toembryonic transition in cattle, it is also possible that the regulatory mechanisms and maternal effect genes involved may not be identical to those described for the mouse. For example, available evidence indicates the functional role of the $J Y-1$ gene in early embryogenesis is species specific as a functional $J Y-1$ gene is not present in the murine genome. Furthermore, oocyte-derived follistatin does not make a functional contribution to control of early embryogenesis in mice as the follistatin gene is not expressed in oocytes and follistatin mutant embryos display normal progression through early embryonic development (Matzuk et al., 1995). Thus, a systematic search for additional regulatory molecules mediating this key window in early embryonic development in cattle is warranted along with studies to test their functional contribution to early embryogenesis. Such scientific advancements will greatly increase knowledge of maternal control of early embryonic development in cattle with potential practical application to in vitro embryo production and potentially reproductive efficiency in vivo in cattle.

\section{MicroRNAs: small non-coding RNA regulators of development}

During oogeneis, mammalian oocyte is transcriptionally active and accumulates a large pool of mRNA molecules and protein required for the early development until the embryonic genome activation (EGA) (Gosden, 2002). Depending on the species embryonic genome activation starts at a specific time after fertilization for example it begins during the two-cell stage in mice; the four-cell stage in humans, rats and pigs, and during the eight-cell to 16-cell 
stage in cattle and sheep (Telford et al., 1990) (Fig. 2). Activation of embryonic genome is also accompanied by a gradual degradation of maternal mRNAs and proteins. Degradation of untranslated maternal mRNAs is shown to be critical in several species (Bachvarova et al., 1985; Paynton et al., 1988; Sagata et al., 1989; Memili and First, 1999). In mouse embryos, 90 percent of maternal mRNA is degraded by the two-cell stage, coincident with the complete genome activation (Bachvarova et al., 1985; Paynton et al., 1988). Furthermore, injection of oocyte-specific c-mos mRNA into Xenopus two-cell embryos inhibits clevage (Sagata et al., 1989). Thus degradation of maternal mRNAs is critical to embryogenesis and represents a conserved mechanism of vertebrate development.

Multiple negative regulatory mechanisms are reported to be critical for posttranscriptional regulation of maternal transcripts, such as transcript deadenylation and interaction with RNA-binding proteins in a nonspecific or sequence-specific fashion (Bettegowda and Smith, 2007). Recent studies in zebrafish have established a role for microRNAs (miRNA) as key regulatory molecules targeting maternal mRNA for degradation during the maternal to zygotic transition (Giraldez et al., 2006). MicroRNAs are approximately 21-nucleotide (nt) endogenous small noncoding RNAs that bind primarily to the 3' UTR of target mRNAs to repress their translation and accelerate their decay (Bartel, 2004). The majority of miRNAs are evolutionarily conserved across species boundaries and play essential roles in regulating many distinct processes such as animal development and growth, cell differentiation, signal transduction, cancer, disease, virus immune defense, programmed cell death, insulin secretion and metabolism (Ambros, 2004; He and Hannon, 2004; Wienholds and Plasterk, 2005).

\section{A. MicroRNA biogenesis}

MicroRNA genes reside in regions of the genome as distinct transcriptional units as well as in clusters of polycistronic units carrying the information of several microRNAs (Bartel, 2004). The mammalian miRNA biogenesis pathway can be divided into multiple steps. Initially, in 
nucleus miRNA genes are transcribed by RNA polymerase II, yielding long primary microRNAs (pri-miRNAs) of hundred to thousands of bases in length (Bartel, 2004). Pri-miRNAs are processed in the nucleus into $\sim 70-80$ nucleotide precursor miRNAs (pre-miRNAs) by the ribonuclease III enzyme Drosha together with the double-stranded RNA (dsRNA)-binding domain containing the protein DGCR8 (Kim, 2005; Tomari and Zamore, 2005). The excised 70-nt fold-back dsRNA precursor (pre-miRNA) is then exported to the cytoplasm by Exportin-5 in the presence of Ran-GTP as cofactor (Bartel, 2004). In the cytoplasm, the pre-miRNAs are processed by the RNase III enzyme Dicer to form 22-nucleotide duplex miRNA (Bartel, 2004). Next the miRNA:miRNA* duplex are separated by helicases and based on the strength of the 5' end pairing, one single stand is chosen as the mature miRNA, the opposing strand referred to as the miRNA* is degraded rapidly following the separation (Bartel, 2004). Mature miRNAs are incorporated into silencing complexes that contain Argonaute protein and bind their mRNA targets, which are often in the 3' untranslated region (UTR), resulting in translation inhibition or possible target mRNA degradation in animals (Bartel, 2004).

\section{B. Approaches to microRNA discovery}

MicroRNAs (miRNAs) were first identified in Caenorhabditis elegans through genetic screens for aberrant development (Lee et al., 1993; Wightman et al., 1993) and later found in a number of multicellular eukaryotes. miRNA identification relies largely on two approaches: experimental approach (cloning and sequencing of small RNA libraries) and computational approach (Berezikov et al., 2006). The experimental approach is the most preferred method for the identification of miRNAs. In this method the expression of small RNAs is first established, and bioinformatics is then used to identify the microRNAs that meet structural requirements (Berezikov et al., 2006). The limitation of the experimental approach is that it is difficult to find the miRNAs that are expressed at a low level and at very specific stages or in rare cell type. However, the experimental approach remains the best choice for identification of miRNAs in 
organisms whose genomes have not been sequenced. In computational-driven approaches, candidate miRNAs are predicted in whole genome on the basis of structural features and phylogenetic conservation, which are essential characteristics of miRNA. Several computational programs such as MIRscan (Lee, 2003) and MiRAlign (Wang et al., 2005) have been developed for identification of known miRNA homologs from organisms whose genome sequences are available. However, computationally predicted candidate miRNAs need further experimental validation.

\section{Predicting miRNA targets in animals}

MicroRNAs are important regulatory molecules that control gene expression at the posttranscriptional levels. It is predicted that 1 to $5 \%$ of genes encode for miRNA and they regulate the expression of as many as $30 \%$ of mRNA (Lewis et al., 2003). Since, experimental identification of the miRNA targets is difficult there has been an explosion of algorithms that predict miRNA targets. However, computational prediction of miRNA targets is more challenging in animals than plants due to the imperfect complementarity of miRNAs to their target mRNA (Yoon and De Micheli, 2006). Almost all algorithms use relatively similar detection principles, and are based on the previous knowledge on the pairing of mRNAs and miRNA such as lin-4 (Lee et al., 1993) and let-7 in C. elegans (Reinhart et al., 2000), as well as bantam in Drosophila (Brennecke et al., 2003). The minimal requirements for a functional miRNA-target pairing used by most target prediction algorithms (Target Scan, PicTar and Microinspector) are 1. The miRNA sequence should be complementary to the 3' UTR sequence of potential target mRNAs, especially the strong binding in the seed region (the first seven to eight base pairs in the 5' end of miRNA) is very important for targeting (Brennecke et al., 2005). 2. The conservation of target 3' UTR sites in related genomes is critical; especially the conservation around the seed region should be considered (Lewis et al., 2005). 3. A strong secondary structure at the miRNA-binding 
site on the target is an important feature for effective silencing of the target (Brennecke et al., 2005).

\section{MicroRNAs mediated regulation of early embryonic development}

The role of miRNAs during early embryogenesis has been assessed by analyzing animals that are deficient in DICER. DICER, a ribonuclease III type endonuclease, is highly expressed in oocytes, and its expression is spatio-temporally regulated during oocyte maturation and fertilization, with greatest decrease at the two-cell stage when maternal transcripts are globally degraded (Cui et al., 2007). Dicer- knockout and knokdown mutants exhibit a lack of miRNA production and arrest during embryogenesis in zebrafish and mice (Bernstein et al., 2003; Wienholds et al., 2003; Giraldez et al., 2005; Murchison et al., 2007; Tang et al., 2007). The first major developmental transition that occurs following fertilization is the maternal-to-embryonic transition (MET) in which the maternally inherited proteins that drive the developmental programme initially were replaced with zygotically produced transcripts.

A role for miRNAs in the regulation of the MZT was uncovered with discovery of miR-430 in zebrafish (Giraldez et al., 2006). miR-430 is encoded by a large gene family and it is the most abundant miRNA family expressed during early zebrafish development (Giraldez et al., 2005). Expression of the miR-430 initiates at the moment of maternal-to-embryonic transition, and targets to over 300 maternal transcripts in zebrafish by binding to the complementary sites in their 3' UTR and promoting their deadenylation and cleareance of maternal transcripts during early embryogenesis (Giraldez et al., 2006). In the absence of miR-430 activity, these maternal mRNAs accumulate and are thought to interfere with embryonic morphogenesis (Giraldez et al., 2006). Similarly to findings in the zebrafish, mouse mature oocytes depleted of maternal miRNAs failed to progress through the first cell division due to disorganized spindle formation, indicating that the maternal miRNAs are essential for the mouse early embryonic development and miRNA regulation of the MET is a conserved regulatory mechanism (Tang et al., 2007). 
In summary, multiple mechanisms regulate RNA synthesis and degradation during early embryogenesis. miRNAs represent a subset of small RNAs and play critical role in the repression of maternal mRNA translation. To date much of the work in the non-traditional animal models has focused on miRNA profiling in different tissues and stages of development, but the expression, regulation and function of several miRNAs still needs to be determined. Our understanding of miRNAs functions in the oocyte and early embryonic development is in its infancy and much remains to be uncovered, which will provide insight into we can enhance reproductive efficiency and design of better reprogramming strategies.

\section{SUMOylation: a novel post-translational modification in regulating mammalian development}

Post-translational modifications of proteins play a critical role in most cellular processes through their unique ability to alter rapidly and reversibly the functions of preexisting proteins, multiprotein complexes, and intracellular structures. In addition to phosphorylation, acetylation and ubiquitylation, recently several small ubiquitin-like proteins (Ubls) have been discovered to be reversible post-translational protein modifiers. Among Ubls, SUMO (small ubiquitin modifier) is the best characterized (Hay, 2005). However, unlike ubiquitin that targets proteins for degradation, SUMO-modification affects the target proteins intercellular localization, interactions, stability and activity (Hay, 2005) thereby affecting a wide range of cellular processes, including gene transcription, cell cycle, protein stability, nuclear localization, signal transduction, protein-protein interactions and chromatin dynamics (Geiss-Friedlander and Melchior, 2007).

SUMO constitutes a highly conserved protein family ubiquitously expressed throughout the eukaryotic kingdom. SUMO proteins are $\sim 10 \mathrm{kD}$ in size and share only $\sim 18 \%$ sequence identity with ubiquitin, but the three-dimensional structure of SUMO is virtually super imposable 
on that of ubiquitin (Johnson, 2004). Organisms, such as S. cerevisiae, C. elegans and D. melanogaster, have a single SUMO gene whereas vertebrates contain at least four SUMO genes, namely SUMO-1, 2, 3 and the mostly recently identified SUMO-4 (Table 2) (GeissFriedlander and Melchior, 2007). However, plants contain even more SUMO genes, with eight in A. thaliana (Table 2) (Johnson, 2004). SUMO proteins can be divided into two sub-families: SUMO-1 proteins and SUMO-2/SUMO-3 proteins (Melchior, 2000). Within a given species, SUMO2/3 proteins are present at much higher levels than SUMO-1 (Johnson, 2004). Although members of each sub-family are nearly identical, SUMO1 and SUMO2/3 proteins share only about $50 \%$ amino-acid sequence identity. SUMO-1, 2, 3 are ubiquitously expressed in all tissue and at all developmental stages and use the same conjugation machinery, but their functions are different, such as they conjugate to different target proteins, respond differently to stress, are differentially affected by isopeptidase enzymes, and can be distinguished by their ability (SUMO2/3) or inability (SUMO1) to form SUMO chains (Melchior, 2000).

\section{A. The SUMO conjugation pathway (SUMOylation)}

SUMOylation, the conjugation of SUMO peptide to the target protein, results in the formation of an isopeptide bond between the C-terminal Glycine residue of the modifier protein and the $\varepsilon$-amino group of a Lysine residue in the acceptor protein by a series of enzymatic reactions similar to those involved in the ubiquitination (Johnson, 2004). SUMOylation is a highly conserved pathway from yeast to humans and mostly targets specific proteins that contains a consensus motif $\psi \mathrm{KXE}$, where $\psi$ represents a large hydrophobic amino acid, $\mathrm{K}$ is the SUMO attachment site, $X$ is any residue and $E$ is a glutamic acid (Johnson, 2004). Modification of target proteins by SUMO is an ATP-dependent enzymatic cascade involving three key enzymes - E1 activating enzyme (the heterodimer Aos1-Uba2), E-2 conjugating enzyme (Ubc9) and several E3 ligating enzymes (PIAS, RanBP2/Nup358 and Pc2) (Fig. 4). Newly synthesized SUMO is immature, as it cannot conjugate to its targets until a SUMO-specific protease 
generates a mature SUMO by removing some carboxy-terminus residues and exposing the two glycine residue (Hay, 2005). Mature SUMO, is then activated by the SUMO-specific E1 activating enzyme heterodimer AOS1-UBA2. This reaction uses ATP for the formation of a SUMO-adenylate conjugate. Next, activated SUMO is transferred from UBA2 to the active site cysteine (Cys) of the SUMO-specific E2 conjugating enzyme (Ubc9), forming a thioester linkage between the catalytic Cys residue of Ubc9 and the C-terminal carboxy group of SUMO. In the last step, Ubc9 transfers SUMO to the target protein (substrate), forming an isopeptide bond between the C-terminal Glycine residue of SUMO and a Lysine side chain of the target. This step is usually facilitated by SUMO E3 ligases, but some targets are efficiently SUMOylated by E2 conjugating enzyme (Ubc9). SUMOylation is a reversible modification, and cleavage of the isopeptide bond between SUMO and its target is carried out efficiently by SUMO-specific proteases of the SENP/UIp family. Both the released SUMO and target are then recycled for subsequent rounds of SUMOylation (Fig. 4) (Melchior, 2000; Johnson, 2004; Hay, 2005; GeissFriedlander and Melchior, 2007).

\section{B. Emerging role of SUMOylation during development}

SUMOylation is a key regulator of numerous biological and cellular events, including gene transcription, cell cycle, protein stability, nuclear localization, signal transduction, proteinprotein interactions and chromatin dynamics. Recently, SUMO and SUMO pathway genes were shown to be important in diverse reproductive functions such as steroid receptor activity, ovulation, gametogenesis and embryogenesis (Broday et al., 2004; Jones, 2006; Abdel-Hafiz et al., 2009; Wang et al., 2010). In C. elegans, the reproductive system is a major SUMO target during postembryonic development, and is required for gonandal and uterine-vulval morphogenesis (Broday et al., 2004). Lack of SUMO-conjugating enzyme (Ubc9) in C.elegans leads to embryonic lethality due to pleiotrphic defects during larval development (Jones et al., 2002). In D.melanogaster, mutations in the semushi (semi) gene, Ubc9 (SUMO-conjugating 
enzyme) ortholog, blocks nuclear import of the transcription factor Bicoid (Bcd) and results in impaired embryogenesis (Epps and Tanda, 1998). Another mutation in the D.melanogaster Ubc9 homologue, termed lesswright, dominantly suppresses the nondisjunction and cytological defects of female meiotic mutations that affect spindle formation (Apionishev et al., 2001). Knockdown of Ubc9 in zebrafish embryos leads to early embryonic apoptosis and inactivation of zygotic Ubc9 function causes more specific developmental defects in brain, eyes and pharyngeal arches due to defects in G2/M transition and mitosis during organogenesis (Nowak and Hammerschmidt, 2006). Conditional deletion of Ubc9 in chicken DT40 cells causes polynucleated and cell cycle-independent apoptosis (Hayashi et al., 2002). Loss of Ubc9 in mouse embryos causes severe defects in the chromosome segregation and nuclear organization and embryos die at early postimplantation stage (Nacerddine et al., 2005). Together, these studies indicate that SUMO and its pathway genes can influence developmental programs of both vertebrate and invertebrate metazoans.

Work over the last decade has shown that SUMOylation is an important regulator of protein modification and is essential in a number of different biological pathways. However, investigations in regard to how SUMO affects biological processes are still limited and poorly understood. Many basic questions regarding SUMO components, mechanism of action and SUMO target proteins remain unanswered and needs further investigation. 
Table 1. Oocyte specific genes addressed in this chapter potentially required for early embryonic development in cattle.

\begin{tabular}{|c|c|c|c|c|c|c|}
\hline Gene name/ symbol & $\begin{array}{c}\text { Year } \\
\text { discovered }\end{array}$ & Protein & Domain/motif & $\begin{array}{l}\text { Species } \\
\text { first } \\
\text { identified }\end{array}$ & Key Function & $\begin{array}{l}\text { Published Work } \\
\text { in Bovine }\end{array}$ \\
\hline $\begin{array}{l}\text { Factor in the germline } \\
\text { alpha (Figla) }\end{array}$ & 1997 & $\begin{array}{l}\text { Transcription } \\
\text { factor }\end{array}$ & Helix-loop-helix & Mouse & Folliculogenesis & None \\
\hline $\begin{array}{c}\text { Newborn ovary } \\
\text { homeobox gene } \\
(\text { Nobox })\end{array}$ & 2002 & $\begin{array}{l}\text { Transcription } \\
\text { factor }\end{array}$ & $\begin{array}{l}\text { Homeobox } \\
\text { domain }\end{array}$ & Mouse & $\begin{array}{l}\text { Folliculogenesis and } \\
\text { early embryogenesis }\end{array}$ & None \\
\hline $\begin{array}{l}\text { Spermatogenesis and } \\
\text { Oogenesis specific } \\
\text { basic helix-loop-helix } 1 \\
\text { and } 2 \text { (Sohlh1and } \\
\text { Sohlh2) }\end{array}$ & 2006 & $\begin{array}{l}\text { Transcription } \\
\text { factor }\end{array}$ & Helix-loop-helix & Mouse & $\begin{array}{c}\text { Early } \\
\text { Folliculogenesis }\end{array}$ & None \\
\hline $\begin{array}{c}\text { Oocyte-specific } \\
\text { homeobox gene family } \\
\text { (Obox) }\end{array}$ & 2002 & $\begin{array}{l}\text { Transcription } \\
\text { factor }\end{array}$ & $\begin{array}{l}\text { Homeobox } \\
\text { domain }\end{array}$ & Mouse & Unknown & None \\
\hline $\begin{array}{l}\text { Deleted in Azoospermia } \\
\text { Like gene (Dazl) }\end{array}$ & 1996 & $\begin{array}{l}\text { RNA binding } \\
\text { protein }\end{array}$ & $\begin{array}{l}\text { RNA binding } \\
\text { domain }\end{array}$ & Mouse & $\begin{array}{l}\text { Folliculogenesis and } \\
\text { oocyte maturation }\end{array}$ & $\begin{array}{l}\text { Liu et al (2007); } \\
\text { Zhang et al } \\
(2008)\end{array}$ \\
\hline $\begin{array}{c}\text { Y box protein } 2 \\
(Y b \times 2)\end{array}$ & 1990 & $\begin{array}{l}\text { RNA binding } \\
\text { protein }\end{array}$ & $\begin{array}{l}\text { S1-like cold-shock } \\
\text { domain }\end{array}$ & Xenopus & $\begin{array}{l}\text { Folliculogenesis and } \\
\text { early embryogenesis }\end{array}$ & $\begin{array}{l}\text { Vigneault et al } \\
\qquad(2004)\end{array}$ \\
\hline $\begin{array}{c}\text { Cytoplasmic } \\
\text { polyadenylation } \\
\text { element-binding } \\
\text { protein1 } \\
\text { (Cpeb1) }\end{array}$ & 1994 & $\begin{array}{l}\text { RNA binding } \\
\text { protein }\end{array}$ & $\begin{array}{l}\text { RNA binding } \\
\text { domain }\end{array}$ & Xenopus & $\begin{array}{l}\text { Folliculogenesis, } \\
\text { oocyte maturation } \\
\text { and early } \\
\text { embryogenesis }\end{array}$ & $\begin{array}{l}\text { Uzbekova et al } \\
\qquad(2008)\end{array}$ \\
\hline $\begin{array}{c}\text { Maternal antigen that } \\
\text { embryo require } \\
(M A T E R)\end{array}$ & 2000 & Antigen & $\begin{array}{l}\text { NACHT NTPase; } \\
\text { Leu-rich repeat }\end{array}$ & Mouse & $\begin{array}{l}\text { Early embryonic } \\
\text { development }\end{array}$ & $\begin{array}{l}\text { Pennetier et al } \\
(2004,2006)\end{array}$ \\
\hline $\begin{array}{c}\text { Factor located in } \\
\text { oocytes permitting } \\
\text { embryonic development } \\
(F L O P E D)\end{array}$ & 2008 & $\begin{array}{l}\text { RNA-binding } \\
\text { protein }\end{array}$ & A typical KH & Mouse & $\begin{array}{c}\text { Early embryonic } \\
\text { development }\end{array}$ & None \\
\hline Zygote arrest 1 (Zar1) & 2003 & $\begin{array}{l}\text { Transcriptional } \\
\text { regulator }\end{array}$ & $\begin{array}{l}\text { A typical PHD } \\
\text { domain }\end{array}$ & Mouse & $\begin{array}{l}\text { Early embryonic } \\
\text { development }\end{array}$ & $\begin{array}{l}\text { Brevini et al } \\
(2004) ; \\
\text { Uzbekova et al } \\
(2006)\end{array}$ \\
\hline
\end{tabular}




\begin{tabular}{|c|c|c|c|c|c|c|}
\hline Nucleoplamin2 (Npm2) & 1980 & $\begin{array}{c}\text { Nuclear } \\
\text { chaperone }\end{array}$ & Nucleoplasmin & Xenopus & $\begin{array}{c}\text { Early embryonic } \\
\text { development }\end{array}$ & $\begin{array}{l}\text { Lingenfelter et al } \\
\qquad(2008)\end{array}$ \\
\hline $\begin{array}{c}\text { Developmental } \\
\text { pluripotency associated } \\
3 \text { (Dppa3) }\end{array}$ & 2002 & Basic protein & SAP-like domain & Mouse & $\begin{array}{l}\text { Early embryonic } \\
\text { development }\end{array}$ & $\begin{array}{l}\text { Thélie et al } \\
\text { (2007) }\end{array}$ \\
\hline $\begin{array}{c}\text { Octamer binding } \\
\text { transcription factor } 4 \\
\text { (Oct4) }\end{array}$ & 1990 & $\begin{array}{l}\text { Transcription } \\
\text { factor }\end{array}$ & $\begin{array}{l}\text { POU specific and } \\
\text { Homeobox }\end{array}$ & Mouse & $\begin{array}{l}\text { Early embryonic } \\
\text { development and } \\
\text { pluripotency }\end{array}$ & $\begin{array}{c}\text { Gandolfi et al } \\
(1997) ; \text { van Eijk } \\
(1999) ; \\
\text { Kurosaka (2005) }\end{array}$ \\
\hline JY1 & 2007 & $\begin{array}{l}\text { Secreted } \\
\text { Protein }\end{array}$ & $\begin{array}{l}\text { No significant } \\
\text { matches }\end{array}$ & Bovine & $\begin{array}{l}\text { Early embryonic } \\
\text { development }\end{array}$ & $\begin{array}{l}\text { Bettegowda et al } \\
\qquad(2007)\end{array}$ \\
\hline $\begin{array}{l}\text { Importin alpha } 8 \\
\text { (Kpna7) }\end{array}$ & 2009 & $\begin{array}{l}\text { Nuclear } \\
\text { transport } \\
\text { receptor }\end{array}$ & $\begin{array}{l}\text { Importin- } \beta \text { binding } \\
\text { domain and } \\
\text { armadillo (ARM) } \\
\text { motifs }\end{array}$ & Bovine & $\begin{array}{l}\text { Early embryonic } \\
\text { development }\end{array}$ & $\begin{array}{c}\text { Tejomurthula et } \\
\text { al (2009) }\end{array}$ \\
\hline
\end{tabular}


Table 2. Components of SUMOylation

\begin{tabular}{|c|c|c|c|c|c|}
\hline Organism & SUMO & E1 & E2 & E3 & $\begin{array}{c}\text { SUMO } \\
\text { protease }\end{array}$ \\
\hline Yeast & SUMO-1 & Aos1, Uba2 & Ubc9 & Siz1,2 & Ulp1, 2 \\
\hline Arabidopsis & $\begin{array}{c}\text { Several SUMO } \\
\text { genes }\end{array}$ & $\begin{array}{c}\text { SAE1a, b and } \\
\text { SAE2 }\end{array}$ & SCE1a, b, c & Siz1,2 & $\begin{array}{c}\text { Ulp1 a-d } \\
\text { Ulp2 a-h }\end{array}$ \\
\hline Mouse & SUMO-1, 2, 3 & SAE1, SAE2 & Ubc9 & PIAS3 & SENP2 \\
\hline Human & SUMO-1, 2, 3, 4 & Aos1, Uba2 & Ubc9 & PIAS1 & SENP1 \\
\hline Bovine & SUMO-1, 2, 3 & Aos1, Uba2 & Ubc9 & PIAS1 & SENP1 \\
\hline
\end{tabular}




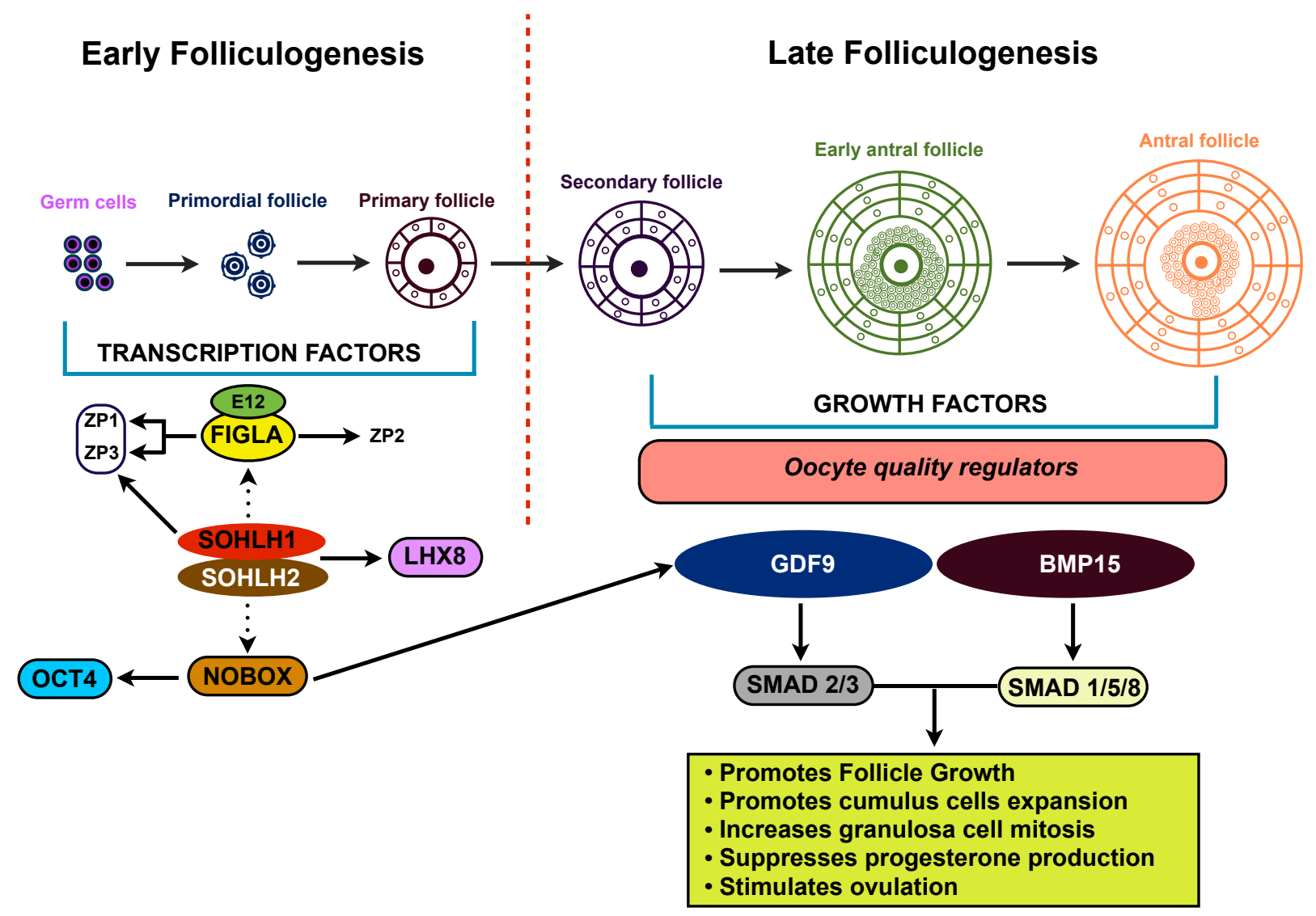

Figure 1. During the early folliculogenesis, clusters of germ cells break down to form primordial follicles, which upon activation become primary follicles. A number of oocyte-specific transcription factors (FIGLA, NOBOX, SOHLH1, SOHLH2 and LHX8) are known to regulate each other and a number of other genes essential for folliculogenesis, fertilization and early embryonic development. Mice lacking these transcription factors show loss of follicles at the primordial follicle-to-primary follicle transition or before primordial follicle formation. During late folliculogensis (secondary follicle to antral follicle) oocyte-derived bone morphogenetic protein 15 (BMP15) and growth differentiation factor 9 (GDF9) act via SMAD 1/5/8 and 2/3 signaling pathway, to elicit cellular responses that are essential for folliculogenesis and ovulation. Dotted lines indicate indirect transcriptional regulation where as solid lines indicate direct transcriptional regulation. 


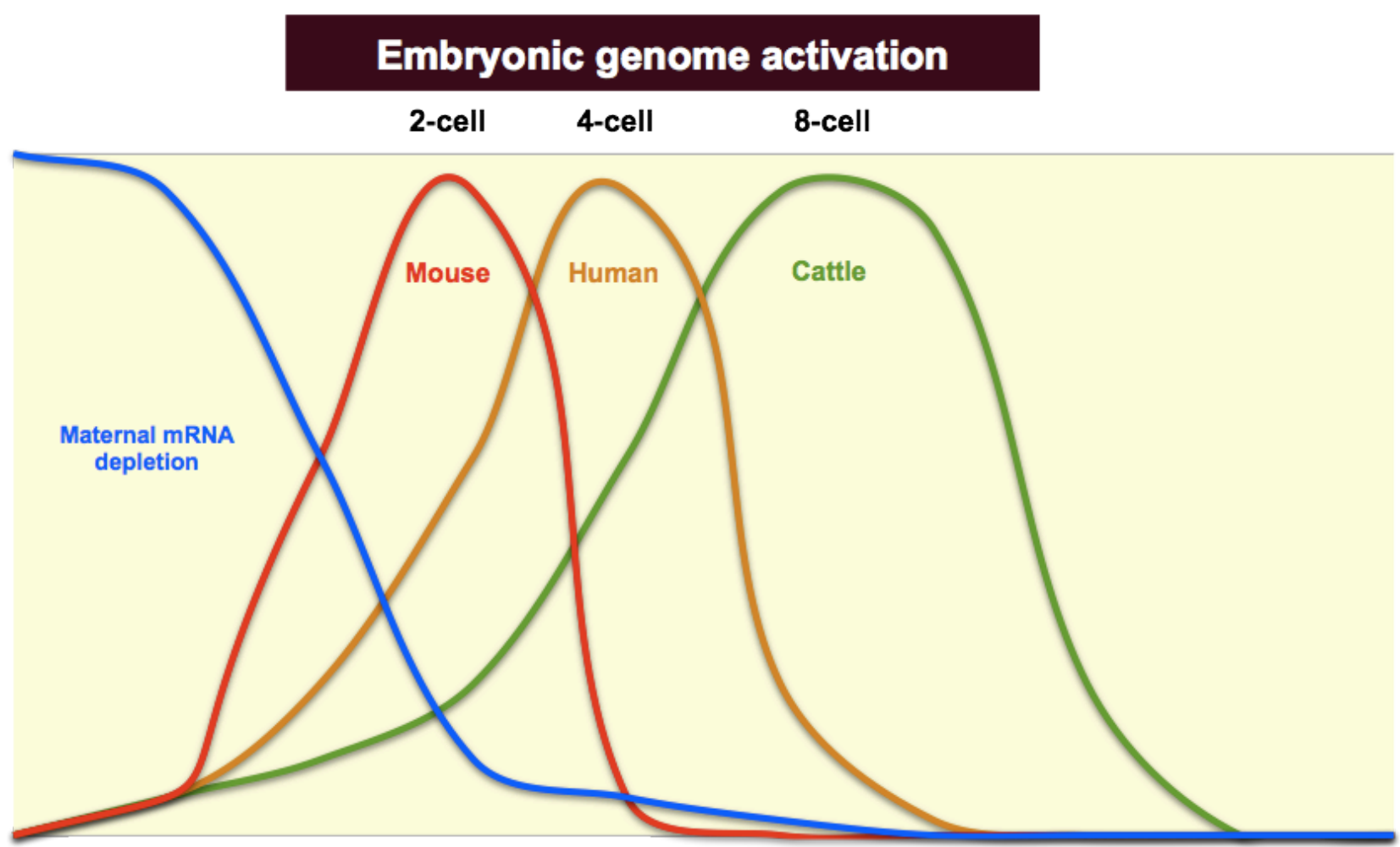

Figure 2. Embryonic genome activation (EGA) in different species. 


\section{Cattle}

\section{Chromain remodelling and epigenetic modifications}

Degradation of maternal mRNA and proteins

\section{Required for progression to blastocyst stage}

\section{JY1, KPNA7, FST \& OCT4}

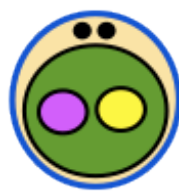

One-cell

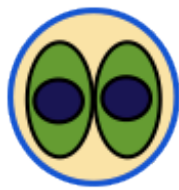

Two-cell

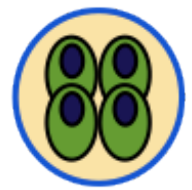

Four-cell

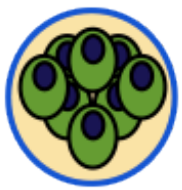

Eight-cell

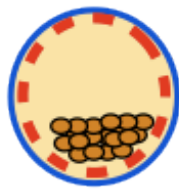

Blastocyst

\section{Role in bovine embryos ??}

FIGLA, NOBOX, ZAR1, NPM2, MATER, FLOPED, FILIA,TLE6, DPPA3

Figure 3. Oocyte-derived regulators and regulatory events during the bovine maternal-toembryonic transition and subsequent stages of early embryogenesis. 


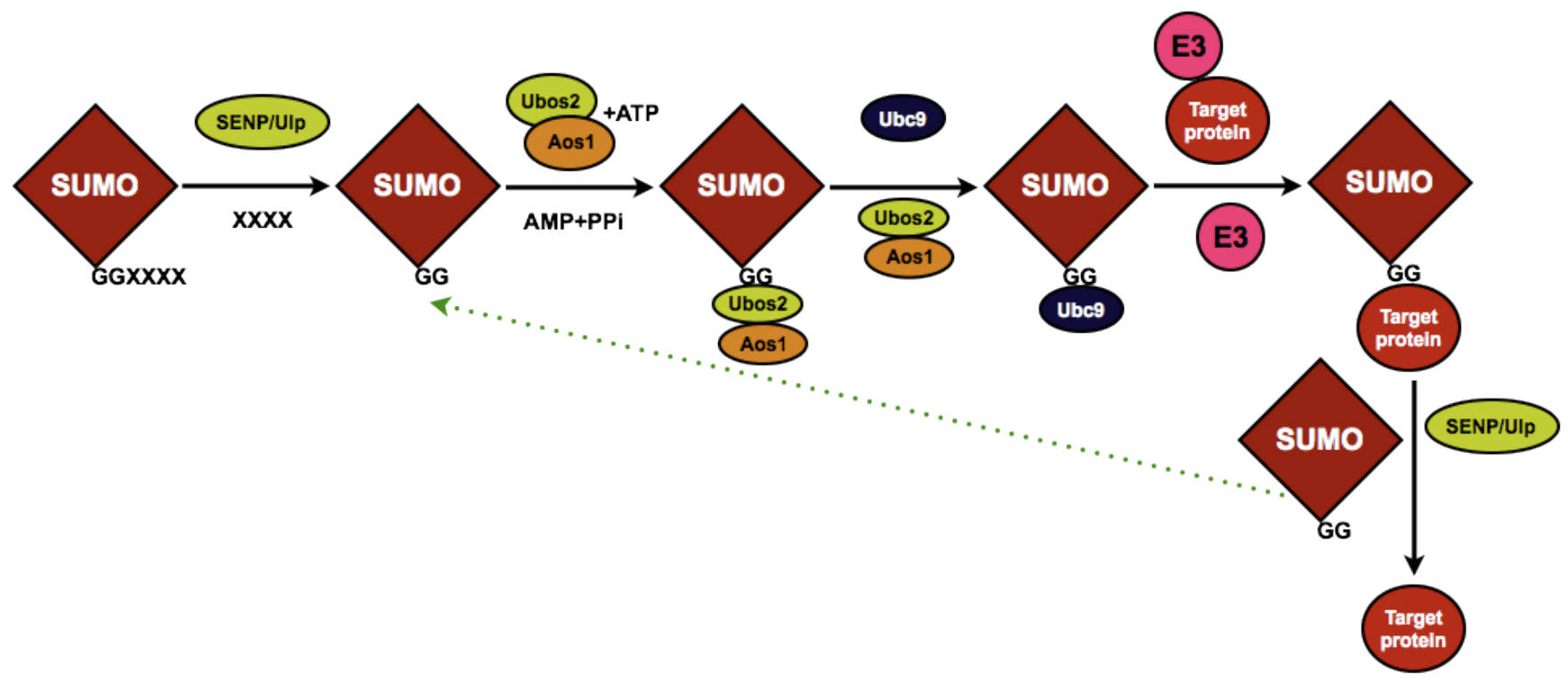

Figure 4. The SUMO conjugation pathway (SUMOylation) 


\section{REFERENCES}

Abdel-Hafiz, H., Dudevoir, M.L., Horwitz, K.B., 2009. Mechanisms underlying the control of progesterone receptor transcriptional activity by SUMOylation. J Biol Chem 284, 9099-9108.

Ambros, V., 2004. The functions of animal microRNAs. Nature 431, 350-355.

Andreu-Vieyra, C., Y.N. Lin, and M. M. Matzuk. 2006. Mining the oocyte transcriptome. Trends Endocrinol Metab 17, 136-143.

Apionishev, S., Malhotra, D., Raghavachari, S., Tanda, S., Rasooly, R.S., 2001. The Drosophila UBC9 homologue lesswright mediates the disjunction of homologues in meiosis I. Genes Cells 6, 215-224.

Aravind, L. and E. V. Koonin. 2000. SAP - a putative DNA-binding motif involved in chromosomal organization. Trends Biochem Sci 25, 112-114.

Bachvarova, R., De Leon, V., Johnson, A., Kaplan, G., Paynton, B.V., 1985. Changes in total RNA, polyadenylated RNA, and actin mRNA during meiotic maturation of mouse oocytes. Dev Biol 108, 325-331.

Bajoghli, B. 2007. Evolution of the Groucho/Tle gene family: gene organization and duplication events. Dev Genes Evol 217, 613-618.

Ballow, D. J., Y. Xin, Y. Choi, S. A. Pangas, and A. Rajkovic. 2006. Sohlh2 is a germ cellspecific bHLH transcription factor. Gene Expr Patterns 6, 1014-1018.

Bartel, D., 2004. MicroRNAs:: Genomics, Biogenesis, Mechanism, and Function. Cell 116, 281297.

Bayne R, da Silva S, Anderson R. 2004. Increased expression of the FIGLA transcription factor is associated with primordial follicle formation in the human fetal ovary. Mol Hum Reprod 10, 373-381.

Bebbere, D., L. Bogliolo, F. Ariu, S. Fois, G. G. Leoni, S. Tore, S. Succu, F. Berlinguer, S. Naitana, and S. Ledda. 2008. Expression pattern of zygote arrest 1 (ZAR1), maternal antigen that embryo requires (MATER), growth differentiation factor 9 (GDF9) and bone morphogenetic 
protein 15 (BMP15) genes in ovine oocytes and in vitro-produced preimplantation embryos. Reprod Fertil Dev 20, 908-915.

Berezikov, E., Cuppen, E., Plasterk, R.H.A., 2006. Approaches to microRNA discovery. Nat Genet 38 Suppl, S2-7.

Bernstein, E., Kim, S.Y., Carmell, M.A., Murchison, E.P., Alcorn, H., Li, M.Z., Mills, A.A., Elledge, S.J., Anderson, K.V., Hannon, G.J., 2003. Dicer is essential for mouse development. Nat Genet 35, 215-217.

Bettegowda, A., Smith, G.W., 2007. Mechanisms of maternal mRNA regulation: implications for mammalian early embryonic development. Front Biosci 12, 3713-3726.

Bettegowda, A., K.-B. Lee, and G. W. Smith. 2008a. Cytoplasmic and nuclear determinants of the maternal-to-embryonic transition. Reprod Fertil Dev 20, 45-53.

Bettegowda, A., O. Patel, K. Lee, K. Park, M. Salem, J. Yao, J. Ireland, and G. Smith. 2008b. Identification of novel bovine cumulus cell molecular markers predictive of oocyte competence: functional and diagnostic implications. Biology of Reproduction 79, 301-309.

Bettegowda, A. and G. W. Smith. 2007. Mechanisms of maternal mRNA regulation: implications for mammalian early embryonic development. Front Biosci 12, 3713-3726.

Bettegowda, A., J. Yao, A. Sen, Q. Li, K.-B. Lee, Y. Kobayashi, O. V. Patel, P. M. Coussens, J. J. Ireland, and G. W. Smith. 2007. JY-1, an oocyte-specific gene, regulates granulosa cell function and early embryonic development in cattle. Proc Natl Acad Sci USA 104, 17602-17607. Boyer, L. A., D. Mathur, and R. Jaenisch. 2006. Molecular control of pluripotency. Curr Opin Genet Dev 16, 455-462.

Brekhman, V., J. Itskovitz-Eldor, E. Yodko, M. Deutsch, and J. Seligman. 2000. The DAZL1 gene is expressed in human male and female embryonic gonads before meiosis. Mol Hum Reprod 6, 465-468. 
Brennecke, J., Hipfner, D.R., Stark, A., Russell, R.B., Cohen, S.M., 2003. bantam encodes a developmentally regulated microRNA that controls cell proliferation and regulates the proapoptotic gene hid in Drosophila. Cell 113, 25-36.

Brennecke, J., Stark, A., Russell, R.B., Cohen, S.M., 2005. Principles of microRNA-target recognition. PLoS Biol 3, e85.

Brevini, T., F. Cillo, S. Colleoni, G. Lazzari, C. Galli, and F. Gandolfi. 2004. Expression pattern of the maternal factor zygote arrest 1 (Zar1) in bovine tissues, oocytes, and embryos. Mol Reprod Dev 69, 375-380.

Broday, L., Kolotuev, I., Didier, C., Bhoumik, A., Gupta, B., Sternberg, P., Podbilewicz, B., Ronai, Z., 2004. The small ubiquitin-like modifier (SUMO) is required for gonadal and uterinevulval morphogenesis Caenorhabditis elegans. Gene Dev 18, 2380-2391.

Broker, L. E., F. A. Kruyt, and G. Giaccone. 2005. Cell death independent of caspases: a review. Clin Cancer Res 11, 3155-3162.

Burns, K., M. Viveiros, Y. Ren, P. Wang, F. DeMayo, D. Frail, J. Eppig, and M. Matzuk. 2003. Roles of NPM2 in chromatin and nucleolar organization in oocytes and embryos. Science 300, 633-636.

Cauffman, G., H. Van de Velde, I. Liebaers, and A. Van Steirteghem. 2005. DAZL expression in human oocytes, preimplantation embryos and embryonic stem cells. Mol Hum Reprod 11, 405411.

Cheng, W.-C., H. M. Hsieh-Li, Y.-J. Yeh, and H. Li. 2007. Mice lacking the Obox6 homeobox gene undergo normal early embryonic development and are fertile. Dev Dyn 236(9): 2636-2642. Choi, Y., D. J. Ballow, Y. Xin, and A. Rajkovic. 2008a. Lim homeobox gene, Ihx8, is essential for mouse oocyte differentiation and survival. Biology of Reproduction 79, 442-449.

Choi, Y. and A. Rajkovic. 2006a. Characterization of NOBOX DNA binding specificity and its regulation of Gdf9 and Pou5f1 promoters. J Biol Chem 281, 35747-35756. 
Choi, Y. and A. Rajkovic. 2006b. Genetics of early mammalian folliculogenesis. Cell Mol Life Sci $63,579-590$.

Choi, Y., D. Yuan, and A. Rajkovic. 2008b. Germ cell-specific transcriptional regulator sohlh2 is essential for early mouse folliculogenesis and oocyte-specific gene expression. Biology of Reproduction 79, 1176-1182.

Collier, B., B. Gorgoni, C. Loveridge, H. J. Cooke, and N. K. Gray. 2005. The DAZL family proteins are PABP-binding proteins that regulate translation in germ cells. EMBO $\mathrm{J} 24,2656-$ 2666.

Cooke, H. J., M. Lee, S. Kerr, and M. Ruggiu. 1996. A murine homologue of the human DAZ gene is autosomal and expressed only in male and female gonads. Hum Mol Genet 5, 513-516. Cui, X.S., X.Y. Li, X.J. Yin, I. K. Kong, J.-J. Kang, and N.-H. Kim. 2007. Maternal gene transcription in mouse oocytes: genes implicated in oocyte maturation and fertilization. J Reprod Dev 53, 405-418.

Cui, X., Shen, X., Kim, N., 2007. Dicer1 expression in preimplantation mouse embryos: Involvement of Oct3/4 transcription at the blastocyst stage. Biochemical and biophysical research communications 352, 231-236.

Damiani, P., R. A. Fissore, J. B. Cibelli, C. R. Long, J. J. Balise, J. M. Robl, and R. T. Duby. 1996. Evaluation of developmental competence, nuclear and ooplasmic maturation of calf oocytes. Mol Reprod Dev 45, 521-534.

Danforth, D. R. 1995. Endocrine and paracrine control of oocyte development. Am J Obstet Gynecol 172, 747-752.

Dong, J., D. F. Albertini, K. Nishimori, T. R. Kumar, N. Lu, and M. M. Matzuk. 1996. Growth differentiation factor-9 is required during early ovarian folliculogenesis. Nature $383,531-535$.

Dube, J. L., P. Wang, J. Elvin, K. M. Lyons, A. J. Celeste, and M. M. Matzuk. 1998. The bone morphogenetic protein 15 gene is X-linked and expressed in oocytes. Mol Endocrinol 12, 18091817. 
Elvin, J. A., C. Yan, and M. M. Matzuk. 2000. Oocyte-expressed TGF-beta superfamily members in female fertility. Mol Cell Endocrinol 159, 1-5.

Epifano, O. and J. Dean. 2002. Genetic control of early folliculogenesis in mice. Trends Endocrinol Metab 13, 169-173.

Eppig, J. 2001. Oocyte control of ovarian follicular development and function in mammals. Reproduction 122, 829-838.

Eppig, J. J., K. Wigglesworth, and F. L. Pendola. 2002. The mammalian oocyte orchestrates the rate of ovarian follicular development. P Natl Acad Sci Usa 99, 2890-2894.

Epps, J.L., Tanda, S., 1998. The Drosophila semushi mutation blocks nuclear import of bicoid during embryogenesis. Curr Biol 8, 1277-1280.

Foygel, K., B. Choi, S. Jun, D. E. Leong, A. Lee, C. C. Wong, E. Zuo, M. Eckart, R. A. Reijo Pera, W. H. Wong, and M. W. M. Yao. 2008. A novel and critical role for Oct4 as a regulator of the maternal-embryonic transition. PLoS ONE 3, e4109.

Frehlick, L. J., J. M. Eirín-López, and J. Ausió. 2007. New insights into the nucleophosmin/nucleoplasmin family of nuclear chaperones. Bioessays $29,49-59$.

Geiss-Friedlander, R., Melchior, F., 2007. Concepts in sumoylation: a decade on. Nat Rev Mol Cell Biol 8, 947-956.

Giraldez, A.J., Cinalli, R.M., Glasner, M.E., Enright, A.J., Thomson, J.M., Baskerville, S., Hammond, S.M., Bartel, D.P., Schier, A.F., 2005. MicroRNAs regulate brain morphogenesis in zebrafish. Science 308, 833-838.

Giraldez, A.J., Mishima, Y., Rihel, J., Grocock, R.J., Van Dongen, S., Inoue, K., Enright, A.J., Schier, A.F., 2006. Zebrafish MiR-430 promotes deadenylation and clearance of maternal mRNAs. Science 312, 75-79.

Goldfarb, D. S., A. H. Corbett, D. A. Mason, M. T. Harreman, and S. A. Adam. 2004. Importin alpha: a multipurpose nuclear-transport receptor. Trends Cell Biol 14, 505-514. 
Gosden, R.G., 2002. Oogenesis as a foundation for embryogenesis. Mol Cell Endocrinol 186, 149-153.

Gu, W., S. Tekur, R. Reinbold, J. J. Eppig, Y. C. Choi, J. Z. Zheng, M. T. Murray, and N. B. Hecht. 1998. Mammalian male and female germ cells express a germ cell-specific Y-Box protein, MSY2. Biology of Reproduction 59, 1266-1274.

Haston, K. M., J. Y. Tung, and R. A. Reijo Pera. 2009. Dazl functions in maintenance of pluripotency and genetic and epigenetic programs of differentiation in mouse primordial germ cells in vivo and in vitro. PLoS ONE 4, e5654.

Hay, R.T., 2005. SUMO: a history of modification. Mol Cell 18, 1-12.

Hayashi, T., Seki, M., Maeda, D., Wang, W., Kawabe, Y.-i., Seki, T., Saitoh, H., Fukagawa, T., Yagi, H., Enomoto, T., 2002. Ubc9 is essential for viability of higher eukaryotic cells. Exp Cell Res 280, 212-221.

He, L., Hannon, G.J., 2004. MicroRNAs: small RNAs with a big role in gene regulation. Nat Rev Genet 5, 522-531.

Huntriss J, Hinkins M, Picton HM. 2006. cDNA cloning and expression of the human NOBOX gene in oocytes and ovarian follicles. Mol Hum Reprod 12, 283-289.

Hu, W., L. Gauthier, B. Baibakov, M. Jimenez-Movilla, and J. Dean. 2010. FIGLA, a basic helixloop-helix transcription factor, balances sexually dimorphic gene expression in postnatal oocytes. Mol Cell Biol 30, 3661-3671.

Hussein, T. S., J. G. Thompson, and R. B. Gilchrist. 2006. Oocyte-secreted factors enhance oocyte developmental competence. Dev Biol 296, 514-521.

Inskeep, E. K. and R. A. Dailey. 2005. Embryonic death in cattle. Vet Clin Nort Am Food Anim Pract 21, 437-461.

Johnson, E.S., 2004. Protein modification by SUMO. Annu Rev Biochem 73, 355-382.

Joshi, S., H. Davies, L. P. Sims, S. E. Levy, and J. Dean. 2007. Ovarian gene expression in the absence of FIGLA, an oocyte-specific transcription factor. BMC Dev Biol 7, 67. 
Jones, D., Crowe, E., Stevens, T.A., Candido, E.P.M., 2002. Functional and phylogenetic analysis of the ubiquitylation system in Caenorhabditis elegans: ubiquitin-conjugating enzymes, ubiquitin-activating enzymes, and ubiquitin-like proteins. Genome Biol 3, 0002.0001.

Jones, M.C., 2006. Regulation of the SUMO pathway senitizes differentiating human endometrial stromal cells to progesterone. PNAS 103, 16272-16277.

Katsu, Y., M. Yamashita, and Y. Nagahama. 1997. Isolation and characterization of goldfish Y box protein, a germ-cell-specific RNA-binding protein. EUR J BIOCHEM 249, 854-861.

Kidder, G. M. and A. A. Mhawi. 2002. Gap junctions and ovarian folliculogenesis. Reproduction 123, 613-620.

Kim, V.N., 2005. MicroRNA biogenesis: coordinated cropping and dicing. Nature Reviews Molecular Cell Biology, Published online: 01 December 2007; | doi:10.1038/nrm2293 6, 376385.

Knight, P. G. and C. Glister. 2001. Potential local regulatory functions of inhibins, activins and follistatin in the ovary. Reproduction $121,503-512$.

Krisher, R. L. 2004. The effect of oocyte quality on development. J Anim Sci 82 E-Suppl: E1423.

Kurosaka, S., S. Eckardt, and K. McLaughlin. 2004. Pluripotent lineage definition in bovine embryos by Oct4 transcript localization. Biol Reprod 71, 1578-1582.

Laskey, R. A., B. M. Honda, A. D. Mills, and J. T. Finch. 1978. Nucleosomes are assembled by an acidic protein which binds histones and transfers them to DNA. Nature 275, 416-420.

Lee, 2003. Vertebrate microRNA genes. Science 299, 1540.

Lee, K. B., A. Bettegowda, G. Wee, J. J. Ireland, and G. W. Smith. 2009. Molecular determinants of oocyte competence: potential functional role for maternal (oocyte-derived) follistatin in promoting bovine early embryogenesis. Endocrinology 150, 2463-2471.

Lee, R.C., Feinbaum, R.L., Ambros, V., 1993. The C. elegans heterochronic gene lin-4 encodes small RNAs with antisense complementarity to lin-14. Cell 75, 843-854. 
Lengner, C. J., G. G. Welstead, and R. Jaenisch. 2008. The pluripotency regulator Oct4: a role in somatic stem cells? Cell Cycle 7, 725-728.

Lewis, B., Shih, I., Jones-Rhoades, M., Bartel, D., Burge, C., 2003. Prediction of mammalian microRNA targets. Cell 115, 787-798.

Lewis, B.P., Burge, C.B., Bartel, D.P., 2005. Conserved seed pairing, often flanked by adenosines, indicates that thousands of human genes are microRNA targets. Cell 120, 15-20.

Li, L., B. Baibakov, and J. Dean. 2008. A subcortical maternal complex essential for preimplantation mouse embryogenesis. Dev Cell 15, 416-425.

Li, L., P. Zheng, and J. Dean. 2010. Maternal control of early mouse development. Development $137,859-870$.

Liang, L., S. M. Soyal, and J. Dean. 1997. FIGalpha, a germ cell specific transcription factor involved in the coordinate expression of the zona pellucida genes. Development $124,4939-$ 4947.

Liu, J., K. Linher, and J. Li. 2009. Porcine DAZL messenger RNA: its expression and regulation during oocyte maturation. Mol Cell Endocrinol 311, 101-108.

Liu, W.-S., A. Wang, Y. Uno, D. Galitz, C. W. Beattie, and F. A. Ponce de León. 2007. Genomic structure and transcript variants of the bovine DAZL gene. Cytogenet Genome Res 116, 65-71. Lonergan, P. 2007. State-of-the-art embryo technologies in cattle. Soc. Reprod. Fertil. Suppl. 64: $315-325$.

Luciano, A. M., V. Lodde, M. S. Beretta, S. Colleoni, A. Lauria, and S. Modina. 2005. Developmental capability of denuded bovine oocyte in a co-culture system with intact cumulusoocyte complexes: role of cumulus cells, cyclic adenosine 3',5'-monophosphate, and glutathione. Mol Reprod Dev 71, 389-397.

Ma, J., D. Milan, and D. Rocha. 2009. Chromosomal assignment of the porcine NALP5 gene, a candidate gene for female reproductive traits. Anim Reprod Sci 112, 397-401. 
Matsumoto, K., F. Meric, and A. P. Wolffe. 1996. Translational repression dependent on the interaction of the Xenopus Y-box protein FRGY2 with mRNA. Role of the cold shock domain, tail domain, and selective RNA sequence recognition. J Biol Chem 271, 22706-22712.

Matzuk, M. M., N. Lu, H. Vogel, K. Sellheyer, D. R. Roop, and A. Bradley. 1995. Multiple defects and perinatal death in mice deficient in follistatin. Nature $374,360-363$.

McNeilly, J. R., P. T. Saunders, M. Taggart, M. Cranfield, H. J. Cooke, and A. S. McNeilly. 2000. Loss of oocytes in Dazl knockout mice results in maintained ovarian steroidogenic function but altered gonadotropin secretion in adult animals. Endocrinology 141, 4284-4294.

Melchior, F., 2000. SUMO--nonclassical ubiquitin. Annual review of cell and developmental biology 16,591 .

Memili, E. and N. L. First. 1999. Control of gene expression at the onset of bovine embryonic development. Biol Reprod 61, 1198-1207.

Mendez, R. and J. D. Richter. 2001. Translational control by CPEB: a means to the end. Nature Reviews Molecular Cell Biology, Published online: 01 December 2007; | doi:10.1038/nrm2293 2, 521-529.

Michailidis, G., A. Argiriou, and M. Avdi. 2010. Expression of chicken zygote arrest 1 (Zar1) and Zar1-like genes during sexual maturation and embryogenesis. Vet Res Commun 34, 173-184.

Moley, K. H. and J. R. Schreiber. 1995. Ovarian follicular growth, ovulation and atresia. Endocrine, paracrine and autocrine regulation. Adv Exp Med Biol 377, 103-119.

Mota, G. B., R. I. Batista, R. V. Serapiao, M. C. Boite, J. H. Viana, C. A. Torres, and L. S. de Almeida Camargo. 2010. Developmental competence and expression of the MATER and ZAR1 genes in immature bovine oocytes selected by brilliant cresyl blue. Zygote 18, 209-216.

Murchison, E.P., Stein, P., Xuan, Z., Pan, H., Zhang, M.Q., Schultz, R.M., Hannon, G.J., 2007. Critical roles for Dicer in the female germline. Gene Dev 21, 682-693. 
Nacerddine, K., Lehembre, F., Bhaumik, M., Artus, J., Cohen-Tannoudji, M., Babinet, C., Pandolfi, P.P., Dejean, A., 2005. The SUMO pathway is essential for nuclear integrity and chromosome segregation in mice. Dev Cell 9, 769-779.

Nakamura, T., K. Takio, Y. Eto, H. Shibai, K. Titani, and H. Sugino. 1990. Activin-binding protein from rat ovary is follistatin. Science $247,836-838$.

Nganvongpanit, K., H. Müller, F. Rings, M. Hoelker, D. Jennen, E. Tholen, V. Havlicek, U. Besenfelder, K. Schellander, and D. Tesfaye. 2006. Selective degradation of maternal and embryonic transcripts in in vitro produced bovine oocytes and embryos using sequence specific double-stranded RNA. Reproduction 131, 861-874.

Nichols, J., B. Zevnik, K. Anastassiadis, H. Niwa, D. Klewe-Nebenius, I. Chambers, H. Schöler, and A. Smith. 1998. Formation of pluripotent stem cells in the mammalian embryo depends on the POU transcription factor Oct4. Cell 95, 379-391.

Nowak, M., Hammerschmidt, M., 2006. Ubc9 regulates mitosis and cell survival during zebrafish development. Mol Biol Cell 17, 5324-5336.

Ohsugi, M., P. Zheng, B. Baibakov, L. Li, and J. Dean. 2008. Maternally derived FILIA-MATER complex localizes asymmetrically in cleavage-stage mouse embryos. Development 135, 259269.

Ovitt, C. and H. Scholer. 1998. The molecular biology of Oct-4 in the early mouse embryo. Mol Hum Reprod 4, 1021-1031.

Padmanabhan, K. and J. D. Richter. 2006. Regulated Pumilio-2 binding controls RINGO/Spy mRNA translation and CPEB activation. Gene Dev 20, 199-209.

Pangas, S. A. 2007. Growth factors in ovarian development. Semin Reprod Med 25, 225-234.

Pangas, S. A., Y. Choi, D. J. Ballow, Y. Zhao, H. Westphal, M. M. Matzuk, and A. Rajkovic. 2006. Oogenesis requires germ cell-specific transcriptional regulators Sohlh1 and Lhx8. P Natl Acad Sci Usa 103, 8090-8095. 
Paradis, F., C. Vigneault, C. Robert, and M.-A. Sirard. 2005. RNA interference as a tool to study gene function in bovine oocytes. Mol Reprod Dev 70, 111-121.

Patel, O. V., A. Bettegowda, J. J. Ireland, P. M. Coussens, P. Lonergan, and G. W. Smith. 2007. Functional genomics studies of oocyte competence: Evidence that reduced transcript abundance for follistatin is associated with poor developmental competence of bovine oocytes. Reproduction 133, 95-106.

Payer, B., M. Saitou, S. C. Barton, R. Thresher, J. P. C. Dixon, D. Zahn, W. H. Colledge, M. B. L. Carlton, T. Nakano, and M. A. Surani. 2003. Stella is a maternal effect gene required for normal early development in mice. Curr Biol 13, 2110-2117.

Paynton, B.V., Rempel, R., Bachvarova, R., 1988. Changes in state of adenylation and time course of degradation of maternal mRNAs during oocyte maturation and early embryonic development in the mouse. Dev Biol 129, 304-314.

Pei, D. 2009. Regulation of pluripotency and reprogramming by transcription factors. J Biol Chem 284, 3365-3369.

Pennetier, S., C. Perreau, S. Uzbekova, A. Thelie, B. Delaleu, P. Mermillod, and R. DalbiesTran. 2006a. MATER protein expression and intracellular localization throughout folliculogenesis and preimplantation embryo development in the bovine. BMC Dev Biol 6: 26.

Pennetier, S., C. Perreau, S. Uzbekova, A. Thélie, B. Delaleu, P. Mermillod, and R. DalbièsTran. 2006b. MATER protein expression and intracellular localization throughout folliculogenesis and preimplantation embryo development in the bovine. BMC Dev Biol 6: 26.

Pennetier, S., S. Uzbekova, C. Perreau, P. Papillier, P. Mermillod, and R. Dalbiès-Tran. 2004. Spatio-temporal expression of the germ cell marker genes MATER, ZAR1, GDF9, BMP15, and VASA in adult bovine tissues, oocytes, and preimplantation embryos. Biology of Reproduction $71,1359-1366$.

Philpott, A. and G. H. Leno. 1992. Nucleoplasmin remodels sperm chromatin in Xenopus egg extracts. Cell 69, 759-767. 
Philpott, A., G. H. Leno, and R. A. Laskey. 1991. Sperm decondensation in Xenopus egg cytoplasm is mediated by nucleoplasmin. Cell $65,569-578$.

Picton, H., D. Briggs, and R. Gosden. 1998. The molecular basis of oocyte growth and development. Mol Cell Endocrinol 145, 27-37.

Qin Y, Shi Y, Zhao Y, Carson SA, Simpson JL, Chen Z-J. 2009. Mutation analysis of NOBOX homeodomain in Chinese women with premature ovarian failure. Fertility and sterility 91, 15071509.

Racki, W. J. and J. D. Richter. 2006. CPEB controls oocyte growth and follicle development in the mouse. Development 133, 4527-4537.

Rajkovic, A., S. A. Pangas, D. Ballow, N. Suzumori, and M. M. Matzuk. 2004. NOBOX deficiency disrupts early folliculogenesis and oocyte-specific gene expression. Science 305, 1157-1159.

Rajkovic, A., C. Yan, W. Yan, M. Klysik, and M. Matzuk. 2002. Obox, a family of homeobox genes preferentially expressed in germ cells. Genomics 79, 711-717.

Reinhart, B.J., Slack, F.J., Basson, M., Pasquinelli, A.E., Bettinger, J.C., Rougvie, A.E., Horvitz, H.R., Ruvkun, G., 2000. The 21-nucleotide let-7 RNA regulates developmental timing in Caenorhabditis elegans. Nature 403, 901-906.

Revel, F., P. Mermillod, N. Peynot, J. P. Renard, and Y. Heyman. 1995. Low developmental capacity of in vitro matured and fertilized oocytes from calves compared with that of cows. J Reprod Fertil 103, 115-120.

Richter, J. D. 2007. CPEB: a life in translation. Trends in Biochemical Sciences 32, 279-285.

Romar, R., T. De Santis, P. Papillier, C. Perreau, A. Thelie, M. Dell'aquila, P. Mermillod, and R. Dalbies-Tran. 2011. Expression of Maternal Transcripts During Bovine Oocyte In Vitro Maturation is Affected by Donor Age. Reprod Domest Anim 46, e23-30. 
Ruggiu, M., R. Speed, M. Taggart, S. J. McKay, F. Kilanowski, P. Saunders, J. Dorin, and H. J. Cooke. 1997. The mouse Dazla gene encodes a cytoplasmic protein essential for gametogenesis. Nature 389, 73-77.

Ruzanov, P. V., V. M. Evdokimova, N. L. Korneeva, J. W. Hershey, and L. P. Ovchinnikov. 1999. Interaction of the universal mRNA-binding protein, p50, with actin: a possible link between mRNA and microfilaments. J Cell Sci 112, 3487-3496.

Sagata, N., Watanabe, N., Vande Woude, G.F., Ikawa, Y., 1989. The c-mos proto-oncogene product is a cytostatic factor responsible for meiotic arrest in vertebrate eggs. Nature $342,512-$ 518.

Sato, M., T. Kimura, K. Kurokawa, Y. Fujita, K. Abe, M. Masuhara, T. Yasunaga, A. Ryo, M. Yamamoto, and T. Nakano. 2002. Identification of PGC7, a new gene expressed specifically in preimplantation embryos and germ cells. Mech Dev 113, 91-94.

Schams, D., B. Berisha, M. Kosmann, R. Einspanier, and W. M. Amselgruber. 1999. Possible role of growth hormone, IGFs, and IGF-binding proteins in the regulation of ovarian function in large farm animals. Domest Anim Endocrinol 17, 279-285.

Schultz, R. M. 2002. The molecular foundations of the maternal to zygotic transition in the preimplantation embryo. Hum Reprod Update 8(4): 323-331.

Schultz, R. M., W. Davis, P. Stein, and P. Svoboda. 1999. Reprogramming of gene expression during preimplantation development. J Exp Zool 285, 276-282.

Sirard, M. A., F. Richard, P. Blondin, and C. Robert. 2006. Contribution of the oocyte to embryo quality. Theriogenology 65, 126-136.

Sommerville, J. and M. Ladomery. 1996. Transcription and masking of mRNA in germ cells: involvement of Y-box proteins. Chromosoma 104, 469-478.

Soyal, S. M., A. Amleh, and J. Dean. 2000. FIGalpha, a germ cell-specific transcription factor required for ovarian follicle formation. Development 127, 4645-4654. 
Sreenan, J. M. and M. G. Diskin. 1983. Early embryonic mortality in the cow: its relationship with progesterone concentration. Vet Rec 112, 517-521.

Stoka, V., B. Turk, and V. Turk. 2005. Lysosomal cysteine proteases: structural features and their role in apoptosis. IUBMB Life 57, 347-353.

Sun, Q.Y., K. Liu, and K. Kikuchi. 2008. Oocyte-specific knockout: a novel in vivo approach for studying gene functions during folliculogenesis, oocyte maturation, fertilization, and embryogenesis. Biology of Reproduction 79, 1014-1020.

Suzumori, N., C. Yan, M. M. Matzuk, and A. Rajkovic. 2002. Nobox is a homeobox-encoding gene preferentially expressed in primordial and growing oocytes. Mech Dev 111, 137-141.

Tafuri, S. R. and A. P. Wolffe. 1990. Xenopus Y-box transcription factors: molecular cloning, functional analysis and developmental regulation. P Natl Acad Sci Usa 87, 9028-9032.

Tang, F., Kaneda, M., O'Carroll, D., Hajkova, P., Barton, S.C., Sun, Y.A., Lee, C., Tarakhovsky, A., Lao, K., Surani, M.A., 2007. Maternal microRNAs are essential for mouse zygotic development. Genes Dev 21, 644-648.

Tay, J., R. Hodgman, M. Sarkissian, and J. D. Richter. 2003. Regulated CPEB phosphorylation during meiotic progression suggests a mechanism for temporal control of maternal mRNA translation. Gene Dev 17, 1457-1462.

Tay, J. and J. D. Richter. 2001. Germ cell differentiation and synaptonemal complex formation are disrupted in CPEB knockout mice. Dev Cell 1, 201-213.

Tejomurtula, J., K.-B. Lee, S. K. Tripurani, G. W. Smith, and J. Yao. 2009. Role of importin alpha8, a new member of the importin alpha family of nuclear transport proteins, in early embryonic development in cattle. Biology of Reproduction 81, 333-342.

Telford, N. A., A. J. Watson, and G. A. Schultz. 1990. Transition from maternal to embryonic control in early mammalian development: a comparison of several species. Mol. Reprod. Dev. $26,90-100$. 
Thélie, A., P. Papillier, S. Pennetier, C. Perreau, J. M. Traverso, S. Uzbekova, P. Mermillod, C. Joly, P. Humblot, and R. Dalbiès-Tran. 2007. Differential regulation of abundance and deadenylation of maternal transcripts during bovine oocyte maturation in vitro and in vivo. BMC Dev Biol 7, 125.

Tomari, Y., Zamore, P.D., 2005. MicroRNA biogenesis: drosha can't cut it without a partner. Curr Biol 15, R61-64.

Tong, Z.-B., C. A. Bondy, J. Zhou, and L. M. Nelson. 2002. A human homologue of mouse Mater, a maternal effect gene essential for early embryonic development. Hum Reprod 17, 903911.

Tong, Z.-B., L. Gold, A. De Pol, K. Vanevski, H. Dorward, P. Sena, C. Palumbo, C. A. Bondy, and L. M. Nelson. 2004. Developmental expression and subcellular localization of mouse MATER, an oocyte-specific protein essential for early development. Endocrinology 145, 14271434.

Tong, Z., L. Gold, K. Pfeifer, H. Dorward, E. Lee, C. Bondy, J. Dean, and L. Nelson. 2000. Mater, a maternal effect gene required for early embryonic development in mice. Nat Genet 26, 267-268.

Tong, Z. B. and L. M. Nelson. 1999. A mouse gene encoding an oocyte antigen associated with autoimmune premature ovarian failure. Endocrinology 140, 3720-3726.

Uzbekova, S., Y. Arlot-Bonnemains, J. Dupont, R. Dalbiès-Tran, P. Papillier, S. Pennetier, A. Thélie, C. Perreau, P. Mermillod, C. Prigent, and R. Uzbekov. 2008. Spatio-temporal expression patterns of aurora kinases $\mathrm{a}, \mathrm{B}$, and $\mathrm{C}$ and cytoplasmic polyadenylation-element-binding protein in bovine oocytes during meiotic maturation. Biology of Reproduction 78, 218-233.

Uzbekova, S., M. Roy-Sabau, R. Dalbies-Tran, C. Perreau, P. Papillier, F. Mompart, A. Thelie, S. Pennetier, J. Cognie, V. Cadoret, D. Royere, P. Monget, and P. Mermillod. 2006. Zygote arrest 1 gene in pig, cattle and human: evidence of different transcript variants in male and female germ cells. Reprod Biol Endocrinol 4, 12. 
van Eijk, M. J., M. A. van Rooijen, S. Modina, L. Scesi, G. Folkers, H. T. van Tol, M. M. Bevers, S. R. Fisher, H. A. Lewin, D. Rakacolli, C. Galli, C. de Vaureix, A. O. Trounson, C. L. Mummery, and F. Gandolfi. 1999. Molecular cloning, genetic mapping, and developmental expression of bovine POU5F1. Biology of Reproduction 60, 1093-1103.

Vigneault, C., S. McGraw, L. Massicotte, and M.-A. Sirard. 2004a. Transcription factor expression patterns in bovine in vitro-derived embryos prior to maternal-zygotic transition. Biology of Reproduction 70, 1701-1709.

Vigneault, C., S. McGraw, L. Massicotte, and M. A. Sirard. 2004b. Transcription factor expression patterns in bovine in vitro-derived embryos prior to maternal-zygotic transition. Biol Reprod 70, 1701-1709.

Wang, Z.-B., Ou, X.-H., Tong, J.-S., Li, S., Wei, L., Ouyang, Y.-C., Hou, Y., Schatten, H., Sun, Q.-Y., 2010. The SUMO pathway functions in mouse oocyte maturation. Cell Cycle 9.

Wang, X., Zhang, J., Li, F., Gu, J., He, T., Zhang, X., Li, Y., 2005. MicroRNA identification based on sequence and structure alignment. Bioinformatics 21, 3610-3614.

Wianny, F. and M. Zernicka-Goetz. 2000. Specific interference with gene function by doublestranded RNA in early mouse development. Nat Cell Biol 2, 70-75.

Wienholds, E., Koudijs, M., Van Eeden, F., Cuppen, E., Plasterk, R., 2003. The microRNAproducing enzyme Dicer1 is essential for zebrafish development. Nat Genet 35, 217-218.

Wienholds, E., Plasterk, R.H.A., 2005. MicroRNA function in animal development. FEBS Lett $579,5911-5922$

Wightman, B., Ha, I., Ruvkun, G., 1993. Posttranscriptional regulation of the heterochronic gene lin-14 by lin- 4 mediates temporal pattern formation in C. elegans. Cell 75, 855-862.

Wolffe, A. P., S. Tafuri, M. Ranjan, and M. Familari. 1992. The Y-box factors: a family of nucleic acid binding proteins conserved from Escherichia coli to man. New Biol 4, 290-298. 
Wu, X., M. Viveiros, J. Eppig, Y. Bai, S. Fitzpatrick, and M. Matzuk. 2003a. Zygote arrest 1 (Zar1) is a novel maternal-effect gene critical for the oocyte-to-embryo transition. Nat Genet 33, 187-191.

Wu, X., P. Wang, C. A. Brown, C. A. Zilinski, and M. M. Matzuk. 2003b. Zygote arrest 1 (Zar1) is an evolutionarily conserved gene expressed in vertebrate ovaries. Biol Reprod 69, 861-867.

Yang, J., S. Medvedev, J. Yu, L. C. Tang, J. E. Agno, M. M. Matzuk, R. M. Schultz, and N. B. Hecht. 2005. Absence of the DNA-/RNA-binding protein MSY2 results in male and female infertility. P Natl Acad Sci Usa 102, 5755-5760.

Yao, J., X. Ren, J. Ireland, P. Coussens, T. Smith, and G. Smith. 2004. Generation of a bovine oocyte cDNA library and microarray: resources for identification of genes important for follicular development and early embryogenesis. Physiological genomics 19, 84.

Yen, P. H. 2004. Putative biological functions of the DAZ family. Int J Androl 27, 125-129.

Yu, J., M. Deng, S. Medvedev, J. Yang, N. B. Hecht, and R. M. Schultz. 2004. Transgenic RNAi-mediated reduction of MSY2 in mouse oocytes results in reduced fertility. Dev Biol 268, 195-206.

Yu, J., N. B. Hecht, and R. M. Schultz. 2001. Expression of MSY2 in mouse oocytes and preimplantation embryos. Biol Reprod 65, 1260-1270.

Yu, J., N. B. Hecht, and R. M. Schultz. 2002. RNA-binding properties and translation repression in vitro by germ cell-specific MSY2 protein. Biol Reprod 67, 1093-1098.

Yoon, S., De Micheli, G., 2006. Computational identification of microRNAs and their targets. Birth Defects Res C Embryo Today 78, 118-128.

Zhang, L., S. Jiang, P. J. Wozniak, X. Yang, and R. A. Godke. 1995. Cumulus cell function during bovine oocyte maturation, fertilization, and embryo development in vitro. Mol Reprod Dev $40,338-344$.

Zhang, Q., Q. Li, J. Li, X. Li, Z. Liu, D. Song, and Z. Xie. 2008. b-DAZL: A novel gene in bovine spermatogenesis. Progress in Natural Science 18, 1209-1218. 
Zhao H, Chen Z-J, Qin Y, Shi Y, Wang S, Choi Y, Simpson JL, Rajkovic A. 2008. Transcription factor FIGLA is mutated in patients with premature ovarian failure. Am J Hum Genet 82, 13421348.

Zhao X, Suzumori N, Yamaguchi M, Suzumori K. 2005. Mutational analysis of the homeobox region of the human NOBOX gene in Japanese women who exhibit premature ovarian failure. Fertility and sterility $83,1843-1844$.

Zheng, P. and J. Dean. 2009. Role of Filia, a maternal effect gene, in maintaining euploidy during cleavage-stage mouse embryogenesis. Proc Natl Acad Sci USA 106, 7473-7478. 


\section{STATEMENT OF PROBLEM}

Reproductive efficiency is a major determinant of economic success of domestic livestock operations. In domestic ruminants, embryonic and fetal death account for approximately $75 \%$ of all reproductive loss and $57 \%$ of failure of pregnancy in cattle is due to early embryonic loss. In cattle, only $30-40 \%$ of oocytes after fertilization and culture in vitro, are able to reach the blastocyst stage and $60-70 \%$ of in vitro-derived embryos are capable of initiating successful pregnancies after embryo transfer. In addition, in vitro-derived offspring are susceptible to large offspring syndrome resulting from certain culture conditions. The exact contribution of compromised competence of in vitro-derived embryos to embryonic loss in farm animals is unclear, and hampered by an incomplete understanding of important genes required for embryonic development. Therefore, the present studies were conducted to understand the function and regulation of oocyte-specific transcription factors in mediating key developmental events critical to success of early embryonic development and provide foundation for future investigation on the identification of molecular biomarkers predictive of oocyte quality, which would be useful in developing assays to test oocyte developmental competence and strategies to enhance in vitro development rate, including improved media formulation. 


\section{OBJECTIVES}

In efforts to understand the function and regulation of oocyte-specific transcription factors during early embryonic development in cattle, the objectives of this study are to:

1. Clone and characterize the expression of bovine FIGLA and NOBOX.

2. Functionally analyze the effect of siRNA-induced knockdown of NOBOX on bovine early embryonic development and blastocyst cell allocation.

3. Determine if a specific microRNA is responsible for the degradation of the FIGLA and NOBOX mRNA and inhibition of its translation following embryonic genome activation in bovine early embryos.

4. Cloning and expression analysis of bovine fetal ovary microRNAs

5. Elucidate the role of SUMOylation in regulating bovine oocyte-specific proteins. 
CHAPTER-1 


\title{
A novel functional role for the oocyte-specific transcription factor newborn ovary homeobox (NOBOX) during early embryonic development in cattle
}

\author{
Swamy K. Tripurani ${ }^{1}$, Kyung-Bon Lee ${ }^{2,3}$, Lei Wang ${ }^{1}$, Gabbine Wee ${ }^{2,3}$, George W. Smith ${ }^{2,3,4}$, \\ Young S. Lee ${ }^{5}$, Keith E. Latham ${ }^{5,6}$, and Jianbo Yao ${ }^{1 *}$
}

Endocrinology 2011 Mar; 152 (3): 1013-1023

${ }^{1}$ Laboratory of Animal Biotechnology and Genomics, Division of Animal and Nutritional Sciences, West Virginia University, Morgantown, WV 26506.

${ }^{2}$ Laboratory of Mammalian Reproductive Biology and Genomics, Departments of Animal Science ${ }^{3}$ and Physiology ${ }^{4}$, Michigan State University, East Lansing, Michigan 48824.

${ }^{5}$ The Fels Institute for Cancer Research and Molecular Biology, and ${ }^{6}$ Department of Biochemistry Temple University, Philadelphia, Pennsylvania.

KEYWORDS: NOBOX, oocyte, early embryogenesis and cattle

\section{AUTHOR'S CONTRIBUTIONS}

SKT designed and performed most of the experiments including cloning and expression analysis of NOBOX, preparation of NOBOX siRNA, and analysis of gene expression in microinjection experiments. SKT also drafted the manuscript. KBL and GW performed the microinjection experiments. LW assisted for immunohistochemistry experiment. KEL and YSL provided microarray data. GWS and JY designed the study and supervised the experimental work. 


\section{ABSTRACT}

Newborn ovary homeobox (NOBOX) is an oocyte-specific transcription factor essential for folliculogenesis and expression of many germ-cell specific genes in mice. Here we report the characterization of the bovine $N O B O X$ gene and its role in early embryogenesis. The cloned cDNA for bovine NOBOX contains an open reading frame encoding a protein of 500 amino acids with a conserved homeodomain. mRNA for NOBOX is preferentially expressed in ovaries and undetectable by RT-PCR in somatic tissues examined. NOBOX protein is present in oocytes throughout folliculogenesis. NOBOX is expressed in a stage-specific manner during oocyte maturation and early embryonic development and of maternal origin. Knockdown of NOBOX in early embryos using small interfering RNA demonstrated that NOBOX is required for embryonic development to the blastocyst stage. Depletion of NOBOX in early embryos caused significant down-regulation of genes associated with transcriptional regulation, signal transduction and cell cycle regulation during embryonic genome activation. In addition, NOBOX depletion in early embryos reduced expression of pluripotency genes (POU5F1/OCT4 and NANOG) and number of inner cell mass cells in embryos that reached the blastocyst stage. This study demonstrates that NOBOX is an essential maternal-derived transcription factor during bovine early embryogenesis, which functions in regulation of embryonic genome activation, pluripotency gene expression and blastocyst cell allocation. 


\section{INTRODUCTION}

During oogenesis, there is an accumulation and storage of maternal RNAs and proteins that are obligatory not only for successful folliculogenesis and germ cell maturation, but also for activation of the embryonic genome and subsequent early embryonic development (De Sousa et al., 1998; Amleh and Dean, 2002). A growing body of evidence supports a role for oocyte derived growth factors, such as growth differentiation factor- 9 and bone morphogenetic protein15 in regulation of ovarian follicular development and several oocyte specific transcription factors have been identified that are required for follicle formation or progression during development. For example, FIGLA (Factor in the germline $\alpha$ ), an oocyte-specific basic helixloop-helix $(\mathrm{bHLH})$ transcription factor required for primordial follicle formation (Soyal et al., 2000), is implicated in the coordinate expression of the three zona pellucida genes (Zp1, Zp2, Zp3) essential for fertilization (Liang et al., 1997). However less is known about maternal regulation of early embryonic development.

The time period during development spanning from fertilization until when control of early embryogenesis changes from regulation by oocyte-derived factors to regulation by products of the embryonic genome is referred to as the "maternal-to-embryonic transition". The products of numerous maternal-effect genes transcribed and stored during oogenesis mediate this transition. Maternal antigen that embryos required (Mater or NIrp5) is the first oocytespecific maternal factor identified in mouse and is known to be essential for the development of embryos beyond the two-cell stage (Tong et al., 2000). The roles of additional oocyte-specific genes Zar1 (Zygotic arrest 1) and Npm2 (Nucleoplasmin 2) in early embryonic development have been revealed from gene targeting studies in mice. Zar1-knockout embryos are arrested at the one cell stage and show marked reduction in the synthesis of the transcription-requiring complex during the maternal-to-embryonic transition (Wu et al., 2003). Npm2-knockout females have fertility defects due to reduced cleavage, absence of coalesced nucleoar structures and 
heterochromatin loss, suggesting that $\mathrm{Npm} 2$ is a critical chromatin remodeling during early embryonic development (Burns et al., 2003). Recently, another maternal-effect gene, FILIA was discovered in mice. FILIA binds to MATER and is essential for maintaining euploidy during cleavage-stage embryogenesis (Zheng and Dean, 2009).

Understanding of maternal-effect genes required for early embryogenesis has clearly been enhanced through results of gene targeting studies in mice. However, due to inherent species-specific differences in the duration and number of cell cycles required for embryonic genome activation and completion of the maternal-to-embryonic transition in mice vs. humans and cattle or other livestock species (Bettegowda et al., 2008a), the regulatory mechanisms and maternal effect genes mediating this transition may vary. Furthermore, understanding of the regulatory role of many known oocyte derived transcription factors in early embryonic development through gene targeting models is limited due to defective follicular development and female sterility. One such transcription factor is newborn ovary homeobox (NOBOX)encoding gene). NOBOX mRNA and protein are preferentially expressed in the germ cells throughout folliculogenesis (Suzumori et al., 2002). Female mice lacking NOBOX are infertile due to postnatal oocyte loss and a disrupted transition in follicular development from primordial to primary follicle (Rajkovic et al., 2004). Furthermore, expression of numerous genes in oocytes linked to female fertility (e.g. Pou5f1/Oct4, Gdf9, Bmp15, Zar1, and Mos) and certain microRNAs were drastically reduced in newborn ovaries that lack NOBOX (Rajkovic et al., 2004; Choi et al., 2007). Recently, mutations in the NOBOX gene that are associated with premature ovarian failure in humans have been identified (Qin et al., 2007; Qin et al., 2009). However, despite its established role in control of oocyte gene expression, the requirement of NOBOX for early embryonic development has not been investigated.

We hypothesize that maternal (oocyte-derived) NOBOX also is required for early embryonic development and expression of NOBOX-responsive genes at embryonic genome activation critical for normal blastocyst development. The objectives of the present studies were 
1) to clone and determine intraovarian localization of the bovine NOBOX gene, and 2) to elucidate the functional role of bovine NOBOX in early embryonic development.

\section{MATERIALS AND METHODS}

\section{Tissue collection}

Bovine tissue samples including adult ovary, adult testis, liver, thymus, kidney, muscle, heart, cortex (brain), spleen, pituitary, adrenal, lung, fetal ovary and fetal testis were obtained at a local slaughterhouse. Age of fetuses from which fetal ovaries were collected was estimated by measuring the crown-rump length (Richardson et al., 1990). Granulosa cells (Murdoch et al., 1981) and cumulus cells (Bettegowda et al., 2008b) were isolated as described. All samples were frozen in liquid nitrogen and stored at $-80^{\circ} \mathrm{C}$ until use.

\section{RNA isolation, cDNA synthesis and RT-PCR analysis}

Total RNA was extracted using TRIzol reagent (Invitrogen, Carlsbad, CA) according to the manufacturer's instructions. After treatment with TURBO ${ }^{\mathrm{TM}}$ DNase I (Ambion, Inc., Austin, TX), reverse transcription was performed on approximately $1 \mu \mathrm{g}$ of isolated RNA in $20 \mu \mathrm{l}$ of reaction solution using Superscript III reverse transcriptase (Invitrogen). The RT-PCR was performed by denaturation at $95 \mathrm{C}$ for 3 minutes followed by 35 cycles of $95 \mathrm{C}$ for $30 \mathrm{sec}, 58 \mathrm{C}$ for $45 \mathrm{sec}$ and $72 \mathrm{C}$ for $90 \mathrm{sec}$ and final extension at $72 \mathrm{C}$ for $10 \mathrm{~min}$. The amplified products

were separated through a $1 \%$ agarose gel containing ethidium bromide. Amplification of cDNA for bovine ribosomal protein L19 (RPL19) was used as a positive control for RNA quality and RT. See Table 1 for the list of primer sequences.

\section{Cloning of Bovine NOBOX cDNA}


Based on the predicted cDNA sequence for the bovine NOBOX gene in the National Center for Biotechnology Information Database, primers were designed (Table 1) to amplify $1500 \mathrm{bp}$ fragment from bovine fetal ovary (enriched source of oocytes). The amplified cDNA fragment (1500 bp) was cloned using a TOPO cloning kit (Invitrogen) and completely sequenced. Gene-specific rapid amplification of cDNA ends (RACE) primers (Table 1) were designed based on the obtained sequence, and 5' and 3' RACE was performed to extend the $5^{\text {' }}$ and 3' end of the cDNA sequence using the second-generation 5'/3' RACE kit (Roche Diagnostics, Indianapolis, IN) according to the manufacturer's protocol.

\section{Northern Blot Analysis}

For determining the size of the bovine NOBOX transcript, Northern blot analysis was performed as described previously (Tejomurtula et al., 2009).

\section{Immunohistochemistry}

Immunohistochemistry was performed using Ultrasensitive avidin-biotin-peroxidase complex staining kit (Pierce Chemical Co., Rockford, IL) according to the manufacturer's instructions. Briefly, approximately $10-\mu \mathrm{m}$ serial sections of bovine fetal ovary (d 230 of gestation) were prepared and mounted onto polylysine-coated slides. The sections were deparaffinized in xylene and then rehydrated in graded alcohol. After treatment with $0.3 \%$ hydrogen peroxide in methanol to eliminate endogenous peroxidase activity, the sections were blocked for 30 min with blocking buffer. After blocking, rabbit polyclonal anti-NOBOX antibody (ab41612; Abcam, Cambridge, MA) diluted 1:100 in blocking buffer was applied to each section and incubated for $1 \mathrm{~h}$. The sections were then washed for $15 \mathrm{~min}$ in PBS, and incubated with biotinylated anti-rabbit IgG for $1 \mathrm{~h}$, followed by incubation with avidin-biotin-peroxidase complex reagent for $1 \mathrm{~h}$ at room temperature. The sections were developed using a metal-enhanced DAB Substrate kit (Pierce) for 2-10 $\mathrm{min}$ and were then counterstained with VECTOR 
Hematoxylin QS (Vector Laboratories, Burlingame, CA) and mounted with Permount (Fisher Scientific, Fair Lawn, NJ). For negative controls, sections were incubated in the absence of antiNOBOX antibody.

\section{Quantitative real-time RT-PCR}

The oocytes and embryo samples used in the experiment included germinal vesicle (GV)- and metaphase II (MII)-stage oocytes and pronuclear, two-cell, four-cell, eight-cell, 16-cell and morula- and blastocyst- stage embryos ( $n=5$ pools of 10 embryos) generated by in vitro fertilization of abattoir-derived oocytes as described elsewhere (Bettegowda et al., 2006). Procedures used for RNA isolation, cDNA synthesis and quantitative real-time PCR analysis of mRNA abundance during oocyte maturation and early embryonic development were conducted as described previously (Bettegowda et al., 2006; Tejomurtula et al., 2009). See Table 1 for the list of primer sequences.

\section{RNAi experiments}

Knockdown of endogenous NOBOX in bovine embryos was performed via microinjection of NOBOX small interfering RNA (siRNA). RNAi experiments were conducted according to our published procedures (Bettegowda et al., 2007; Lee et al., 2009; Tejomurtula et al., 2009) with modifications noted herein. The publicly available siRNA design algorithm (siRNA target finder, Ambion) was used to design four distinct siRNA species targeting the open reading frame of bovine NOBOX mRNA (designated as siRNA species 1, 2, 3 and 4 respectively). The candidate siRNA species were interrogated by using the basic local alignment tool program (http://blast.ncbi.nlm.nih.gov/Blast.cgi) to rule out homology to any other known genes in the bovine expressed sequence tag and genomic database. The NOBOX siRNA species were synthesized using the Silencer siRNA construction kit (Ambion) according to the manufacture's instructions. The sense and antisense oligonucleotide template sequences for both siRNA 
species are given in Table 1. Procedures for in vitro maturation of oocytes (obtained from abattoir-derived ovaries) and in vitro fertilization to generate zygotes for microinjection, and for subsequent embryo culture were conducted basically as described elsewhere (Bettegowda et al., 2006). Presumptive zygotes collected at 16-18 h post insemination (hpi) were used in all microinjection experiments. Each individual siRNA species was validated for efficacy of NOBOX mRNA knockdown in early embryos. Presumptive zygotes were microinjected with approximately $20 \mathrm{pl}$ of individual NOBOX siRNA species ( $25 \mu \mathrm{m}$ concentration each) and fourcell embryos were collected at $42-44 \mathrm{hpi}$ for real-time PCR analysis of NOBOX mRNA. Uninjected embryos and embryos injected with a negative siRNA (universal control No. 1; Ambion) were used as control groups ( $n=4$ pools of 10 embryos per treatment). Efficacy of NOBOX siRNA in reducing NOBOX protein in early embryos was determined by NOBOX immunostaining of eight-cell embryos collected $72 \mathrm{hpi}(\mathrm{n}=10-15$ embryos per group). The development of the uninjected or injected embryos (with NOBOX siRNA or negative control siRNA) was evaluated by recording the proportion of embryos that cleaved (48 $\mathrm{h}$ after insemination) and reached eight- to 16 -cell stage (72 $\mathrm{h}$ after insemination) and blastocyst stage (7 days after insemination). Each group contained 25-30 embryos per treatment ( $n=4$ replicates).

\section{Immunofluorescent Staining}

Immunoflorescent staining was performed according to previously published procedures (Silva et al., 2003) with modifications noted herein. Oocytes and embryos were fixed in $4 \%$ paraformaldehyde in PBS for $30 \mathrm{~min}$ at room temperature. Fixed oocytes and embryos were washed in PBS three times and quenched for $5 \mathrm{~min}$ with $0.05 \%$ (wt/vol) solution of sodium borohydrate in PBS to reduce fluorescence background. They were washed again in PBS three times and permeabilized with $0.1 \%$ Triton $\mathrm{X}-100$ in PBS for $15 \mathrm{~min}$. After washing with PBS samples were incubated in blocking solution ( $2 \%$ BSA and $10 \%$ normal goat serum in PBS) for 
at least $1 \mathrm{~h}$. Immunoflorescent staining was performed by incubating samples in rabbit polyclonal anti-NOBOX antibody diluted $1: 50$ in PBS containing $0.5 \%$ (wt/vol) BSA and $0.1 \%$ (wt/vol) $\mathrm{NaN}_{3}$ overnight at $4^{\circ} \mathrm{C}$. Oocytes and embryos were then washed for 45 min in PBS containing $0.1 \%(\mathrm{wt} / \mathrm{vol})$ Tween-20 at room temperature, transferred to the fluorescein isothiocyanate-conjugated secondary antibody (F9887; Sigma-Aldrich) diluted in PBS containing $0.5 \%$ (wt/vol) BSA and $3 \%$ normal goat serum and incubated for $60 \mathrm{~min}$. Finally they were washed with PBS containing $0.1 \%$ (wt/vol) Tween-20 for 30 min and mounted on slides using an anti-fading medium containing 4', 6-diamidino-2-phenylindole (ProLong® Gold antifade reagent with DAPI, Invitrogen). At least 10 oocytes/embryos were processed for each stage/treatment, and experiments were replicated at least three times. For negative control, the oocytes and embryos were incubated in the absence of anti-NOBOX antibody.

\section{Identification of zygotic transcripts in eight-cell embryos by microarray analysis}

In vitro maturation of oocytes and in vitro fertilization were conducted as described (Bettegowda et al., 2006). Presumptive zygotes were cultured in potassium simplex optimization medium containing $0.3 \% \mathrm{BSA}$ in the presence or absence of $50 \mathrm{mg} / \mathrm{ml}$ of the transcription inhibitor alpha-amanitin and eight-cell embryos collected $52 \mathrm{~h}$ later. Groups of eight-cell embryos were pooled within treatment $(n=10$ embryos per pool; $n=3$ replicates for alphaamanitin and $n=4$ replicates for untreated controls) and frozen in $20 \mu$ l PicoPure lysis buffer and RNA purification was performed using PicoPure RNA isolation kit. Purified RNA was subjected to two rounds of reverse transcription and in vitro transcription with biotinylated nucleotides according to Affymetrix (Santa Clara, CA) two-cycle eukaryotic target labeling protocol. Biotin-labeled cRNA samples were fragmented and hybridized to Affymetrix Bovine Genome Arrays at the University of Pennsylvania Microarray Core Facility. Raw probe level data were imported into Affymetrix Expression Console 1.1, and a quantile normalization and summarization were performed using the Robust Multichip Analysis function. For Significant 
Analysis of Microarray, analysis probe sets were first filtered by detection calls using Affymetrix MAS 5.0. Only those probe sets called 'Present' in at least three out of four replicates were considered for Significant Analysis of Microarray. Probe sets identified as differentially expressed at the False Discovery Rate less than 5\% were analyzed further by Student t-test. Probe sets that were higher in untreated embryos at $P<0.05$ and hence down-regulated by $\alpha$ amanitin treatment were considered as alpha-amanitin sensitive probe sets representing transcripts of embryonic origin in eight-cell embryos.

\section{Effect of NOBOX knockdown on expression of predicted NOBOX responsive genes at embryonic genome activation}

To determine the effects NOBOX knockdown on expression of predicted NOBOXresponsive genes at EGA, presumptive zygotes were subjected to NOBOX siRNA microinjection. Uninjected embryos and embryos injected with a negative control scrambled siRNA (universal control No. 1; Ambion) were used as control groups. After microinjection, groups of embryos were cultured in $75-$ to $90-\mu$ drops of potassium simplex optimization medium (Specialty Media, Phillipsburg, NJ) supplemented with $0.3 \%$ BSA and eight-cell embryos were collected at 52 hpi for real time PCR analysis of predicted NOBOX responsive genes ( $n=10$ embryos per treatment; $n=4$ replicates). See Table 1 for the list of primer sequences. oPOSSUM analysis software (http://www.cisreg.ca/cgibin/oPOSSUM/opossum) (Ho Sui et al., 2007) was used to identify the NOBOX binding elements (NBE) in the promoter regions of zygotic transcripts at EGA. A combination of a $Z$ score more than 10 , Fisher $P$ value $<0.01$ and transcription factor binding score more than 10 was used, which is known to provide minimal likelihood of false positive results (Ho Sui et al., 2007).

Effects of NOBOX knockdown on cell allocation to trophectoderm and inner cell mass in bovine blastocyts 
To determine the effect of NOBOX depletion on total cell numbers and allocation to TE vs. ICM cells, NOBOX siRNA injected embryos that reached the blastocyst stage were subjected to differential staining using previously published procedure (Machaty et al., 1998). The uninjected embryos and negative control siRNA injected embryos that reached the blastocyst stage were used as controls. At least 10 blastocyts were processed for each treatment, and experiments were replicated four times. A subset of blastocysts from each treatment group were pooled ( $n=4$ pools of three blastocysts) and subjected to real-time RTPCR analysis of mRNA abundance for POU5F1/OCT4, ICM marker NANOG and TE marker CDX2. See Table 1 for the list of primer sequences.

\section{Statistical Analysis}

For real-time PCR experiments, differences in NOBOX mRNA abundance were analyzed by one-way ANOVA using the general linear models procedure of SAS. For microinjection experiments, rates of embryo development (eight- to 16-cell and blastocyst stages) and blastocyst cell numbers (TE, ICM and total cell numbers) percent data were subjected to arc-sin transformation before analysis as described above. Differences in treatment means were compared using Fisher's protected least significant difference test. Different letters indicate significant differences $(P<0.05)$.

\section{RESULTS}

\section{Complementary DNA (cDNA) cloning and genome organization of bovine NOBOX}

Using the primers designed based on the predicted bovine NOBOX cDNA sequence; we successfully amplified a cDNA fragment (1500 bp) representing the coding region of bovine NOBOX from bovine fetal ovary cDNA. Northern blot analysis revealed a single transcript of 
approximately $2.2 \mathrm{~kb}$ in bovine adult ovary sample (Fig. 1A). Thus additional 5' - (463 bp) and 3' - (312 bp) sequences were obtained using RACE procedures. The assembled full-length NOBOX cDNA (HQ589330) is 2275 bp containing an open reading frame encoding a protein of 500 amino acids with a conserved homeodomain and typical nuclear localization signal (Fig. 2). The predicted NOBOX protein shares $61 \%$ and $49 \%$ amino acid sequence identity with its human and mouse counterparts, respectively (Fig. 3). A basic local alignment tool search of the bovine genome database at National Centre for Biotechnology Information revealed that the bovine NOBOX gene is located on chromosome 4, and spans approximately $5.5 \mathrm{~kb}$. Exon and intron boundaries of the genes were determined using the Spidey program (http://www.ncbi.nlm.nih.gov/IEB/Research/Ostell/Spidey/). The bovine NOBOX gene has seven exons and six introns as determined by the program (Table 2), and all splice sites are in agreement with the consensus sequence (GT-AG rule).

\section{Tissue distribution of bovine NOBOX mRNA}

RT-PCR analysis of RNA samples from a panel of 14 different bovine tissues revealed that expression of $N O B O X$ mRNA is restricted to adult and fetal ovaries with very minor expression in adult testicular samples (Fig. 1B). Analysis of NOBOX mRNA expression in bovine fetal ovaries of different developmental stages showed that the NOBOX mRNA could be detected in fetal ovaries harvested as early as 100 days of gestation period (when primary follicles start to form in cows), and is highly abundant in the fetal ovaries of late gestation (Fig. 1C). RT-PCR analysis using RNA isolated from oocytes, granulosa cells and cumulus cells indicates that bovine $N O B O X$ is expressed in oocytes but not in other follicular somatic cells examined (Fig. 1D).

\section{Intraovarian and intra-oocyte localization of NOBOX protein}


Immunohistochemical localization of NOBOX protein within fetal ovary sections revealed that NOBOX protein is present in oocytes of growing follicles at the primordial (Fig. 4A panel A; single layer of flattened granulosa cells), primary (Fig. 4A panel B; single layer of cuboidal granulosa cells), secondary (Fig. 4A panel b; multiple layers of cuboidal granulosa cells) through antral follicle stages (Fig. 4A panel C). Immunoreactivity was not detected in granulosa cells, theca cells, cumulus cells and control tissue sections incubated in absence of NOBOX antibody (Fig. 4A panel D). Immunocytochemical analysis of NOBOX protein in GV oocytes using confocal spinning disk microscopy demonstrated that NOBOX protein is localized in both the nucleus and cytoplasm (Fig. 4B).

\section{Spatiotemporal expression of bovine NOBOX mRNA and protein during oocyte maturation and early embryonic development}

To determine the function of NOBOX during bovine early embryonic development, the temporal expression characteristics of NOBOX in oocytes and early bovine embryos were first investigated. NOBOX mRNA was abundant in germinal vesicle and metaphase II stage oocytes, as well as pronuclear to eight-cell stage embryos, but barely detectable in embryos collected at morula and blastocyst stages (Fig. 5A) suggesting that NOBOX mRNA was maternal in origin. Furthermore, NOBOX mRNA abundance in eight-cell embryos was not diminished by culture in the presence of the transcriptional inhibitor alpha-amanitin (data not shown). Immunocytochemical analysis demonstrated that NOBOX protein was abundant in GV- and MIIstage oocytes as well as in pronuclear, two-cell and four-cell stage embryos, but immunostaining for the NOBOX protein abundance declined by the eight-cell stage and was barely detectable at morula and blastocyst stages (Fig. 5B). Based on the observed spatiotemporal expression pattern, we hypothesized that NOBOX may have a functional role in bovine early embryonic development. 


\section{NOBOX is required for bovine early embryonic development}

To investigate the function of NOBOX in early embryonic development, we performed RNAi experiments to reduce NOBOX expression in bovine embryos. Four NOBOX siRNA species targeting different regions of the $N O B O X$ transcript were produced in vitro, and initial experiments were performed to test the efficacy and specificity in silencing the NOBOX gene. siRNA 2 and siRNA3 each resulted in a more than $80 \%$ reduction $(\mathrm{P}<0.05)$ in NOBOX mRNA in four-cell embryos relative to uninjected control (Fig. 6). Microinjection of a cocktail of NOBOX siRNA2 and 3 significantly reduced NOBOX mRNA levels in four-cell embryos by more than 95\% relative to uninjected and negative control siRNA-injected embryos (Fig. 7A). Microinjection of the siRNA mixture (siRNA2 and siRNA3) also dramatically reduced NOBOX immunostaining in eight-cell embryos (Fig. 7B). Further analysis by Western blot also showed reduced NOBOX protein in siRNA-injected embryos (Fig. 8).

To determine whether knockdown of NOBOX in bovine embryos has any effect on embryonic development, cleavage rate and proportion of embryos developing to eight- to 16-cell and blastocyst stage for NOBOX siRNA injected $v s$. uninjected and negative control siRNA injected embryos were determined. NOBOX siRNA (siRNA2 and siRNA3) injection into bovine zygotes did not affect the cleavage rates (Fig. 9A) but reduced the proportion of embryos developing to eight- to 16-cell stage (Fig. 9B) and blastocyst stage (Fig. 9C) relative to the uninjected and negative control siRNA-injected embryos. These results clearly indicate that knockdown of NOBOX in bovine zygotes impaired development to the blastocyst stage.

\section{NOBOX is essential for induction of specific zygotic transcripts during embryonic genome activation}

Given the effect on preimplantation development, we tested whether NOBOX regulates expression of zygotic transcripts synthesized during embryogenesis. Microarray analysis of control and $\alpha$-amanitin treated embryos collected at the eight-cell stage was used to identify 
transcripts of embryonic origin induced coincident with EGA. A total of 198 gene transcripts, which were decreased by 10 -fold and greater range in $\alpha$-amanitin treated eight-cell stage embryos was selected to identify NOBOX binding elements (NBE) in their promoter regions using the oPOSSUM analysis software (http://www.cisreg.ca/cgibin/oPOSSUM/opossum) (Ho Sui et al., 2007). A total of 21 genes with NBEs that are significantly overrepresented in their promoter regions was identified (Table 3). Six such genes (JAG1, WEE1, PITX2, CCNE1, KLF5 and FZD8) were chosen for further examination based on their function and importance during embryogenesis. Interestingly, all six mRNAs were significantly diminished in abundance in NOBOX siRNA injected embryos collected at the eight-cell stage (Fig. $10 \mathrm{~A}-\mathrm{F}$ ). The expression of these transcripts was also suppressed in the $\alpha$-amanitin treated embryos collected at eightcell stage, confirming they originated from the embryonic genome. Our results suggest that NOBOX either directly or indirectly up-regulates expression of genes from the embryonic genome linked to early development.

\section{NOBOX regulation of blastocyst cell allocation}

NOBOX directly regulates the transcription of Pou5f1/Oct4 in mouse oocytes during folliculogenesis (Choi and Rajkovic, 2006). Therefore, we sought to address whether the expression of POU5F1/OCT4 and other genes linked to blastocyst cell allocation (NANOG and CDX2) was affected in the NOBOX siRNA-injected embryos that reached the blastocyst stage. By performing quantitative real-time PCR analysis, we found that the POU5F1/OCT4 and NANOG mRNA expression levels were significantly reduced in the NOBOX siRNA-injected embryos that reached the blastocyst stage compared to the uninjected embryos and negative control siRNA-injected embryos that reached the blastocyst stage (Fig. 11 A-B). No effect of NOBOX siRNA on CDX2 (marker of TE) mRNA abundance in the resulting blastocysts was observed (Fig. $11 \mathrm{C}$ ). NOBOX knockdown dramatically reduced the numbers of ICM cells and total cell numbers but did not influence numbers of TE cell in resulting blastocysts (Fig. 11 D-F). 
Collectively, these results support a functional role for NOBOX in regulating pluripotency genes and cell allocation in bovine blastocysts.

\section{DISCUSSION}

Our results established a functional role for the oocyte derived transcription factor NOBOX in regulation of early embryonic development. NOBOX is expressed in a stage-specific manner during early embryonic development and its depletion in bovine zygotes by siRNA microinjection impaired embryo development to the blastocyst stage. Moreover, knockdown of NOBOX affected the expression of genes from the embryonic genome critical to early development and expression of pluripotency genes and blastocyst cell allocation were altered in the NOBOX siRNA-injected embryos that reached the blastocyst stage. Previous studies have established an important functional requirement for NOBOX for normal follicular development in mice (Rajkovic et al., 2004; Choi et al., 2007) and women (Qin et al., 2007; Qin et al., 2009) and ovarian expression of specific genes linked to fertility. To our knowledge, a functional role for NOBOX in regulation of early embryonic development has not been reported.

The data for mouse and bovine together thus indicate an important functional requirement of the oocyte transcription factor NOBOX in the regulation of both follicular development and early embryogenesis. However, a requirement of NOBOX for early embryonic development could not be directly ascertained from previous gene targeting studies in mice. Whereas the contribution of gene targeting technology to enhanced understanding of oocyte regulation of follicular development and early embryonic development is unquestionable, important functional roles of oocyte derived gene products in early embryogenesis could, in fact, be undetected in gene-targeting models with an ovarian phenotype due to disruptions in follicular development that preclude development/release of oocytes from null mutant mothers and presence of oocyte derived RNA and protein for targeted gene in null mutant embryos 
derived from mothers heterozygous for the mutation. These limitations to the study of the functional role of oocyte-derived factors in early embryogenesis can be overcome by cytoplasmic microinjection of double stranded RNA (dsRNA) into wild type embryos post fertilization, which can result in specific and effective translational block through later stages of preimplantation embryo development (Wianny and Zernicka-Goetz, 2000; Paradis et al., 2005; Schellander et al., 2007). The absence of targeted gene product during these developmental stages would reveal important information on gene function and unmask a functional role in early embryogenesis that may not be detectable using conventional gene-targeting strategies. Results of the present studies clearly support a functional role for NOBOX in regulation of multiple aspects of early embryonic development in cattle. For reasons stated above, it is unclear whether observed role of NOBOX in early embryogenesis is conserved across multiple species, including the mouse, or in fact the role of NOBOX in early embryogenesis is species specific. It is known that EGA occurs later in monoovulatory species such as cattle and primates including human, compared with the polyovulatory mouse. Thus the maternal-effect genes required to promote initial cleavage divisions and ensure successful early embryonic development in such monotocous species may be distinct from those required in the polytocous mouse model. A species-specific role for the oocyte specific JY-1 gene in regulation of early embryonic development in cattle has been reported previously (Bettegowda et al., 2007).

The inability of an embryo to reprogram chromatin and activate transcription of important genes during EGA critical to subsequent development is believed to be the one of the major cause of embryo developmental block in vitro (Betts, 2001; Sirard et al., 2006) and presumably early embryonic loss in general. Among the early genes that are transcribed at EGA include genes involved in cell cycle progression, transcription regulation, signal transduction, epigenetic modification, transporters and metabolism (Misirlioglu et al., 2006). However, the specific maternal transcription factors that mediate up-regulation of these early expressed transcripts and proteins during embryonic development are poorly defined. Our results indicate that siRNA 
mediated ablation of NOBOX in early embryos blocks induction of key zygotic transcripts at EGA linked to transcriptional (KLF5, PITX2) (Parisi et al., 2008; Rodríguez-León et al., 2008), cell cycle (WEE1, CCNE2) (Tominaga et al., 2006; Gotoh et al., 2007) and signaling functions (JAG1, FZD8) (Deardorff et al., 1998; Xue et al., 1999) during embryogenesis. Hence, the reduced development of NOBOX-depleted embryos to the blastocyst stage may be attributed to defects in EGA and absence of expression of specific zygotic transcripts critical to development.

The first cell lineage allocation event in mammalian embryogenesis occurs at compaction in mouse embryos and results in the formation of the ICM and TE lineages in the blastocyst (Rossant and Tam, 2009). Multiple lines of evidence indicate the transcription factor Oct4 is essential for the control of early lineage development (Pei, 2009) and the level of Oct4 is crucial for determining the development of distinct cell fates of embryonic stem (ES) cells. Artificial repression of Pou5f1/Oct4 in ES cells induces differentiation of the TE lineage; but when Pou5f1/Oct4 is overexpressed ES cells differentiate mainly into primitive endoderm-like cells (Niwa et al., 2000). In addition, only 1.5 fold-elevated expression of Pou5f1/Oct4 in germ cells leads to development of gonadal tumors (Gidekel et al., 2003) and loss of Pou5f1/Oct4 in germ cells results in apoptosis (Kehler et al., 2004). Furthermore, morpholino-mediated depletion of Pou5f1/Oct4 in one- to two-cell stage mouse embryos affected embryonic development prior to the blastocyst stage (Foygel et al., 2008). Interestingly, such studies also reported that Pou5f1/Oct4 plays a critical role in reprogramming the early embryo during the maternal-to-embryonic transition by regulating genes that encode for transcriptional and posttranscriptional regulators (Foygel et al., 2008). Therefore, Pou5f1/Oct4 expression must be strictly controlled in a developmental stage- and cell type-specific manner. However, the precise mechanism and the number of transcription factors involved in the regulation POU5F1/OCT4 levels in vivo during development are not well understood. Recently, several factors have been identified, such as NANOG (Pan et al., 2006), SOX2 (Chew et al., 2005), FOXD3 (Pan et al., 2006) and SALL4 (Zhang et al., 2006), that are critical in modulating embryonic stem cell 
pluripotency and early embryonic development via transcriptional regulation of POU5F1/OCT4. Results of the present studies demonstrated that ablation of NOBOX in early embryos significantly reduced the zygotic transcription of POU5F1/OCT4 in embryos that reached the blastocyst stage, indicating that NOBOX is also a key regulator of POU5F1/OCT4 expression during early embryonic development. NOBOX binding and transactivation of the mouse Pou5f1/Oct4 promoter have been previously reported (Choi and Rajkovic, 2006).

Ablation of NOBOX in early embryos also impacted cell lineage determination in embryos that reached the blastocyst stage resulting in reduced total cell numbers and numbers of ICM cells. Effects of NOBOX depletion on cell allocation in embryos reaching the blastocyst stage may be directly linked to reduced expression of POU5F1/OCT4. Previous studies demonstrated that POU5F1/OCT4 knockdown in bovine zygotes resulted in reduced numbers of ICM cells in resulting blastocysts (Nganvongpanit et al., 2006). Reduced expression of NANOG mRNA in blastocysts derived from NOBOX siRNA injected embryos was also observed in the present studies. Previous studies reported that POU5F1/OCT4 is required for the transcriptional regulation of Nanog, because knockdown of Pou5f1/Oct4 through RNAi in mouse ES cells significantly reduced Nanog promoter activity (Rodda et al., 2005). Hence, the decreased expression of NANOG mRNA and reduced number of ICM cells might also be directly attributed to down-regulation of POU5F1/OCT4 expression in NOBOX-depleted embryos.

No effect of NOBOX ablation on numbers of TE cells or expression of the TE specific transcription factor CDX2 mRNA was observed in the present studies, supporting specific effects of NOBOX ablation on the ICM lineage. In contrast, Pou5f1/Oct4 regulation of Cdx2 and the TE lineage has been reported previously in the mouse model. Suppression of Pou5f1/Oct4 mRNA in mouse ES cells caused induction of characteristics of trophectodermal differentiation and an increase in expression of the trophoblast-specific factor CDX2 (Velkey and O'Shea, 2003; Hay et al., 2004). More recent studies have described the function of maternally and zygotically provided CDX2 in maintaining appropriate polarization of blastomeres at the eight- 
and 16-cell stage and TE lineage-specific differentiation during early development of the mouse embryo (Jedrusik et al., 2010). More detailed analysis will be required to determine the specific mechanisms responsible for reduced numbers of ICM, but not TE cells in blastocysts derived from NOBOX-depleted embryos and the specific role of oocyte-derived NOBOX in regulatory networks in embryo-derived pluripotent stem cells.

In summary, results of the present studies establish a novel functional role for NOBOX during early embryonic development in the bovine model. Results support an important requirement of NOBOX for embryonic development to the blastocyst stage and blastocyst cell allocation and suggest that NOBOX mediates up-regulation of specific zygotic transcripts at EGA critical to subsequent development. Results also provide critical new information regarding the spatiotemporal expression of NOBOX during oocyte and early embryonic development. In the unique developmental context of the maternal-embryonic transition, accompanied by deadenylation and degradation of maternal transcripts, it will be interesting to determine the post transcriptional regulatory mechanisms that mediate observed temporal changes in NOBOX mRNA and protein in early embryos and the functional significance of this expression pattern characteristic of other maternal effect genes critical to early embryogenesis.

\section{ACKNOWLEDGMENTS}

This work was supported by National Research Initiative Competitive Grant \#200835203-19094 from the USDA National Institute of Food and Agriculture (GWS), Agriculture and Food Research Initiative Competitive Grant \#2009-65203-05706 from the USDA National Institute of Food and Agriculture (JY), National Institutes of Health Grant RR15253 (KL) and funds from the West Virginia Agricultural and Forestry Experiment Station (Hatch project No. 427). The study is published with the approval of the station director as scientific paper No. 
3085. The authors would like to thank Dr. Jason Knott and Dr. Jason B. Cibelli (Michigan State University) for graciously supporting our microscopy work. 
Table 1. List of primers used in this study

\begin{tabular}{|c|c|c|c|}
\hline Gene Name & Primer Name & Primer sequence (5' to $\left.3^{\prime}\right)$ & Application \\
\hline \multirow[t]{20}{*}{ NOBOX } & NOBOX-ATG-F & ATGAAGGCCTGCCAGCGCCC & cDNA cloning \\
\hline & NOBOX-TAG-R & CTAGGGGCCATGGCCACTCT & cDNA cloning \\
\hline & NOBOX-RACE-3SP1 & GGAGCGGCCCCCGGCCCCCGAG & 3`RACE \\
\hline & NOBOX-RACE-3SP2 & CCGAGGAAGAAGACAAGAGTG & $3^{`} \mathrm{RACE}$ \\
\hline & NOBOX-RACE-3SP3 & AAGAGTGGCCATGGCCCCTAG & $3^{`} \mathrm{RACE}$ \\
\hline & NOBOX-RACE-5SP1 & GGGGCGCTGGCAGGCCTTCAT & 5`RACE \\
\hline & NOBOX-RACE-5SP2 & CCTTCATAGGCCCAGTCCCTTCC & 5`RACE \\
\hline & NOBOX-RACE-5SP3 & CCTTCCCCAGGGGCCTCTGACGG & 5`RACE \\
\hline & NOBOX-RTPCR-F & TGGAGGAGCTAGAAAGGCTCT & RT-PCR analysis \\
\hline & NOBOX-RTPCR-R & GTGTTGGAAGAACTGGGTCTG & RT-PCR analysis \\
\hline & NOBOX-Real time-F & AGACCCAGTTCTTCCAACACC & Real Time PCR \\
\hline & NOBOX-Real time-R & CACAGGACAAGGCAAAGAGAG & Real Time PCR \\
\hline & NOBOX-siRNA-AS1 & AAGCAGAAGAAGCCTAGGGATCCTGTCTC & siRNA synthesis \\
\hline & NOBOX-siRNA-S1 & AAATCCCTAGGCTTCTTCTGCCCTGTCTC & siRNA synthesis \\
\hline & NOBOX-siRNA-AS2 & AAGTGGCGAAAAATGAATGGGCCTGTCTC & siRNA synthesis \\
\hline & NOBOX-siRNA-S2 & AАCCCATTCATTTTTCGCCACCСTGTCTC & siRNA synthesis \\
\hline & NOBOX-siRNA-AS3 & AAGACCСTCTCTTTGCCTTGTCСTGTCTC & siRNA synthesis \\
\hline & NOBOX-siRNA-S3 & AAACAAGGCAAAGAGAGGGTCCCTGTCTC & siRNA synthesis \\
\hline & NOBOX-siRNA-AS4 & AAGTTGAAGGAAAGACTGGACCCTGTCTC & siRNA synthesis \\
\hline & NOBOX-siRNA-S4 & AAGTCCAGTCTTTCCTTCAACССTGTCTC & siRNA synthesis \\
\hline \multirow[t]{2}{*}{ RPS18 } & RPS18-RealTime-F & GTGGTGTTGAGGAAAGCAGACA & $\begin{array}{c}\text { Real IIme PCR (endogenous } \\
\text { control) }\end{array}$ \\
\hline & RPS18-RealTime-R & TGATCACACGTTCCACCTCATC & $\begin{array}{c}\text { Real Time PCR (endogenous } \\
\text { control) }\end{array}$ \\
\hline \multirow[t]{2}{*}{ RPL19 } & RPL19-RTPCR-F & GAAATCGCCAATGCCAACTC & RT-PCR control \\
\hline & RPL19-RTPCR-R & GAGCCTTGTCTGCCTTCA & RT-PCR control \\
\hline \multirow[t]{3}{*}{ GFP } & GFP-Realtime-F & CAACAGCCACAACGTCTATATCATG & $\begin{array}{l}\text { Real Time PCR (exogenous } \\
\text { control) }\end{array}$ \\
\hline & & & Real Time PCR (exogenous \\
\hline & GFP-Realtime-R & ATGTTGTGGCGGATCTTGAAG & control) \\
\hline \multirow[t]{2}{*}{ JAG1 } & JAG1-Real time-F & CTGCATTTAGGGAGTATTCT & Real Time PCR \\
\hline & JAG1-Real time-R & GATTTCCTCACTTAAGGCAG & Real Time PCR \\
\hline \multirow[t]{2}{*}{ WEE1 } & WEE1-Real time-F & GCCTTGTGAATTTGCTGCTAT & Real Time PCR \\
\hline & WEE1-Real time-R & CCAATGCACTAGCTTCAAAGT & Real Time PCR \\
\hline \multirow[t]{2}{*}{ PITX2 } & PITX2- Real time-F & AGCTGTGCAAGAATGGCTTT & Real Time PCR \\
\hline & PITX2- Real time-R & GCTCATGGACGAGATGGAAT & Real Time PCR \\
\hline \multirow[t]{2}{*}{ CCNE2 } & CCNE2-Realtime-F & CAGGTTTGGAATGGGACAAC & Real Time PCR \\
\hline & CCNE2-Realtime-R & CCTGGTGGTTTTTCAGTGCT & Real Time PCR \\
\hline \multirow[t]{2}{*}{ FZD8 } & FZD8-Realtime-F & TGCCATTTGCTGAGCTTGAA & Real Time PCR \\
\hline & FZD8-Realtime-R & AGCAGAGTCGAGGGAGAAAACTT & Real Time PCR \\
\hline \multirow[t]{2}{*}{ KLF5 } & KLF5-Realtime-F & CTCAGACAGGTAGCCCCATCTC & Real Time PCR \\
\hline & & GCTTTGGGAAGAACACTGCAA & Real Time PCR \\
\hline \multirow[t]{2}{*}{ NANOG } & NANOG-Realtime-F & AAAGTTACGTGTCCTTGCAAACG & Real Time PCR \\
\hline & NANOG-Realtime-R & GAGGAGGGAAGAGGAGAGACAGT & Real Time PCR \\
\hline \multirow[t]{2}{*}{ CDX2 } & CDX2-Realtime-F & CGTCTGGAGCTGGAGAAGGA & Real Time PCR \\
\hline & CDX2-Realtime-R & CGGCCAGTTCGGCTTTC & Real Time PCR \\
\hline \multirow{3}{*}{$\begin{array}{l}\text { Pou5f1 } \\
\text { (OCT4) }\end{array}$} & & & \\
\hline & OCT4- Realtime-F & AGGTGTTCAGCCAAACGACTA & Real Time PCR \\
\hline & OCT4- Realtime-R & TCTCCTGCAGATTCTCGTTGT & Real Time PCR \\
\hline
\end{tabular}


Table 2. Genomic organization of bovine NOBOX gene

\begin{tabular}{llllll}
\hline Exon no. & Size $(\mathbf{b p})$ & Sequence & Intron no. & Size $(\mathbf{b p})$ & Sequence \\
\hline 1 & 841 & TGTACCGCTCGGgtaagtcc & 1 & 385 & tcttctagACCAGCTGGAGG \\
2 & 106 & CAGCGCATCATGgtaaaggg & 2 & 319 & ccctacagGTGTGGTTCCAG \\
3 & 109 & CAACCAATGCAGgtaagact & 3 & 774 & gccaccagCTCTGTGGCCGA \\
4 & 73 & ATTCCCTTCCAGgtgagccg & 4 & 223 & gttcccagAGCCGTCCATGC \\
5 & 231 & GTGGGGAACAAGgtacttgt & 5 & 470 & ccccacagCATCACTCCACC \\
6 & 301 & CCGGGAATGTGGgtgagtcg & 6 & 920 & ccccacagGTACGGTGCCCT \\
7 & 591 & & & & \\
\hline
\end{tabular}

Exon and intron sizes are given in base pairs. Intronic and exonic sequences are shown in lower-case and upper case characters, respectively. The first and last two bases of the introns (gt and ag for donors and acceptor splice sites, respectively) are shown in bold and underlined. 
Table 3. List of zygotic transcripts ( $\alpha$-amanitin sensitive) with NOBOX binding elements (NBE) significantly over-represented in their promoter regions, as identified using oPOSSUM analysis software

\begin{tabular}{|c|c|c|c|c|c|}
\hline Accession no & Gene Name & Symbol & $\begin{array}{c}\text { Fold } \\
\text { change }\end{array}$ & TFBS & Function \\
\hline NM 001046199.1 & Collagen, type XI, alpha 2 & COL11A2 & 36.475 & 10.325 & Extracellular matrix structural constituent \\
\hline NM_001045882 & $\begin{array}{c}\text { Diablo homolog } \\
\text { (Drosophila), nuclear gene } \\
\text { encoding mitochondrial } \\
\text { protein }\end{array}$ & DIABLO & 35.736 & 11.363 & Apoptosis \\
\hline NM_001109789 & $\begin{array}{l}\text { Pre-mRNA-processing factor } \\
39 \text { (PRP39 homolog) }\end{array}$ & PRPF39 & 19.351 & 11.012 & RNA processing \\
\hline NM_001097991 & $\begin{array}{c}\text { Pituitary homeobox } 2 \\
\text { (Paired-like homeodomain } \\
\text { transcription factor 2) }\end{array}$ & PITX2 & 28.877 & 10.503 & $\begin{array}{l}\text { Cell differentiation and WNT signalling } \\
\text { pathway, TGF beta pathway }\end{array}$ \\
\hline NM_001110191 & Deleted liver cell 1 & DCL1 & 12.797 & 10.854 & Cell adhesion and migration \\
\hline NM_001034378 & $\begin{array}{l}\text { Ankyrin repeat domain- } \\
\text { containing protein } 1\end{array}$ & ANKRD1 & 19.659 & 10.503 & $\begin{array}{c}\text { Protein binding, transcription corepressor } \\
\text { activity }\end{array}$ \\
\hline XM_594382 & $\begin{array}{c}\text { Achaete-scute homolog } 1 \\
\text { (HASH1) }\end{array}$ & ASCL1 & 11.641 & 11.363 & Transcriptional regulation \\
\hline NM_001034658 & $\begin{array}{l}\text { WD repeat-containing } \\
\text { protein } 89\end{array}$ & WDR89 & 19.486 & 10.834 & Unknown \\
\hline XM_616193 & $\begin{array}{l}\text { Lysine-specific demethylase } \\
\text { 3A (similar to JMJD1A) }\end{array}$ & KDM3A & 10.556 & 10.325 & $\begin{array}{l}\text { DNA methylation, histone modification, } \mathrm{X} \\
\text { chromosome activation }\end{array}$ \\
\hline XM_001252464 & $\begin{array}{l}\text { RING finger protein } 43 \\
\text { Precursor }\end{array}$ & RNF43 & 57.738 & 11.363 & Ubiquitin pathway \\
\hline NM_134447 & $\begin{array}{l}\text { Unconventional prefoldin } \\
\text { RPB5 interactor }\end{array}$ & C19orf2 & 15.247 & 10.325 & Transcriptional corepressor activity \\
\hline XM_001251494 & Protein jagged-1 Precursor & JAG1 & 19.536 & 11.157 & Notch signalling pathway \\
\hline XM_590860 & $\begin{array}{l}\text { Zinc finger } \mathrm{CCHC} \text { domain- } \\
\text { containing protein } 6\end{array}$ & $\mathrm{ZCCHC6}$ & 17.795 & 10.854 & DNA binding \\
\hline XM_866142 & $\begin{array}{l}\text { DnaJ homolog subfamily B } \\
\text { member } 9\end{array}$ & DNAJB9 & 111.660 & 10.503 & Chaperone activity \\
\hline NM_001101054 & $\begin{array}{l}\text { Cyclin-dependent kinase } 4 \\
\text { inhibitor C }\end{array}$ & CDKN2C & 12.659 & 10.325 & $\begin{array}{c}\text { Cyclin-dependent protein kinase inhibitor } \\
\text { activity }\end{array}$ \\
\hline NM_001015665 & G1/S-specific cyclin-E2 & CCNE2 & 13.031 & 10.834 & $\begin{array}{c}\text { p53 signalling / cell cycle / cyclin-dependent } \\
\text { protein kinase inhibitor activity }\end{array}$ \\
\hline NM_001101205 & WEE1 homolog & Wee1 & 12.907 & 10.567 & DNA binding / Protein binding/ Cell cycle \\
\hline XM_869051 & $\begin{array}{l}\text { Frizzled homolog } 8 \\
\text { (Drosophila) }\end{array}$ & FZD8 & 13.981 & 11.012 & WNT signalling pathway \\
\hline NM_001083727 & Kruppel-like factor 5 & KLF5 & 18.090 & 10.065 & RNA polymerase II transcription factor activity \\
\hline NM_001046074 & myc proto-oncogene protein & MYC & 19.806 & 10.834 & $\begin{array}{l}\text { Transcription factor activity/ DNA binding/ } \\
\text { Protein binding }\end{array}$ \\
\hline
\end{tabular}


A.

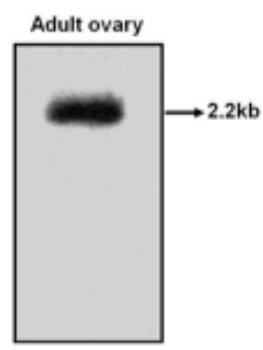

B.

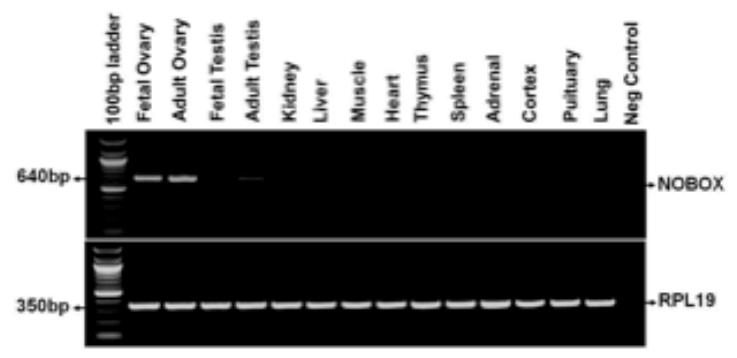

D.

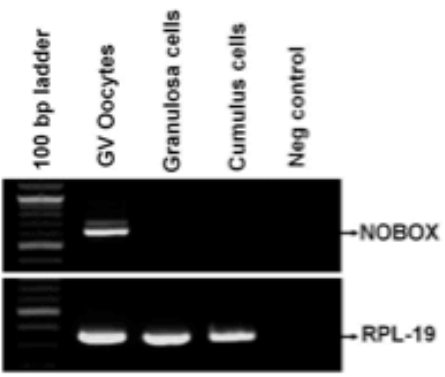

Figure 1. Expression of $N O B O X$ mRNA. A) Northern blot analysis of bovine NOBOX transcript. B) Bovine NOBOX mRNA expression in ovary, testis and 11 somatic tissues determined by RTPCR analysis. C) RT-PCR analysis of bovine NOBOX mRNA expression in bovine fetal ovaries of different developmental stages. D) Expression of bovine NOBOX mRNA in GV stage oocytes, granulosa cells and cumulus cells. Bovine RLP19 was used as an internal control. 


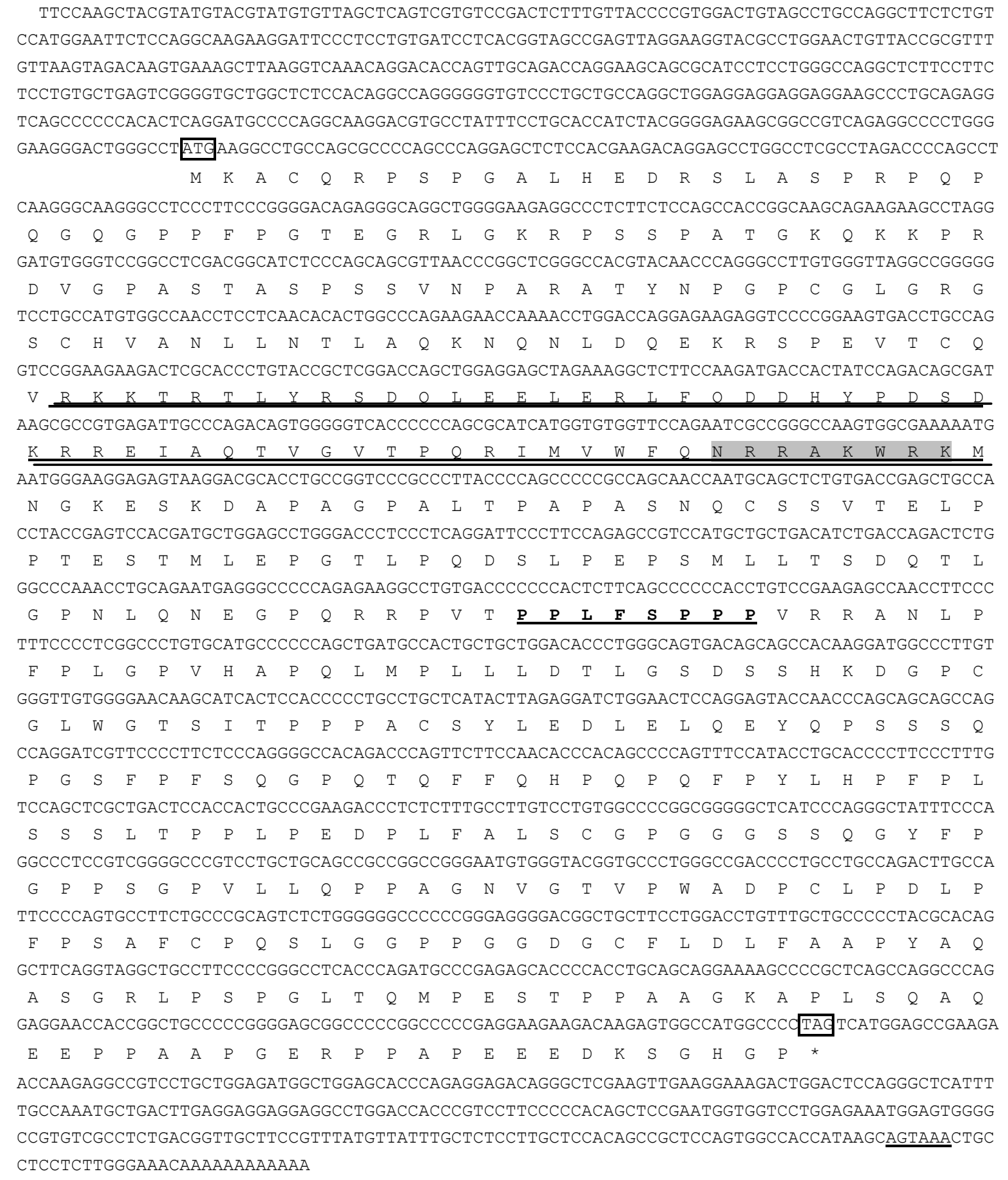

Figure 2. The full-length $N O B O X$ cDNA sequence and predicted amino acid sequence of the NOBOX protein. The initiator ATG and stop codon TAA are boxed and the polyadenylation signal is bold and underlined. The homeodomain region is bold and double underlined. The 
nuclear localization signal (NRRAKWRK) within the homoedomain region is shaded. A putative proline-rich site for binding to an Src Homology 3 (SH3) domain is bold and italicized. 


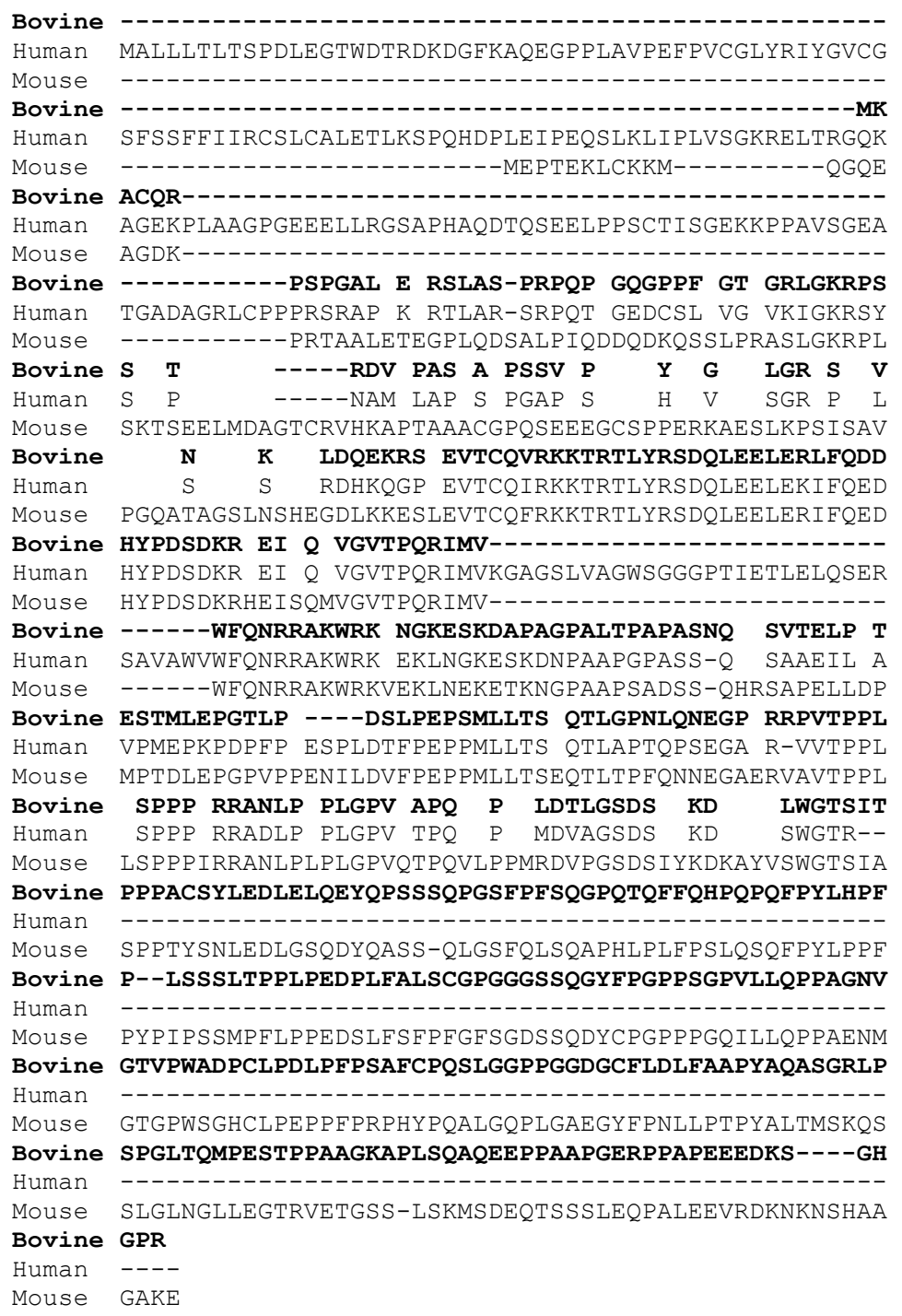

Figure 3. Multiple alignment of the deduced amino acid sequence of NOBOX bovine, human and mouse using ClustalW analysis. 
A

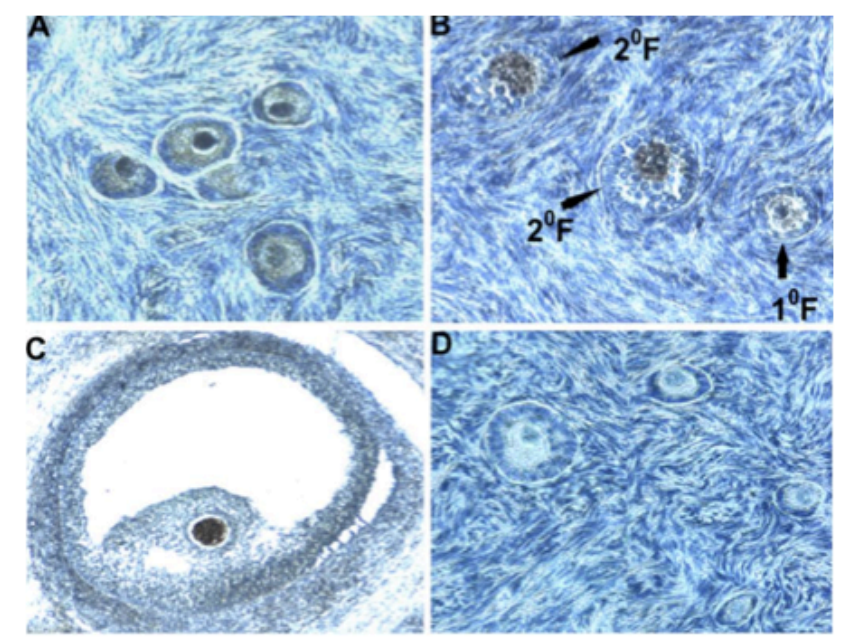

B

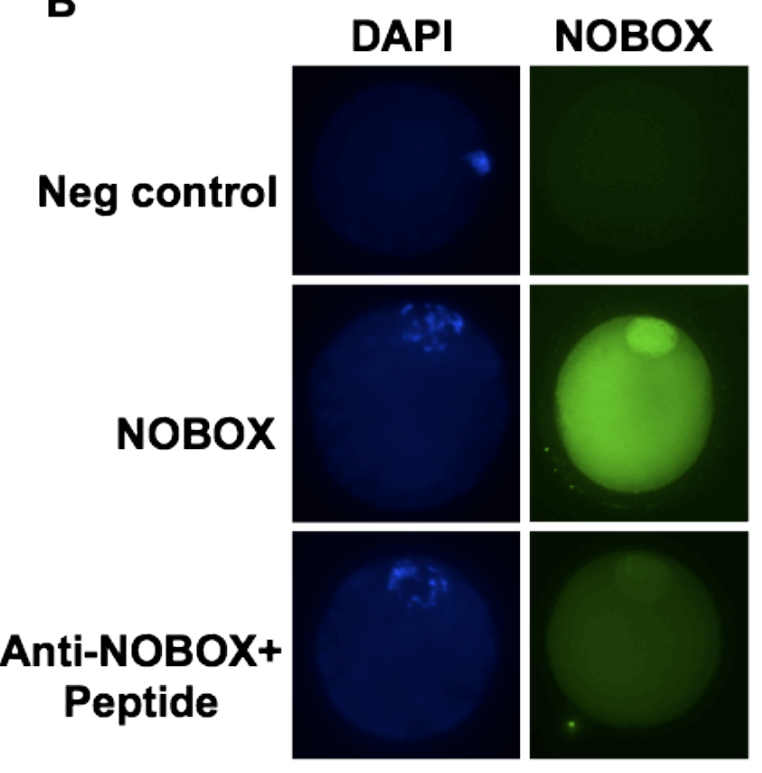

Figure 4. Intraovarian and intra-oocyte localization of NOBOX protein. A) Immunohistochemical localization of NOBOX protein in bovine adult ovary. Oocyte-specific localization of NOBOX protein in primordial follicles (panel A), primary follicle (panel $B, 1^{0} \mathrm{~F}$ ), secondary follicle (panel $\mathrm{B}, 2^{0} \mathrm{~F}$ ) and antral follicle (panel $\mathrm{C}$ ) was observed. No staining signal was observed in the oocytes incubated in the absence of NOBOX antibody (panel D). B) Localization of NOBOX protein in GV oocytes by immunocytochemical analysis using confocal spinning disk microscopy. For negative control, oocytes were incubated with NOBOX antibody preabsorbed with excess antigen (ab41611; Abcam, Cambridge, MA). 


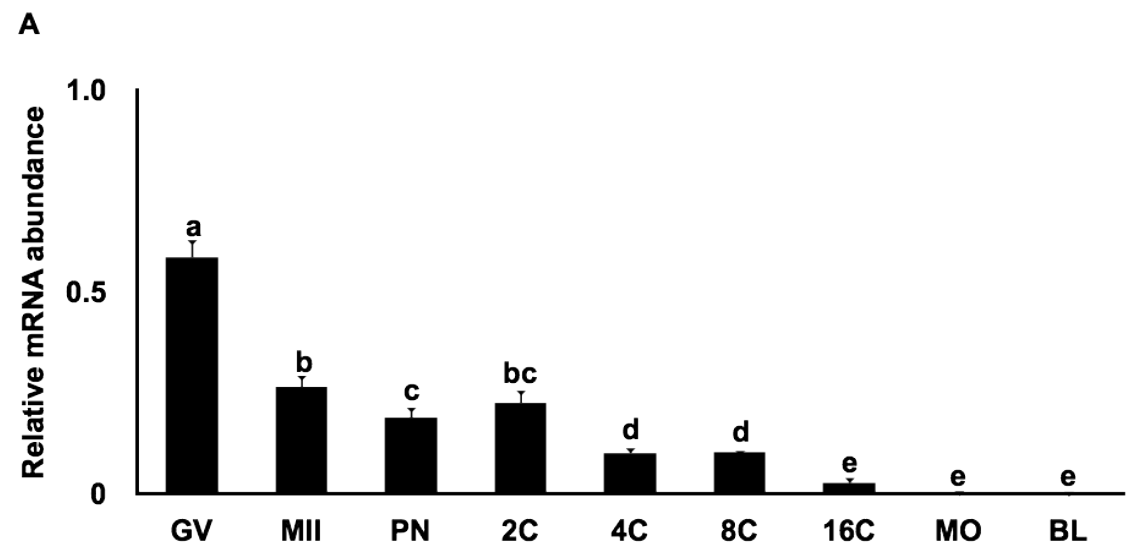

Stages of oocyte and embryo development

B

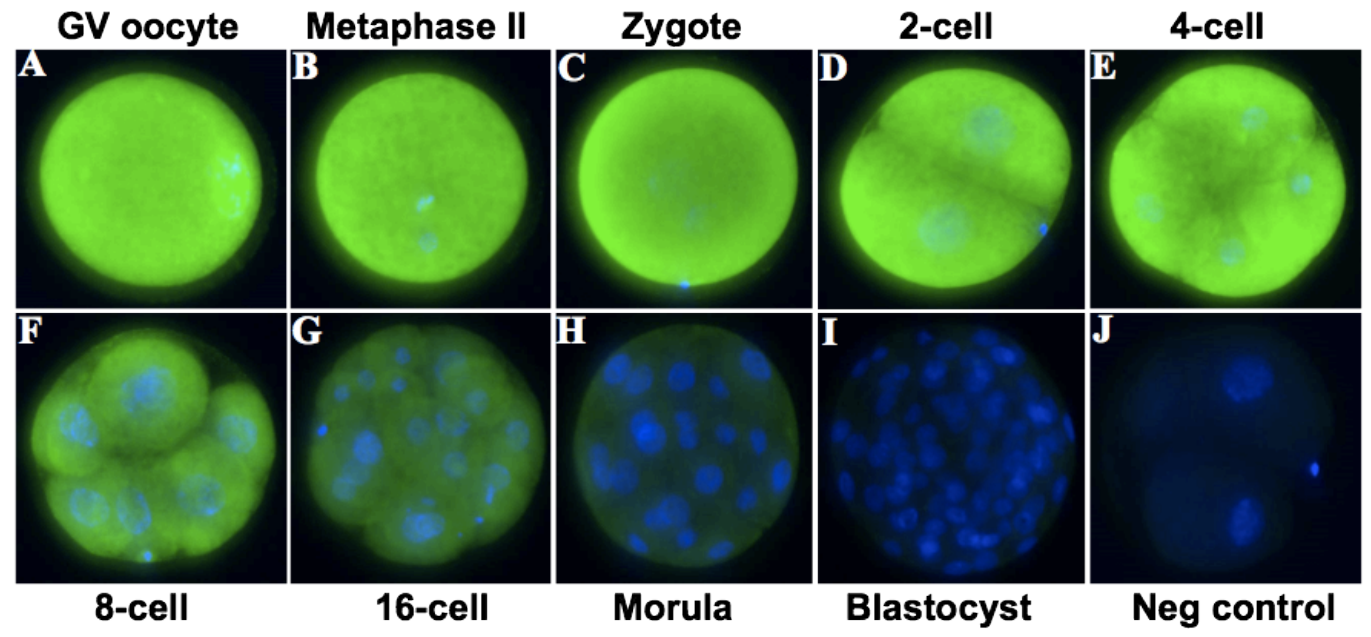

Figure 5. Expression characteristics of bovine NOBOX mRNA and protein during oocyte maturation and early embryonic development. A) Relative abundance of NOBOX mRNA in bovine oocytes and in vitro produced bovine early embryos: GV and MII stage oocytes, pronuclear (PN), two-cell (2C), four-cell (4C), eight-cell (8C), 16-cell (16C), morula (MO) and blastocyst $(B L)$ - stage embryos. Nobox transcript levels were normalized relative to abundance of exogenous control (GFP) RNA and are shown as mean \pm SEM ( $n=4$ pools of 10 embryos per treatment). Different letters indicate statistical difference $(P<0.05)$. B) Immunofluorescent localization of NOBOX protein during oocyte maturation and pre-implantation bovine embryos. Nuclear DNA was stained with 4, 6-diamidino-2-phenylindole (DAPI). Neg, Negative. 


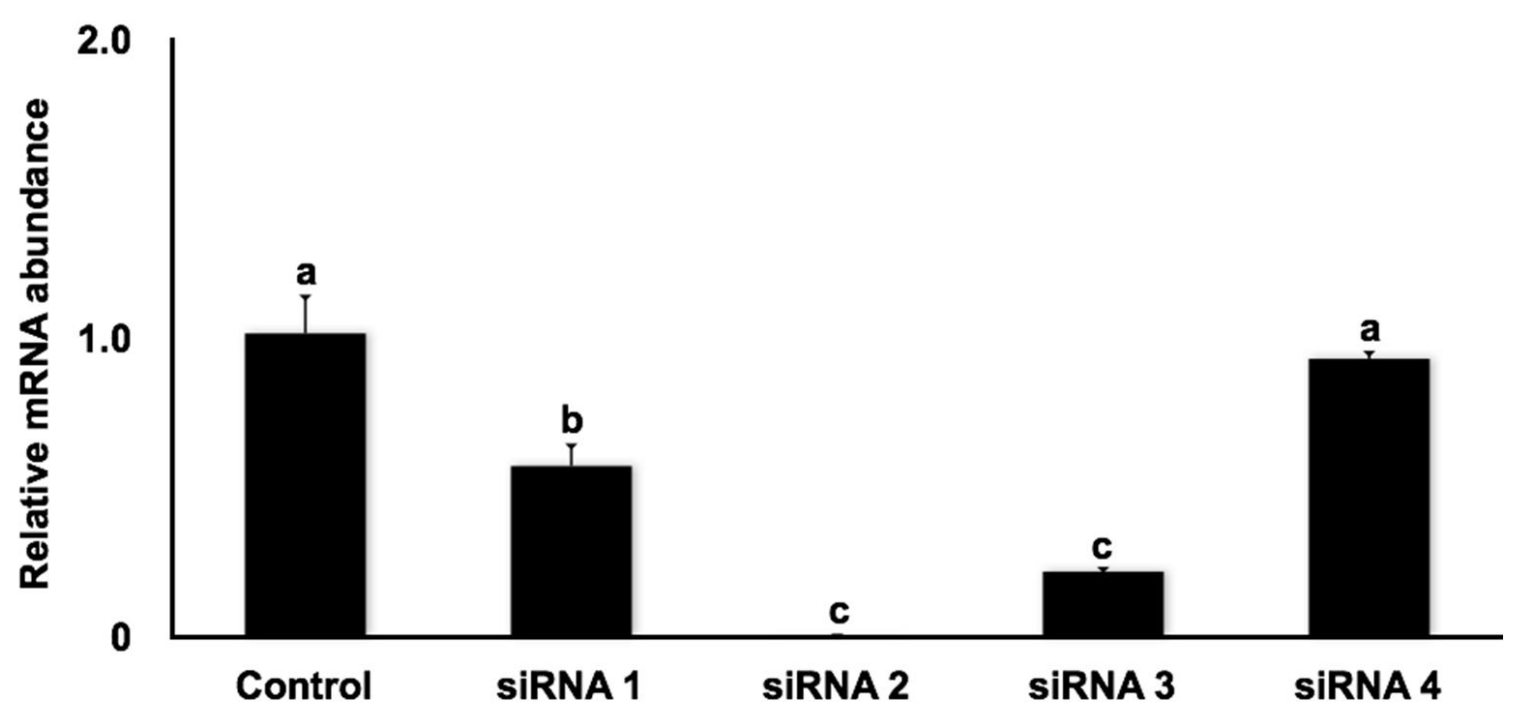

Figure 6. Validation of NOBOX siRNA species for efficacy of NOBOX mRNA knockdown in 4cell stage embryos. Quantitative real-time PCR analysis of NOBOX mRNA expression after microinjection of individual siRNA species targeting different exons in NOBOX transcript at presumptive zygote stage. Data were normalized relative to abundance of endogenous control ribosomal protein S18 $(R S P 18)$ and are shown as mean \pm SEM $(n=4$ pools of 5 embryos per treatment). Different letters indicate statistical difference $(P<0.05)$. 
A

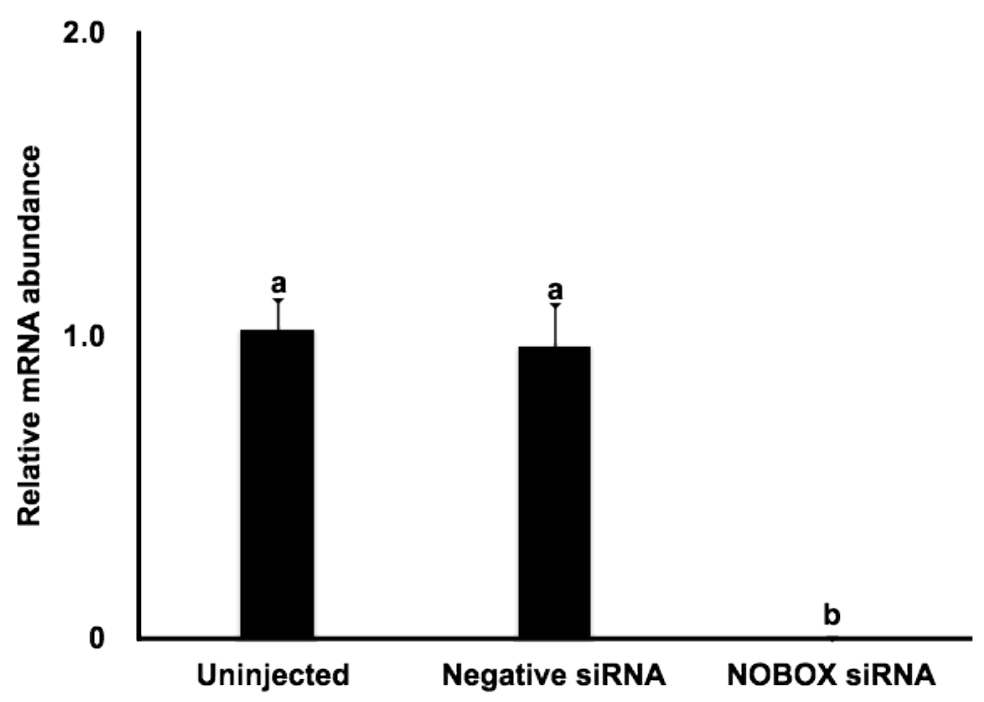

B

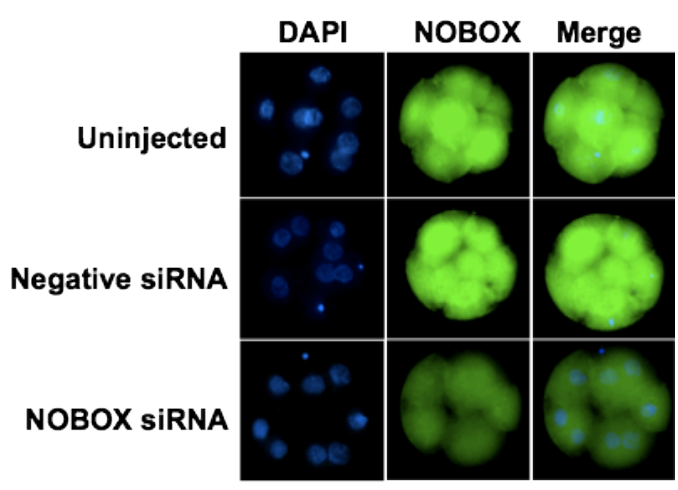

Figure 7. Effect of $N O B O X$ siRNA injection in bovine zygotes on expression of NOBOX mRNA and protein in resulting embryos. A) Effect of NOBOX siRNA microinjection on abundance of NOBOX mRNA in four-cell embryos as determined by real-time PCR. Data were normalized relative to abundance of endogenous control ribosomal protein S18 (RSP18) and are shown as mean \pm SEM ( $n=4$ pools of 10 embryos per treatment). Different letters indicate statistical difference $(P<0.05)$. B) Effect of NOBOX siRNA microinjection on abundance of NOBOX protein in eight-cell stage embryos as determined by immunofluorescent staining $(n=4$ pools of 5-10 embryos per treatment). Uninjected embryos and embryos injected with a nonspecific siRNA (Neg siRNA) were used as control. Nuclear DNA was stained with 4', 6-diamidino-2phenylindole (DAPI). 
A

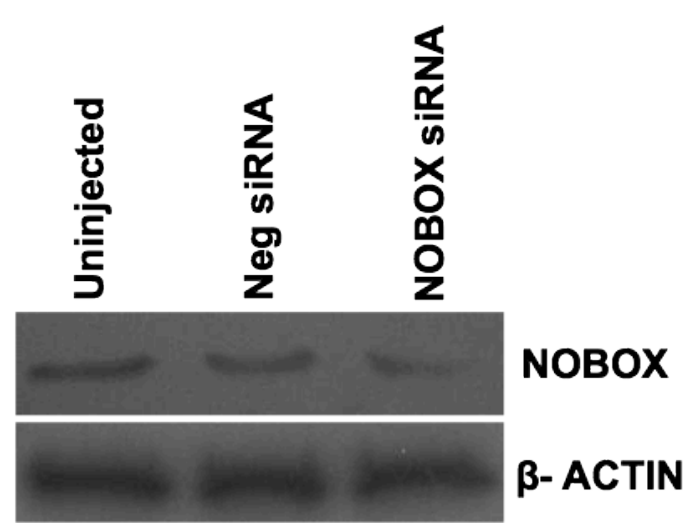

B

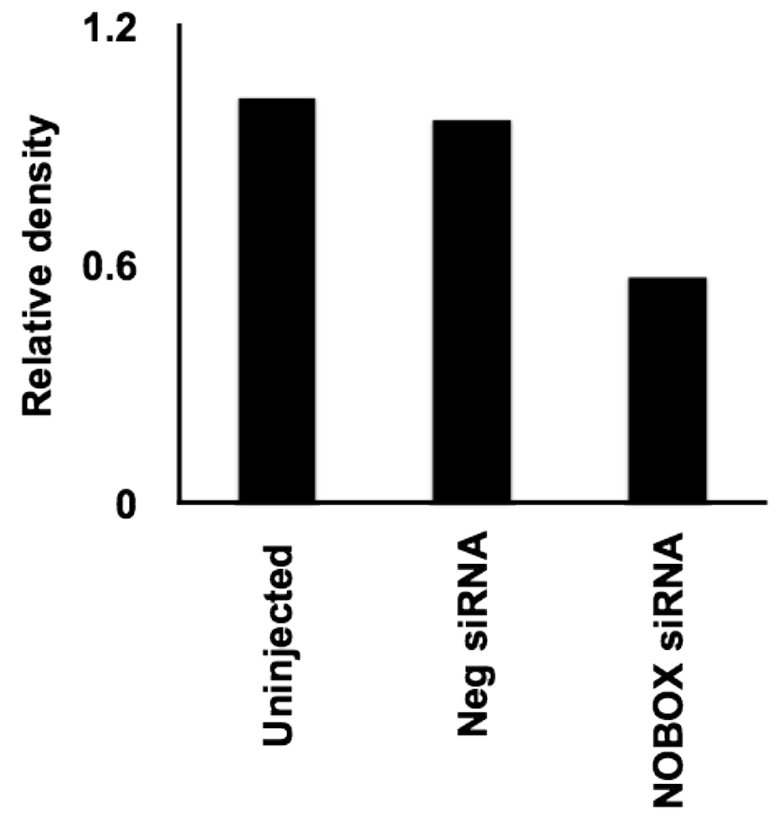

Figure 8. Effect of NOBOX siRNA microinjection on NOBOX protein abundance in embryos. A) Western blot analysis of NOBOX protein abundance in eight- to 16-cell embryos injected with the NOBOX siRNA mixture (25 embryos per lane). The analysis was performed as described (18). B) Densitometric analysis of protein bands on the Western blot represented in A using the FluorChem imaging system and Alpha EaseFC software (Alpha Innotech Corporation, San Leandro, CA). 
A

Cleaving embryos (48h)

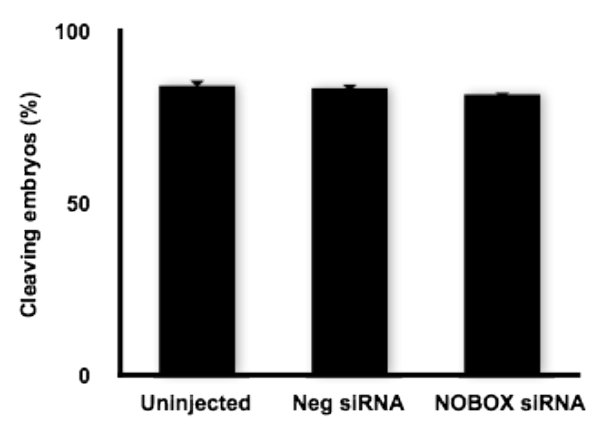

B

8-16 cell embryos (72h)

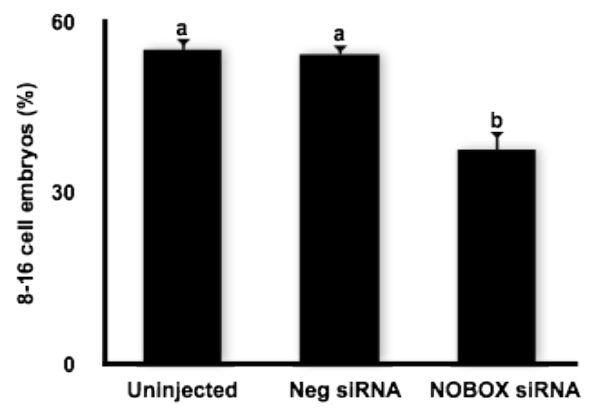

C

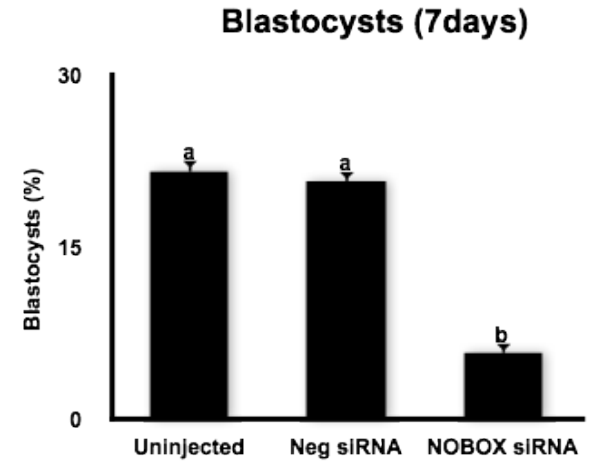

Figure 9. Effect of RNAi mediated depletion of NOBOX on early embryonic development A) Proportion of embryos that cleaved within $48 \mathrm{~h}$ after fertilization B) Proportion of embryos developing to eight- to 16 -cell stage (determined $72 \mathrm{hpi}$ ) C) Proportion of embryos developing to blastocyst stage (determined on $d 7$ ). Uninjected embryos and embryos injected with a nonspecific siRNA (Neg siRNA) were used as controls. Data are expressed as mean \pm SEM from four replicates ( $n=25-30$ zygotes per treatment per replicate). Values with different letters across treatments indicate significant differences (P 0.05). Neg, Negative. 
A

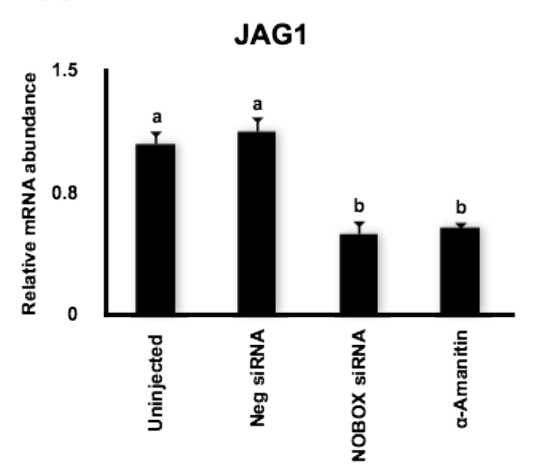

D

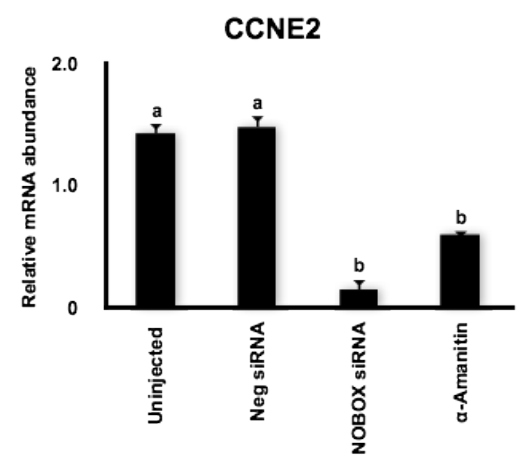

B

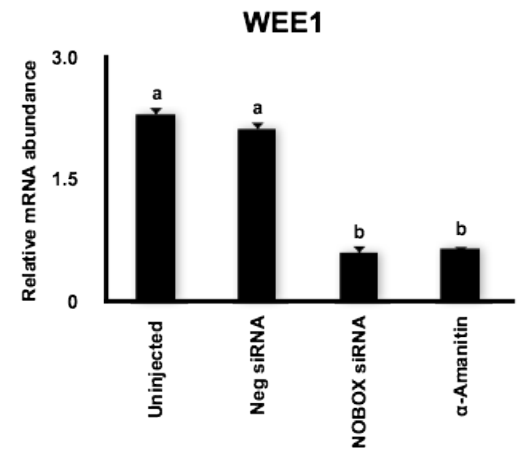

E

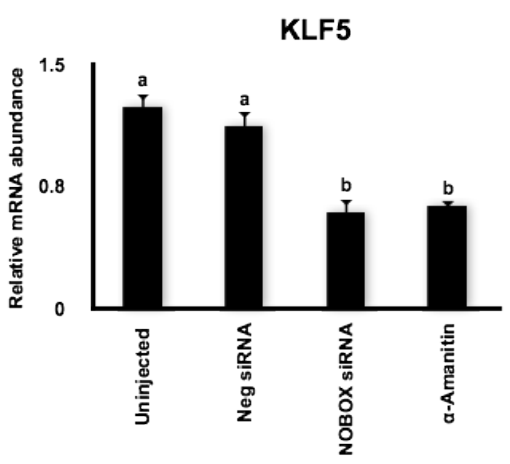

C

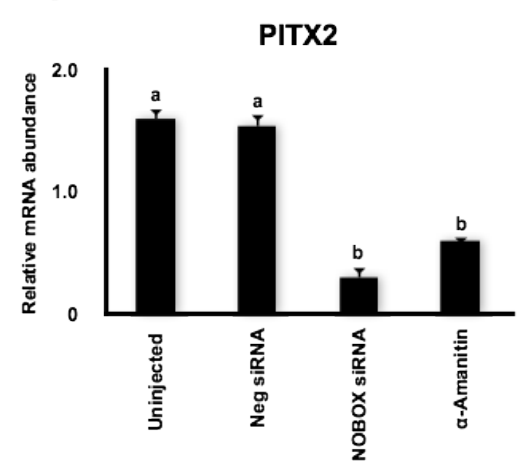

$\mathbf{F}$

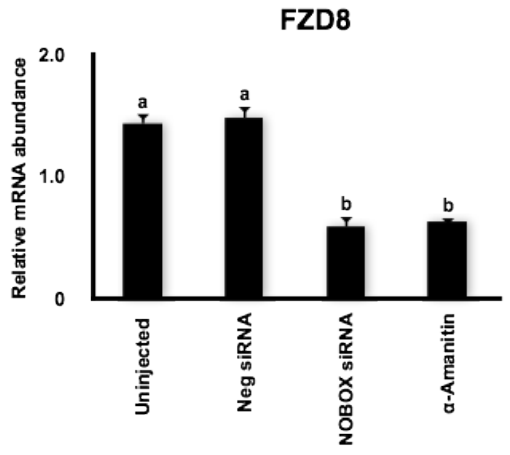

Figure 10. Knockdown of NOBOX down-regulates the expression of zygotic transcripts $(\alpha-$ amanitin sensitive) in eight-cell stage embryos. Quantitative real-time PCR was used to analyze the expression level of zygotic genes containing NBEs in their promoter regions: JAG1 (A), WEE1 (B), PITX2 (C), CCNE2 (D), KLF5 (E), and FZD8 (F). Data were normalized relative to abundance of endogenous control ribosomal protein S18 (RSP18) and are shown as mean \pm SEM ( $n=4$ pools of 10 embryos per treatment). Uninjected embryos and embryos injected with a nonspecific siRNA (Neg siRNA) were used as controls. $\alpha$-amanitin treated embryos were used to confirm the zygotic origin of the transcripts. Different letters indicate statistical difference $(P<$ 0.05). Neg, Negative. 

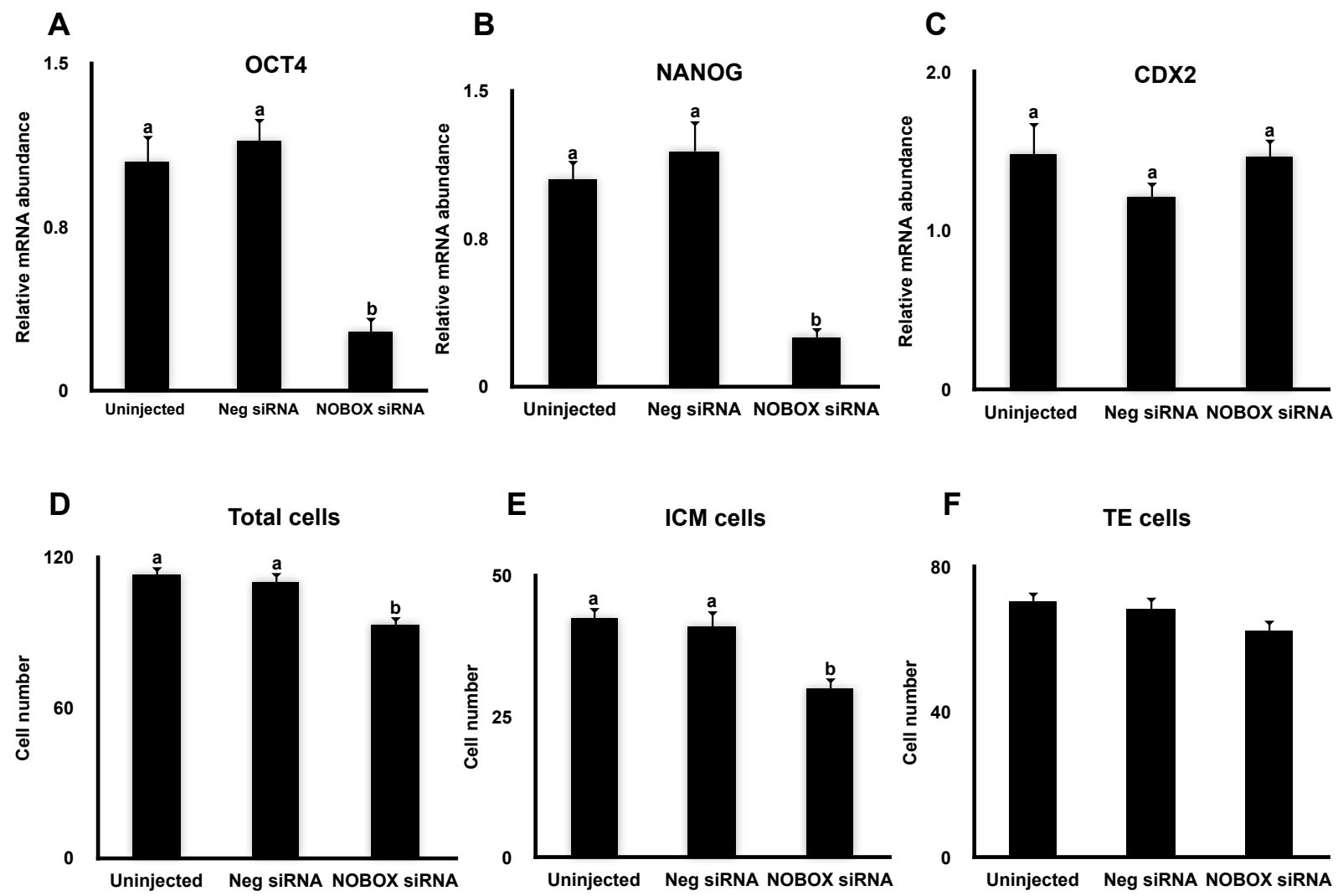

Figure 11. Knockdown of NOBOX alters the expression of pluripotency genes and bovine blastocyst cell allocation. Expression of POU5F1/OCT4 (A), NANOG (B) and CDX2 (C) in bovine blastocysts collected on day 7 after insemination. Data were normalized relative to abundance of endogenous control ribosomal protein S18 (RSP18) and are shown as mean \pm SEM ( $n=4$ pools of three blastocyst per treatment). Uninjected embryos and embryos injected with a nonspecific siRNA (Neg siRNA) were used as control. Different letters indicate statistical difference $(P<0.05)$. NOBOX regulation of bovine blastocyst cell allocation (D) number of TE cells $(E)$ number of ICM cells $(F)$ and total cell numbers. Data are expressed as mean \pm SEM from four replicates ( $n=25-30$ blastocysts per replicate). Uninjected embryos and embryos injected with a nonspecific siRNA (Neg siRNA) were used as control. Different letters indicate statistical difference $(P<0.05)$. 


\section{REFERENCES}

Amleh, A., Dean, J., 2002. Mouse genetics provides insight into folliculogenesis, fertilization and early embryonic development. Hum Reprod Update 8, 395-403.

Bettegowda, A., Lee, K.-B., Smith, G.W., 2008a. Cytoplasmic and nuclear determinants of the maternal-to-embryonic transition. Reprod Fertil Dev 20, 45-53.

Bettegowda, A., Patel, O., Lee, K., Park, K., Salem, M., Yao, J., Ireland, J., Smith, G., 2008b. Identification of novel bovine cumulus cell molecular markers predictive of oocyte competence: functional and diagnostic implications. Biology of Reproduction 79, 301-309.

Bettegowda, A., Patel, O.V., Ireland, J.J., Smith, G.W., 2006. Quantitative analysis of messenger RNA abundance for ribosomal protein L-15, cyclophilin-A, phosphoglycerokinase, beta-glucuronidase, glyceraldehyde 3-phosphate dehydrogenase, beta-actin, and histone $\mathrm{H} 2 \mathrm{~A}$ during bovine oocyte maturation and early embryogenesis in vitro. Mol Reprod Dev 73, 267278.

Bettegowda, A., Yao, J., Sen, A., Li, Q., Lee, K.-B., Kobayashi, Y., Patel, O.V., Coussens, P.M., Ireland, J.J., Smith, G.W., 2007. JY-1, an oocyte-specific gene, regulates granulosa cell function and early embryonic development in cattle. Proc Natl Acad Sci USA 104, 17602-17607.

Betts, 2001. Genetic regulation of embryo death and senescence. Theriogenology, 1-21.

Burns, K., Viveiros, M., Ren, Y., Wang, P., DeMayo, F., Frail, D., Eppig, J., Matzuk, M., 2003. Roles of NPM2 in chromatin and nucleolar organization in oocytes and embryos. Science 300, 633-636.

Chew, J.-L., Loh, Y.-H., Zhang, W., Chen, X., Tam, W.-L., Yeap, L.-S., Li, P., Ang, Y.-S., Lim, B., Robson, P., Ng, H.-H., 2005. Reciprocal transcriptional regulation of Pou5f1 and Sox2 via the Oct4/Sox2 complex in embryonic stem cells. Molecular and Cellular Biology 25, 6031-6046.

Choi, Y., Qin, Y., Berger, M.F., Ballow, D.J., Bulyk, M.L., Rajkovic, A., 2007. Microarray analyses of newborn mouse ovaries lacking Nobox. Biol Reprod 77, 312-319. 
Choi, Y., Rajkovic, A., 2006. Characterization of NOBOX DNA binding specificity and its regulation of Gdf9 and Pou5f1 promoters. J Biol Chem 281, 35747-35756.

De Sousa, P.A., Watson, A.J., Schultz, G.A., Bilodeau-Goeseels, S., 1998. Oogenetic and zygotic gene expression directing early bovine embryogenesis: a review. Mol Reprod Dev 51, $112-121$.

Deardorff, M.A., Tan, C., Conrad, L.J., Klein, P.S., 1998. Frizzled-8 is expressed in the Spemann organizer and plays a role in early morphogenesis. Development 125, 2687-2700.

Foygel, K., Choi, B., Jun, S., Leong, D.E., Lee, A., Wong, C.C., Zuo, E., Eckart, M., Reijo Pera, R.A., Wong, W.H., Yao, M.W.M., 2008. A novel and critical role for Oct4 as a regulator of the maternal-embryonic transition. PLoS ONE 3, e4109.

Gidekel, S., Pizov, G., Bergman, Y., Pikarsky, E., 2003. Oct-3/4 is a dose-dependent oncogenic fate determinant. Cancer Cell 4, 361-370.

Gotoh, T., Shigemoto, N., Kishimoto, T., 2007. Cyclin E2 is required for embryogenesis in Xenopus laevis. Dev Biol 310, 341-347.

Hay, D.C., Sutherland, L., Clark, J., Burdon, T., 2004. Oct-4 knockdown induces similar patterns of endoderm and trophoblast differentiation markers in human and mouse embryonic stem cells. Stem Cells 22, 225-235.

Ho Sui, S.J., Fulton, D.L., Arenillas, D.J., Kwon, A.T., Wasserman, W.W., 2007. oPOSSUM: integrated tools for analysis of regulatory motif over-representation. Nucleic acids research 35, W245-252.

Jedrusik, A., Bruce, A.W., Tan, M.H., Leong, D.E., Skamagki, M., Yao, M., Zernicka-Goetz, M., 2010. Maternally and zygotically provided Cdx2 have novel and critical roles for early development of the mouse embryo. Dev Biol 344, 66-78.

Kehler, J., Tolkunova, E., Koschorz, B., Pesce, M., Gentile, L., Boiani, M., Lomelí, H., Nagy, A., McLaughlin, K.J., Schöler, H.R., Tomilin, A., 2004. Oct4 is required for primordial germ cell survival. EMBO Rep 5, 1078-1083. 
Lee, K.-B., Bettegowda, A., Wee, G., Ireland, J.J., Smith, G.W., 2009. Molecular determinants of oocyte competence: potential functional role for maternal (oocyte-derived) follistatin in promoting bovine early embryogenesis. Endocrinology 150, 2463-2471.

Liang, L., Soyal, S.M., Dean, J., 1997. FIGalpha, a germ cell specific transcription factor involved in the coordinate expression of the zona pellucida genes. Development $124,4939-$ 4947.

Machaty, Z., Day, B., Prather, R., 1998. Development of early porcine embryos in vitro and in vivo (vol 59, pg 451, 1998). Biology of Reproduction 59, 1016-1016.

Misirlioglu, M., Page, G.P., Sagirkaya, H., Kaya, A., Parrish, J.J., First, N.L., Memili, E., 2006. Dynamics of global transcriptome in bovine matured oocytes and preimplantation embryos. Proc Natl Acad Sci USA 103, 18905-18910.

Murdoch, W.J., Dailey, R.A., Inskeep, E.K., 1981. Preovulatory changes prostaglandins E2 and F2 alpha in ovine follicles. J Anim Sci 53, 192-205.

Nganvongpanit, K., Müller, H., Rings, F., Hoelker, M., Jennen, D., Tholen, E., Havlicek, V., Besenfelder, U., Schellander, K., Tesfaye, D., 2006. Selective degradation of maternal and embryonic transcripts in in vitro produced bovine oocytes and embryos using sequence specific double-stranded RNA. Reproduction 131, 861-874.

Niwa, H., Miyazaki, J., Smith, A.G., 2000. Quantitative expression of Oct-3/4 defines differentiation, dedifferentiation or self-renewal of ES cells. Nat Genet 24, 372-376.

Pan, G., Li, J., Zhou, Y., Zheng, H., Pei, D., 2006. A negative feedback loop of transcription factors that controls stem cell pluripotency and self-renewal. FASEB J 20, 1730-1732.

Paradis, F., Vigneault, C., Robert, C., Sirard, M.-A., 2005. RNA interference as a tool to study gene function in bovine oocytes. Mol Reprod Dev 70, 111-121.

Parisi, S., Passaro, F., Aloia, L., Manabe, I., Nagai, R., Pastore, L., Russo, T., 2008. Klf5 is involved in self-renewal of mouse embryonic stem cells. Journal of Cell Science 121, 26292634. 
Pei, D., 2009. Regulation of pluripotency and reprogramming by transcription factors. J Biol Chem 284, 3365-3369.

Qin, Y., Choi, Y., Zhao, H., Simpson, J.L., Chen, Z.-J., Rajkovic, A., 2007. NOBOX homeobox mutation causes premature ovarian failure. Am J Hum Genet 81, 576-581.

Qin, Y., Shi, Y., Zhao, Y., Carson, S.A., Simpson, J.L., Chen, Z.-J., 2009. Mutation analysis of NOBOX homeodomain in Chinese women with premature ovarian failure. Fertility and sterility $91,1507-1509$.

Rajkovic, A., Pangas, S.A., Ballow, D., Suzumori, N., Matzuk, M.M., 2004. NOBOX deficiency disrupts early folliculogenesis and oocyte-specific gene expression. Science 305, 1157-1159.

Richardson, C., Jones, P.C., Barnard, V., Hebert, C.N., Terlecki, S., Wijeratne, W.V., 1990. Estimation of the developmental age of the bovine fetus and newborn calf. Vet Rec 126, 279284.

Rodda, D., Chew, J., Lim, L., Loh, Y., Wang, B., Ng, H., Robson, P., 2005. Transcriptional regulation of nanog by OCT4 and SOX2. Journal of Biological Chemistry 280, 24731.

Rodríguez-León, J., Rodríguez Esteban, C., Martí, M., Santiago-Josefat, B., Dubova, I., Rubiralta, X., Izpisúa Belmonte, J.C., 2008. Pitx2 regulates gonad morphogenesis. P Natl Acad Sci Usa 105, 11242-11247.

Rossant, J., Tam, P.P.L., 2009. Blastocyst lineage formation, early embryonic asymmetries and axis patterning in the mouse. Development 136, 701-713.

Schellander, K., Hoelker, M., Tesfaye, D., 2007. Selective degradation of transcripts in mammalian oocytes and embryos. Theriogenology 68 Suppl 1, S107-S115.

Silva, C., Groome, N., Knight, P., 2003. Immunohistochemical localization of inhibin/activin alpha, beta(A) and beta(B) subunits and follistatin in bovine oocytes during in vitro maturation and fertilization. Reproduction 125, 33-42.

Sirard, M.-A., Richard, F., Blondin, P., Robert, C., 2006. Contribution of the oocyte to embryo quality. Theriogenology 65, 126-136. 
Soyal, S.M., Amleh, A., Dean, J., 2000. FIGalpha, a germ cell-specific transcription factor required for ovarian follicle formation. Development 127, 4645-4654.

Suzumori, N., Yan, C., Matzuk, M.M., Rajkovic, A., 2002. Nobox is a homeobox-encoding gene preferentially expressed in primordial and growing oocytes. Mech Dev 111, 137-141.

Tejomurtula, J., Lee, K.-B., Tripurani, S.K., Smith, G.W., Yao, J., 2009. Role of importin alpha8, a new member of the importin alpha family of nuclear transport proteins, in early embryonic development in cattle. Biology of Reproduction 81, 333-342.

Tominaga, Y., Li, C., Wang, R.-H., Deng, C.-X., 2006. Murine Wee1 plays a critical role in cell cycle regulation and pre-implantation stages of embryonic development. Int J Biol Sci 2, 161170.

Tong, Z., Gold, L., Pfeifer, K., Dorward, H., Lee, E., Bondy, C., Dean, J., Nelson, L., 2000. Mater, a maternal effect gene required for early embryonic development in mice. Nat Genet 26, 267-268.

Velkey, J.M., O'Shea, K.S., 2003. Oct4 RNA interference induces trophectoderm differentiation in mouse embryonic stem cells. Genesis $37,18-24$.

Wianny, F., Zernicka-Goetz, M., 2000. Specific interference with gene function by doublestranded RNA in early mouse development. Nat Cell Biol 2, 70-75.

Wu, X., Viveiros, M., Eppig, J., Bai, Y., Fitzpatrick, S., Matzuk, M., 2003. Zygote arrest 1 (Zar1) is a novel maternal-effect gene critical for the oocyte-to-embryo transition. Nat Genet 33, 187191.

Xue, Y., Gao, X., Lindsell, C., Norton, C., Chang, B., Hicks, C., Gendron-Maguire, M., Rand, E., Weinmaster, G., Gridley, T., 1999. Embryonic lethality and vascular defects in mice lacking the Notch ligand JAGGED1. Hum Mol Genet 8, 723-730.

Zhang, J., Tam, W.-L., Tong, G.Q., Wu, Q., Chan, H.-Y., Soh, B.-S., Lou, Y., Yang, J., Ma, Y., Chai, L., Ng, H.-H., Lufkin, T., Robson, P., Lim, B., 2006. Sall4 modulates embryonic stem cell 
pluripotency and early embryonic development by the transcriptional regulation of Pou5f1. Nat Cell Biol 8, 1114-1123.

Zheng, P., Dean, J., 2009. Role of Filia, a maternal effect gene, in maintaining euploidy during cleavage-stage mouse embryogenesis. Proc Natl Acad Sci USA 106, 7473-7478. 
CHAPTER-2 


\title{
MicroRNA-196a regulates bovine newborn ovary homeobox gene (NOBOX) expression during early embryogenesis
}

\author{
Swamy K Tripurani ${ }^{1}$, Kyung-Bon Lee ${ }^{2,3}$, Gabbine Wee ${ }^{2,3}$, George W. Smith ${ }^{2,3,4}$, Jianbo Yao ${ }^{1^{*}}$ \\ ${ }^{1}$ Laboratory of Animal Biotechnology and Genomics, Division of Animal and Nutritional Sciences, West \\ Virginia University, Morgantown, WV 26506. \\ ${ }^{2}$ Laboratory of Mammalian Reproductive Biology and Genomics, Departments of Animal Science ${ }^{3}$ and \\ Physiology ${ }^{4}$, Michigan State University, East Lansing, Michigan 48824.
}

KEYWORDS: NOBOX, bovine, oocyte, early embryogenesis, microRNA, maternal-to-embryonic transition.

\section{AUTHOR'S CONTRIBUTIONS}

SKT designed and performed most of the experiments including expression analysis of miRNA, preparation of constructs, cell transfection and analysis of gene expression. SKT also drafted the manuscript. KBL and GW performed the microinjection experiments. GWS and JY designed the study and supervised the experimental work. 


\section{ABSTRACT}

Oocyte-derived maternal RNAs drive early embryogenesis when the newly formed embryo is transcriptionally inactive. Recent studies in zebrafish have identified the role of microRNAs during the maternal-to-embryonic transition (MET). MicroRNAs are short RNAs that bind to the 3' UTR of target mRNAs to repress their translation and accelerate their decay. Newborn ovary homeobox gene (NOBOX) is a transcription factor that is preferentially expressed in oocytes and essential for folliculogenesis in mice. NOBOX knockout mice are infertile and lack of NOBOX disrupts expression of many germ-cell specific genes and microRNAs. We recently reported the cloning and expression of bovine NOBOX during early embryonic development and our gene knockdown studies indicate that NOBOX is a maternal effect gene essential for early embryonic development. As NOBOX is a maternal transcript critical for development and NOBOX is depleted during early embryogenesis, we hypothesized that NOBOX is targeted by microRNAs for silencing and/or degradation. Using an algorithm "Microlnspector", a potential microRNA recognition element (MRE) for miR-196a was identified in the 3' UTR of the bovine NOBOX mRNA. Expression analysis of miR-196a in bovine oocytes and during early embryonic development indicated that it is expressed both in oocytes and embryos and tends to increase at the four-cell and eight-cell stages. Ectopic expression of NOBOX and miR-196a in HeLa cells inhibited the expression of NOBOX protein compared to the control cells without miR-196a. Similarly, the activity of a luciferase construct containing the entire 3' UTR of bovine NOBOX was suppressed, and the regulation was abolished by mutations in the miR-196a binding site indicating that the predicted MRE is critical for the direct and specific binding of miR-196a to the NOBOX mRNA. Furthermore, ectopic expression of miR-196a mimic in bovine early embryos significantly reduced the NOBOX expression at the both mRNA and protein levels. Collectively, our results demonstrate that miR-196a is a bona fide negative regulator of NOBOX during bovine early embryogenesis. 


\section{INTRODUCTION}

The earliest stages of embryonic development in vertebrates primarily rely on the maternal RNA and proteins synthesized during oogenesis (Schultz, 2002; Li et al., 2010). The period of maternal control of embryonic development varies among species according to the onset of embryonic genome activation and the degradation of maternal gene products (DeRenzo and Seydoux, 2004). The major onset of embryonic genome activation begins during the two-cell stage in mice; the four-cell stage in humans, rats and pigs, and during the eight-cell to 16-cell stage in cattle and sheep (Telford et al., 1990). Upon fertilization, in mouse embryos, 90 percent of the maternal mRNA is degraded by the two-cell stage, coincident with the complete activation of the embryonic genome (Bachvarova et al., 1985; Paynton et al., 1988). There is direct evidence that maternal mRNA clearance is critical for early embryonic development. For example oocyte-specific c-mos mRNA, essential for regulating meiotic arrest at metaphase, is degraded soon after fertilization and injection of c-mos protein into Xenopus two-cell embryos induces cleavage arrest (Sagata et al., 1989). In mouse, maternal mRNA degradation is dependent on the 3' untranslated region (3' UTR) of the mRNA transcript. For example, chimeric mRNAs composed of the c-mos coding region fused to the hypoxanthine phosphoribosyltransferase (Hprt) 3' UTR have reduced rates of degradation following microinjection into mouse fertilized oocytes (Alizadeh et al., 2005). Thus degradation of maternal mRNAs is critical to embryogenesis and represents a conserved mechanism of vertebrate development.

Multiple negative regulatory mechanisms are critical for post-transcriptional regulation of maternal transcripts, such as transcript deadenylation and interaction with RNA-binding proteins in a nonspecific or sequence-specific fashion (Bettegowda and Smith, 2007). Recent studies in zebrafish have established a role for microRNAs (miRNA) as key regulatory molecules targeting maternal mRNA for degradation during the maternal-to-embryonic transition (MET) (Giraldez et al., 2006). MicroRNAs are endogenous small noncoding RNAs that bind primarily to the 3' UTR 
of target mRNAs to repress their translation and accelerate their decay (Bartel, 2004). The majority of miRNAs are evolutionarily conserved across species boundaries and play essential roles in regulating many distinct processes such as animal development and growth, cell differentiation, signal transduction, cancer, disease, virus immune defense, programmed cell death, insulin secretion and metabolism (Ambros, 2004; He and Hannon, 2004; Wienholds and Plasterk, 2005).

In recent years, several studies have revealed the significance of miRNAs in reproduction and embryonic development. For example, targeted disruption of Dicer, a key enzyme involved in miRNA processing and the synthesis of small interfering RNAs from long double-stranded RNA (Carmell and Hannon, 2004; Jaskiewicz and Filipowicz, 2008) in mice and zebrafish resulted in embryonic lethality due to abnormalities in morphogenesis, cell division and chromosome organization (Bernstein et al., 2003; Giraldez et al., 2005; Kanellopoulou et al., 2005; Tang et al., 2007; Nagaraja et al., 2008). In zebrafish, miR-430 has been linked to maternal mRNA decay accompanying the maternal-to-embryonic transition (Giraldez et al., 2006). At the onset of embryonic genome activation, the level of miR-430 substantially increases and the miRNA targets several hundred maternally provided mRNAs by binding to the complementary sites in their 3' UTR and promotes their deadenylation (Giraldez et al., 2006). Furthermore, miR-196a regulates mammalian development via targeting homoeobox clusters (Yekta et al., 2004) and misexpression of miR-196a leads to specific eye anomalies in a dose-dependent manner in Xenopus laevis (Qiu et al., 2009).

Newborn ovary homeobox gene (NOBOX) is a transcription factor, identified by in silico subtraction of expressed sequence tags (ESTs) derived from newborn ovaries in mice (Suzumori et al., 2002). NOBOX mRNA and protein are preferentially expressed in oocytes throughout folliculogenesis (Rajkovic et al., 2004). Nobox knockout mice are infertile due to disrupted folliculogenesis and expression of many germ-cell specific genes and miRNAs is perturbed in such animals (Rajkovic et al., 2004; Choi et al., 2007). Furthermore, mutations in 
the NOBOX gene associated with premature ovarian failure have been described in humans (Qin et al., 2007; Qin et al., 2009). We recently established a key role for NOBOX in bovine early embryonic development (Tripurani et al., 2011). Bovine NOBOX is stage-specifically expressed during oocyte maturation and early embryonic development and of maternal origin. Depletion of NOBOX in bovine zygotes by siRNA microinjection impaired embryo development to the blastocyst stage. Furthermore, knockdown of NOBOX affected the expression of genes from the embryonic genome critical to early development and expression of pluripotency genes was altered in the inner cell mass of NOBOX siRNA injected embryos that reached the blastocyst stage. However, despite its established role in folliculogenesis and early embryonic development, the post-transcriptional regulation of NOBOX has not been investigated. Given the importance of NOBOX, as a maternal transcript critical for development, and observed depletion of NOBOX during MET, we hypothesized that NOBOX is targeted by miRNAs for silencing and/or degradation in early embryos. In this study we identified a miRNA (miR-196a) targeting bovine NOBOX, examined the temporal expression of miR-196a during bovine early embryonic development and determined the effect and specificity of miR-196a in regulating bovine NOBOX expression both exogenously (HeLa cells) and endogenously in early embryos.

\section{MATERIALS AND METHODS}

\section{Bioinformatics Analysis}

To examine the possibility of NOBOX regulation by miRNAs, we searched for potential microRNA recognition elements (MRE) in the NOBOX 3' UTR using Microinspector (http://bioinfo.uni-plovdiv.bg/microinspector/), an algorithm for detection of possible interactions between miRNAs and target mRNA sequences (Rusinov et al., 2005). 


\section{Tissue collection, RNA isolation and microRNA expression analysis}

Bovine tissue sample collection, total RNA isolation and miRNA expression analysis in multiple tissues, oocytes and early embryos were performed as described previously (Tripurani et al., 2010).

\section{Plasmid construction}

The full-length bovine NOBOX mRNA sequence was amplified from bovine adult ovary cDNA samples by PCR using gene-specific primers containing restriction sites BamHI/Xhol (Supplemental data table 1 for the list of primer sequences). The PCR product was digested with BamHI and Xhol enzymes and subsequently cloned into pcDNA3.1 (Invitrogen, Carlsbad, CA) vector digested with the same enzymes. pcDNA3.1: miRNA196a was constructed by PCR amplifying a $\sim 220$ nt region of genomic sequence surrounding pre-miR-196a from bovine genomic DNA sample using primers containing restriction sites BamHI/Xhol (Supplemental data table 1 for the list of primer sequences). The PCR product was digested and subsequently cloned into pcDNA3.1 vector digested with BamHI and Xhol. For construction of a vector containing NOBOX-3' UTR fused to the 3' end of a luciferase reporter, we used the dual luciferase pmirGLO vector (Promega, Madison, WI). The NOBOX 3' UTR was amplified from pcDNA3.1: NOBOX construct using primers containing restriction sites Sacl/Xbal (Supplemental data table 1 for the list of primer sequences). The PCR product was digested with Sacl and Xbal and subsequently cloned into dual luciferase pmirGLO vector digested with the same enzymes. Mutation of the mir-196a miRNA recognition element (MRE) in the NOBOX 3' UTR was performed using the QuickChange site-directed mutagenesis kit (Stratagene, Santaclara, CA) according to the manufacturer's instructions. (Supplemental data table 1 for the list of primer sequences).

\section{Cell culture and Reporter assay}


HeLa cells were cultured in DMEM (Invitrogen, Carlsbad, CA) containing 10\% FBS and $1 \%$ penicillin/streptomycin (Invitrogen, Carlsbad, CA). For transient transfection, FuGENE6 (Roche Applied Science, Indianapolis, IN) was used according to manufacturer's instructions. Following transfection, cells were incubated for $48 \mathrm{~h}$ before harvest for western blotting and luciferase assay. Luciferase assay was performed using the Dual-Glo luciferase assay system (Promega, Madison, WI) as described by the manufacturer. Firefly luciferase activity was normalized to renilla luciferase activity to adjust for variations in transfection efficiency among experiments. All transfection experiments were performed in quadruplicate $(n=4)$ with data averaged from four independent experiments.

\section{Western blot analysis}

Western blot was performed as previously described (Tejomurtula et al., 2009) with minor modifications. After $48 \mathrm{~h}$ of transfection, HeLa cell lysates were harvested and washed once with phosphate-buffered saline (PBS), suspended in $50 \mu \mathrm{l}$ of PBS, and mixed with an equal volume of Laemmli sample buffer (Bio-Rad, Hercules, CA). Protein samples (15 $\mu$ g/each) were separated on a 4-20\% gradient polyacrylamide gel (Bio-Rad, Hercules, CA) and electroblotted onto a polyvinylindene difluoride (PVDF) membrane (Bio-Rad, Hercules, CA). Following transfer and blocking in $5 \%$ nonfat dry milk in Tris-buffered saline containing $0.1 \%$

Tween-20 (TBST) for one hour, the membrane was then incubated in NOBOX antibody (ab41612; Abcam, Cambridge, MA) diluted 1:100 in blocking buffer overnight at $4^{\circ} \mathrm{C}$. After washing three times with TBST, the membrane was incubated for $1 \mathrm{~h}$ with horseradish peroxidase-conjugated goat anti-rabbit IgG (Pierce, Rockford, IL) diluted 1:10 000 in blocking solution. The membrane was washed again with TBST, followed by detection with SuperSignal West Pico Chemiluminescent Substrate (Pierce, Rockford, IL). The membrane was stripped in Restore Plus Western Blot Stripping Buffer (Pierce, Rockford, IL), followed by detection of $\beta$ - 
actin (ACTB) protein (positive control) using anti- $\beta$-actin antibody (Ambion, Austin, TX) and horseradish peroxidase-conjugated goat anti-mouse IgG (Pierce, Rockford, IL).

\section{Microinjection experiments}

Procedures for in vitro maturation of oocytes (obtained from abattoir-derived ovaries) and in vitro fertilization to generate zygotes for microinjection and for subsequent embryo culture were conducted basically as described (Bettegowda et al., 2006; Bettegowda et al., 2007). Presumptive zygotes collected at 16-18 hours post-fertilization (hpf) were used in all microinjection experiments. Mature miRNA-196a mimic (MIMAT0000226) and negative control cel-miR-67 (CN-001000-01-05) were obtained from Dharmacon Technologies (Dharmacon Inc, Lafayette, CO), and diluted with RNase free water to a final concentration of $10 \mu \mathrm{M}$ and $20 \mu \mathrm{M}$ before microinjection (The final concentration used for microinjection was $20 \mu \mathrm{M}$ based on initial experiments showing this concentration is more effective in repressing Nobox expression). Approximately $20 \mathrm{pl}$ of miRNA mimic $(20 \mu \mathrm{M})$ was injected into the cytoplasm of zygotes using an inverted Nikon microscope equipped with micromanipulators (Narishige International USA, Inc., East Meadow, NY). Uninjected embryos and embryos injected with above negative control miRNA were used as control groups. Each group contained $25-30$ embryos per replicate $(n=4)$. After microinjection, groups of embryos were cultured in 75 - to $90-\mu l$ drops of potassium simplex optimization medium (KSOM) (Specialty Media, Phillipsburg, NJ) supplemented with 0.3\% bovine serum albumin (BSA) until $72 \mathrm{~h}$ after insemination at which time point embryos were collected. The efficiency of NOBOX mRNA/protein knockdown in miRNA-196a mimic injected and control embryos was determined by quantitative real-time PCR analysis and immunocytochemistry in eight-cell stage embryos as described previously [30]. Imaging was performed using confocal spinning-disk microscopy. Optical sections every $1 \mu \mathrm{m}$ were acquired for each embryo and MetaMorph software (Universal Imaging, Downingtown, PA, USA) was 
used for image acquisition and analysis.

\section{Statistical Analysis}

One-way ANOVA using the general linear models (GLM) procedure of SAS were used to determine the significance of differences in mRNA abundance and between the treated samples and the controls where values resulted from the luciferase reporter assay, quantitative real-time PCR and western blots. Different letters indicate significant differences $(P<0.05)$.

\section{RESULTS AND DISCUSSION}

\section{miR-196a binds to the 3' UTR of bovine NOBOX}

MicroRNAs regulate mRNA translation rate by perfect or imperfect base pairing with the 3' UTR regions of their targets (Rajewsky, 2006). It has been predicted that one miRNA can potentially regulate translation of up to a hundred mRNAs, which creates a challenge for experimentally validating miRNA-specific targets (Bartel, 2009). To identify miRNAs that potentially regulate NOBOX expression, we analyzed the $3^{\prime}$ UTR sequence of bovine NOBOX using the "Microinspector" algorithm to predict potential miRNA target sites (Rusinov et al., 2005). miR-196a was chosen for further studies, because the predicted MRE in the bovine NOBOX 3' UTR had a low predicted free energy of hybridization with the cognate miRNA (-19.8 $\mathrm{kcal} / \mathrm{mol}$ ), suggesting a stable miRNA: mRNA duplex within the 9 nucleotide (nt) seed region at the 5 ' end of the miRNA (Fig. 1). This seed sequence is an important determinant of miRNAinduced repression of gene expression (Brennecke et al., 2005). RNA secondary structure prediction analysis using Mfold (Zuker, 2003) revealed that the apparent miR-196a binding site was positioned on a hairpin-loop structure, in an exposed position, which might facilitate miRNA accessibility. In addition, when the NOBOX sequence was analyzed with other miRNA target 
prediction algorithms, miR-196a always was listed as a top candidate miRNA, further indicating that miRNA-196a might be a potential post-transcriptional regulator of NOBOX in early embryos. The lack of conservation of miR-196a recognition sequence in bovine NOBOX might be due to the rapid drifting of 3' UTR during evolution (Bartel, 2009; Shen-Orr et al., 2010). Furthermore, it has been reported that a large fraction of bona fide targets of microRNA would be missed (Bentwich, 2005; Giraldez et al., 2006; Bartel, 2009) if evolutionary conservation were used as the sole criterion for predicting targets. Moreover, recent studies support a functional role for this specific miRNA as miR-196a targets specific homeobox genes (HoxB8, HoxC8, HoxD8 and HoxA7) in mouse embryos and mammalian cells and plays a major role in animal development (Yekta et al., 2004). Thus, the functional role of miR-196a in regulation of NOBOX was further investigated.

\section{miR-196a is spatio-temporally regulated during development}

To determine the tissue specific expression pattern of miR-196a, quantitative real-time PCR was performed. As shown in Fig. 2A, miR-196a is expressed predominantly in kidney; it is also detected significantly in fetal and adult ovary, brain and hypothalamus. A similar expression pattern was observed in mice where miR-196a is enriched in the kidney and adult reproductive tissues (Landgraf et al., 2007). In order to examine if miR-196a expression is inversely correlated to bovine NOBOX expression during early embryonic development, we analyzed miR-196 expression during oocyte maturation and early embryogenesis. Expression analysis indicates that bovine miR-196a is increased in four-cell and eight-cell stage embryos relative to germinal vesicle stage oocytes and declines at morula and blastocyst stages (Fig. 2B). The increased expression level of miR-196a near the eight-cell stage of embryogenesis potentially indicates miR-196a involvement in maternal transcript degradation during the maternal-tozygotic transition, as was observed for miR-430 in zebrafish (Giraldez et al., 2006) miR-427 in Xenopus (Lund et al., 2009) and miR-290 in mouse (Tang et al., 2007). Moreover, when the 
spatio-temporal expression pattern of miR-196a is compared with the expression pattern of bovine NOBOX during early embryogenesis, miR-196a expression increases steadily from twocell to eight-cell stage of embryogenesis, while NOBOX expression decreases gradually during the same period (Tripurani et al., 2011). Thus, the inverse relationship between miR-196a and NOBOX expression/activity supports the proposed role of miR-196a as a physiological regulator of NOBOX during early embryogenesis.

\section{miR-196a specifically suppresses the expression of bovine NOBOX}

To confirm the binding of miR-196a to bovine NOBOX in vitro, HeLa cell transfection studies were conducted. A significant inhibition of NOBOX expression was observed in HeLa cells ectopically expressing both NOBOX and miR-196a (Fig. 3A) relative to cells transfected with NOBOX alone. Semi-quantitative analysis of western blot data showed a significant inhibition of NOBOX expression in the miR-196a-transfected cells (Fig. 3B). These results unequivocally show that bovine NOBOX is regulated at the post-transcriptional level by miR$196 a$ and further supports the hypothesis that miR-196a is responsible for the negative regulation of NOBOX.

Furthermore, luciferase reporter assays were performed to validate specificity of the miR-196a regulation of NOBOX through the predicted miR-196a recognition sequence in the 3' UTR of NOBOX. NOBOX 3' UTR sequence was inserted downstream of the firefly luciferase coding region. Mutations in the predicted MRE in the 3' UTR of the NOBOX for miR-196a were created such that interaction between miR-196a and NOBOX is compromised (Fig. 4A). Ectopic expression of miR-196a by transfection of miR-196a duplex into the HeLa cells suppressed activity of a chimeric luciferase construct containing the miR-196a MRE of NOBOX at its 3' end (Fig.4B). Luciferase activity was restored when a four-base mismatch mutation was introduced into the seed region of the miRNA-196a recognition sequence in the NOBOX 3' UTR (Fig. 4B). 
These data indicate the predicted MRE is critical for the direct and specific binding of miR-196a to NOBOX transcript.

\section{miR-196a represses endogenous NOBOX in bovine early embryos}

Since we determined in heterologous systems that miR-196a is capable of regulating NOBOX expression through direct binding to the 3' UTR of its mRNA, the ability of miR-196a to regulate endogenous NOBOX expression in early embryos was determined. Microinjection of miRNA mimics into zygotes has been utilized previously as a tool to determine effects of overexpression of specific miRNAs in mouse and zebrafish embryos (Krützfeldt et al., 2006; Begemann, 2008; Spruce et al., 2010). Ectopic expression of miR-196a mimic in bovine embryos effectively reduced NOBOX protein expression in eight-cell embryos compared to uninjected and the negative control miRNA-injected embryos (Fig. 5A). Furthermore, recent studies have suggested that miRNAs not only inhibit productive translation but also accelerates target mRNA decay (Bagga et al., 2005; Lim et al., 2005). Microinjection of miR-196a mimic in bovine embryos significantly reduced NOBOX mRNA levels in eight-cell embryos by more than $80 \%$ relative to uninjected and negative control miRNA-injected embryos (Fig. 5B).

The degradation of the untranslated maternal RNA pool is very critical to early embryonic development (Schultz, 2002). The translation potential of a maternal mRNA transcript is affected by the length of the poly (A) tail as it confers mRNA stability and stimulates translation via interaction of poly (A) binding protein (PABP) with the $5^{\prime} \mathrm{m} 7 \mathrm{G}$ cap (Curtis et al., 1995; Amano, 2005). Moreover, maternal mRNAs are dependent on post-transcriptional and post-translational mechanisms to regulate their activity, as they cannot be repressed at the transcriptional level (Vasudevan et al., 2006; Bettegowda and Smith, 2007). Recent studies in zebrafish and Xenopus found that miRNAs promote deadenylation of target mRNAs and induce maternal mRNA degradation/clearance during early embryogenesis (Giraldez et al., 2006; Lund et al., 2009), indicating that miRNA-induced clearance of maternal mRNAs might be a universal 
mechanism during MET. Thus, a similar mechanism is likely to be involved in the miR-196a negative regulation of NOBOX expression in bovine embryos during MET.

miR-196a is an evolutionary conserved miRNA that has been identified in a wide range of vertebrate species. It is expressed from intergenic regions of HOX gene clusters, and targets several HOX genes in these clusters, which are known to play crucial roles during development (Yekta et al., 2004; Sehm et al., 2009; Braig et al., 2010). Recent studies showed that $75 \%$ of tumors express high levels of miR-196a and miR-196a is involved in regulating key pathways such as AKT signaling, p53 and WNT signaling pathways (Andl et al., 2006; Schimanski et al., 2009). It has also been reported that miR-196a is differently regulated during polycystic kidney disease suggesting that miR-196 is important for normal functioning of kidney (Pandey et al., 2008). The involvement of miR-196a in regulating the expression of NOBOX supports a new role of this miRNA in early embryonic development during MET.

\section{CONCLUSION}

Collectively, our results demonstrate the ability of miR-196a to negatively regulate NOBOX expression in a sequence specific fashion and the ability of miR-196a to suppress NOBOX mRNA and protein in early embryos. Future studies of interest will investigate whether loss of miR-196a has any effect on the early embryonic development and identify putative miR196a targets by next generation sequencing analysis of miR-196a depleted and wild type embryos.

\section{ACKNOWLEDGMENTS}

This work was supported by National Research Initiative Competitive Grant \#200835203-19094 from the USDA National Institute of Food and Agriculture (GWS), Agriculture and 
Food Research Initiative, Competitive Grant \#2009-65203-05706 from the USDA National Institute of Food and Agriculture (JY) and funds from the West Virginia Agricultural and Forestry Experiment Station (Hatch project No. 427). 
Table 1. List of primers used in this study

\begin{tabular}{|c|c|c|c|}
\hline $\begin{array}{l}\text { Gene } \\
\text { Name }\end{array}$ & Primer Name & Primer Sequence (5' to $\left.3^{\prime}\right)$ & Application \\
\hline miR-196a & $\begin{array}{l}\text { NOBOX-BamHI-F } \\
\text { NOBOX-Xhol-R } \\
\text { NOBOX-3'UTR-Sacl-F } \\
\text { NOBOX-3'UTR-Xbal-R } \\
\text { NOBOX-3UTRmut-F } \\
\text { NOBOX-3UTRmut-R } \\
\text { NOBOX-Real time-F } \\
\text { NOBOX-Real time-R } \\
\text { RPS18-RealTime-F } \\
\text { RPS18-RealTime-R } \\
\text { miR-196a-RT } \\
\text { miR-196a-BamHI-F } \\
\text { miR-196a-Xhol-R } \\
\text { miR-125b-RT }\end{array}$ & $\begin{array}{c}\text { TATGGATCCTTCCAAGCTACGTATGTACG } \\
\text { ATACTCGAGAGGCAGTTTACTGCTTATGGTGG } \\
\text { TATGAGCTCTCATGGAGCCGAAGAACCAAGA } \\
\text { ATATCTAGAGTTTCCCAAGAGGAGGCAGTT } \\
\text { CGCTCCAGTGGCCACCATAAGCAGTTTTGAGCCTCCTCTTGGG } \\
\text { CCCAAGAGGAGGCTCAAAACTGCTTATGGTGGCCACTGGAGCG } \\
\text { AGACCCAGTTCTTCCAACACC } \\
\text { GTGGTGTTGAGGAAAGCAGACA } \\
\text { TGATCACACGTTCCACCTCATC } \\
\text { UAGGUAGUUUCAUGUUGUGGG } \\
\text { TATGGATCCGACGGGGCTGAATTTCTTCC } \\
\text { ATACTCGAGCACTGGGGAGGGTAGGAGCGGGATA } \\
\text { TCCCTGAGACCCTAACTTGTGA }\end{array}$ & $\begin{array}{c}\text { Cloning of NOBOX } \\
\text { mRNA into pcDNA3.1 } \\
\text { Cloning of NOBOX } \\
\text { mRNA into pCDNA3.1 } \\
\text { Cloning of NOBOX } \\
\text { 3`UTR into pmirGLO } \\
\text { vector } \\
\text { Cloning of NOBOX } \\
\text { 3'UTR into pmirGLO } \\
\text { vector } \\
\text { Generating mutant } \\
\text { NOBOX 3'UTR for } \\
\text { luciferase reporter assay } \\
\text { Generating mutant } \\
\text { NOBOX 3'UTR for } \\
\text { luciferase reporter assay } \\
\text { Real Time PCR } \\
\text { Real Time PCR } \\
\text { Real Time PCR } \\
\text { (endogenous control) } \\
\text { Real Time PCR } \\
\text { (endogenous control) } \\
\text { Real Time PCR } \\
\text { Cloning of miR-196a into } \\
\text { pcDNA3.1 } \\
\text { Cloning of miR-196a into } \\
\text { pcDNA3.1 } \\
\text { Real Time PCR } \\
\text { (endogenous control) }\end{array}$ \\
\hline
\end{tabular}




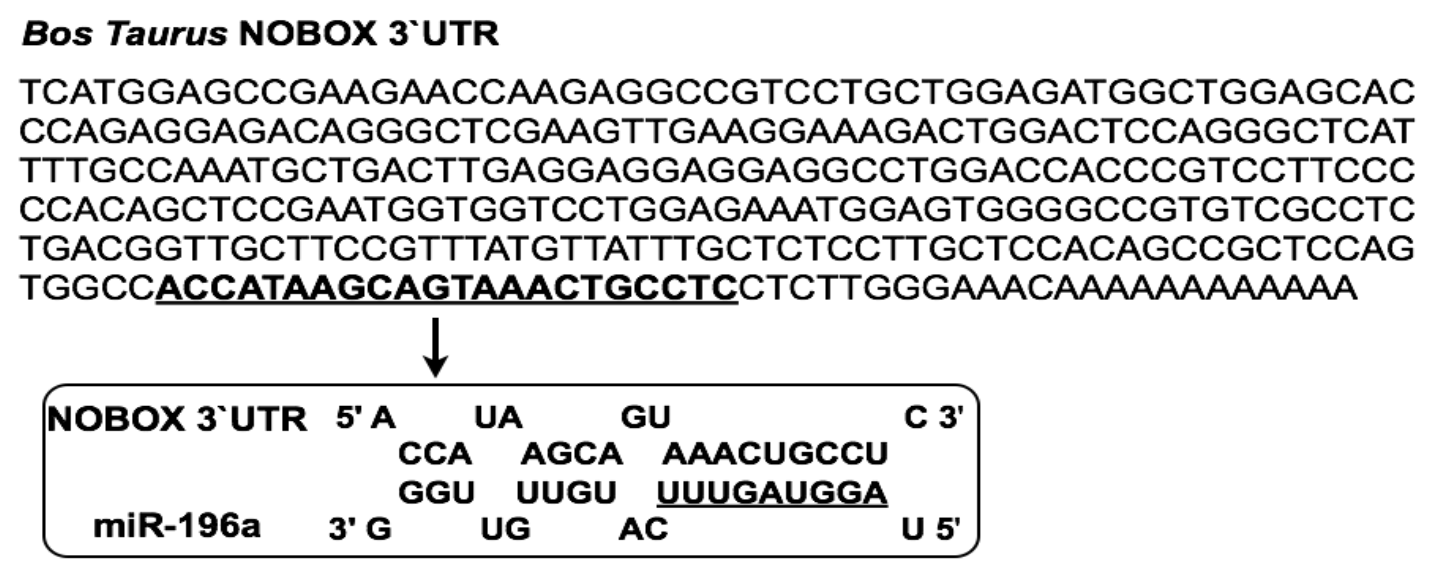

Figure 1. miR-196a binds to the 3' UTR of bovine NOBOX. Predicted binding site of miR-196a within the 3' UTR of the bovine NOBOX mRNA (underlined region). 
A

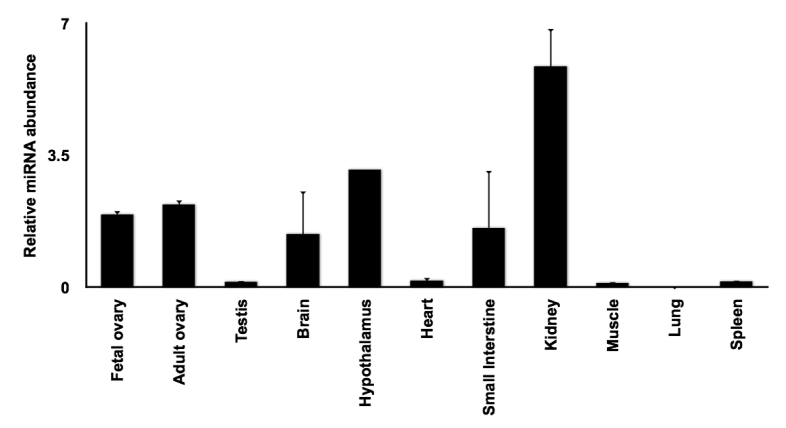

B

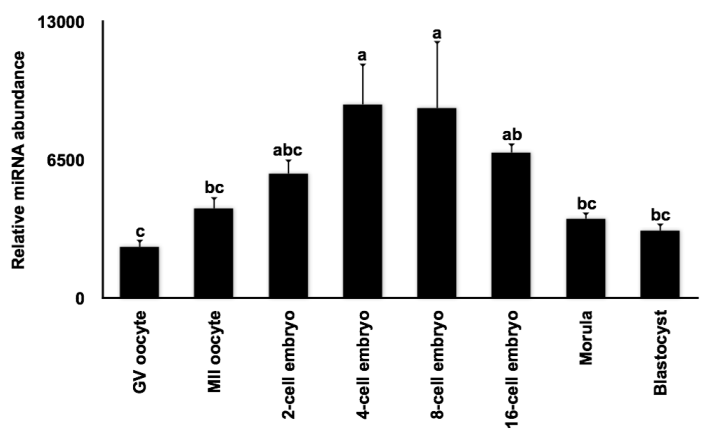

Figure 2. Spatial and temporal expression profile of miR-196a. (A) Tissue distribution of miR196a analyzed by quantitative real-time PCR. Quantity of miRNA-196a was normalized to abundance of RPS18 mRNA and abundance expressed as relative fold change using the sample with the lowest value as the calibrator $(n=4$ per tissue; mean \pm SEM depicted). (B) Relative abundance of miR-196a in bovine oocytes and in vitro produced bovine early embryos ( $n=4$ pools of five oocytes/embryos each). Quantity of miRNA was normalized relative to abundance of miR-125b. The relative amount of miR-196a was expressed as relative fold change using the sample with the lowest value as the calibrator $(n=4$, mean \pm SEM). Different letters indicate statistical difference $(P<0.05)$. 
A

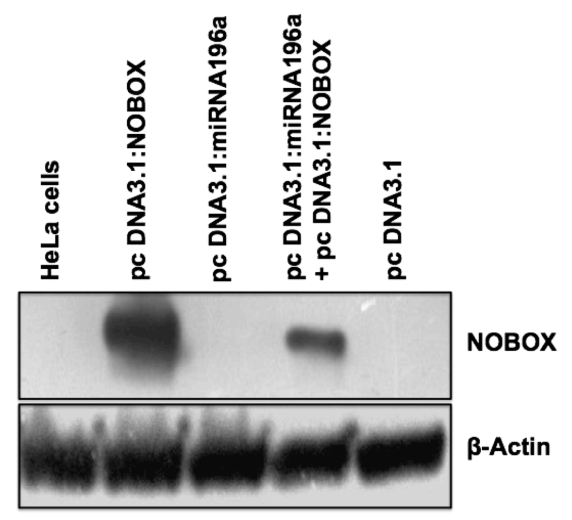

B

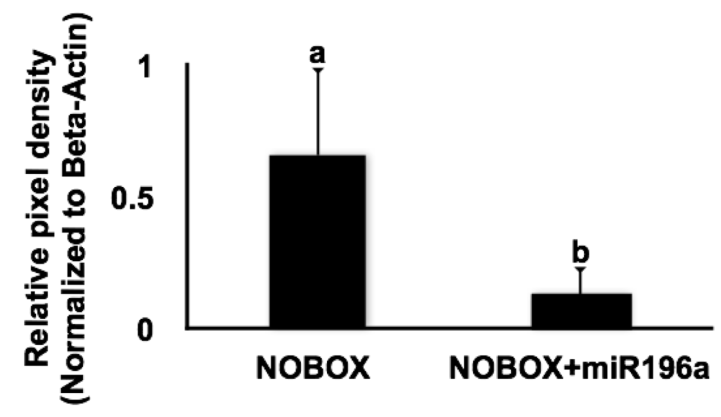

Figure 3. Regulation of bovine NOBOX expression by miR-196a in vitro in HeLa cells. (A) Representative Western blot showing specific suppression of bovine NOBOX by miR-196a in HeLa cells. $\beta$-Actin was used as loading control. The experiment was repeated four times with similar results, and a representative experiment is shown. (B) Semi-quantitative analysis of miRNA-196a regulation of NOBOX expression in transfected HeLa cells. Abundance of NOBOX protein in each sample was determined by densitometry and normalized relative to abundance of $\beta$-Actin protein (control). Data are expressed as mean relative pixel density $(n=4$ mean \pm SEM). Different letters indicate statistical difference $(P<0.05)$. 
A

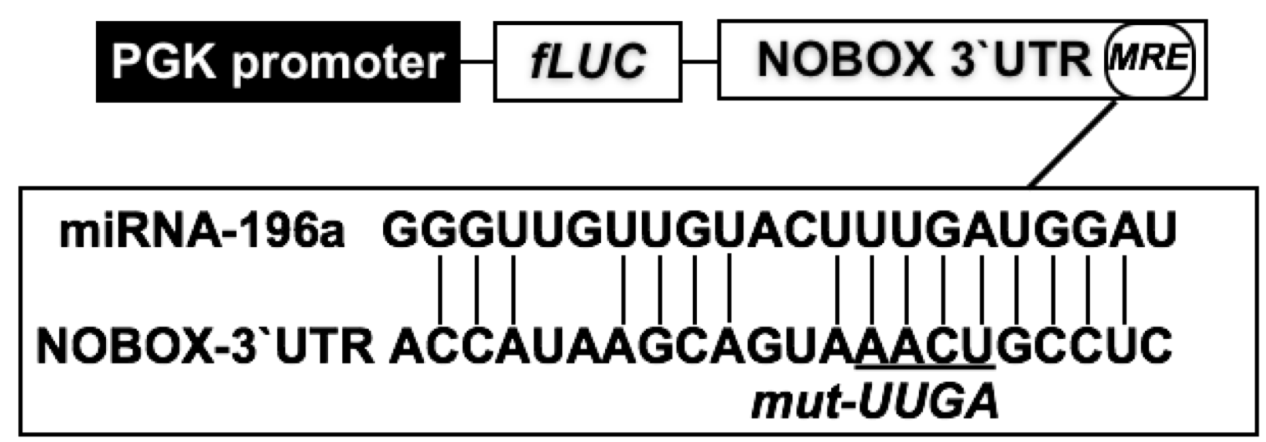

B

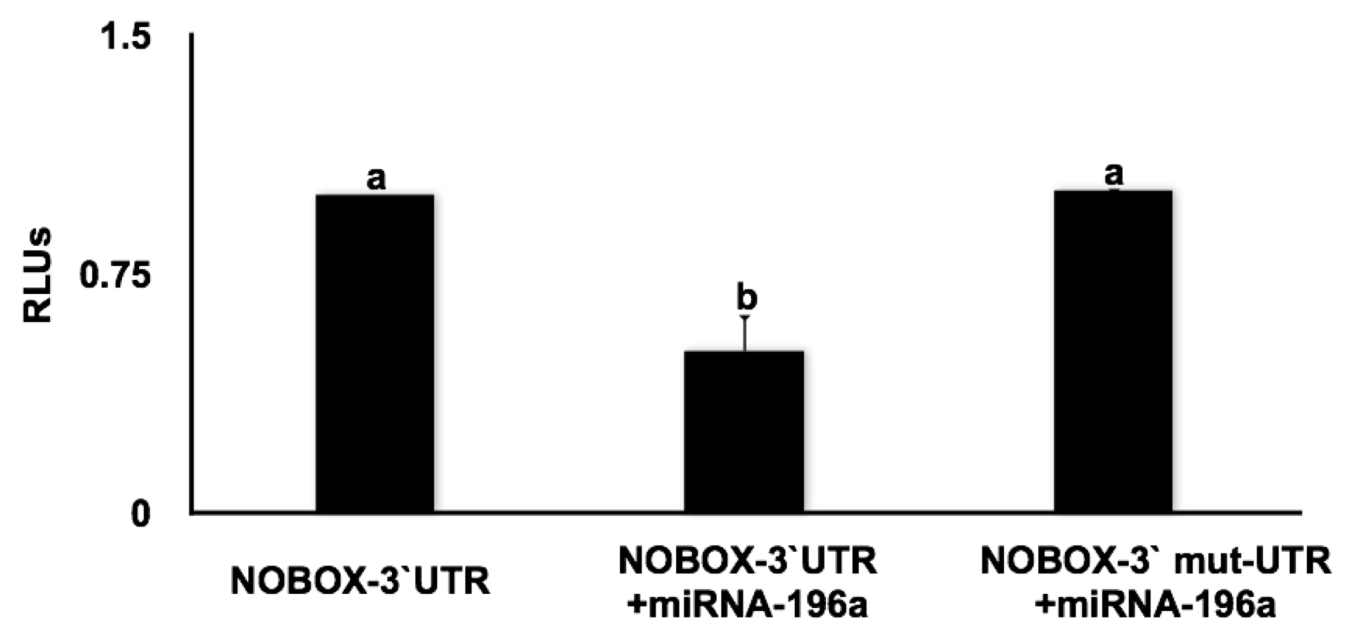

Figure 4. miR-196a specifically binds to the 3 ' UTR of bovine NOBOX and regulates its expression. (A) Schematic of the luciferase reporter constructs used to demonstrate sequence specificity in recognition sequence in bovine NOBOX 3' UTR mediating miR-196a mediated repression. Nucleotides changed to generate the target site mutant 3' UTR are underlined (B) Repression of luciferase activity due to specific interaction between miR-196a and the predicted MRE in the luciferase-NOBOX-3' UTR constructs. Repression of luciferase reporter gene activity by miR-196a was abolished when the MRE was mutated. Data is presented as relative firefly luciferase units (RLUs). Relative firefly luciferase values were determined by a ratio of firefly to renilla luciferase with the negative control (cells transfected with native NOBOX-3' UTR construct alone) set at 1 . Each group represents the mean \pm SEM of four wells for an 
experiment repeated four times with similar results. Different letters indicate statistical difference $(P<0.05)$. 
A

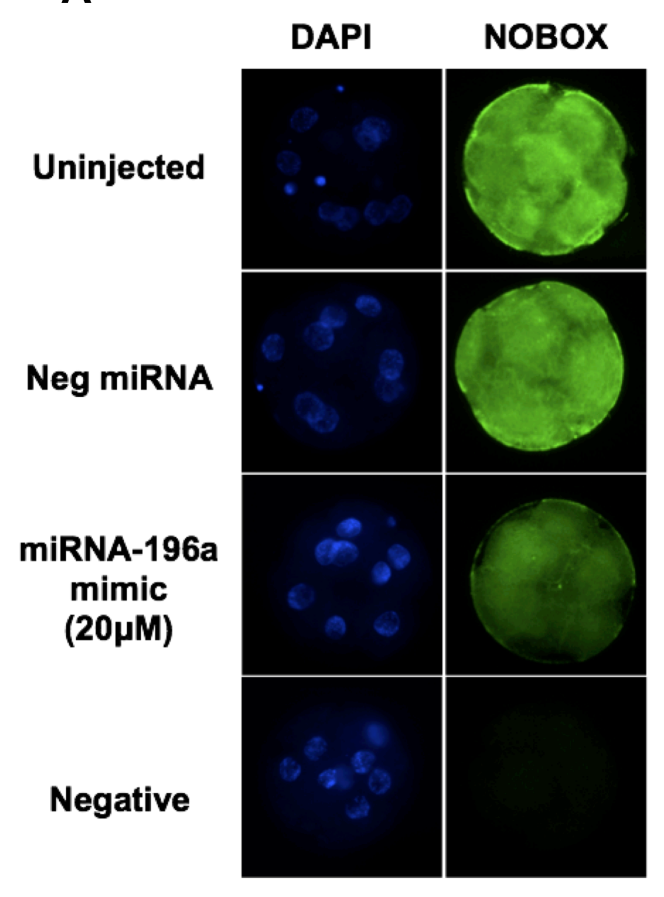

B

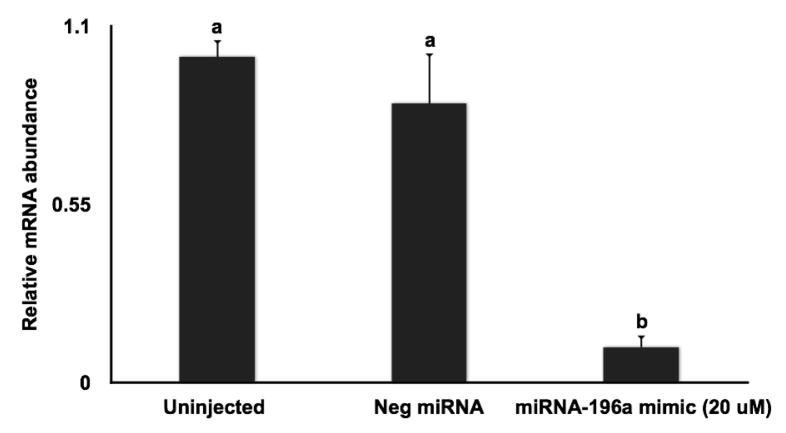

Figure 5. Microinjection of miR-196a mimic represses endogenous NOBOX expression in bovine early embryos. (A) Effect of miR-196a mimic microinjection on abundance of NOBOX protein in 8-cell stage embryos as determined by immunocytochemical analysis using confocal spinning-disk microscopy ( $n=4$ pools of 5-10 embryos per treatment). Uninjected embryos and embryos injected with a nonspecific miRNA (Neg miRNA) were used as controls. Nuclear DNA was stained with DAPI. (B) Effect of miR-196a mimic microinjection on abundance of NOBOX mRNA in eight-cell embryos as determined by real-time PCR. Data were normalized relative to abundance of endogenous control ribosomal protein S18 (RSP18) and are shown as mean \pm SEM ( $n=4$ pools of 10 embryos per treatment). Different letters indicate statistical difference $(P$ $<0.05)$ 


\section{REFERENCES}

Alizadeh, Z., Kageyama, S.-I., Aoki, F., 2005. Degradation of maternal mRNA in mouse embryos: selective degradation of specific mRNAs after fertilization. Mol. Reprod. Dev. 72, 281290.

Amano, 2005. Mechanism of Translation in the period of oocyte to zygote trasition in mammals. J.Mamm.Ova. Res, 1-11.

Ambros, V., 2004. The functions of animal microRNAs. Nature 431, 350-355.

Andl, T., Murchison, E.P., Liu, F., Zhang, Y., Yunta-Gonzalez, M., Tobias, J.W., Andl, C.D., Seykora, J.T., Hannon, G.J., Millar, S.E., 2006. The miRNA-processing enzyme dicer is essential for the morphogenesis and maintenance of hair follicles. Curr Biol 16, 1041-1049.

Bachvarova, R., De Leon, V., Johnson, A., Kaplan, G., Paynton, B.V., 1985. Changes in total RNA, polyadenylated RNA, and actin mRNA during meiotic maturation of mouse oocytes. Dev Biol 108, 325-331.

Bagga, S., Bracht, J., Hunter, S., Massirer, K., Holtz, J., Eachus, R., Pasquinelli, A.E., 2005. Regulation by let-7 and lin-4 miRNAs results in target mRNA degradation. Cell 122, 553-563. Bartel, D., 2004. MicroRNAs:: Genomics, Biogenesis, Mechanism, and Function. Cell 116, 281297.

Bartel, D.P., 2009. MicroRNAs: target recognition and regulatory functions. Cell 136, 215-233.

Begemann, G., 2008. MicroRNAs and RNA interference in zebrafish development. Zebrafish 5, 111-119.

Bentwich, I., 2005. Prediction and validation of microRNAs and their targets. FEBS Lett 579, 5904-5910.

Bernstein, E., Kim, S.Y., Carmell, M.A., Murchison, E.P., Alcorn, H., Li, M.Z., Mills, A.A., Elledge, S.J., Anderson, K.V., Hannon, G.J., 2003. Dicer is essential for mouse development. Nat Genet 35, 215-217. 
Bettegowda, A., Patel, O.V., Ireland, J.J., Smith, G.W., 2006. Quantitative analysis of messenger RNA abundance for ribosomal protein L-15, cyclophilin-A, phosphoglycerokinase, beta-glucuronidase, glyceraldehyde 3-phosphate dehydrogenase, beta-actin, and histone $\mathrm{H} 2 \mathrm{~A}$ during bovine oocyte maturation and early embryogenesis in vitro. Mol Reprod Dev 73, 267278.

Bettegowda, A., Smith, G.W., 2007. Mechanisms of maternal mRNA regulation: implications for mammalian early embryonic development. Front Biosci 12, 3713-3726.

Bettegowda, A., Yao, J., Sen, A., Li, Q., Lee, K.-B., Kobayashi, Y., Patel, O.V., Coussens, P.M., Ireland, J.J., Smith, G.W., 2007. JY-1, an oocyte-specific gene, regulates granulosa cell function and early embryonic development in cattle. Proc Natl Acad Sci USA 104, 17602-17607.

Braig, S., Mueller, D.W., Rothhammer, T., Bosserhoff, A.-K., 2010. MicroRNA miR-196a is a central regulator of HOX-B7 and BMP4 expression in malignant melanoma. Cell. Mol. Life Sci. $67,3535-3548$.

Brennecke, J., Stark, A., Russell, R.B., Cohen, S.M., 2005. Principles of microRNA-target recognition. PLoS Biol 3, e85.

Carmell, M.A., Hannon, G.J., 2004. RNase III enzymes and the initiation of gene silencing. Nat Struct Mol Biol 11, 214-218.

Choi, Y., Qin, Y., Berger, M.F., Ballow, D.J., Bulyk, M.L., Rajkovic, A., 2007. Microarray analyses of newborn mouse ovaries lacking Nobox. Biol Reprod 77, 312-319.

Curtis, D., Lehmann, R., Zamore, P.D., 1995. Translational regulation in development. Cell 81, 171-178.

DeRenzo, C., Seydoux, G., 2004. A clean start: degradation of maternal proteins at the oocyteto-embryo transition. Trends Cell Biol 14, 420-426.

Giraldez, A.J., Cinalli, R.M., Glasner, M.E., Enright, A.J., Thomson, J.M., Baskerville, S., Hammond, S.M., Bartel, D.P., Schier, A.F., 2005. MicroRNAs regulate brain morphogenesis in zebrafish. Science 308, 833-838. 
Giraldez, A.J., Mishima, Y., Rihel, J., Grocock, R.J., Van Dongen, S., Inoue, K., Enright, A.J., Schier, A.F., 2006. Zebrafish MiR-430 promotes deadenylation and clearance of maternal mRNAs. Science 312, 75-79.

He, L., Hannon, G.J., 2004. MicroRNAs: small RNAs with a big role in gene regulation. Nat Rev Genet 5, 522-531.

Jaskiewicz, L., Filipowicz, W., 2008. Role of Dicer in posttranscriptional RNA silencing. Curr Top Microbiol Immunol 320, 77-97.

Kanellopoulou, C., Muljo, S.A., Kung, A.L., Ganesan, S., Drapkin, R., Jenuwein, T., Livingston, D.M., Rajewsky, K., 2005. Dicer-deficient mouse embryonic stem cells are defective in differentiation and centromeric silencing. Gene Dev 19, 489-501.

Krützfeldt, J., Poy, M.N., Stoffel, M., 2006. Strategies to determine the biological function of microRNAs. Nat Genet 38 Suppl, S14-19.

Landgraf, P., Rusu, M., Sheridan, R., Sewer, A., lovino, N., Aravin, A., Pfeffer, S., Rice, A., Kamphorst, A.O., Landthaler, M., Lin, C., Socci, N.D., Hermida, L., Fulci, V., Chiaretti, S., Foà, R., Schliwka, J., Fuchs, U., Novosel, A., Müller, R.-U., Schermer, B., Bissels, U., Inman, J., Phan, Q., Chien, M., Weir, D.B., Choksi, R., De Vita, G., Frezzetti, D., Trompeter, H.-I., Hornung, V., Teng, G., Hartmann, G., Palkovits, M., Di Lauro, R., Wernet, P., Macino, G., Rogler, C.E., Nagle, J.W., Ju, J., Papavasiliou, F.N., Benzing, T., Lichter, P., Tam, W., Brownstein, M.J., Bosio, A., Borkhardt, A., Russo, J.J., Sander, C., Zavolan, M., Tuschl, T., 2007. A mammalian microRNA expression atlas based on small RNA library sequencing. Cell $129,1401-1414$

Li, L., Zheng, P., Dean, J., 2010. Maternal control of early mouse development. Development $137,859-870$.

Lim, L.P., Lau, N.C., Garrett-Engele, P., Grimson, A., Schelter, J.M., Castle, J., Bartel, D.P., Linsley, P.S., Johnson, J.M., 2005. Microarray analysis shows that some microRNAs downregulate large numbers of target mRNAs. Nature 433, 769-773. 
Lund, E., Liu, M., Hartley, R.S., Sheets, M.D., Dahlberg, J.E., 2009. Deadenylation of maternal mRNAs mediated by miR-427 in Xenopus laevis embryos. RNA 15, 2351-2363.

Nagaraja, A.K., Andreu-Vieyra, C., Franco, H.L., Ma, L., Chen, R., Han, D.Y., Zhu, H., Agno, J.E., Gunaratne, P.H., DeMayo, F.J., Matzuk, M.M., 2008. Deletion of Dicer in somatic cells of the female reproductive tract causes sterility. Mol Endocrinol 22, 2336-2352.

Pandey, P., Brors, B., Srivastava, P.K., Bott, A., Boehn, S.N.E., Groene, H.-J., Gretz, N., 2008. Microarray-based approach identifies microRNAs and their target functional patterns in polycystic kidney disease. BMC Genomics 9, 624.

Paynton, B.V., Rempel, R., Bachvarova, R., 1988. Changes in state of adenylation and time course of degradation of maternal mRNAs during oocyte maturation and early embryonic development in the mouse. Dev Biol 129, 304-314.

Qin, Y., Choi, Y., Zhao, H., Simpson, J.L., Chen, Z.-J., Rajkovic, A., 2007. NOBOX homeobox mutation causes premature ovarian failure. Am J Hum Genet 81, 576-581.

Qin, Y., Shi, Y., Zhao, Y., Carson, S.A., Simpson, J.L., Chen, Z.-J., 2009. Mutation analysis of NOBOX homeodomain in Chinese women with premature ovarian failure. Fertil Steril 91, 15071509.

Qiu, R., Liu, Y., Wu, J.Y., Liu, K., Mo, W., He, R., 2009. Misexpression of miR-196a induces eye anomaly in Xenopus laevis. Brain Res Bull 79, 26-31.

Rajewsky, N., 2006. microRNA target predictions in animals. Nat Genet 38 Suppl, S8-13.

Rajkovic, A., Pangas, S.A., Ballow, D., Suzumori, N., Matzuk, M.M., 2004. NOBOX deficiency disrupts early folliculogenesis and oocyte-specific gene expression. Science 305, 1157-1159.

Rusinov, V., Baev, V., Minkov, I.N., Tabler, M., 2005. Microlnspector: a web tool for detection of miRNA binding sites in an RNA sequence. Nucleic Acids Res 33, W696-700.

Sagata, N., Watanabe, N., Vande Woude, G.F., Ikawa, Y., 1989. The c-mos proto-oncogene product is a cytostatic factor responsible for meiotic arrest in vertebrate eggs. Nature $342,512-$ 518. 
Schimanski, C.C., Frerichs, K., Rahman, F., Berger, M., Lang, H., Galle, P.R., Moehler, M., Gockel, I., 2009. High miR-196a levels promote the oncogenic phenotype of colorectal cancer cells. World J Gastroenterol 15, 2089-2096.

Schultz, R.M., 2002. The molecular foundations of the maternal to zygotic transition in the preimplantation embryo. Hum Reprod Update 8, 323-331.

Sehm, T., Sachse, C., Frenzel, C., Echeverri, K., 2009. miR-196 is an essential early-stage regulator of tail regeneration, upstream of key spinal cord patterning events. Dev Biol 334, 468480.

Shen-Orr, S.S., Pilpel, Y., Hunter, C.P., 2010. Composition and regulation of maternal and zygotic transcriptomes reflects species-specific reproductive mode. Genome Biol 11, R58.

Spruce, T., Pernaute, B., Di-Gregorio, A., Cobb, B.S., Merkenschlager, M., Manzanares, M., Rodriguez, T.A., 2010. An early developmental role for miRNAs in the maintenance of extraembryonic stem cells in the mouse embryo. Dev Cell 19, 207-219.

Suzumori, N., Yan, C., Matzuk, M.M., Rajkovic, A., 2002. Nobox is a homeobox-encoding gene preferentially expressed in primordial and growing oocytes. Mech Dev 111, 137-141.

Tang, F., Kaneda, M., O'Carroll, D., Hajkova, P., Barton, S.C., Sun, Y.A., Lee, C., Tarakhovsky, A., Lao, K., Surani, M.A., 2007. Maternal microRNAs are essential for mouse zygotic development. Genes Dev 21, 644-648.

Tejomurtula, J., Lee, K.-B., Tripurani, S.K., Smith, G.W., Yao, J., 2009. Role of importin alpha8, a new member of the importin alpha family of nuclear transport proteins, in early embryonic development in cattle. Biol Reprod 81, 333-342.

Telford, N.A., Watson, A.J., Schultz, G.A., 1990. Transition from maternal to embryonic control in early mammalian development: a comparison of several species. Mol. Reprod. Dev. 26, 90100.

Tripurani, S.K., Lee, K.-B., Wang, L., Wee, G., Smith, G.W., Lee, Y.S., Latham, K.E., Yao, J., 2011. A Novel Functional Role for the Oocyte-Specific Transcription Factor Newborn Ovary 
Homeobox (NOBOX) during Early Embryonic Development in Cattle. Endocrinology 152, 10131023.

Tripurani, S.K., Xiao, C., Salem, M., Yao, J., 2010. Cloning and analysis of fetal ovary microRNAs in cattle. Anim Reprod Sci 120, 16-22.

Vasudevan, S., Seli, E., Steitz, J.A., 2006. Metazoan oocyte and early embryo development program: a progression through translation regulatory cascades. Gene Dev 20, 138-146.

Wienholds, E., Plasterk, R.H.A., 2005. MicroRNA function in animal development. FEBS Lett $579,5911-5922$.

Yekta, S., Shih, I.-H., Bartel, D.P., 2004. MicroRNA-directed cleavage of HOXB8 mRNA. Science 304, 594-596.

Zuker, M., 2003. Mfold web server for nucleic acid folding and hybridization prediction. Nucleic Acids Research 31, 3406. 
CHAPTER-3 


\title{
Cloning and expression analysis of fetal ovary-expressed microRNAs in cattle
}

\author{
Swamy K Tripurani", Caide Xiao*, Mohamed Salem and Jianbo Yao* \\ Animal Reproduction Science 2010 Jul; 120(1-4): 16-22 \\ *Laboratory of Animal Biotechnology and Genomics, Division of Animal and Nutritional Sciences, West \\ Virginia University, Morgantown, WV 26506.
}

KEYWORDS: microRNA (miRNA), oocyte, folliculogenesis, embryogenesis

\section{AUTHOR'S CONTRIBUTIONS}

SKT designed and performed most of the experiments including bioinformatics and expression analysis of miRNA. SKT also drafted the manuscript. CX constructed the fetal ovary miRNA library. MS performed microRNA target predictions. JY designed the study and supervised the experimental work. 


\section{ABSTRACT}

Ovarian folliculogenesis and early embryogenesis are complex processes, which require tightly regulated expression and interaction of a multitude of genes. Small endogenous RNA molecules, termed microRNAs (miRNAs), are involved in the regulation of gene expression during folliculogenesis and early embryonic development. To identify miRNAs expressed in bovine oocytes/ovaries, a bovine fetal ovary miRNA library was constructed. Sequence analysis of random clones from the library identified 679 miRNA sequences, which represent 58 distinct bovine miRNAs. Of these distinct miRNAs, 42 are known bovine miRNAs present in the miRBase database and the remaining 16 miRNAs include 15 new bovine miRNAs that are homologous to miRNAs identified in other species, and one novel miRNA, which does not match any miRNAs in the database. The precursor sequences for 14 of the new 15 miRNAs as well as the novel miRNA were identified from the bovine genome database and their hairpin structures were predicted. Expression analysis of the 58 miRNAs in fetal ovaries in comparison to somatic tissue pools identified eight miRNAs predominantly expressed in fetal ovaries. Further analysis of the expression of these eight miRNAs in germinal vesicle (GV) stage oocytes identified two miRNAs (bta-mir424 and bta-mir-10b) that are highly abundant in GV oocytes. Both miRNAs show similar expression patterns during oocyte maturation and preimplantation development of bovine embryos, being abundant in GV and MII stage oocytes, as well as in early stage embryos (until 16-cell stage). The amount of the novel miRNA is relatively small in oocytes and early cleavage embryos but greater in blastocysts, suggesting a role of this miRNA in blastocyst cell differentiation. 


\section{INTRODUCTION}

MicroRNAs (miRNAs) are single-stranded endogenous non-coding small RNAs ranging in size from 19 to 24 nucleotides (nt). It is estimated that 1 to $5 \%$ of the genes in the genome encode for miRNAs (Lim et al., 2003), which may regulate up to $30 \%$ of the genes (Lewis et al., 2003). Many miRNA genes are transcribed by RNA polymerase II, yielding primary miRNAs (Bartel, 2004; He and Hannon, 2004), which are processed by Drosha into miRNA precursors (pre-miRNAs) of approximately $70 \mathrm{nt}$ (Lee et al., 2003). The pre-miRNAs are then transported to the cytoplasm and processed by DICER to form an miRNA:miRNA* duplex (Bartel, 2004; He and Hannon, 2004). Mature miRNAs associate with an Argonaute protein and act either at the 3' untranslated region (UTR) (Bentwich, 2005; Rajewsky, 2006) or the amino acid coding region of the transcript (Tay et al., 2008) resulting in the suppression of the target gene expression (Ambros, 2004). The majority of miRNAs are evolutionarily conserved across species boundaries and are important regulators of molecular and cellular processes such as brain morphogenesis (Giraldez et al., 2005), cardiomyocyte proliferation/differentiation (Zhao et al., 2005), viral defense (Lecellier et al., 2005) and insulin secretion (Poy et al., 2004).

Ovarian folliculogenesis and early embryogenesis are complex and coordinated biological processes, which require tightly regulated expression and interaction of large groups of genes. Maternal transcripts and proteins synthesized and stored in oocytes during oogenesis are indispensable for proper recommencement of meiosis and early embryogenesis prior to embryonic genome activation (De Sousa et al., 1998). Genes specifically expressed in oocytes are known to play important roles in folliculogenesis and early development (Zheng and Dean, 2007). Recent studies indicate that miRNAs may play a critical role in controlling the expression of genes essential for folliculogenesis and early embryogenesis (Zhao and Rajkovic, 2008; Carletti and Christenson, 2009). Loss of maternal miRNAs by specific deletion of Dicer results in an arrest of zygotic development in mice (Tang et al., 2007) and a specific miRNA, miR-430, has been shown to be responsible of the degradation of many maternally expressed mRNAs in 
zebrafish (Giraldez et al., 2006). Efforts to identify miRNAs expressed in mouse ovaries have been made using either microarray approach (Choi et al., 2007) or cloning approach (Ro et al., 2007). However, the role of individual miRNAs in oocyte and embryonic development in mammalian species is currently unknown.

In recent years, cattle has been recognized as an important model animal for biochemistry, reproduction and nutrition research as cattle and human genomes contain many identical genes, and even the whole chromosomes of two species are configured in the similar way when compared to mouse (Gibs et al., 2006). Computational and experimental methods have been used to identify miRNAs in cattle (Coutinho et al., 2007; Gu et al., 2007). To date, 615 bovine miRNAs have been identified (miRBase release 14.0). In an attempt to identify miRNAs specifically or predominantly expressed in oocytes, a miRNA library was constructed from bovine fetal ovaries (a rich source of oocytes). This study reports the cloning of 58 miRNAs expressed in bovine fetal ovaries, discovery of new bovine miRNAs including one that is completely novel, and identification of two miRNAs that are highly abundant in oocytes and early cleavage embryos.

\section{MATERIALS AND METHODS}

\section{Tissue collection and RNA isolation}

Bovine tissue samples including liver, kidney, muscle, heart, brain, hypothalamus, spleen, lung, small intestine and fetal ovary were collected at a local abattoir. Fetal age was estimated based on crown-rump length (Richardson et al., 1990). All samples were frozen in liquid nitrogen and stored at $-80^{\circ} \mathrm{C}$ until use. Total RNA was isolated using the TRIzol reagent (Invitrogen, Carlsbad, CA) according to the manufacturer's instruction. Concentrations of 
isolated RNA were determined by measuring absorbance at $260 \mathrm{~nm}$ using a Nanodrop spectrophotometer (Thermo scientific, Wilmington, DE).

\section{MicroRNA library construction and sequencing}

The miRNA library was constructed using the small RNA cloning kit mirCat ${ }^{\mathrm{TM}}$ (IDT DNA, Coralville, IA) according to the manufacturer's instruction with minor modifications (Ramachandra et al., 2008). Briefly, a pool of total RNA $(500 \mu \mathrm{g})$ isolated from two fetal ovaries (230 and 250 days of gestation, respectively) was size fractionated using a doubleconcentration (3\% and $15 \%$ ) denaturing polyacrylamide gel. Small RNAs were purified from the excised gels and 3' linker (5' phosphorylated) was ligated to the small RNAs in the absence of ATP. The 3' linker-ligated small RNAs were size fractionated and purified again, and then ligated to 5 ' linker in the presence of ATP. The ligation products were reverse transcribed using

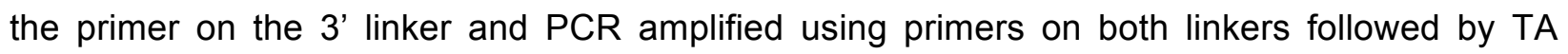
cloning using pGEM-T easy vector system (Promega, Madison, WI). A total of 1536 clones were randomly picked from the library and sequenced (Agencourt Biosciences Corporation, Beverly, MA).

\section{Bioinformatic analysis}

Low quality sequences and sequences with no inserts were removed first. Vector and adapter sequences were then removed from the remaining good quality sequences. A total of 685 sequences of typical miRNA size (19-24 nt) were obtained after removing smaller sequences (<18 nt) and used for further analysis. To identify miRNAs, all small RNA sequences were initially analyzed using the miRbase search tool (http://microrna.sanger.ac.uk/sequences/search.shtml). If a small RNA matches to a registered bovine miRNA, it was classified as a known bovine miRNA. If a small RNA matches to a registered miRNA identified in other animal species but not in cattle, it was considered as a new 
bovine miRNA. If a small RNA is $19-24 \mathrm{nt}$ long but does not match any registered miRNAs in the miRBase database, it was considered as a potentially novel bovine miRNA. Each identified miRNA was located in the bovine genome using the BLAT function in the UCSC genome browser (http://genome.ucsc.edu/) (Karolchik et al., 2008). The genomic sequence containing the miRNA with 100 nt flanking sequences was analyzed for hairpin structure using the Mfold program (version 3.2) at (http://mfold.bioinfo.rpi.edu/cgi-bin/rna-form1.cgi) (Zuker, 2003). Prediction of target genes was performed using TargetScan (http://www.targetscan.org/).

\section{MicroRNA expression analysis}

The relative amount of miRNAs was determined by quantitative real-time PCR using the miScript PCR system (Qiagen, Valencia, CA) according to the manufacturer's protocol. Total RNA ( $1 \mu \mathrm{g}$ from somatic tissues or fetal ovaries, $\mathrm{n}=3$ ) was converted to cDNA using miScript reverse transcriptase mix (Qiagen, Valencia, CA). The cDNA was then used for real time PCR quantification of miRNA using a miRNA specific primer and the miScript universal primer (Qiagen, Valencia, CA). Ribosomal protein S18 (RPS18) gene was used as an endogenous control. The primers for miRNAs and the control gene are listed in Table 1. The Bio-Rad iCycler iQ Real Time Detection System was used to perform the quantitative analysis using miScript QuantiTect SYBR Green PCR master mix (Qiagen, Valencia, CA) in 25- $\mu$ l reaction volumes containing $300 \mathrm{nM}$ of each primer and cDNA derived from $0.1 \mu \mathrm{g}$ of total RNA. Cycling parameters were $95 \mathrm{C}$ for $15 \mathrm{~min}$, and then 40 cycles of $95 \mathrm{C}$ for $15 \mathrm{sec}, 55 \mathrm{C}$ for $30 \mathrm{sec}$ and 70 C for $30 \mathrm{sec}$. Standard curves for all miRNAs and the endogenous control were constructed using the 10-fold serial dilution of a cDNA from a pool of somatic tissues. For each sample, the quantity of miRNA and the reference gene mRNA (RPS18) was determined from the appropriate standard curves. The quantity of the miRNA was then divided by the quantity of the reference gene to obtain a normalized value. The expression of the miRNA was expressed as relative fold change. When comparing miRNA expression between fetal ovaries and pools of 
somatic tissues, the somatic tissue pools were used as a calibrator. When comparing the expression of the novel miRNA in multiple tissues, the tissue with the lowest expression was used as a calibrator. The heatmap showing relative miRNA expression between fetal ovaries and pools of somatic tissues was constructed using Multiexperiment Viewer (MeV) software.

GV oocytes and early stage embryos used for quantitative measurement of miRNA expression were purchased from Bomed, Inc (Madison, WI). cDNA from oocyte and embryo samples ( $n=3$ pools of 5 each) was prepared by lysing the samples in 1 X miScript RT buffer containing $0.5 \% \mathrm{NP}-40$ at $95 \mathrm{C}$ for $5 \mathrm{~min}$ followed by addition of miScript reverse transcriptase mix (Qiagen, Valencia, CA) and incubation at $37 \mathrm{C}$ for $60 \mathrm{~min}$. The cDNA was then used for determination of miRNA expression by quantitative real time PCR as described above. mir-125b was used as an endogenous control to normalize the target miRNA expression in oocytes and early embryos as this miRNA has been shown to be expressed consistently in preimplantation mouse embryos (Byrne and Warner, 2008).

\section{RESULTS AND DISCUSSION}

\section{Cloning and identification of miRNAs from bovine fetal ovary}

A miRNA library was constructed using small RNA isolated from bovine fetal ovaries. Sequencing of 1536 randomly selected clones from the library generated a total of 684 good quality sequences of typical mature miRNA size (19-24 nt). Public database search revealed that the majority of these small RNA sequences are miRNAs (679 out of 684 ) and only a small fraction represents degraded mRNA or tRNA (Table 2). The majority of the miRNAs are $20-23$ nt in size, which is the typical size range for DICER-derived products and the 21-22 nt size class is predominant (Fig. 1). Furthermore, the majority of the bovine miRNAs begin with a 5' uridine, a characteristic of miRNAs (Bartel, 2004). 
Among the 679 miRNA sequences, 635 of them represent 42 distinct bovine miRNAs already annotated in the miRbase database (Table 3). The remaining 44 miRNAs include 43 representing 15 distinct miRNAs that are conserved among other animal species but not yet identified in cattle, and one miRNA that does not match any known miRNAs registered in the miRbase database (Table 4). A search of the bovine genome database revealed chromosomal locations and potential precursors for all newly identified miRNAs except for bta-mir-652. The new bovine miRNAs will be submitted to the miRNA registry website at http://microRNA.sanger.ac.uk/registry for official annotation. Overall, nearly all cloned bovine miRNAs from fetal ovaries are homologous to known miRNAs in animal species, supporting the notion that miRNAs are evolutionarily conserved (Bartel, 2004).

The miRNAs cloned from bovine fetal ovaries vary greatly in their representation in the cloned population, with $50 \%$ of them being represented by at least two clones (Table 3 and Table 4). bta-mir-99a and bta-mir-125b are the most abundant miRNAs in the cloned miRNA population, accounting for $33 \%$ and $31 \%$ of all cloned miRNAs. This observation is consistent with the data from a mouse study where there was great abundance of these two miRNAs in ovaries (Mishima et al., 2008). In addition, there are 80 clones representing miRNAs of the btalet-7 family that consists of 10 isoforms $\left(a, b, c, d, e, f, g, a^{*}, b^{*}, e^{*}\right)$. let-7, the founding member of the family is required for timing of cell fate determination (Pasquinelli et al., 2000; Reinhart et al., 2000). The relative abundance of these miRNAs in ovaries may suggest their housekeeping cellular roles during ovarian development.

One of the important criteria that distinguish miRNAs from other endogenous small RNAs is the ability of the miRNA-surrounding sequence to adopt a hairpin structure with the miRNA positioned within one stand of the hairpin in order to be excised during the Dicer processing (Ambros et al., 2003). To confidently annotate the newly identified bovine miRNAs, they were aligned to the bovine genomic sequences in the UCSC genome browser to identify the miRNA precursor sequences. Precursor sequences for 14 of the 15 new bovine miRNAs 
were identified in the current bovine genome database. A total of 17 genomic loci were found including 12 single-copy loci corresponding to 12 miRNAs, two loci encoding bta-miR-299-5p and three loci for bta-miR-339-5p (Fig. 2). The genomic locus for bta-miR-652 was not identified, presumably due to incompleteness of the bovine genome sequence. All precursor sequences identified for the new bovine miRNAs are in the typical size range (70-100 nt) for animal miRNA precursors (Bartel, 2004) and can form thermodynamically stable hairpin structures that fulfill the miRNA biogenesis criteria (Fig. 2).

\section{Analysis of cloned bovine miRNAs}

To identify miRNAs specifically or predominantly expressed in fetal ovaries, the relative abundance of all cloned bovine miRNAs in fetal ovaries and pools of somatic tissues (brain, hypothalamus, liver, spleen, heart, lung, kidney, small intestine and muscle) was assessed by quantitative real time PCR. The data are shown as a heatmap in Fig. 3. Of the 58 miRNAs tested, eight miRNAs including bta-miR-99a, bta-miR-10b, bta-miR-199a-3p, bta-miR-199a-5p, bta-miR-424, bta-miR-100, bta-miR-455 and bta-miR-214* showed over 10-fold greater in relative abundance in fetal ovaries compared to the somatic tissue pools. Some of these miRNAs (e.g. bta-miR-99a, bta-miR-10b, bta-miR-100 and bta-miR-424) are also abundantly present in human ovaries (Liang et al., 2007). Sequencing-based miRNA expression profiling has often been used as a tool to measure the relative abundance of miRNAs (Landgraf et al., 2007). The expression data for many of these miRNAs (e.g. bta-miR-99a) appear to match the cloning frequency data; however, some of them (e.g. bta-miR-199a-3p, bta-miR-199a-5p) are represented by only a few copies from the sequencing data (Table 3 and Table 4). Such discrepancies between cloning frequency and expression results have been reported previously for miRNAs in cattle as well as in other species (Sempere et al., 2004; Gu et al., 2007; Reddy et al., 2009). 
The ovary contains multiple somatic cell types such as granulose cells, theca cells and cumulus cells in addition to oocytes. Therefore, the miRNAs cloned from the fetal ovaries may be derived from either oocytes or somatic cell types. To determine the cellular origin, we examined the expression of the eight miRNAs predominantly expressed in fetal ovaries in germinal vesicle (GV) stage oocytes. As shown in Fig. 4, two miRNAs, bta-mir-424 and bta-mir$10 \mathrm{~b}$, were in greater relative abundance in GV oocytes relative to the remaining six miRNAs abundantly present in fetal ovaries, suggesting that these six miRNAs are expressed primarily in the ovarian somatic cells. To further investigate the role of bta-mir-424 and bta-mir-10b in oocyte maturation and early embryogenesis, relative amounts of these two miRNAs in GV and MII stage oocytes, and two-cell, four-cell, eight-cell, 16-cell, morula and blastocyst stage embryos were assessed. The expression patterns of the two miRNAs are very similar, being highly abundant in GV and MII stage oocytes as well as in early stage embryos (until 16-cell) with a tendency of decreasing in morula and blastocyst stage embryos (Fig. 5). Such expression patterns indicate that these miRNAs are maternally inherited and may potentially be involved in the maternal transcript turnover during zygotic gene activation (Giraldez et al., 2006).

\section{Characterization of the novel bovine miRNA}

Many oocyte-specific genes are important for folliculogenesis, fertilization and early development (Zheng and Dean, 2007). Such genes are likely regulated by miRNAs specifically or predominantly present in oocytes. Fetal ovary is a rich source of oocytes and cloning of miRNAs from this tissue could lead to the discovery of novel oocyte-specific miRNAs. However, the novel miRNA cloned in this study does not appear to be oocyte-specific as it is expressed in pools of somatic tissues (Fig. 3). To further analyze the profile of this novel miRNA, the relative amount of this miRNA in 12 different bovine tissues was evaluated. Fig. $6 \mathrm{~A}$ shows that the novel miRNA is ubiquitous. Interestingly, the novel miRNA appears to be in greater relative amounts in the brain and hypothalamus than in either adult or fetal ovaries. To investigate the role of this 
novel miRNA in oocyte maturation and early embryonic development, the relative amount of this novel miRNA in GV and MIl stage oocytes as well as in preimplantation stage embryos was eveluated. As shown in Fig. 6B, the relative amount of this novel miRNA is small in oocytes and remains so in early embryos until morula stage when amounts increase, peaking in the blastocyst stage. Such expression profile may suggest a role of this miRNA in blastocyst cell differentiation.

By searching the bovine genome database, a genomic locus for the novel miRNA was identified on chromosome 10. The precursor sequence was predicted to form a hairpin structure that meets the miRNA biogenesis criteria (Fig. 6C). A search of the mouse and human genome database for the novel miRNA failed to identify homologous sequences, indicating that the novel miRNA could be cattle-specific. Although miRNAs are evolutionary conserved, species-specific miRNAs have been reported previously (Bentwich et al., 2005).

To identify potential target genes of the novel miRNA, a target prediction was performed in the present study by searching for the presence of conserved 7-mer sites in the 3' UTR of mRNAs that match exactly the seed region (positions 2-8) of the mature miRNA using TargetScan software. A total of 15 target genes were identified that might be regulated by this novel miRNA (Table 5). Interestingly, most of these genes are involved in signaling pathways and cell differentiation.

\section{CONCLUSION}

Cloning of miRNAs is the starting point to understand the diversity and possible roles of miRNAs in regulation of gene expression in an organism. This study led to the identification of 58 distinct fetal ovary-expressed miRNAs including 15 new bovine miRNAs that are cloned from cattle for the first time and a completely novel miRNA that has never been cloned in other mammalian species. Further analyses of the targets of these ovary-expressed miRNAs will help 
us understand their roles in regulation of gene expression during folliculogenesis and early embryogenesis in cattle.

\section{ACKNOWLEDGEMENTS}

The study is supported by Hatch project 427 (NE 1007) of the West Virginia Agricultural and Forestry Experiment Station and is published with the approval of the station director as scientific paper No. 3063. 
Table 1. List of primers used in the study

\begin{tabular}{|c|c|}
\hline Primer name & Primer sequence (5' to $\left.3^{\prime}\right)$ \\
\hline bta-miR-99a & AACCCGTAGATCCGATCTTGT \\
\hline bta-miR-125b & TCCCTGAGACCCTAACTTGTGA \\
\hline bta-miR-125a & TCCCTGAGACCCTTTAACCTGTG \\
\hline bta-miR-125b-1 & TCССTGAGACCСTAACTTGTGA \\
\hline bta-miR-26a & TTCAAGTAATCCAGGATAGGCT \\
\hline bta-let-7a & TGAGGTAGTAGGTTGTATAGTT \\
\hline bta-let-7b & TGAGGTAGTAGGTTGTGTGGTT \\
\hline bta-let-7c & TGAGGTAGTAGGTTGTATGGTT \\
\hline bta-let-7d & AGAGGTAGTAGGTTGCATAGTT \\
\hline bta-let-7e & TGAGGTAGGAGGTTGTATAGT \\
\hline bta-let-7f & TGAGGTAGTAGATTGTATAGTT \\
\hline bta-let-7g & TGAGGTAGTAGTTTGTACAGTT \\
\hline bta-let-7a* & СТATACAATCTACTGTCTTTCT \\
\hline bta-miR-10a & TACCCTGTAGATCCGAATTTGTG \\
\hline bta-miR-10b & TACCCTGTAGAACCGAATTTGTG \\
\hline bta-miR-126* & CATTATTACTTTTGGTACGCG \\
\hline bta-miR-199a-3p & ACAGTAGTCTGCACATTGGTTA \\
\hline bta-miR-199a-5p & CCCAGTGTTCAGACTACCTGTT \\
\hline bta-miR-181a & AACATTCAACGCTGTCGGTGAGTT \\
\hline bta-miR-23b & ATCACATTGCCAGGGATTACCAC \\
\hline bta-miR-92 & TATTGCACTTGTCCCGGCCTGT \\
\hline bta-miR-30d & TGTAAACATCCCCGACTGGAAGCT \\
\hline bta-miR-127 & TCGGATCCGTCTGAGCTTGGCT \\
\hline bta-miR-99b & CACCCGTAGAACCGACCTTGCG \\
\hline bta-miR-19b & TGTGCAAATCCATGCAAAACTGA \\
\hline bta-miR-145 & GTCCAGTTTTCCCAGGAATCCCT \\
\hline bta-miR-186 & CAAAGAATTCTCСTTTTGGGCT \\
\hline bta-miR-18a & TAAGGTGCATCTAGTGCAGATA \\
\hline bta-miR-151* & TCGAGGAGCTCACAGTCTAGT \\
\hline bta-miR-374a & TTATAATACAACCTGATAAGTG \\
\hline bta-miR-20a & TAAAGTGCTTATAGTGCAGGTAG \\
\hline bta-miR-15a & TAGCAGCACATAATGGTTTGT \\
\hline bta-miR-455 & TATGTGCCTTTGGACTACATC \\
\hline bta-miR-127 & TCGGATCCGTCTGAGCTTGGCT \\
\hline bta-miR-25 & CATTGCACTTGTCTCGGTCTGA \\
\hline bta-miR-320 & AAAAGCTGGGTTGAGAGGGCGA \\
\hline bta-miR-145 & GTCCAGTTTTCCCAGGAATCCCT \\
\hline bta-miR-30e-5p & TGTAAACATCCTTGACTGGAAGCT \\
\hline bta-miR-365 & TAATGCCCCTAAAAATCCTTAT \\
\hline bta-miR-455 & TATGTGCCTTTGGACTACATC \\
\hline bta-miR-369-3p & AATAATACATGGTTGATCTTT \\
\hline bta-miR-30b & TGTAAACATCCTACACTCAGCT \\
\hline bta-miR-150 & TCTCCCAACССTTGTACCAGTGT \\
\hline bta-miR-455* & GCAGTCCATGGGCATATACACT \\
\hline bta-miR-126 & CGTACCGTGAGTAATAATGCG \\
\hline bta-miR-424 & CAGCAGCAATTCATGTTTTGA \\
\hline bta-miR-100 & AACCCGTAGATCCGAACTTGTG \\
\hline bta-miR-30e* & CTTTCAGTCGGATGTTTACAGC \\
\hline bta-miR-214* & GCCTGTCTACACTTGCTGTGC \\
\hline bta-miR-532-3p & CCTCCCACACCCAAGGCTTGCA \\
\hline bta-miR-299-5p & GGTTTACCGTCCCACATACAT \\
\hline bta-let-7b* & TATACAACCTACTGCCTTCCC \\
\hline
\end{tabular}




\begin{tabular}{|c|c|}
\hline bta-let-7e* & CTATACGGCCTCCTAGCTTTCC \\
bta-miR-339-5p & TCCCTGTCCTCCAGGAGCTCAC \\
bta-miR-504 & AGACCCTGGTCTGCACTCTGTC \\
bta-miR-451 & AAACCGTTACCATTACTGAGTT \\
bta-miR-423-5p & TGAGGGGCAGAGAGCGAGACTT \\
bta-miR-652 & AATGGCGCCACTAGGGTTGTG \\
rno-miR-125b* & ACAAGTCAGGCTCTTGGGACCT \\
bta-miR-143 & TGAGATGAAGCACTGTAGCTC \\
novel miRNA & AAAACCCGAATGAACTTTTTGG \\
RPS18-F & GTGGTGTTGAGGAAAGCAGACA \\
RPS18-R & TGATCACACGTT CCACCTCATC \\
\hline
\end{tabular}


Table 2. Identities of the cloned miRNA sequences from bovine fetal ovary

\begin{tabular}{lc}
\hline RNA species & Total sequences \\
\hline Total RNA sequences & 684 \\
Annotated bovine miRNAs & 635 \\
Newly identified bovine miRNAs & \\
Novel miRNAs & b \\
mRNA & 43 \\
tRNA & 1 \\
\hline
\end{tabular}

aSequences homologous to known mammalian miRNAs in the miRbase database

${ }^{b}$ Sequences do not match any known miRNAs in the miRase database 
Table 3. Known miRNAs cloned from bovine fetal ovary

\begin{tabular}{|c|c|c|c|c|c|c|c|}
\hline miRNA & Sequence ( $5^{\prime}$ to $\left.3^{\prime}\right)$ & Size & $\begin{array}{l}\text { Number } \\
\text { of clones }\end{array}$ & Chromosome & Strand & Start & End \\
\hline bta-miR-99a & AACCCGUAGAUCCGAUCUUGU & 21 & 223 & 1 & - & 20137011 & 20137031 \\
\hline bta-miR-125b & UCCCUGAGACCCUAACUUGUGA & 22 & 213 & $15,1^{*}$ & - & $\begin{array}{l}31406392 \\
20087164^{*}\end{array}$ & $\begin{array}{l}31406413 \\
20087185^{*}\end{array}$ \\
\hline bta-let-7c & UGAGGUAGUAGGUUGUAUGGUU & 22 & 32 & $1,8^{\star}, 5^{\wedge}$ & $-,+^{*},+^{\wedge}$ & $\begin{array}{c}20136289 \\
89743304^{\star} \\
123307215^{\wedge}\end{array}$ & $\begin{array}{c}20136310 \\
89743325^{\star} \\
123307236^{\wedge}\end{array}$ \\
\hline bta-miR-125a & UCCCUGAGACCCUUUAACCUGUG & 22 & 26 & 18 & + & 57588678 & 57588700 \\
\hline bta-miR-26a & UUCAAGUAAUCCAGGAUAGGCU & 22 & 25 & $5,22^{*}$ & + & $\begin{array}{l}60085865 \\
11464112^{*}\end{array}$ & $\begin{array}{l}60085886 \\
11464133^{*}\end{array}$ \\
\hline bta-let-7b & UGAGGUAGUAGGUUGUGUGGUU & 22 & 19 & 5 & + & 123308017 & 123308038 \\
\hline bta-miR-10b & UACCCUGUAGAACCGAAUUUGUG & 22 & 14 & 2 & - & 21426250 & 21426272 \\
\hline bta-let-7a & UGAGGUAGUAGGUUGUAUAGUU & 21 & 9 & $15,8^{*}, 5^{\wedge}$ & $-,+^{*},+^{\wedge}$ & $\begin{array}{c}31455172 \\
89743304^{*} \\
123307215^{\wedge}\end{array}$ & $\begin{array}{c}31455193 \\
89743325^{*} \\
123307236^{\wedge}\end{array}$ \\
\hline bta-miR-145 & GUCCAGUUUUCCCAGGAAUCCCU & 23 & 8 & 7 & + & 60270246 & 60270268 \\
\hline bta-miR-126* & CAUUAUUACUUUUGGUACGCG & 21 & 7 & 11 & + & 108009400 & 108009420 \\
\hline bta-let-7a* & CUAUACAAUCUACUGUCUUUCU & 21 & 6 & $8,5^{*}$ &,$++^{*}$ & $\begin{array}{c}89743355 \\
123307263^{*}\end{array}$ & $\begin{array}{r}89743375 \\
123307283^{*}\end{array}$ \\
\hline bta-let-7e & UGAGGUAGGAGGUUGUAUAGU & 22 & 5 & 18 & + & 57588172 & 57588192 \\
\hline bta-let-7f & UGAGGUAGUAGAUUGUAUAGUU & 22 & 4 & $X, 8^{*}$ &,$-+^{*}$ & $\begin{array}{c}58738580 \\
89743658^{*}\end{array}$ & $\begin{array}{l}58738601 \\
89743679^{*}\end{array}$ \\
\hline bta-miR-181a & AACAUUCAACGCUGUCGGUGAGU & 23 & 4 & $16,11^{*}$ &,$-+^{*}$ & $\begin{array}{c}76125661 \\
99136799^{*}\end{array}$ & $\begin{array}{c}76125684 \\
99136822^{*}\end{array}$ \\
\hline bta-miR-10a & UACCCUGUAGAUCCGAAUUUGUG & 22 & 3 & 19 & + & 39116904 & 39116926 \\
\hline $\begin{array}{l}\text { bta-miR- } \\
\text { 199a-3p }\end{array}$ & ACAGUAGUCUGCACAUUGGUUA & 21 & 3 & $7,16^{*}, 11^{\wedge}$ & $-,-^{*},-^{\wedge}$ & $\begin{array}{c}13733563 \\
36247801^{*} \\
102419025^{\wedge}\end{array}$ & $\begin{array}{c}13733584 \\
36247822^{*} \\
102419046^{\wedge}\end{array}$ \\
\hline bta-let-7d & AGAGGUAGUAGGUUGCAUAGUU & 21 & 2 & 8 & + & 89745865 & 89745886 \\
\hline bta-miR-23b & AUCACAUUGCCAGGGAUUACCAC & 23 & 2 & 8 & + & 85962081 & 85962103 \\
\hline bta-miR-92 & UAUUGCACUUGUCCCGGCCUGU & 22 & 2 & Un.004.53, 12 &,-+ & $\begin{array}{c}180994 \\
64665850\end{array}$ & $\begin{array}{c}181015 \\
64665871\end{array}$ \\
\hline bta-miR-30d & UGUAAAC & 24 & 2 & 14 & + & 3527 & 6473550 \\
\hline bta-miR-127 & UCGGAUCCGUCUGAGCUUGGCU & 21 & 2 & 21 & + & 65868487 & 65868508 \\
\hline bta-miR-99b & CACCCGUAGAACCGACCUUGCG & 22 & 2 & 18 & + & 57588003 & 57588024 \\
\hline bta-miR-19b & UGUGCAAAUCCAUGCAAAACUGA & 22 & 2 & $\begin{array}{c}\text { Un.004.53 } \\
12^{*}, 1^{\wedge}\end{array}$ & $-,+^{*},+^{\wedge}$ & $\begin{array}{c}181144 \\
64665734 \\
6894622\end{array}$ & $\begin{array}{c}181166 \\
64665756 \\
6894642\end{array}$ \\
\hline $\begin{array}{c}\text { bta-miR- } \\
125 \mathrm{~b}-1\end{array}$ & UCCCUGAGACCCUAACUUGUGA & 22 & 2 & $15,1^{*}$ & - & $\begin{array}{c}31406392 \\
20087164^{*}\end{array}$ & $\begin{array}{c}31406413 \\
20087185^{*}\end{array}$ \\
\hline bta-let-7g & UGAGGUAGUAGUUUGUACAGUU & 21 & 1 & 22 & + & 49631992 & 49632013 \\
\hline $\begin{array}{l}\text { bta-miR- } \\
\text { 199a-5p }\end{array}$ & CCCAGUGUUCAGACUACCUGUU & 22 & 1 & $7,16^{*}$ & $-z_{-*}$ & $\begin{array}{c}13733604 \\
36247840^{*}\end{array}$ & $\begin{array}{c}13733625 \\
36247861^{*}\end{array}$ \\
\hline bta-miR-186 & CAAAGAAUUCUCCUUUUGGGCU & 22 & 1 & 3, Un.004.158* &,$+-^{*}$ & $\begin{array}{c}79661874 \\
362122^{*}\end{array}$ & $\begin{array}{c}79661895 \\
362142^{*}\end{array}$ \\
\hline bta-miR-18a & UAAGGUGCAUCUAGUGCAGAUA & 22 & 1 & 12, Un.004.53* &,$+-^{*}$ & $\begin{array}{c}64665250 \\
181545^{*}\end{array}$ & $\begin{array}{c}64665271 \\
181566^{*}\end{array}$ \\
\hline bta-miR-151* & UCGAGGAGCUCACAGUCUAGU & 21 & 1 & 14 & + & 2275092 & 2275112 \\
\hline bta-miR-20a & UAAAGUGCUUAUAGUGCAGGUAG & 23 & 1 & $\begin{array}{c}\text { 11, Un.004. } 8^{*} \\
12^{\wedge}, 4^{\wedge \wedge}\end{array}$ & $\begin{array}{c}-,+^{*},+^{\wedge}, \\
-\wedge \wedge\end{array}$ & $\begin{array}{c}3052129 \\
93458^{*} \\
64665560^{\wedge} \\
79200656^{\wedge \wedge}\end{array}$ & $\begin{array}{c}3052151 \\
93480^{*} \\
64665582^{\wedge} \\
79200676^{\wedge}\end{array}$ \\
\hline bt & $\mathrm{U}$ & 21 & 1 & 12 & - & 18887792 & 18887812 \\
\hline bta-miR-455 & UAUGUGCCUUUGGACUACAUC & 21 & 1 & 8 & + & 108764304 & 108764324 \\
\hline bta-miR-127 & UCGGAUCCGUCUGAGCUUGGCU & 21 & 1 & 21 & + & 65868487 & 65868508 \\
\hline bta-miR-25 & CAUUGCACUUGUCUCGGUCUGA & 21 & 1 & 25 & + & 38456026 & 38456047 \\
\hline
\end{tabular}




\begin{tabular}{|c|c|c|c|c|c|c|c|}
\hline bta-miR-320 & AAAAGCUGGGUUGAGAGGGCGA & 21 & 1 & $8,20^{*}$ &,$-+^{*}$ & $\begin{array}{l}72629915 \\
16455541\end{array}$ & $\begin{array}{l}72629936 \\
16455562\end{array}$ \\
\hline bta-miR-145 & GUCCAGUUUUCCCAGGAAUCCCU & 23 & 1 & 7 & + & 60270246 & 60270268 \\
\hline $\begin{array}{c}\text { bta-miR-30e- } \\
5 p\end{array}$ & UGUAAACAUCCUUGACUGGAAGU & 24 & 1 & 3 & - & 112440616 & 112440639 \\
\hline bta-miR-365 & UAAUGCCCCUAAAAAUCCUUAU & 22 & 1 & $19,25^{*}$ &,$-++^{*}$ & $\begin{array}{l}18298087 \\
14332892\end{array}$ & $\begin{array}{l}18298108 \\
14332913\end{array}$ \\
\hline bta-miR-30b & UGUAAACAUCCUACACUCAGCU & 22 & 1 & 14 & + & 6477882 & 6477903 \\
\hline bta-miR-150 & UCUCCCAACCCUUGUACCAGUGU & 23 & 1 & 18 & - & 55905355 & 55905377 \\
\hline bta-miR-455* & GCAGUCCAUGGGCAUAUACACU & 21 & 1 & 8 & + & 108764342 & 108764363 \\
\hline bta-miR-126 & GUACCGUGAGUAAUAAUGCG & 21 & 1 & 11 & + & 108009438 & 108009458 \\
\hline
\end{tabular}


Table 4. Newly identified and novel miRNAs cloned from bovine fetal ovary

\begin{tabular}{|c|c|c|c|c|c|c|c|c|}
\hline miRNA & Sequence (5' to $\left.3^{\prime}\right)$ & Size & $\begin{array}{c}\text { Number } \\
\text { of } \\
\text { clones }\end{array}$ & Chromosome & Strand & Start & End & Homology \\
\hline bta-miR-100 & AACCCGUAGAUCCGAACUUGUG & 22 & 14 & 15 & - & 31460993 & 31461014 & hsa,mml,ptr,rno \\
\hline bta-miR-424 & CAGCAGCAAUUCAUGUUUUGA & 21 & 12 & Un.004.53 & - & 446910 & 446931 & hsa, mml,ptr,rno \\
\hline bta-miR-143 & UGAGAUGAAGCACUGUAGCUC & 21 & 3 & 7 & + & 60268857 & 60268877 & hsa,rno,mml,ptr \\
\hline bta-miR-30e* & CUUUCAGUCGGAUGUUUACAGC & 22 & 2 & 3 & - & 112440576 & 112440597 & mmu,hsa,rno \\
\hline $\begin{array}{c}\text { bta-miR- } \\
125 b^{*}\end{array}$ & ACAAGUCAGGCUCUUGGGACCU & 21 & 2 & 1 & - & 20087125 & 20087146 & hsa,rno,mmu \\
\hline bta-miR-214* & GCCUGUCUACACUUGCUGUGC & 21 & 1 & 16 & - & 36242054 & 36242075 & hsa,mmu,oan \\
\hline $\begin{array}{c}\text { bta-miR-532- } \\
3 p\end{array}$ & CCUCCCACACCCAAGGCUUGCA & 22 & 1 & $x$ & - & 54783146 & 54783167 & hsa,mmu,mml \\
\hline $\begin{array}{c}\text { bta-miR-299- } \\
5 p\end{array}$ & GGUUUACCGUCCCACAUACAU & 21 & 1 & $21,21^{*}$ &,$+-^{*}$ & $\begin{array}{l}66002443 \\
66002472\end{array}$ & $\begin{array}{l}66002464 \\
66002492\end{array}$ & hsa,mmu,rno \\
\hline bta-let-7b* & UAUACAACCUACUGCCUUCCC & 21 & 1 & 5 & + & 123308072 & 123308092 & hsa,rno,mmu \\
\hline bta-let-7e* & CUAUACGGCCUCCUAGCUUUCC & 22 & 1 & 18 & + & 57588217 & 57588238 & hsa,rno,mmu \\
\hline $\begin{array}{c}\text { bta-miR-339- } \\
5 p\end{array}$ & UCCCUGUCCUCCAGGAGCUCAC & 22 & 1 & $21,25^{\star}, 2^{\wedge}$ & $-,+^{*},+^{\wedge}$ & $\begin{array}{c}34506932 \\
43648269^{\star} \\
125415215 \\
\wedge\end{array}$ & $\begin{array}{c}34506953 \\
43648290^{\star} \\
125415236^{\wedge}\end{array}$ & rno,hsa,mmu \\
\hline bta-miR-504 & AGACCCUGGUCUGCACUCUGUC & 22 & 1 & $\mathrm{X}$ & - & 12002402 & 12002423 & hsaa,mmu,mml \\
\hline bta-miR-451 & AAACCGUUACCAUUACUGAGUU & 22 & 1 & 19 & - & 20147907 & 20147928 & hsa,gga,mml \\
\hline $\begin{array}{c}\text { bta-miR-423- } \\
5 p\end{array}$ & UGAGGGGCAGAGAGCGAGACUU & 22 & 1 & 19 & + & 21234499 & 21234520 & hsa,mmu,mml \\
\hline bta-miR-652 & AAUGGCGCCACUAGGGUUGUG & 21 & 1 & $\begin{array}{c}\text { Sequence } \\
\text { unavailable }\end{array}$ & & & & hsa,cfa,mmu \\
\hline $\begin{array}{l}\text { Novel } \\
\text { miRNA }\end{array}$ & AAAACCCGAAUGAACUUUUUGGA & 23 & 1 & $20,10^{*}$ &,$-+^{*}$ & $\begin{array}{c}14022941 \\
103620870^{*}\end{array}$ & $\begin{array}{c}14022963 \\
103620892^{*}\end{array}$ & \\
\hline
\end{tabular}


Table 5. Potential target genes of the novel bovine miRNA

\begin{tabular}{|c|c|c|}
\hline $\begin{array}{l}\text { Gene } \\
\text { symbol }\end{array}$ & Gene name & Function \\
\hline SEMA6C & $\begin{array}{l}\text { Sema domain, transmembrane domain (TM), and } \\
\text { cytoplasmic domain, (semaphorin) } 6 \mathrm{C}\end{array}$ & Cell differentiation/multicellular organismal development \\
\hline YBX1 & Y box binding protein 1 & Regulation of transcription/mRNA processing \\
\hline ZDHHC18 & Zinc finger, DHHC-type containing 18 & Transferase activity/zinc ion binding \\
\hline ZZEF1 & Zinc finger, ZZ-type with EF-hand domain 1 & Regulation of mitotic metaphase/anaphase transition \\
\hline APLNR & Apelin receptor & G-protein coupled receptor protein signaling pathway \\
\hline FRAP1 & $\begin{array}{l}\text { FK506 binding protein 12-rapamycin associated } \\
\text { protein } 1\end{array}$ & TOR signaling pathway/Germ cell development/Cell growth \\
\hline FZD5 & Frizzled homolog 5 & $\begin{array}{l}\text { G-protein coupled receptor protein signaling pathway/Wnt receptor } \\
\text { signaling pathway }\end{array}$ \\
\hline FZD8 & Frizzled homolog 8 & $\begin{array}{l}\text { G-protein coupled receptor protein signaling pathway/Wnt receptor } \\
\text { signaling pathway }\end{array}$ \\
\hline GPR124 & G protein-coupled receptor 124 & Neuropeptide signaling pathway \\
\hline MBTD1 & MBT domain containing 1 & Regulation of transcription \\
\hline MTMR3 & Myotubularin related protein 3 & Protein amino acid dephosphorylation \\
\hline ROCK1 & $\begin{array}{l}\text { Rho-associated, coiled-coil containing protein } \\
\text { kinase } 1\end{array}$ & Rho protein signal transduction/actin cytoskeleton organization \\
\hline TLK2 & Tousled-like kinase 2 & Cell cycle/chromatin modification/intracellular signaling cascade \\
\hline UST & Uronyl-2-sulfotransferase & Carbohydrate biosynthetic process/protein amino acid sulfation \\
\hline ZBTB7B & Zinc finger and BTB domain containing 7B & Cell differentiation/ectoderm development \\
\hline
\end{tabular}




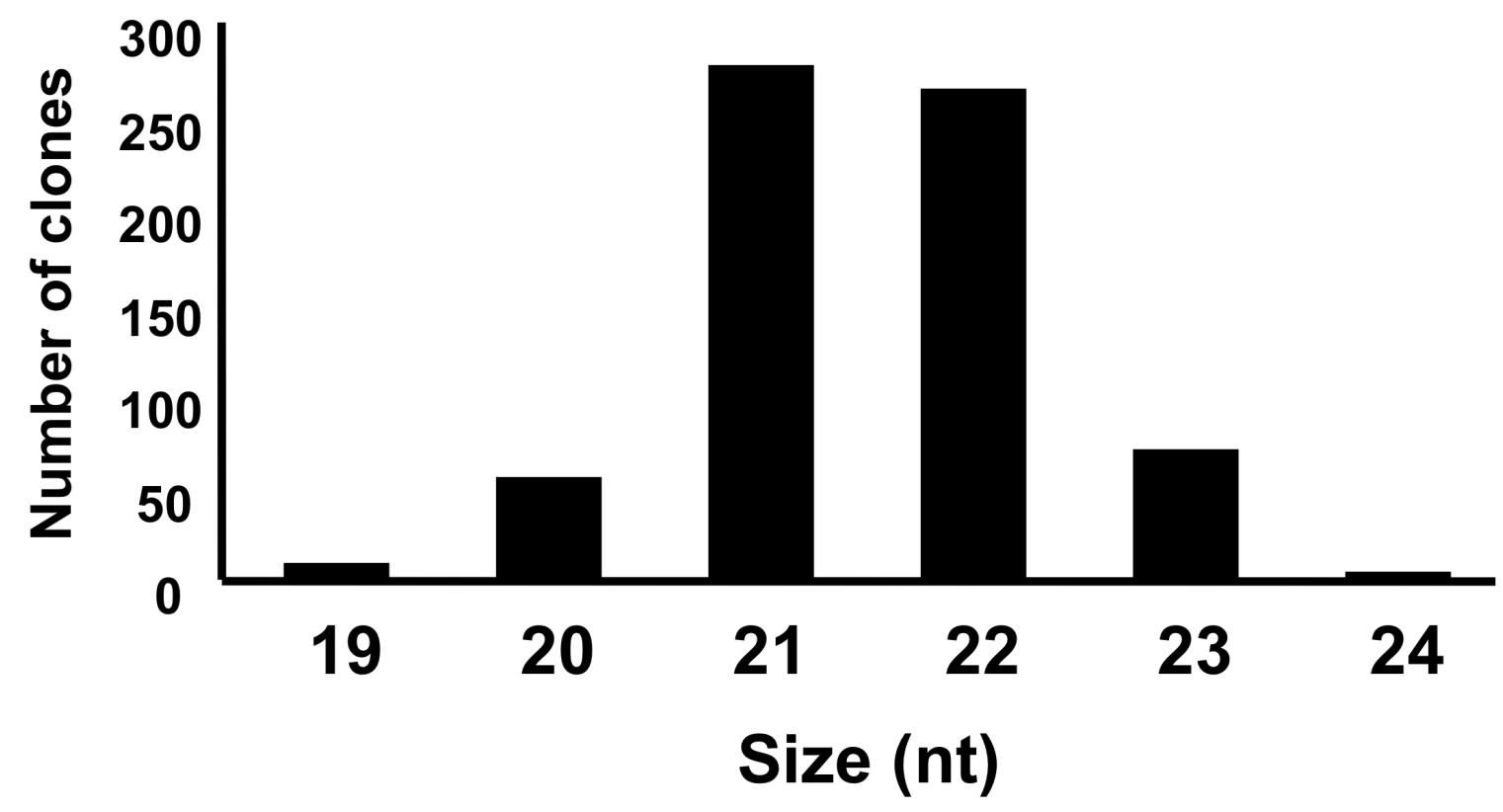

Figure 1. Size distribution of 684 miRNAs cloned from bovine fetal ovaries. 


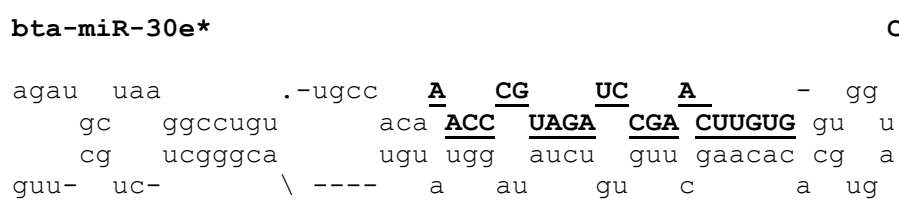

$\operatorname{Chr} 3: 112440576-112440597$

bta-miR-299-5p-2

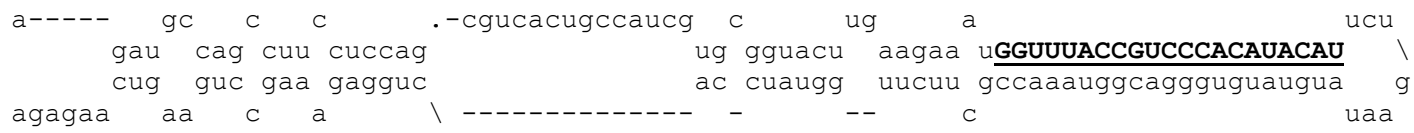

bta-let-7b*

ge gcggg ggcggacccuc

cg cgccc cegceugggag

$\backslash-\mathrm{cg}$

Chr 5:123308072-123308092

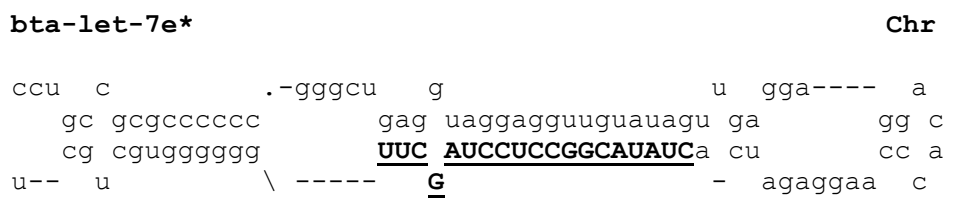

bta-miR-339-5p-1

$\operatorname{Chr} 21: 34506932-34506953$

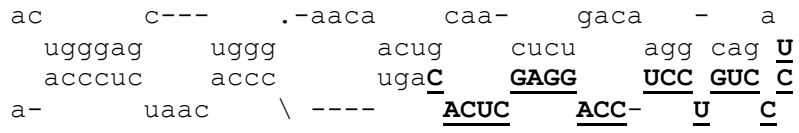




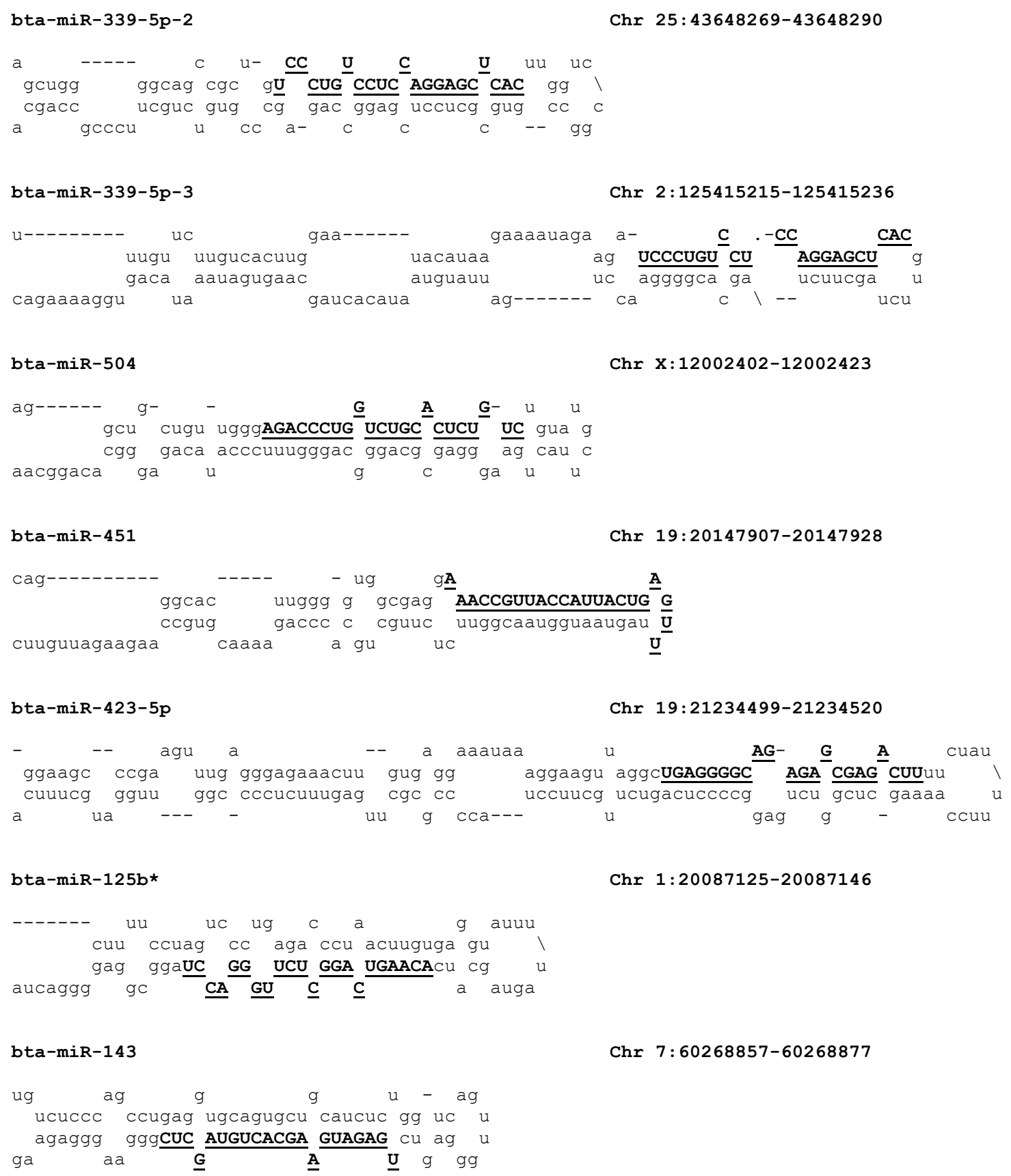

Figure 2. Predicted secondary structures for 14 of the 15 newly identified conserved miRNAs. The mature miRNA sequences are shown in bold and underlined. The predictions were performed using the Mfold program (version 3.2). 


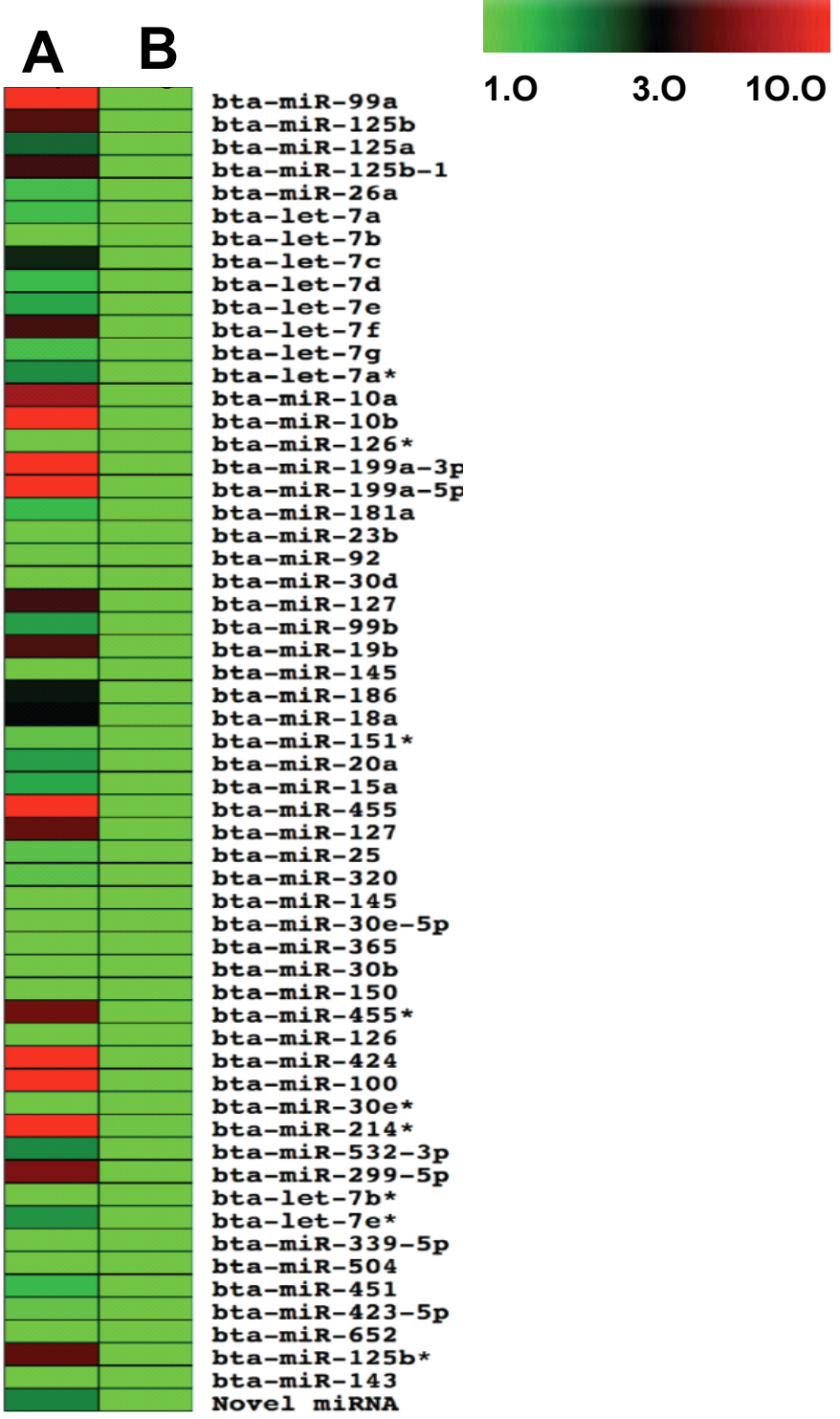

Figure 3. Heatmap representing expression of 58 bovine miRNAs in fetal ovaries $(n=3)$ and somatic tissue pools $(n=3)$. The relative amounts of the miRNAs were determined by quantitative real-time PCR. Quantity of each miRNA was normalized to RPS18 mRNA. The relative amounts of each miRNA were expressed as relative fold change using the somatic tissue pools as the calibrators). 


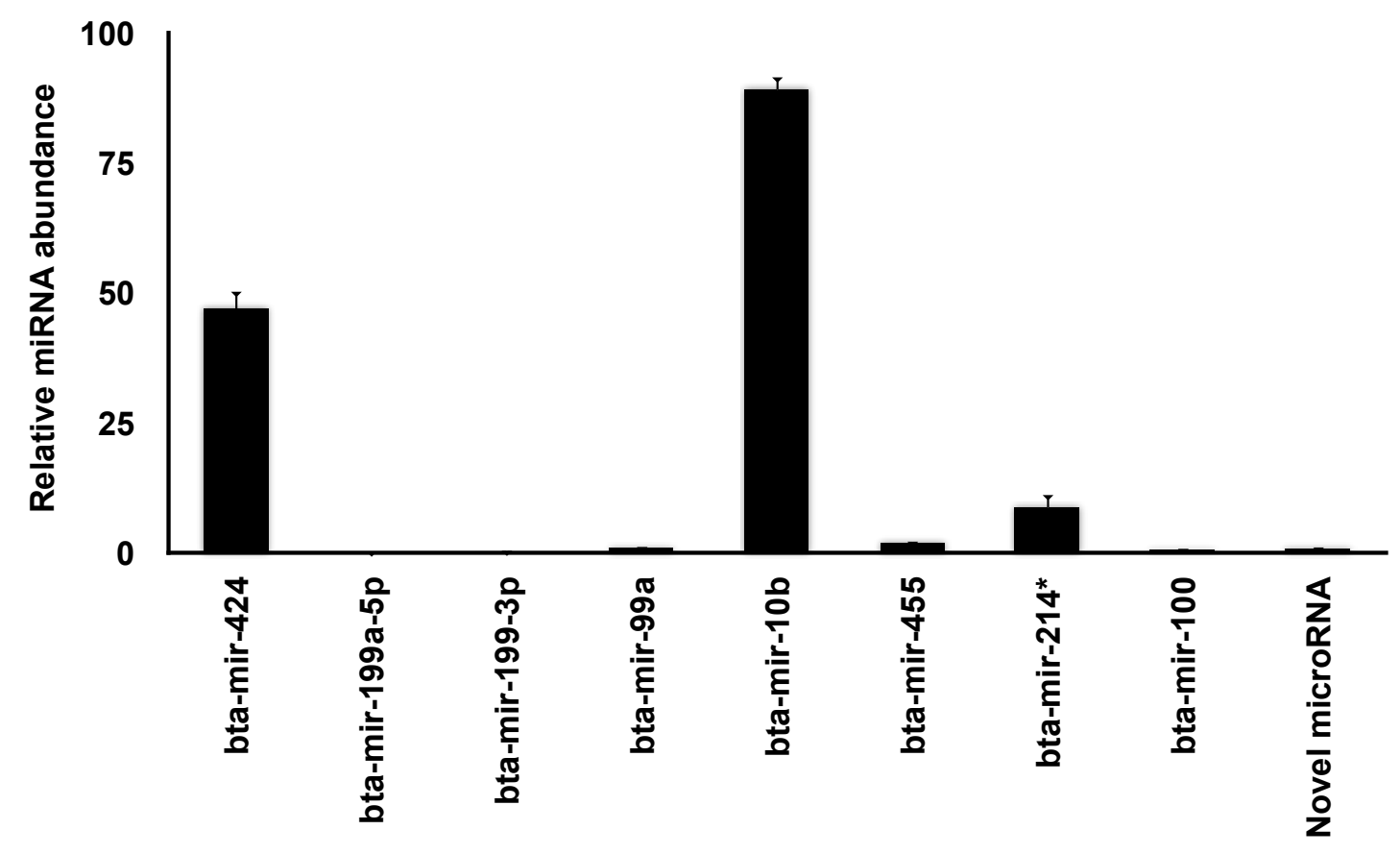

Figure 4. Quantitative real time PCR analysis of expression of eight selected miRNAs (predominant in fetal ovaries) in GV stage oocytes ( $n=3$ pools of 5 each). Quantity of each miRNA was normalized to RPS18 mRNA. The relative amount of each miRNA was expressed as relative fold change using the sample with the lowest expression value as the calibrator $(n=$ 3, mean \pm SEM). 
A

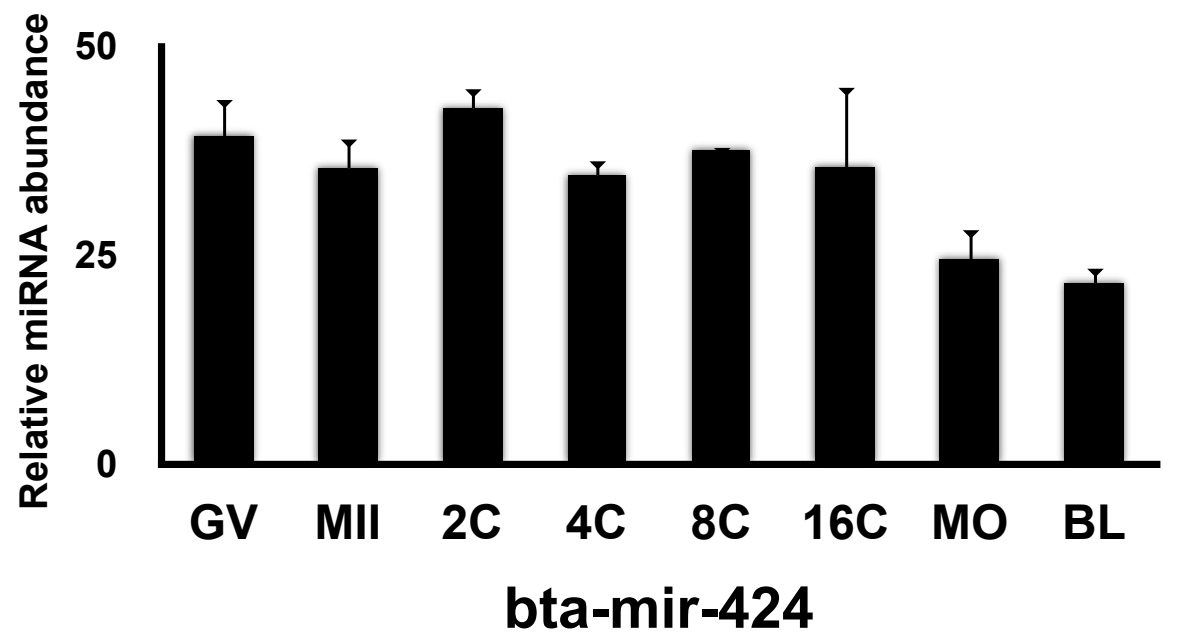

B

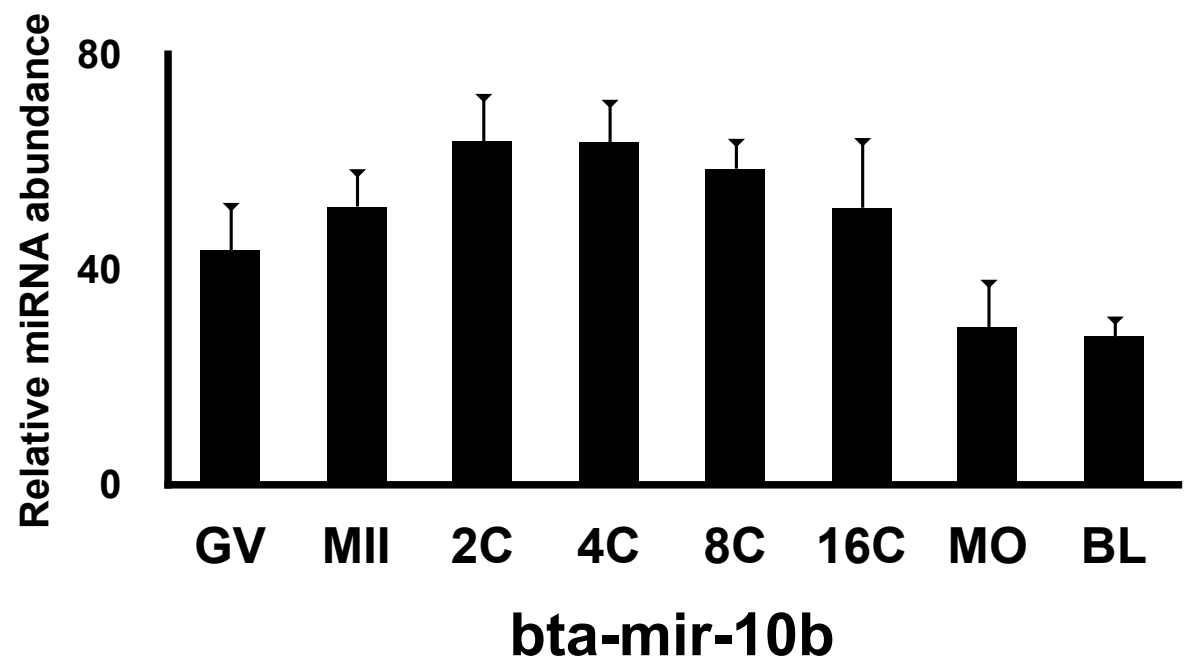

Figure 5. Quantitative real time PCR analysis of bta-mir-424 (A) and bta-mir-10b (B) expression during oocyte maturation and early embryonic development ( $n=3$ pools of 5 each). Quantity of each miRNA was normalized to bta-mir-125b. The relative amount of each miRNA was expressed as relative fold change using the sample with the lowest expression value as the calibrator $(n=3$, mean \pm SEM $)$. 


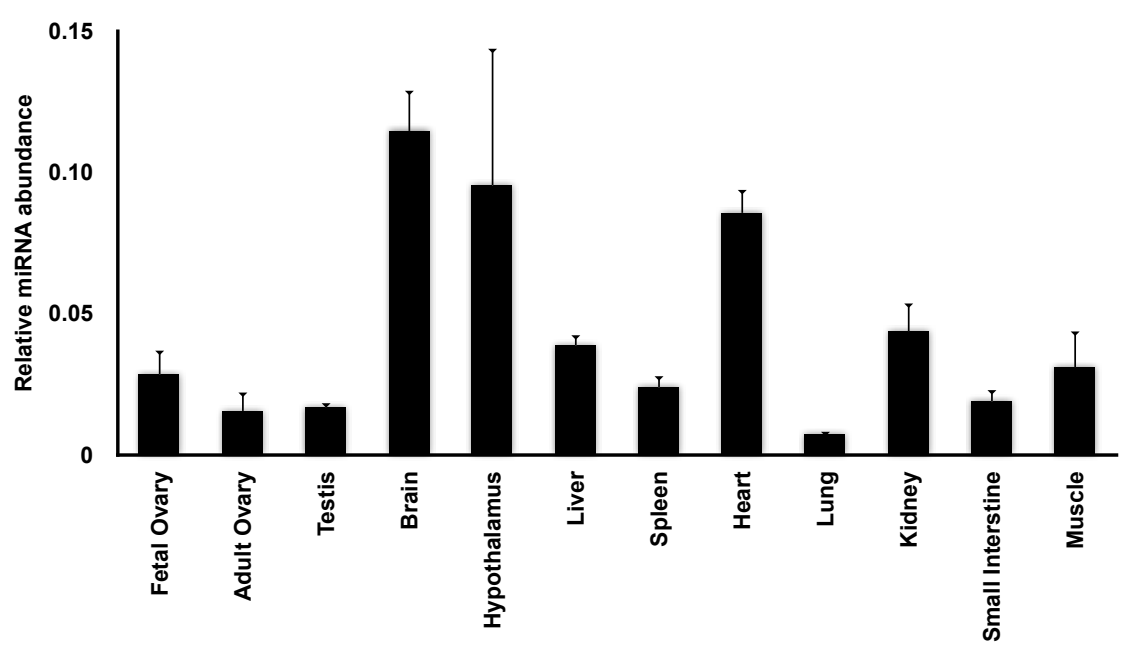

B

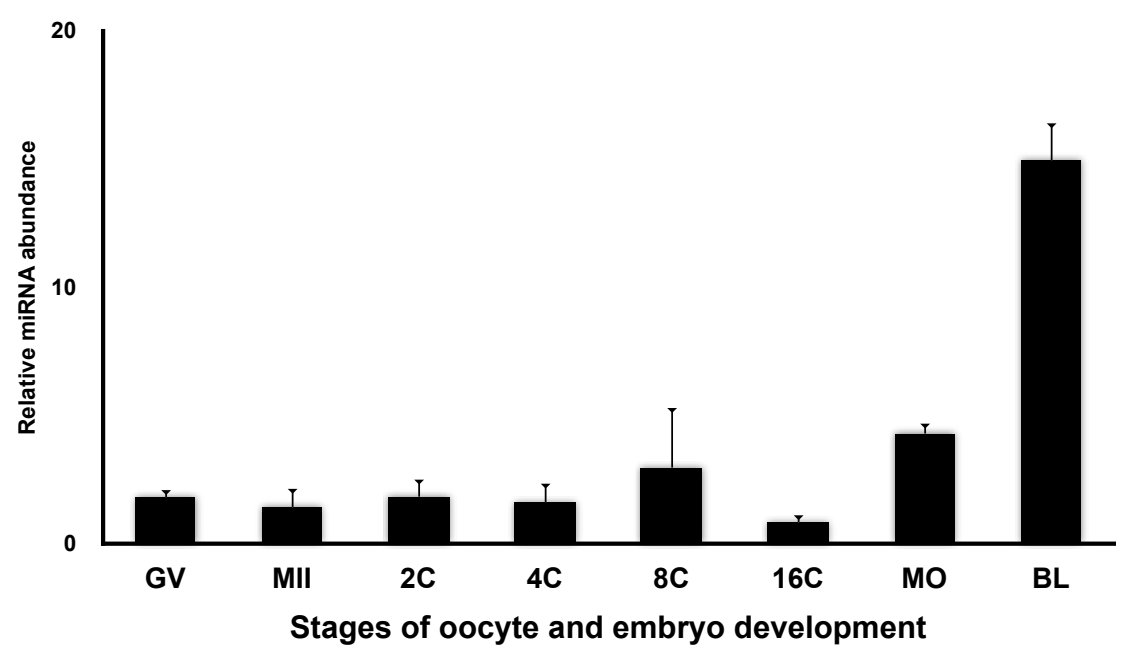

C

\section{Novel miRNA-1}

Chr 20:14022941-14022963

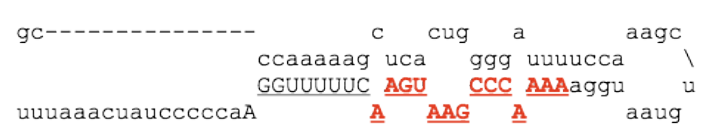

Figure 6. Characterization of the novel bovine miRNA. (A) Tissue distribution of the novel miRNA analyzed by real time PCR. Quantity of the miRNA was normalized to RPS18 mRNA and the relative amount was expressed as relative fold change using the sample with the lowest expression value as the calibrator $(n=3$, mean \pm SEM). (B) Quantitative real time PCR analysis 
of the novel miRNA expression during oocyte maturation and early embryonic development $(n=$ 3 pools of 5 each). Quantity of the miRNA was normalized to bta-mir-125b. The relative amount of each miRNA was expressed as relative fold change using the sample with the lowest expression value as the calibrator $(n=3$, mean \pm SEM). (C) Predicted secondary structure of the novel miRNA. The mature miRNA sequence is shown in bold and underlined. The prediction was performed using the Mfold program (version3.2). 


\section{REFERENCES}

Ambros, V., 2004. The functions of animal microRNAs. Nature 431, 350-355.

Ambros, V., Bartel, B., Bartel, D.P., Burge, C.B., Carrington, J.C., Chen, X., Dreyfuss, G., Eddy, S.R., Griffiths-Jones, S., Marshall, M., Matzke, M., Ruvkun, G., Tuschl, T., 2003. A uniform system for microRNA annotation. RNA 9, 277-279.

Bartel, D.P., 2004. MicroRNAs: genomics, biogenesis, mechanism, and function. Cell 116, 281297.

Bentwich, I., 2005. Prediction and validation of microRNAs and their targets. FEBS Lett 579, 5904-5910.

Bentwich, I., Avniel, A., Karov, Y., Aharonov, R., Gilad, S., Barad, O., Barzilai, A., Einat, P., Einav, U., Meiri, E., Sharon, E., Spector, Y., Bentwich, Z., 2005. Identification of hundreds of conserved and nonconserved human microRNAs. Nat Genet 37, 766-770.

Byrne, M., Warner, C., 2008. MicroRNA expression in preimplantation mouse embryos from Ped gene positive compared to Ped gene negative mice. J Assist Reprod Genet 25, 205-214. Carletti, M.Z., Christenson, L.K., 2009. MicroRNA in the ovary and female reproductive tract. J Anim Sci 87, E29-38.

Choi, Y., Qin, Y., Berger, M.F., Ballow, D.J., Bulyk, M.L., Rajkovic, A., 2007. Microarray analyses of newborn mouse ovaries lacking Nobox. Biol Reprod 77, 312-319.

Coutinho, L.L., Matukumalli, L.K., Sonstegard, T.S., Van Tassell, C.P., Gasbarre, L.C., Capuco, A.V., Smith, T.P., 2007. Discovery and profiling of bovine microRNAs from immune-related and embryonic tissues. Physiol Genomics 29, 35-43.

De Sousa, P.A., Watson, A.J., Schultz, G.A., Bilodeau-Goeseels, S., 1998. Oogenetic and zygotic gene expression directing early bovine embryogenesis: a review. Mol Reprod Dev 51, 112-121. 
Gibs, R., Weinstock, G., Kappes, S., Schook, L., Skow, L., Womack, J., 2006. Bovine GenomicSequencingInitiative.www.genome.gov/Pages/Research/Sequencing/SeqProposals/Bo vineSEQ.pdf, 1-12.

Giraldez, A., Cinalli, R., Glasner, M., Enright, A., Thomson, J., Baskerville, S., Hammond, S., Bartel, D., Schier, A., 2005. MicroRNAs regulate brain morphogenesis in zebrafish. Science 308, 833-838.

Giraldez, A.J., Mishima, Y., Rihel, J., Grocock, R.J., Van Dongen, S., Inoue, K., Enright, A.J., Schier, A.F., 2006. Zebrafish MiR-430 promotes deadenylation and clearance of maternal mRNAs. Science 312, 75-79.

Gu, Z., Eleswarapu, S., Jiang, H., 2007. Identification and characterization of microRNAs from the bovine adipose tissue and mammary gland. FEBS Lett 581, 981-988.

He, L., Hannon, G.J., 2004. MicroRNAs: small RNAs with a big role in gene regulation. Nat Rev Genet 5, 522-531.

Karolchik, D., Kuhn, R.M., Baertsch, R., Barber, G.P., Clawson, H., Diekhans, M., Giardine, B., Harte, R.A., Hinrichs, A.S., Hsu, F., Kober, K.M., Miller, W., Pedersen, J.S., Pohl, A., Raney, B.J., Rhead, B., Rosenbloom, K.R., Smith, K.E., Stanke, M., Thakkapallayil, A., Trumbower, H., Wang, T., Zweig, A.S., Haussler, D., Kent, W.J., 2008. The UCSC Genome Browser Database: 2008 update. Nucleic Acids Res 36, D773-779.

Landgraf, P., Rusu, M., Sheridan, R., Sewer, A., lovino, N., Aravin, A., Pfeffer, S., Rice, A., Kamphorst, A., Landthaler, M., 2007. A Mammalian microRNA Expression Atlas Based on Small RNA Library Sequencing. Cell 129, 1401-1414.

Lecellier, C.H., Dunoyer, P., Arar, K., Lehmann-Che, J., Eyquem, S., Himber, C., Saib, A., Voinnet, O., 2005. A cellular microRNA mediates antiviral defense in human cells. Science 308, 557-560. 
Lee, Y., Ahn, C., Han, J., Choi, H., Kim, J., Yim, J., Lee, J., Provost, P., Radmark, O., Kim, S., Kim, V.N., 2003. The nuclear RNase III Drosha initiates microRNA processing. Nature 425, 415419.

Lewis, B.P., Shih, I.H., Jones-Rhoades, M.W., Bartel, D.P., Burge, C.B., 2003. Prediction of mammalian microRNA targets. Cell 115, 787-798.

Liang, Y., Ridzon, D., Wong, L., Chen, C., 2007. Characterization of microRNA expression profiles in normal human tissues. BMC Genomics 8, 166.

Lim, L.P., Glasner, M.E., Yekta, S., Burge, C.B., Bartel, D.P., 2003. Vertebrate microRNA genes. Science 299, 1540.

Mishima, T., Takizawa, T., Luo, S.S., Ishibashi, O., Kawahigashi, Y., Mizuguchi, Y., Ishikawa, T., Mori, M., Kanda, T., Goto, T., 2008. MicroRNA (miRNA) cloning analysis reveals sex differences in miRNA expression profiles between adult mouse testis and ovary. Reproduction $136,811-822$.

Pasquinelli, A.E., Reinhart, B.J., Slack, F., Martindale, M.Q., Kuroda, M.I., Maller, B., Hayward, D.C., Ball, E.E., Degnan, B., Muller, P., Spring, J., Srinivasan, A., Fishman, M., Finnerty, J., Corbo, J., Levine, M., Leahy, P., Davidson, E., Ruvkun, G., 2000. Conservation of the sequence and temporal expression of let-7 heterochronic regulatory RNA. Nature 408, 86-89.

Poy, M.N., Eliasson, L., Krutzfeldt, J., Kuwajima, S., Ma, X., Macdonald, P.E., Pfeffer, S., Tuschl, T., Rajewsky, N., Rorsman, P., Stoffel, M., 2004. A pancreatic islet-specific microRNA regulates insulin secretion. Nature 432, 226-230.

Rajewsky, N., 2006. microRNA target predictions in animals. Nat. Genet. 38, S8-S13.

Ramachandra, R.K., Salem, M., Gahr, S., Caird E Rexroad, I., Yao, J., 2008. Cloning and characterization of microRNAs from rainbow trout (Oncorhynchus mykiss): Their expression during early embryonic development. BMC Developmental Biology 8, 41. 
Reddy, A.M., Zheng, Y., Jagadeeswaran, G., Macmil, S.L., Graham, W.B., Roe, B.A., Desilva, U., Zhang, W., Sunkar, R., 2009. Cloning, characterization and expression analysis of porcine microRNAs. BMC Genomics 10, 65.

Reinhart, B.J., Slack, F.J., Basson, M., Pasquinelli, A.E., Bettinger, J.C., Rougvie, A.E., Horvitz, H.R., Ruvkun, G., 2000. The 21-nucleotide let-7 RNA regulates developmental timing in Caenorhabditis elegans. Nature 403, 901-906.

Richardson, C., Jones, P.C., Barnard, V., Hebert, C.N., Terlecki, S., Wijeratne, W.V., 1990. Estimation of the developmental age of the bovine fetus and newborn calf. The Veterinary record 126, 279-284.

Ro, S., Song, R., Park, C., Zheng, H., Sanders, K.M., Yan, W., 2007. Cloning and expression profiling of small RNAs expressed in the mouse ovary. RNA 13, 2366-2380.

Sempere, L.F., Freemantle, S., Pitha-Rowe, I., Moss, E., Dmitrovsky, E., Ambros, V., 2004. Expression profiling of mammalian microRNAs uncovers a subset of brain-expressed microRNAs with possible roles in murine and human neuronal differentiation. Genome Biol 5, R13.

Tang, F., Kaneda, M., O'Carroll, D., Hajkova, P., Barton, S.C., Sun, Y.A., Lee, C., Tarakhovsky, A., Lao, K., Surani, M.A., 2007. Maternal microRNAs are essential for mouse zygotic development. Genes Dev 21, 644-648.

Tay, Y., Zhang, J., Thomson, A.M., Lim, B., Rigoutsos, I., 2008. MicroRNAs to Nanog, Oct4 and Sox2 coding regions modulate embryonic stem cell differentiation. Nature 455, 1124-1128.

Zhao, H., Rajkovic, A., 2008. MicroRNAs and mammalian ovarian development. Semin Reprod Med 26, 461-468.

Zhao, Y., Samal, E., Srivastava, D., 2005. Serum response factor regulates a muscle-specific microRNA that targets Hand2 during cardiogenesis. Nature 436, 214-220.

Zheng, P., Dean, J., 2007. Oocyte-specific genes affect folliculogenesis, fertilization, and early development. Semin Reprod Med 25, 243-251. 
Zuker, M., 2003. Mfold web server for nucleic acid folding and hybridization prediction. Nucleic Acids Res 31, 3406-3415. 
APPENDIX-1 


\section{Cloning and expression of bovine factor in the germline alpha (FIGLA) in oocytes and early embryos: a potential target of microRNA-212}

Swamy K Tripurani ${ }^{1}$, Gabbine Wee ${ }^{2,3}$, Kyung-Bon Lee ${ }^{2,3}$, George W. Smith ${ }^{2,3,4}$ and JianboYao ${ }^{1}$

${ }^{1}$ Laboratory of Animal Biotechnology and Genomics, Division of Animal and Nutritional Sciences, West Virginia University, Morgantown, WV 26506.

${ }^{2}$ Laboratory of Mammalian Reproductive Biology and Genomics, Departments of Animal Science ${ }^{3}$ and Physiology ${ }^{4}$, Michigan State University, East Lansing, Michigan 48824.

KEYWORDS: FIGLA, oocyte, cloning, early embryogenesis, microRNA and cattle

\section{AUTHOR'S CONTRIBUTIONS}

SKT designed and performed most of the experiments including cloning and expression analysis of FIGLA and miR-212, preparation of constructs, cell transfection and analysis of gene expression. SKT also drafted the manuscript. KBL and GW performed the microinjection experiments. GWS and JY designed the study and supervised the experimental work. 


\section{ABSTRACT}

Factor In the GermLine Alpha (FIGLA), a basic helix-loop-helix transcription factor, is essential for primordial follicle formation and expression of many oocyte-specific genes that are required for fertilization and early embryonic survival. Here we report the characterization of bovine FIGLA gene and its regulation during early embryogenesis. Expression of bovine FIGLA mRNA is restricted to gonads and can be detected in fetal ovaries harvested as early as 90 days of gestation when primordial follicles start to form. FIGLA mRNA and protein is abundant in germinal vesicle and metaphase II stage oocytes, as well as in embryos from pronuclear to eight-cell stage but barely detectable in embryos collected at morula and blastocyst stages, suggesting that FIGLA might be a maternal effect gene. Recent studies in zebrafish and mice have highlighted the importance of non-coding small RNAs (microRNAs) as key regulatory molecules targeting maternal mRNAs for degradation during embryonic development. We hypothesized that FIGLA, as a maternal transcript, is regulated by microRNAs during early embryogenesis. Computational predictions identified a potential microRNA recognition element (MRE) for miR-212 in the 3' UTR of the bovine FIGLA mRNA. Bovine miR-212 is expressed in oocytes and tends to increase at four-cell and eight-cell stage embryos followed by a decline at morula and blastocyst stages. Transient transfection and reporter assays revealed that miR-212 repressed the expression of FIGLA in a MRE dependent manner. Furthermore, ectopic expression of miR-212 mimic in bovine early embryos dramatically reduced the expression of FIGLA mRNA and protein. Collectively, our results demonstrate that FIGLA is spatio-temporally regulated during bovine early embryogenesis and miR-212 is an important negative regulator of FIGLA during the maternal-to-embryonic transition in bovine embryos. 


\section{INTRODUCTION}

During oocyte growth and follicular development oocytes accumulate maternal effect factors necessary for early embryogenesis (Gosden, 2002). Identification and characterization of maternal (oocyte-derived) genes would be extremely useful in unraveling their specific functions in fertilization, early embryogenesis and preimplantation development. However the identities and functions of key oocyte-specific genes involved in the above processes are relatively unknown, especially in farm animal species. One such oocyte-specific gene is factor in the germline alpha (FIGLA), a critical transcription factor required for primordial follicle formation (Soyal et al., 2000). Lack of FIGLA in mice causes infertility and alters expression of many oocyte specific genes that are required for fertilization and early embryonic survival (Joshi et al., 2007). However, the temporal and cell specific expression of FIGLA in bovine oocytes and early embryos have not been described previously. Furthermore, recent studies in zebrafish have highlighted the importance of non-coding small RNAs (microRNAs) as key regulatory molecules targeting maternal mRNAs for degradation during embryonic development (Giraldez et al., 2006) (3). Therefore, we attempted to study the expression and microRNA-mediated regulation of FIGLA during early embryogenesis in cattle. The objectives of the present study are to 1) Clone bovine FIGLA and determine its expression during bovine early embryogeneis.2) Identify microRNA (miRNA) targeting bovine FIGLA and characterize its expression during early embryogenesis. 3) Determine the effect and specificity of miRNA-212 in regulating bovine FIGLA expression both exogenously (HeLa cells) and endogenously (early embryos).

\section{MATERIALS AND METHODS}

\section{Cloning of Bovine FIGLA cDNA}


Cloning of bovine FIGLA was performed as described in (Tejomurtula et al., 2009) with minor modifications.

\section{RNA preparation and RT-PCR analysis}

RNA isolation from different tissues and RT-PCR analysis were performed as described previously (Tripurani et al., 2011) (Table 1 list of primer sequences).

\section{Northern blot analysis}

To determine the size of bovine FIGLA transcript, a northern blot was performed as described previously (Tejomurtula et al., 2009) with mRNA from an adult ovary sample.

\section{Quantification of FIGLA mRNA and protein in oocytes and early embryos}

Quantitative measurement of FIGLA mRNA and protein expression in oocytes and early mebyros was performed as described previously (Tejomurtula et al., 2009; Tripurani et al., 2011) (Table 1 list of primer sequences).

\section{MicroRNA expression analysis}

Bovine tissue sample collection, total RNA isolation and miRNA expression analysis in multiple tissues, oocytes and early embryos were performed as described previously (Tripurani et al., 2010) (Table 1 list of primer sequences).

\section{Cell transfection and luciferase reporter assays}

HeLa cells were cultured in DMEM containing 10\% FBS and $1 \%$ penicillin/streptomycin. For transient transfection FuGENE6 was used according to the manufacturer's instructions. Luciferase reporter assay was performed using the Dual-Glo luciferase assay system. 


\section{Microinjection experiments}

Presumptive bovine zygotes were microinjected with $20 \mu \mathrm{M}$ of miRNA-212 mimic and cultured for $72 \mathrm{~h}$ in KSOM medium. The efficacy of FIGLA mRNA and protein knockdown was determined by real-time and immunocytochemistry in eight- to 16-cell embryos as described previously (Tripurani et al., 2011).

\section{RESULTS \& DISCUSSION}

\section{cDNA cloning and genome organization of bovine FIGLA}

Using the primers designed based on the predicted bovine FIGLA cDNA sequence; we successfully amplified a cDNA fragment (455 bp) representing the coding region of bovine FIGLA from bovine fetal ovary cDNA. Northern blot analysis detected a single transcript of approximately $0.7 \mathrm{~kb}$ in bovine adult ovary sample (Fig. 2A). Thus additional 5' (42 bp) and 3' (133 bp) sequences were obtained using RACE procedures. The assembled full length FIGLA cDNA is $630 \mathrm{bp}$ containing an open reading frame encoding a protein of 172 amino acids with a conserved basic helix-loop-helix domain (Fig. 1). A blast search of the bovine genome database at $\mathrm{NCBI}$ revealed that the bovine FIGLA gene is located on chromosome 11 and spans approximately $14.7 \mathrm{~kb}$. Exon and intron boundaries of the genes were determined using the Spidey program (http://www.ncbi.nlm.nih.gov/IEB/Research/Ostell/Spidey/). The bovine FIGLA gene has 4 exons and 3 introns as determined by the program (Table 2), and all splice sites are in agreement with the consensus sequence (GT-AG rule).

\section{Expression of bovine FIGLA}

Analysis of tissue distribution by semi-quantitative RT-PCR revealed that FIGLA is exclusively expressed in the gonads (Fig. 2B). Expression analysis in fetal ovaries of different 
developmental stages revealed that FIGLA is expressed as early as 90 days of gestation period (when primordial follicles start to form in cows) and is highly abundant in the fetal ovaries of late gestation (Fig. 2C). Quantitative real-time PCR analysis using RNA isolated from oocytes, granulosa cells, and cumulus cells indicates that bovine FIGLA is expressed in oocytes but not in the surrounding follicular somatic cells (Fig. 2D).

\section{Expression of bovine FIGLA mRNA and protein during oocyte maturation and early embryonic development}

To demonstrate the temporal expression of bovine FIGLA during preimplantation embryo development, real-time PCR analysis was performed. The expression pattern of FIGLA mRNA and protein during early embryogenesis is similar to several known maternal effect genes (Pennetier et al., 2004; Pennetier et al., 2006; Bettegowda et al., 2007; Tejomurtula et al., 2009; Tripurani et al., 2011) (Fig. 3A), dynamically regulated during the window from meiotic maturation through embryonic genome activation. Western blot analysis demonstrated that the size of the FIGLA protein is $\sim 18 \mathrm{kd}$ and that the protein is abundant in GV and MII-stage oocytes as well as in two-cell stage embryos, but the expression drops by the 16-cell stage embryos and barely detectable at the blastocyst stage (Fig. 3B). Overall, the expression pattern of bovine FIGLA i.e non-reactivation at maternal-to-embryonic transition (MET) and degradation of the protein before implantation, suggests a potential role of FIGLA as a maternal effect factor during early embryonic development.

\section{Prediction of microRNA binding site in the 3' UTR of bovine FIGLA}

To examine the possibility of FIGLA regulation by miRNAs, we searched for potential miRNA-binding sites in the 3' UTR region of FIGLA mRNA by using the "Microinspector" algorithm (Rusinov et al., 2005). Computational search identified a total of 17 different miRNAs. Most of the predicted binding sites (miRNA recognition elements, MREs) of these miRNAs in 
the 3' UTR of FIGLA are poorly conserved. Only one specific miRNA, miR-212, targeting the 3' UTR of FIGLA mRNA shows complete conservation of the "seed" region across species (Fig. 4A). The seed region is the most important region of miRNA: mRNA interaction and has been has been repeatedly demonstrated to be a key determinant of miRNA-induced repression of gene expression (Lewis et al., 2003; Brennecke et al., 2005). Furthermore, secondary structure analysis revealed that the MRE in the bovine FIGLA 3' UTR has a low free energy of hybridization with the cognate miRNA $(-20.86 \mathrm{kcal} / \mathrm{mol})$ and the apparent miR-212 binding site was positioned on a hairpin-loop structure in an exposed position (Fig. 4B). These results suggest that miR-212 is likely to be an important regulator of FIGLA and the microRNA: mRNA interaction is evolutionary conserved.

\section{Expression analysis of miR-212}

Quantitative real-time PCR analysis was performed to determine the expression pattern of miR-212. miR-212 was predominantly expressed in hypothalamus and brain; it was also expressed significantly in fetal and adult ovary (Fig. 5A). Expression analysis during oocyte maturation and early embryonic development showed that miR-212 is expressed in germinal vesicle oocytes and tends to increase at the four-cell and eight-cell stage embryos followed by a decline at morula and blastocyst stages (Fig. 5B), suggesting that miR-212 is presumably of maternal origin and potentially involved in maternal transcript degradation during MET. Similar expression pattern were observed for miR-430 in zebrafish (Giraldez et al., 2006), miR-427 in Xenopus (Lund et al., 2009) and miR-290 in mouse (Tang et al., 2007), which are known to play a key role in promoting maternal transcript turnover during maternal-zygotic transition. Furthermore, the expression pattern of miRNA-212 during the early embryogenesis is inversely correlated FIGLA expression during early embryogenesis, such that miR-212 expression increases steadily from two-cell to eight-cell stage of embryogenesis, while FIGLA expression decreases gradually during the same period. The inverse correlation between miR-212 and 
FIGLA expression supports that miR-212 might be a post-transcriptional regulator of FIGLA during maternal-to-embryonic transition.

\section{Effect and specificity of miRNA-212 action on FIGLA expression}

To validate the binding of miR-212 to bovine FIGLA, we ectopically expressed FLAG tagged-FIGLA transcript in HeLa cells. Western blot analysis with an antibody against FLAG shows a significant inhibition of FLAG protein expression in cells expressing bta-miR-212 compared to the control cells without bta-miR-212 (Fig. 6A), indicating that translation of FIGLA is repressed by miR-212. Densitometeric analysis of western blot data showed a significant repression of FIGLA expression in the miR-212 transfected cells (Fig. 6B). In addition, we validated the specificity and the efficacy of miR-212 action; we inserted FIGLA 3' UTR sequence downstream of the firefly luciferase-coding region. A four-base pair mismatch mutation was introduced in the predicted MRE in the 3' UTR of the FIGLA for miR-212 such that interaction between miR-212 and FIGLA was compromised (Fig. 6C). Ectopic expression of miR-212 suppressed the activity of chimeric luciferase construct containing the miR-212 MRE of FIGLA at its 3' end. Suppression of luciferase activity was abolished when a mutation was introduced into the seed region of the miRNA-212 recognition sequence in the FIGLA 3' UTR. These data indicate that the predicted MRE in FIGLA 3' UTR is critical for the direct and specific binding of miR-212 (Fig. 6D).

\section{Effect of miR-212 on FIGLA expression in early embryos}

To further confirm and extend our hypothesis, we investigated whether miR-212 can regulated FIGLA in early embryos. Ectopic expression of miRNA-212 mimic in early embryos significantly repressed the expression of FIGLA mRNA and protein in the eight-cell stage embryos compared to the controls (Fig. 7A, B), indicating that miRNA-212 is a bona fide negative regulator of FIGLA. 


\section{CONCLUSION}

Collectively, our study supports potential a role for maternal FIGLA in early embryogenesis and miRNA-212 in regulating FIGLA expression during MET. Future studies of interest will be to investigate the functional role of FIGLA and miR-212 during bovine early embryogenesis by performing loss-of-function studies.

\section{ACKNOWLEDGMENTS}

This work was supported by National Research Initiative Competitive Grant \#200835203-19094 from the USDA National Institute of Food and Agriculture (GWS), Agriculture and Food Research Initiative, Competitive Grant \#2009-65203-05706 from the USDA National Institute of Food and Agriculture (JY) and funds from the West Virginia Agricultural and Forestry Experiment Station (Hatch project No. 427). 
Table 1. List of primers used in this study

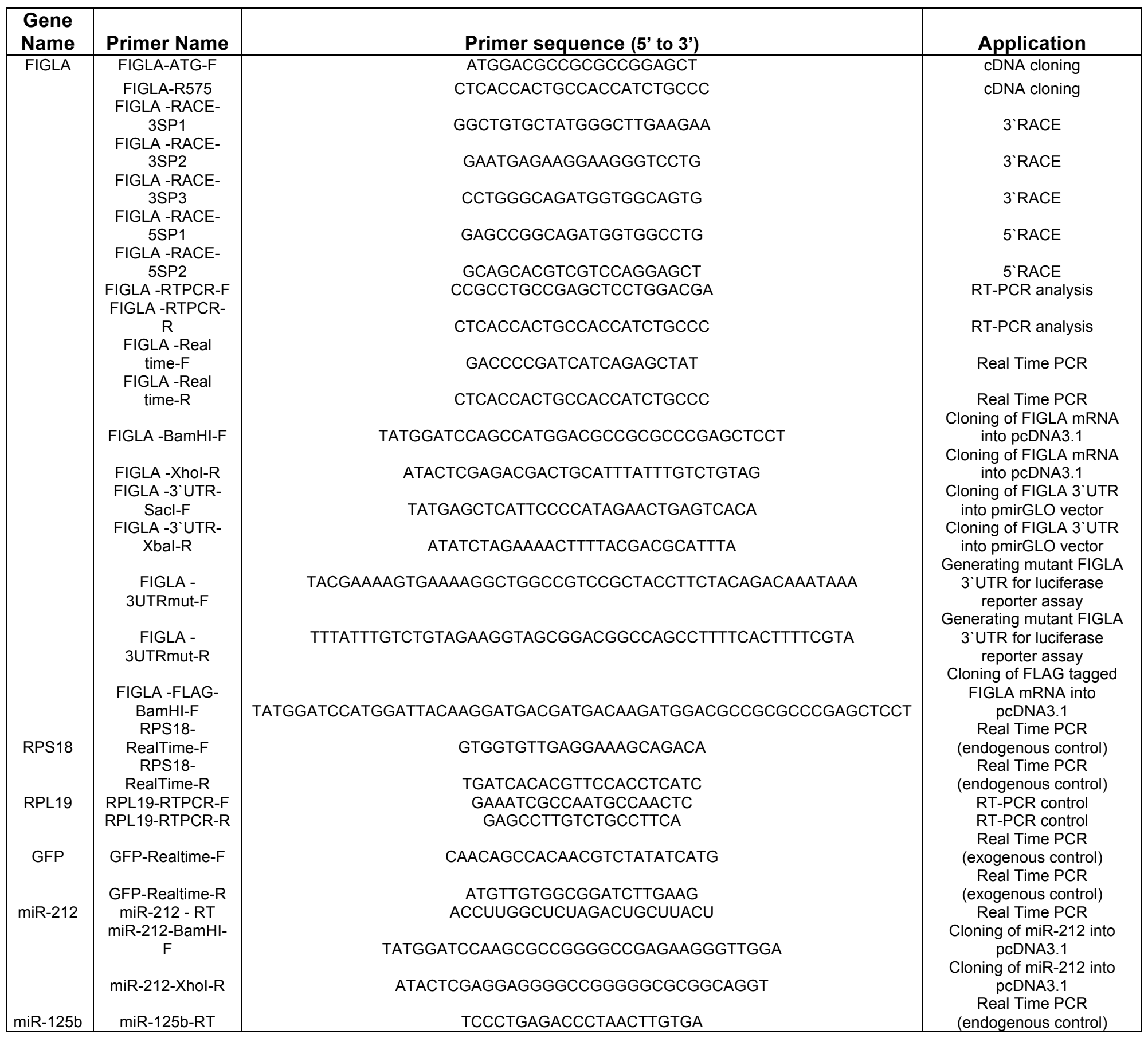


Table 2. Genome organization of bovine FIGLA

\begin{tabular}{llllll}
\hline Exon no. & Size $(\mathrm{bp})$ & Sequence & Intron no. & Size $(\mathrm{bp})$ & Sequence \\
\hline 1 & 231 & CGCGAGCGGgtgagttca & 1 & 4011 & cctttccagATAAAAAAT \\
2 & 153 & GACTCCGAGgtaaaggtt & 2 & 1591 & ggtttctagAAACGAGAC \\
3 & 151 & GTGGCAGTGgtgagttgg & 3 & 8531 & ctgtttcagGTTCTCTCA \\
4 & 77 & & & & \\
\hline
\end{tabular}

${ }^{a}$ Exon and intron sizes are given in base pairs. Intronic and exonic sequences are shown in lower-case and upper case characters, respectively. The first and last two bases of the introns (gt and ag for donors and acceptor splice sites, respectively) are shown in bold and underlined. 


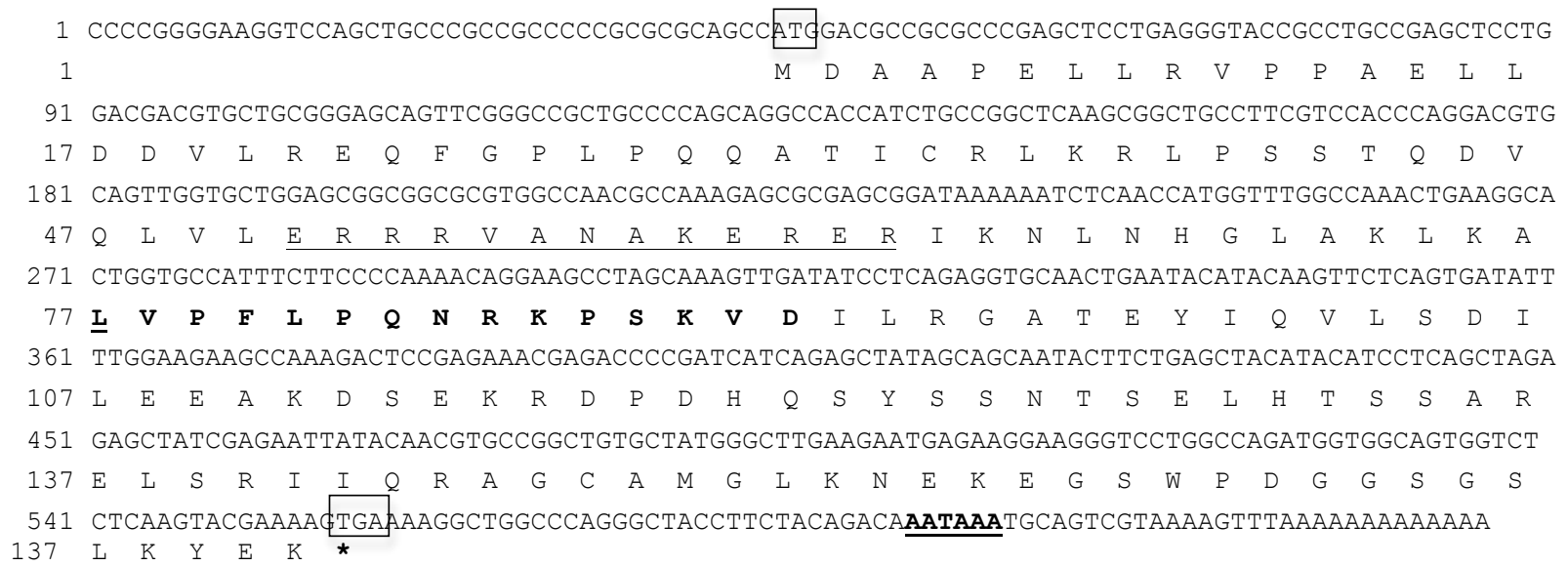

Figure 1. Nucleotide sequence of the bovine FIGLA cDNA with deduced amino acid sequence. The initaitaor "AUG" and the stop "TAG" codons are boxed and the polyadenylation signal is bold and underlined. The basic region is underlined; the two helices are highlighted; and the loop region is bold. 

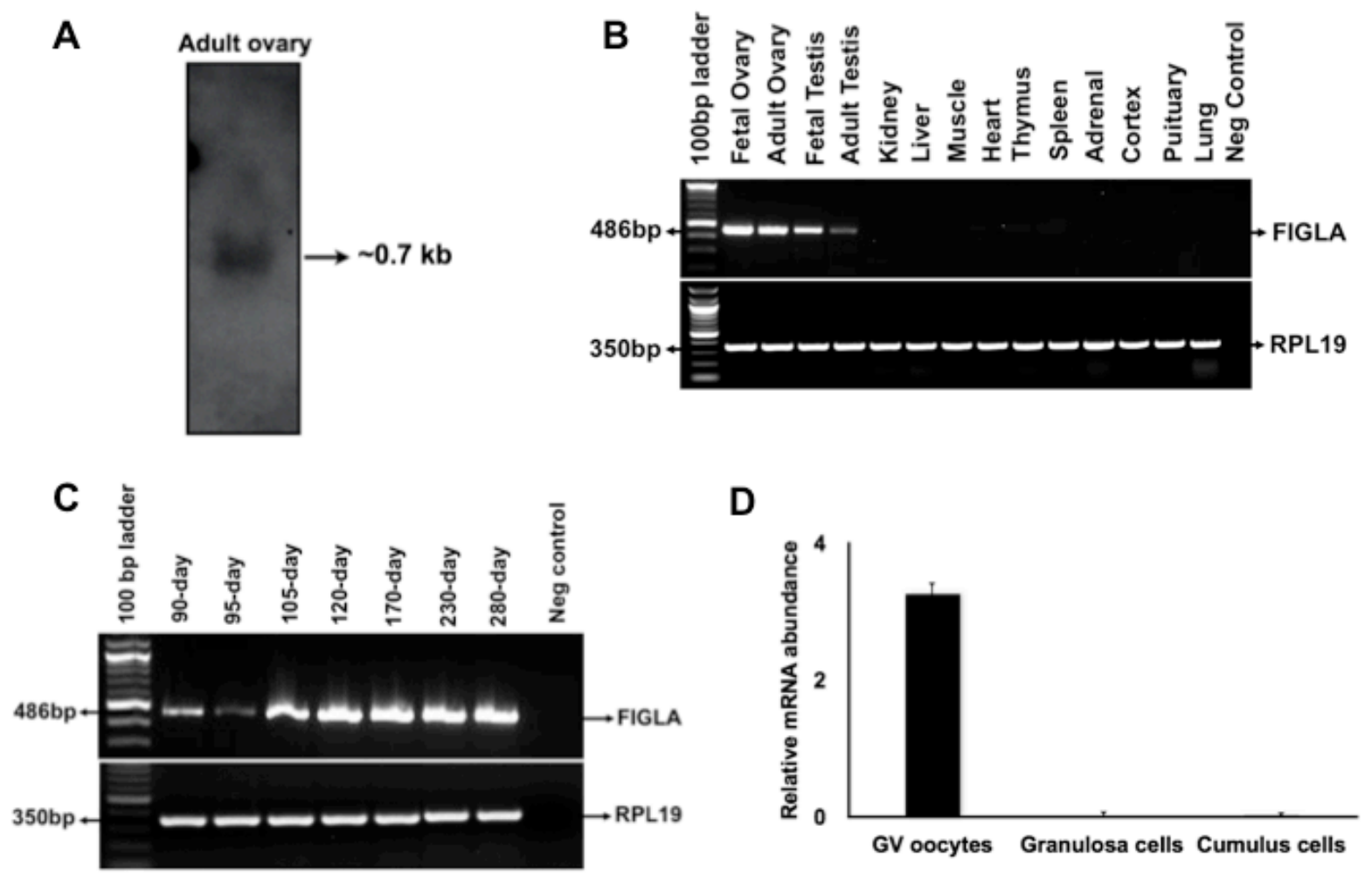

Figure 2. Expression analysis of bovine FIGLA A) Northern blot analysis of FIGLA transcript in adult ovary. B) Expression of FIGLA mRNA in various bovine tissues. C) Expression of FIGLA mRNA in bovine fetal ovaries of different developmental stages. D) Quantitative expression of FIGLA mRNAs in granulose cells, cumulus cells and GV oocytes. 
A

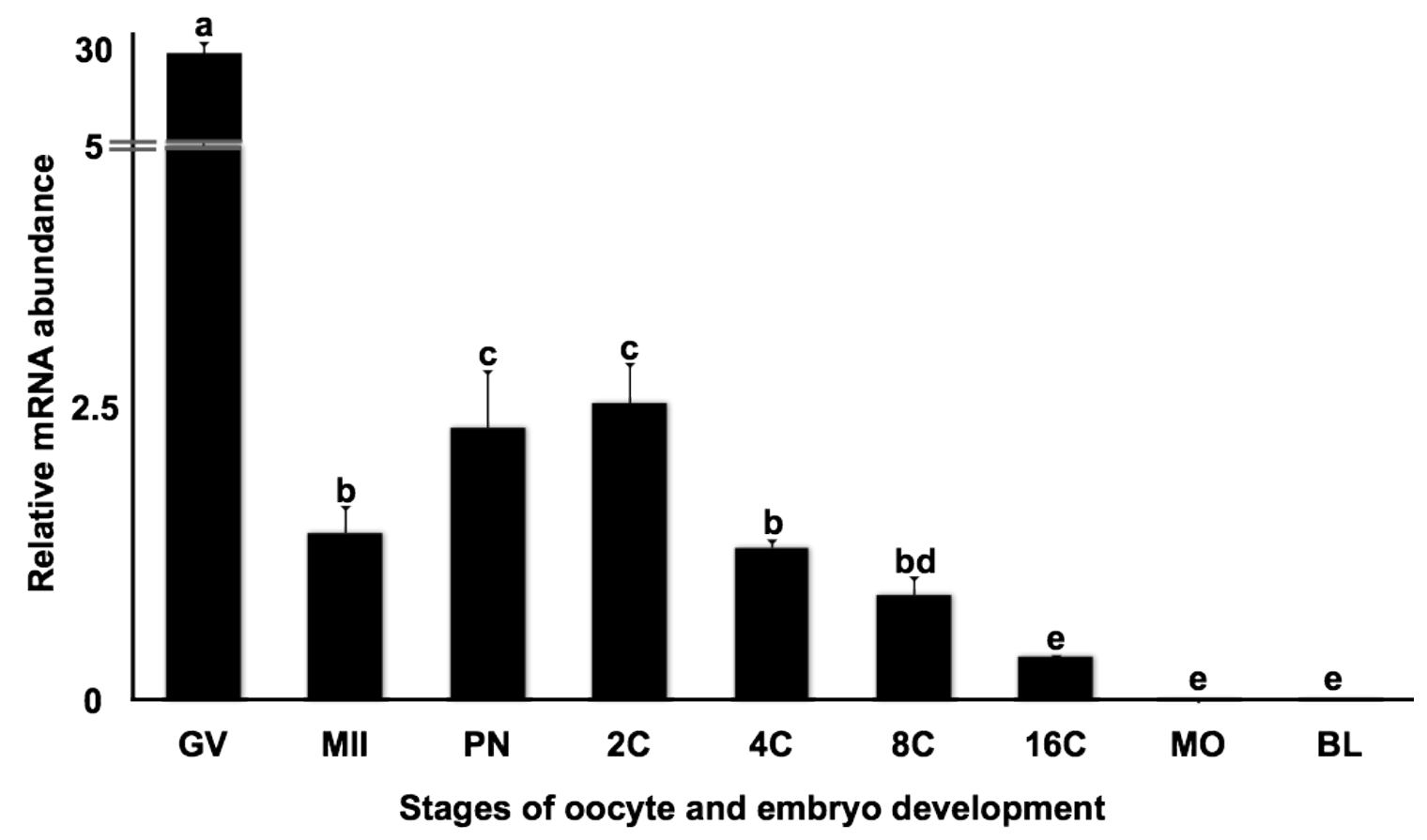

B

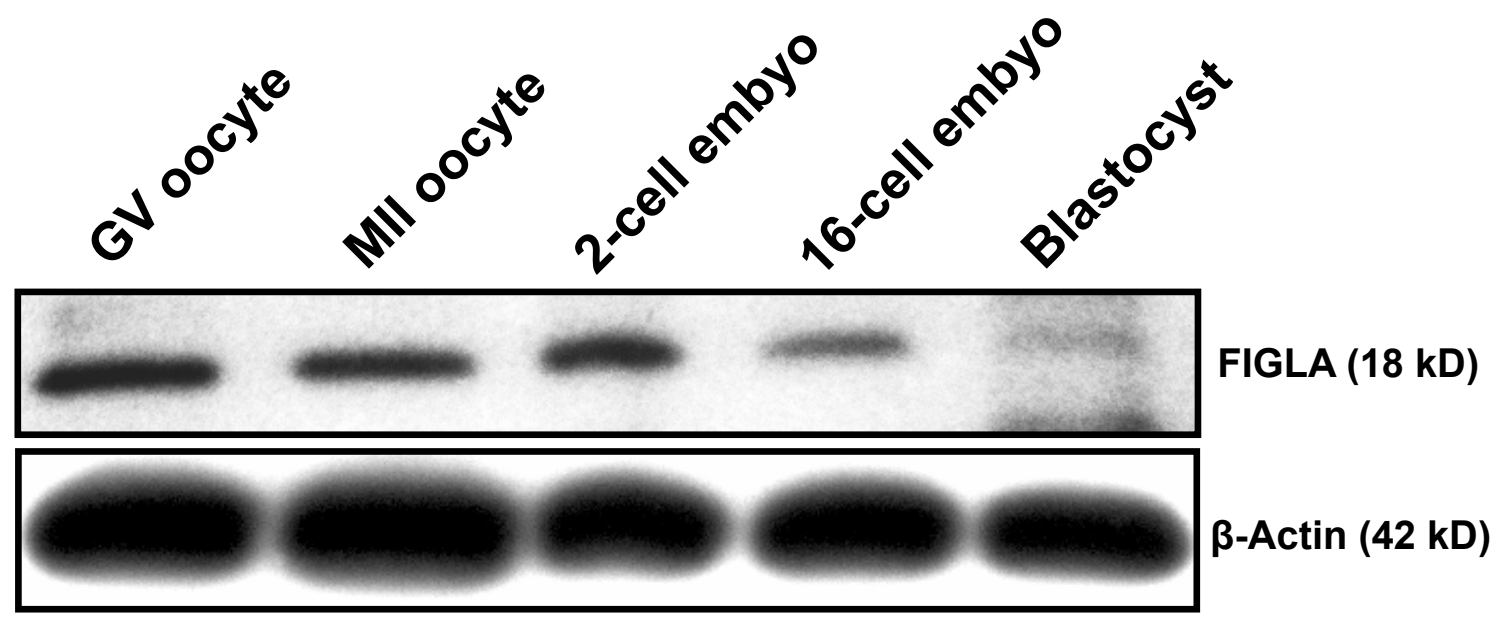

Figure 3. Spatiotemporal expression of FIGLA mRNA and protein during oocyte maturation and early embryonic development. A) Analysis of steady-state levels of FIGLA mRNA in in vitro produced bovine pre-implantation stage embryos. The oocytes and embryo samples used in 
this experiment included GV- and MIl-stage oocytes, pronuclear (PN), 2-cell (2C), 4-cell (4C), 8cell $(8 \mathrm{C})$, 16-cell $(16 \mathrm{C})$, morula $(\mathrm{MO})$-stage and blastocyst (BL)-stage embryos. Data were normalized relative to abundance to exogenous control (GFP) RNA and as shown as mean \pm SEM ( $n=4$ pools of 10 embryos per stage). Different letters indicate statistical difference $(P<$ 0.05). B) Analysis of FIGLA protein in bovine oocytes and early embryos by Western blot analysis using antibodies specifically against FIGLA (25 oocytes or embryos per lane). 


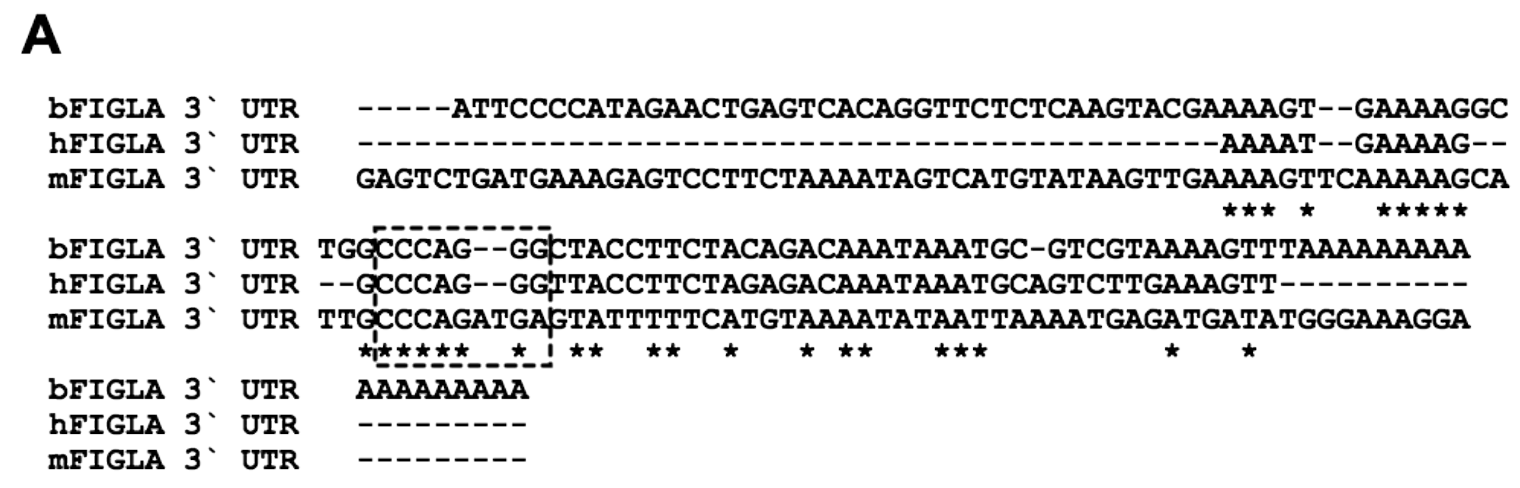

B

$\begin{array}{lll}\text { FIGLA 3'UTR 5' A } & \text { AA G C C } \\ & \text { AGUA AG CUGG CCAGG } \\ \text { bta-miRNA-212 3' } & \text { UCAUU UC GAUC GGUUCC } \\ \text { CG A UC } & \text { A 5' }\end{array}$

Figure 4. miR-212 binding site in FIGLA 3'UTR. A) $3^{\prime}$ UTR alignment of bovine, mouse and human FIGLA cDNA sequences. The outlined box indicates the conserved "seed" region complimentary to miR-212. B) Predicted miR-212 binding site in bovine FIGLA 3'UTR. 

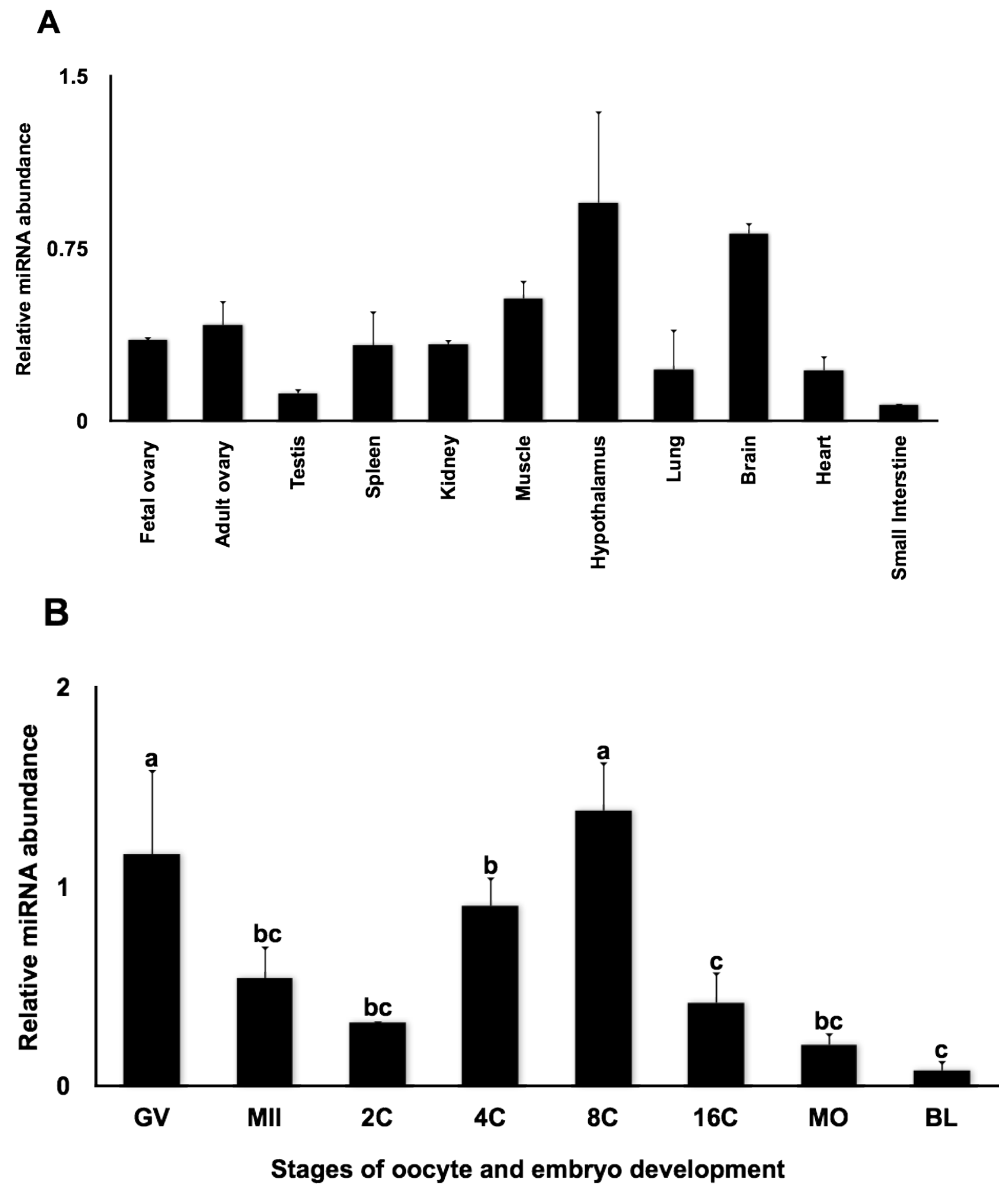

Figure 5. Expression analysis of miR-212. (A) Tissue distribution of miR-212 analyzed by quantitative real-time PCR. Data were normalized to abundance of RPS18 mRNA and 
abundance expressed as relative fold change using the sample with the lowest value as the calibrator ( $n=4$ per tissue; mean \pm SEM depicted). (B) Realtive abundance of miR-212 in bovine oocytes and in vitro produced bovine embryos. Data were normalized to abundance of miR-125b mRNA and expressed as relative fold change using the sample with the lowest value as the calibrator ( $n=4$ pools of five oocytes/embryos each; mean \pm SEM depicted). Different letters indicate statistical difference $(P<0.05)$. 


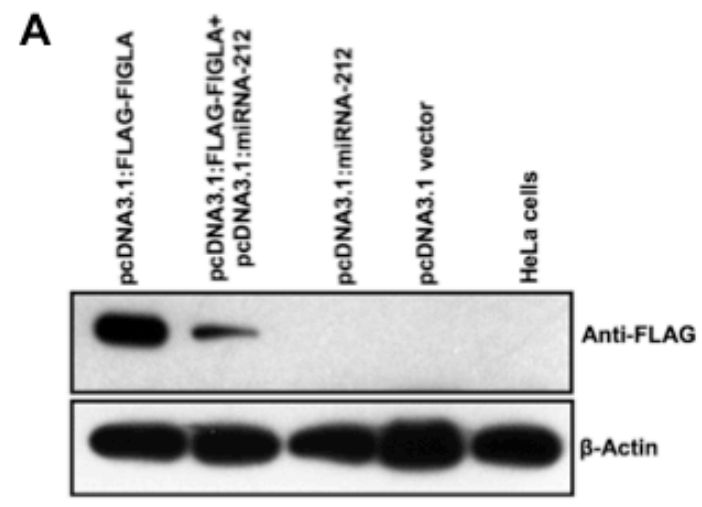

B
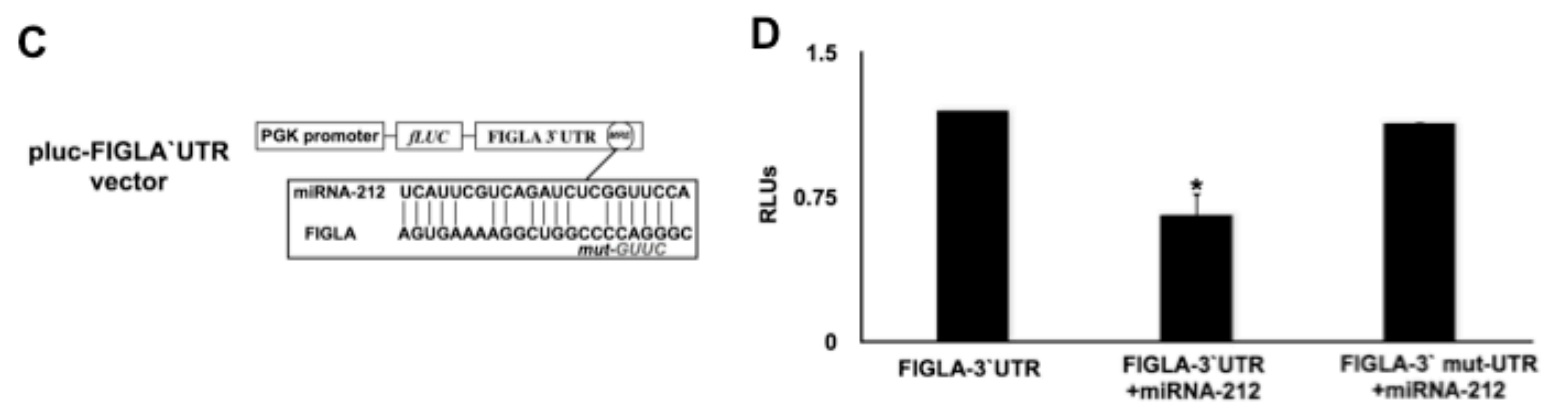

Figure 6. Specific regulation of FIGLA by miR-212 in vitro in HeLa cells. (A) Western blot showing significant downregulation of bovine FIGLA protein by ectopic expression of miR-212 in HeLa cells. $\beta$ - Actin was used as a loading control. (B) The protein levels were quantified from the western blots by densitometry, normalized to the $\beta$-Actin level and presented as fold change \pm SEM $(n=4)$ relative to the FIGLA level of mock transfected cells. (C) Diagram of luciferase reporter construct with putative miR-212 binding site and mutations in the $3^{\prime}$ UTR of FIGLA. (D) Repression of luciferase activity due to specific interaction between miR-212 and the predicted MRE in the luciferase-FIGLA-3 UTR constructs. Repression was abolished when the MRE was mutated. Relative firefly luciferase values were determined by a ratio of firefly to renilla luciferase with the negative control (cells transfected with native FIGLA-3 'UTR construct alone) set at 1 . Each group represents the mean \pm SEM of four wells for an experiment 
repeated six times with similar results. 
A

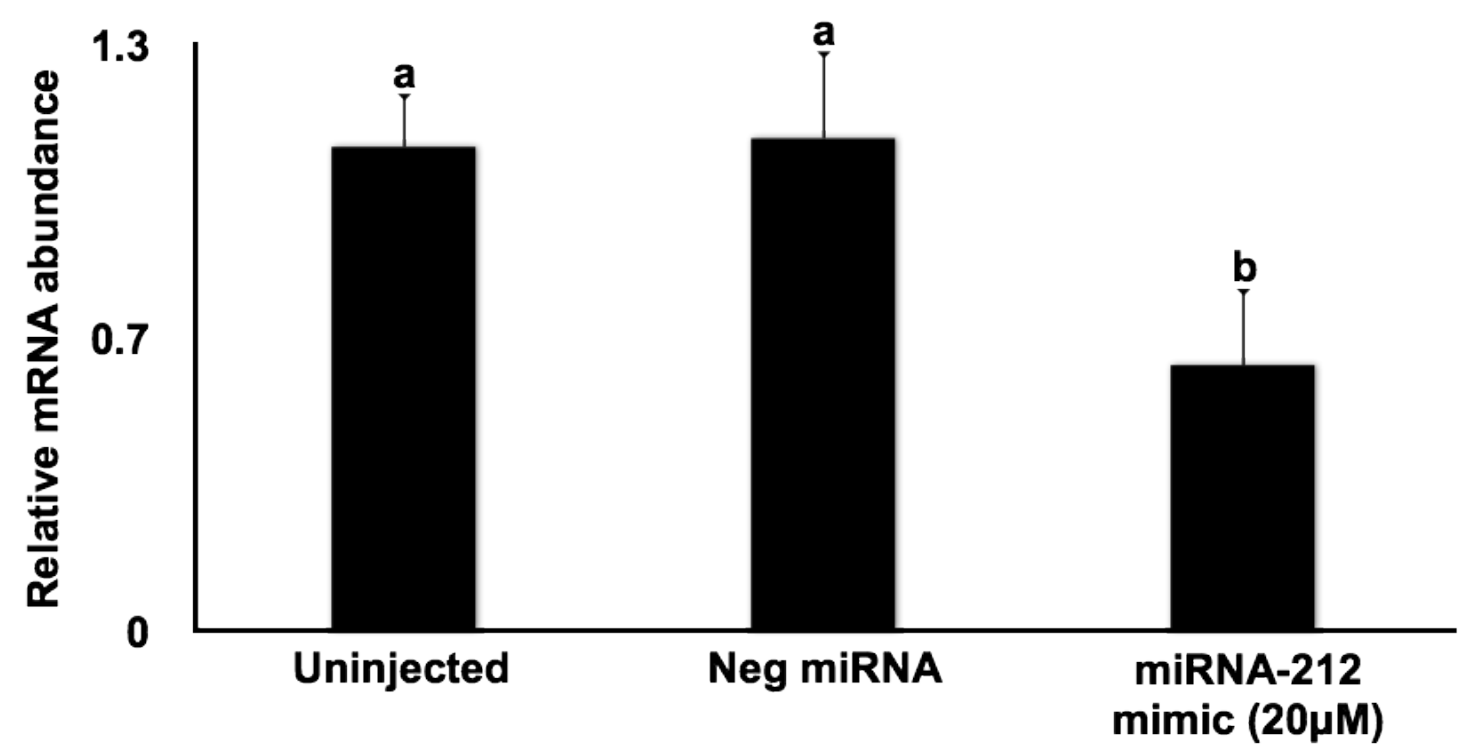

B

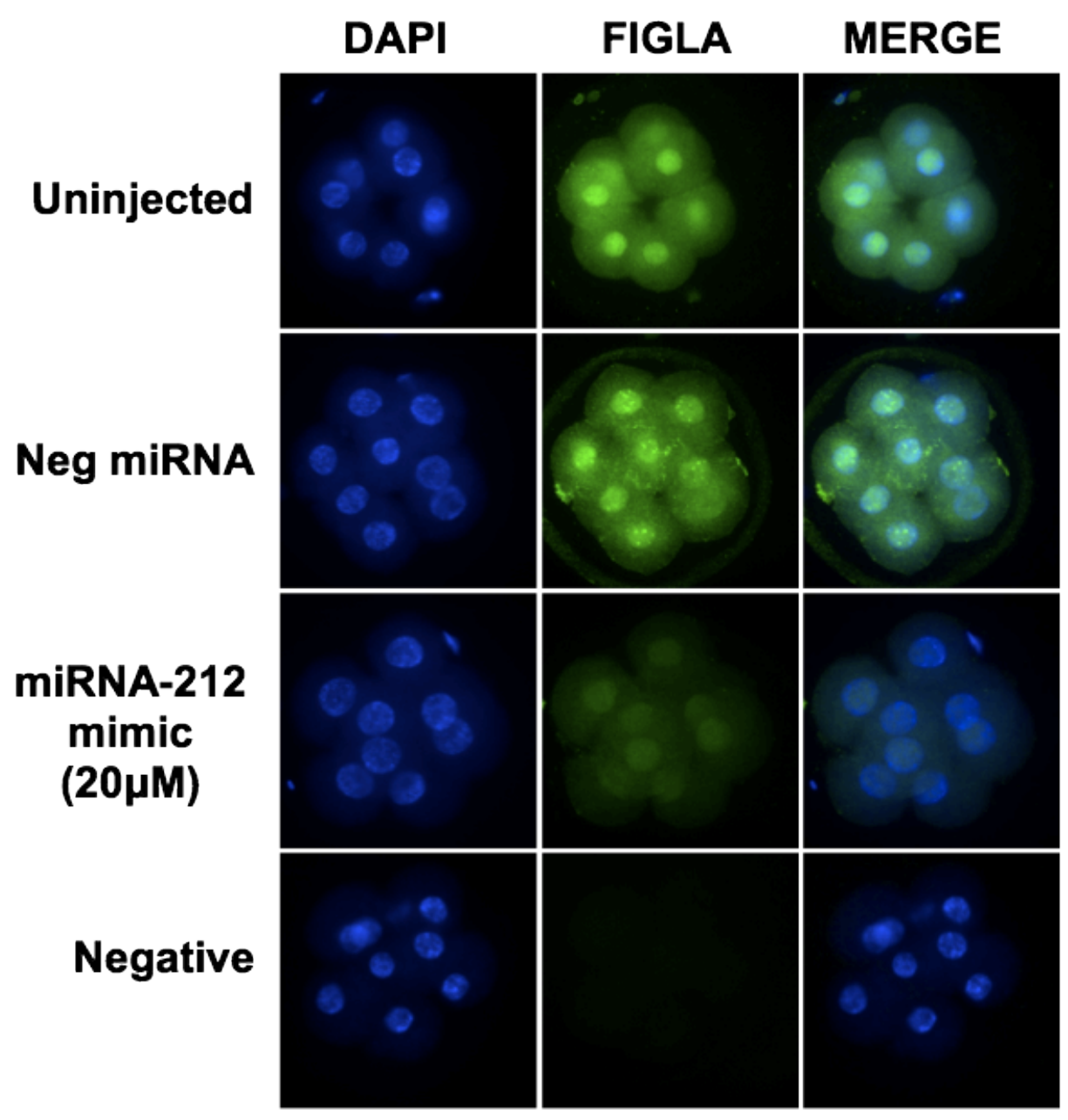


Figure 7. miR-212 represses endogenous FIGLA expression in early embryos. (A) Effect of miR-212 mimic $(20 \mu \mathrm{M})$ microinjection on abundance of FIGLA mRNA in eight-cell embryos as determined by quantitative real-time PCR. Data were normalized relative to abundance of endogenous control ribosomal protein S18 (RSP18) and are shown as mean \pm SEM ( $n=4$ pools of 10 embryos per treatment). Different letters indicate statistical difference $(P<0.05)$. (B) Effect of miR-212 mimic $(20 \mu \mathrm{M})$ microinjection on abundance of FIGLA protein in eight-cell embryos as determined by immuofluorescent staining with anti-FIGLA antibody $(n=4$ pools of 5-10 embryos per treatment). Uninjected embryos and embryos injected with a nonspecific miRNA (Neg miRNA) were used as controls. Nuclear DNA was stained with DAPI. 


\section{REFERENCES}

Bettegowda, A., Yao, J., Sen, A., Li, Q., Lee, K.-B., Kobayashi, Y., Patel, O.V., Coussens, P.M., Ireland, J.J., Smith, G.W., 2007. JY-1, an oocyte-specific gene, regulates granulosa cell function and early embryonic development in cattle. Proc Natl Acad Sci USA 104, 17602-17607.

Brennecke, J., Stark, A., Russell, R.B., Cohen, S.M., 2005. Principles of microRNA-target recognition. PLoS Biol 3, e85.

Giraldez, A.J., Mishima, Y., Rihel, J., Grocock, R.J., Van Dongen, S., Inoue, K., Enright, A.J., Schier, A.F., 2006. Zebrafish MiR-430 promotes deadenylation and clearance of maternal mRNAs. Science 312, 75-79.

Gosden, R.G., 2002. Oogenesis as a foundation for embryogenesis. Mol Cell Endocrinol 186, 149-153.

Joshi, S., Davies, H., Sims, L.P., Levy, S.E., Dean, J., 2007. Ovarian gene expression in the absence of FIGLA, an oocyte-specific transcription factor. BMC Dev Biol 7, 67.

Lewis, B., Shih, I., Jones-Rhoades, M., Bartel, D., Burge, C., 2003. Prediction of mammalian microRNA targets. Cell 115, 787-798.

Lund, E., Liu, M., Hartley, R.S., Sheets, M.D., Dahlberg, J.E., 2009. Deadenylation of maternal mRNAs mediated by miR-427 in Xenopus laevis embryos. RNA 15, 2351-2363.

Pennetier, S., Perreau, C., Uzbekova, S., Thélie, A., Delaleu, B., Mermillod, P., Dalbiès-Tran, R., 2006. MATER protein expression and intracellular localization throughout folliculogenesis and preimplantation embryo development in the bovine. BMC Dev Biol 6, 26.

Pennetier, S., Uzbekova, S., Perreau, C., Papillier, P., Mermillod, P., Dalbiès-Tran, R., 2004. Spatio-temporal expression of the germ cell marker genes MATER, ZAR1, GDF9, BMP15,andVASA in adult bovine tissues, oocytes, and preimplantation embryos. Biology of Reproduction 71, 1359-1366.

Rusinov, V., Baev, V., Minkov, I.N., Tabler, M., 2005. Microlnspector: a web tool for detection of miRNA binding sites in an RNA sequence. Nucleic Acids Res 33, W696-700. 
Soyal, S.M., Amleh, A., Dean, J., 2000. FIGalpha, a germ cell-specific transcription factor required for ovarian follicle formation. Development 127, 4645-4654.

Tang, F., Kaneda, M., O'Carroll, D., Hajkova, P., Barton, S.C., Sun, Y.A., Lee, C., Tarakhovsky, A., Lao, K., Surani, M.A., 2007. Maternal microRNAs are essential for mouse zygotic development. Genes Dev 21, 644-648.

Tejomurtula, J., Lee, K.-B., Tripurani, S.K., Smith, G.W., Yao, J., 2009. Role of importin alpha8, a new member of the importin alpha family of nuclear transport proteins, in early embryonic development in cattle. Biology of Reproduction 81, 333-342.

Tripurani, S.K., Lee, K.-B., Wang, L., Wee, G., Smith, G.W., Lee, Y.S., Latham, K.E., Yao, J., 2011. A Novel Functional Role for the Oocyte-Specific Transcription Factor Newborn Ovary Homeobox (NOBOX) during Early Embryonic Development in Cattle. Endocrinology 152, 10131023.

Tripurani, S.K., Xiao, C., Salem, M., Yao, J., 2010. Cloning and analysis of fetal ovary microRNAs in cattle. Animal Reproduction Science 120, 16-22. 
APPENDIX-2 


\title{
The SUMO-conjugating enzyme Ubc9 is developmentally
}

\section{regulated and interacts with activating transcription factor 7}

\section{interacting protein 2 (ATF7IP2) in cattle}

\author{
Swamy K Tripurani ${ }^{1}$, Lei Wang ${ }^{1}$, Kyung-Bon Lee ${ }^{2,3}$, Gabbine Wee ${ }^{2,3}$, George W. Smith ${ }^{2,3,4}$, \\ Jianbo $\mathrm{Yao}^{1^{*}}$ \\ ${ }^{1}$ Laboratory of Animal Biotechnology and Genomics, Division of Animal and Nutritional Sciences, West \\ Virginia University, Morgantown, WV 26506. \\ ${ }^{2}$ Laboratory of Mammalian Reproductive Biology and Genomics, Departments of Animal Science ${ }^{3}$ and \\ Physiology ${ }^{4}$, Michigan State University, East Lansing, Michigan 48824.
}

KEYWORDS: Ubc9, SUMOylation, oocyte, early embryogenesis, ATF7IP2 and Yeast two hybrid

\section{AUTHOR'S CONTRIBUTIONS}

SKT designed and performed most of the experiments including cloning and expression analysis of Ubc9 and ATF7IP2, preparation of constructs and yeast-two hybrid analysis. SKT also drafted the manuscript. KBL and GW helped to collect embryo samples. LW assisted for yeast-two hybrid experiment. GWS and JY designed the study and supervised the experimental work. 


\section{ABSTRACT}

Sumoylation is a posttranslational modification in which a SUMO (small-ubiquitin-related modifier) moiety is conjugated to specific proteins involved in transcriptional regulation, protein transport, chromosome segregation and signal transduction via an enzymatic cascade. A central component of this cascade is the SUMO-conjugating enzyme Ubc9, which is highly conserved across species and is essential for several developmental processes such as cell cycle regulation, chromosome segregation, cell viability and maintenance of nuclear integrity. However the connection between these developmental roles of Ubc9 and its function during oocyte and early embryonic development remains largely unknown. As the first step towards understanding the physiological role of bovine Ubc9, we analyzed the expression of Ubc9 mRNA in bovine tissues including fetal ovaries of different developmental stages, and characterized the temporal expression patterns of Ubc9 mRNA and protein during oocyte maturation and early embryogenesis. Bovine Ubc9 is ubiquitously expressed in all tissues and can be detected in fetal ovaries as early as 90 days of gestation, and is highly abundant in fetal ovaries of late gestation. Real time PCR analysis and immunocytochemical analysis demonstrated that expression of Ubc9 mRNA and protein is abundant in germinal vesicle (GV) and metaphase II (MII) stage oocytes, as well as in early embryos, but decreases between 8cell and blastocyst stage, suggesting that Ubc9 might be a maternal effect gene. In order to define the molecular mechanisms of Ubc9-dependent biological processes during oogenesis in cattle, we performed yeast two-hybrid assay to identify putative SUMO substrates from a bovine fetal ovary library using Ubc9 as bait. A total of 19 interacting clones were identified including 3 clones encoding activating transcription factor 7 interacting protein 2 (ATF7IP2). Inspection of the ATF7IP2 sequence using SUMOsp 2.0 software program predicted two high probability putative SUMO attachment sites, indicating that ATF7IP2 is a potential SUMO substrate. Real time PCR analysis revealed that ATFIP2 is gonad specific and expression of ATFIP2 mRNA can be detected in fetal ovaries harvested as early as 90 days of gestation and tends to increase 
with increased gestational age. Further analysis using RNA isolated from oocytes, granulosa and cumulus cells of antral follicles indicates that bovine ATF7IP2 mRNA is expressed in oocytes and in surrounding follicular cells. ATF7IP2 is stage-specifically expressed during oocyte maturation and early embryonic development. Collectively, our results suggest that Ubc9 is developmentally regulated in cattle and it interacts with ATF7IP2, a gonad-specific protein, which might play an important role in oocyte development and early embryonic development. 


\section{INTRODUCTION}

Post-translation modification of proteins is an important regulatory mechanism of protein function. In addition to ubiquitin, recently the small ubiquitin-like modifier (SUMO) has been shown to reversibly modify many proteins important for a wide range of cellular processes, including gene transcription, cell cycle, protein stability, nuclear localization, signal transduction, protein-protein interactions and chromatin dynamics (Geiss-Friedlander and Melchior, 2007). SUMO constitutes a highly conserved protein family and are ubiquitously expressed throughout the eukaryotic kingdom. Simple eukaryotes such as yeast, worms and flies have a single SUMO gene, whereas plants and vertebrates express several SUMO proteins. Till date, four SUMO family members, SUMO-1 to SUMO-4 have been found in mammals. SUMO proteins are $10 \mathrm{kD}$ in size and share only $\sim 18 \%$ sequence identity with ubiquitin, but the three-dimensional structure of SUMO is similar to ubiquitin (Melchior, 2000). SUMO-2 and SUMO-3 are $97 \%$ similar to each other and are $50 \%$ identical to SUMO-1 protein that is the most studied (Melchior, 2000). SUMO 1, 2 and 3 are ubiquitously expressed in all tissues and at all developmental stages, whereas SUMO-4 expression is restricted to kidneys and spleen (GeissFriedlander and Melchior, 2007). SUMOylation, the conjugation of SUMO peptide to the target protein, results in the formation of an isopeptide bond between the C-terminal glycine residue of the modifier protein and the $\varepsilon$-amino group of a lysine residue in the acceptor protein by a series of enzymatic reactions similar to those involved in the ubiquitination (Johnson, 2004). SUMOylation is a highly conserved pathway from yeast to humans and mostly targets proteins that contains a consensus motif $\psi \mathrm{KXE}$, where $\psi$ represents a large hydrophobic amino acid, $\mathrm{K}$ is the SUMO attachment site, $\mathrm{X}$ is any residue and $\mathrm{E}$ is a glutamic acid (Johnson, 2004). Unlike ubiquitination, which targets proteins for degradation, SUMOylation affects the target proteins intercellular localization, interactions, stability and activity (Hay, 2005). 
A number of studies indicate that SUMO proteins are essential for diverse reproductive functions, including gametogenesis, ovulation and steroid receptor activity (Broday et al., 2004; Jones, 2006; Abdel-Hafiz et al., 2009; Wang et al., 2010). SUMO-conjugating enzyme, Ubc9 a central component of the SUMOylation pathway has been reported to affect various cellular processes during embryonic development in various organisms. Early studies in drosophila found that loss of Ubc9 have multiple defects in anterior segmentation due to misregulation of the segmentation genes during the drosophila embryogenesis (Epps and Tanda, 1998). RNAimediated knockdown of Ubc9 in C.elegans resulted in the embryonic arrest after gastrulation and pleiotrophic defects in larval development such as vulval eversion at the fourth larval stage and abnormal tail morphology (Jones et al., 2002). Expression of dominant-negative version of Ubc9 in zebrafish embryos leads to early embryonic apoptosis and inactivation of zygotic Ubc9 function causes more specific developmental defects in brain, eyes and pharyngeal arches due to defects in cell cycle (Nowak and Hammerschmidt, 2006). Furthermore, Ubc9-deficient mouse embryos die at the early postimplantation stage due to severe defects in the nuclear organization and chromosome segregation (Nacerddine et al., 2005). Together, these studies indicate that Ubc9 is essential for the normal development of both vertebrate and invertebrate metazoans. However the connection between these developmental roles of Ubc9 and its function during mammalian oogenesis remains largely unknown.

In recent years, cattle has been recognized as a potential model system for comparative genomics and biomedical research, because cattle and humans have similarities in many aspects of their biochemistry, physiology, reproduction and pathology (Malhi et al., 2005; Gibs et al., 2006). Despite the recognized importance of Ubc9 in regulating gene expression during development and other biological processes, there has been little information about the impact of Ubc9 on developmental programs in cattle. In this study, as the first step towards understanding the physiological role of Ubc9, we analyzed the expression of Ubc9 mRNA in bovine tissues including fetal ovaries of different developmental stages, and characterized the 
temporal expression patterns of Ubc9 mRNA and protein during oocyte maturation and early embryogenesis. Furthermore, to define the molecular mechanisms of Ubc9-dependent biological processes during oogenesis in cattle, we performed yeast two-hybrid assay to identify putative SUMO substrates from a bovine fetal ovary library using Ubc9 as bait.

\section{MATERIALS AND METHODS}

\section{Tissue collection, RNA preparation and cDNA synthesis}

Bovine tissue samples including fetal ovary, adult ovary, adult testis, liver, lung, kidney, small intestine and spleen were obtained at a local slaughterhouse. Fetal age was estimated based on crown-rump length (Richardson et al., 1990). Granulosa and cumulus cells were isolated from antral follicles according to a previously established method (Murdoch et al., 1981; Bettegowda et al., 2008). All samples were frozen in liquid nitrogen and stored at $-80^{\circ} \mathrm{C}$ until use. Total RNA was isolated using the TRIzol reagent (Invitrogen, Carlsbad, CA) according to the manufacturer's instruction. Concentrations of isolated RNA were determined by measuring absorbance at $260 \mathrm{~nm}$ using a Nanodrop spectrophotometer (Thermo Scientific, Wilmington, DE). Purity of RNA was determined by calculating the ratio of absorbance at $260 \mathrm{~nm}$ and 280 $\mathrm{nm}$, and integrity of RNA was determined by agarose gel electrophoresis. After treatment with TURBOTM DNasel (Ambion, Inc., Austin, TX), reverse transcription was performed on approximately two micrograms of isolated RNA in $20 \mu$ l of reaction solution using oligo d(T) 18 primer and Superscript III reverse transcriptase (Invitrogen).

\section{Quantitative Real-Time PCR Assay}

The quantification of Ubc9 and ATF7IP2 transcripts was done by real-time quantitative RT-PCR using iQ SYBR Green Supermix (Bio-Rad). Ribosomal protein S18 (RPS18) gene was 
used as an endogenous control. Primers are listed in the supplemental table 1 and were designed using primer 3 input software. Each reaction mixture consisted of $2 \mu$ of cDNA, $1.5 \mu l$ of forward primer $(10 \mu \mathrm{M})$ and reverse primer $(10 \mu \mathrm{M}), 7.5 \mu \mathrm{l}$ of nuclease free water and $12.5 \mu \mathrm{l}$ of iQ SYBR Green Supermix in a total reaction volume of $25 \mu \mathrm{l}$. Reactions were performed in triplicates for each sample on a Bio-Rad CFX 96 ${ }^{\mathrm{TM}}$ Real-Time PCR Detection System (BioRad). Cycling parameters were $95^{\circ} \mathrm{C}$ for $10 \mathrm{~min}$, and then 40 cycles of $95^{\circ} \mathrm{C}$ for $15 \mathrm{~s}, 60{ }^{\circ} \mathrm{C}$ for 30s. Standard curves for each gene and controls were constructed using tenfold serial dilutions of corresponding plasmids containing cDNA inserts for Ubc9, ATF7IP2 and RPS18 [vector pGEM-T Easy (Promega)] and run on same plate as samples. For each sample, the quantity of the mRNA for Ubc9 and ATF7IP2 and the reference gene mRNA (RPS18) was determined from the appropriate standard curves. The quantity of the Ubc9 and ATF7IP2 mRNA was then divided by the quantity of the reference gene to obtain a normalized value. The expression of Ubc9 and ATF7IP2 mRNA was then expressed as relative fold change.

\section{Quantification of Ubc9 and ATF7IP2 mRNA in oocytes and early embryos}

For quantitative measurement of Ubc9 and ATF7IP2 mRNA expression during oocyte maturation and early embryonic development, real-time PCR was performed. The oocytes and embryo samples used in the experiment included GV- and MII-stage oocytes and pronuclear, two-cell, four-cell, eight-cell, 16-cell, and morula- and blastocyst-stage embryos were generated by in vitro maturation, in vitro fertilization and embryo culture of abattoir-derived oocytes as described previously (Bettegowda et al., 2006). Procedures used for RNA isolation, cDNA synthesis, and quantitative real-time PCR analysis of mRNA abundance during oocyte maturation and early embryonic development were conducted as described previously (Bettegowda et al., 2006; Tejomurtula et al., 2009).

\section{Immunocytochemistry}


Localization of Ubc9 protein in oocytes and early embryos was performed according to previously published procedure (Tripurani et al., 2011) using a rabbit monoclonal anti-Ubc9 antibody (1:50 dilution; ab75854; Abcam, Cambridge, MA). At least 10 oocytes/embryo were processed for each stage per treatment, and experiments were replicated at least three times. For negative control, the oocytes and embryos were incubated in the absence of anti-Ubc9 antibody.

\section{Yeast two-hybrid assay}

Yeast two-hybrid screening of a cDNA library from bovine fetal ovary using bovine Ubc9 as the bait was carried out using a Matchmaker ${ }^{\mathrm{TM}}$ Gold Yeast Two-Hybrid System (Clontech Laboratories, Inc., Mountain View, CA, USA) according to the manufacturer's instructions. The bait construct pGBKT7-53-Ubc9 encoding the entire open reading frame of Ubc9 (477bp) fused in frame to the GAL4 DNA binding domain was constructed by inserting the PCR-generated fragment into the Ndel and the BamHI sites of the pGBKT7-53. The bovine fetal ovary cDNA

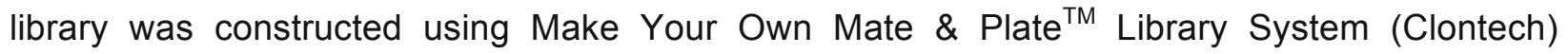
according to the manufacturer's instructions. Yeast strain $\mathrm{Y} 2 \mathrm{H}$ Gold strain was co transformed with pGBKT7-53-Ubc9 and pGADT7-Rec plasmid bovine fetal ovary cDNA library using Yeastmaker $^{\mathrm{TM}}$ Yeast Transformation System 2 (Clontech). The binding specificities of the isolated prey clones were checked after cotransformations by growth on high-stringency selective yeast media. Plasmid DNA from prey yeast clones was extracted using Easy Yeast Plasmid Isolation Kit (Clontech) and sequenced. $\beta$-Galactosidase Liquid Assay was performed to test the specificity of the interaction according to the method described in the manual of the Matchmaker $^{\mathrm{TM}}$ Gold Yeast Two-Hybrid System (Clontech).

\section{Statistical analysis}


Differences in the Ubc9 and ATF7IP2 mRNA abundance were analyzed by one-way ANOVA using the general linear models (GLM) procedure of SAS.

\section{RESULTS AND DISCUSSION}

\section{Expression analysis of Ubc9}

The bovine Ubc9 mRNA sequence was used as a template to design gene-specific primers (Table 1) for expression analysis. To determine the tissue distribution of UBC9, quantitative real-time PCR was performed in cDNA derived from multiple bovine tissues. As shown in Fig. 1A, UBC9 transcripts were expressed ubiquitously expressed in bovine tissues including fetal and adult ovaries, consistent with the expression pattern observed in mouse (Azuma et al., 2001), rat (Golebiowski et al., 2003) and human (Yasugi and Howley, 1996), indicating that SUMOylation pathway is evolutionary conserved and functional in most organs. Among developing ovaries, bovine Ubc9 expression is observed as early as 90 days of gestation (when primordial follicles first observed), and is highly abundant in the fetal ovaries of late gestation (Fig. 1B). Recently Marongiu et al (Marongiu et al., 2010) reported that Ubc9 is co-expressed with FOXL2, a forkhead transcription factor essential factor in the ovarian function in the mouse ovarian follicles at different development stages of development, suggesting that Ubc9 may function during follicular development. Further, Ubc9 was expressed in GV oocytes and surrounding follicular cells (granulosa and cumulus cells (Fig. 1C).

The mRNA and protein expression of the bovine Ubc9 during oocyte maturation and early embryonic development was determined by quantitative real-time PCR and immunocytochemistry. Ubc9 mRNA and protein was found to be highly abundant in the GV and MII-stage oocytes, as well as at early developmental stages (between pronuclear and eight-cell stages) and further downregulated at 16-cell, morula and blastocyst stages (Fig. 1D, E). The expression pattern of Ubc9 mRNA and protein is similar to a number of known maternal effect genes (Tong et al., 2000; Burns et al., 2003; Pennetier et al., 2004; Vigneault et al., 2004; 
Bettegowda et al., 2007; Tejomurtula et al., 2009), dynamically regulated during the window from meiotic maturation through embryonic genome activation. Moreover, results from embryo culture experiments in the presence of the transcription inhibitor $\alpha$-amanitin suggest that the Ubc9 gene is maternal/oocyte derived (data not shown). Overall, the expression pattern of bovine Ubc9 i.e. non-reactivation at maternal-to-embryonic transition (MET) and degradation of the protein before implantation, suggests the role of Ubc9 as a maternal effect factor during early embryonic development.

Recent studies in mouse have shown that Ubc9 mRNA is temporally regulated during oocyte growth and preimplantation development (Ihara et al., 2008) and loss of Ubc9 leads to embryonic lethality (Nacerddine et al., 2005). Embryos from Ubc9 deficient mice were able to develop up to blastocyst stage and undergo implantation, likely due to persistence of maternal protein during preimplantation cleavage stages, but they fail to expand and show apoptosis of inner cell mass (Nacerddine et al., 2005). Furthermore, Ubc9 mutant embryos show major chromosome defects and severe alterations in nuclear organization such as disassembled nucleoli and PML nuclear bodies, misshapen nuclei, as well as mislocalized RanGAP1 and Ran (Nacerddine et al., 2005). Together, these studies reveal a major role for Ubc9 and, by implication, the SUMO pathway in embryonic viability, chromosome segregation and nuclear integrity. However, the role of Ubc9 (maternally-derived) during the early cleavage stages, specifically during the maternal-embryonic transition is still unknown and warrants further investigation due to the dynamic nature of UBC9 during development.

\section{Identification of Ubc9 interacting proteins}

The identification of target proteins for small ubiquitin-like modifiers (SUMOs) is the first step towards a detailed understanding of the cellular functions of SUMOs. Recently, numerous proteins have been identified as SUMO target proteins in several model systems such as yeast, C.elegans, D.melanogaster, A.thaliana including mammals (Müller et al., 2001; Li et al., 2004; 
Panse et al., 2004; Vertegaal et al., 2004; Wohlschlegel et al., 2004; Zhang et al., 2004; Zhao et al., 2004; Talamillo et al., 2008; Elrouby and Coupland, 2010). However, the identity, function and regulation of SUMO target proteins during mammalian oogenesis have not been investigated in depth. In order to elucidate the molecular mechanisms of Ubc9-dependent biological processes during oogenesis in cattle, we performed yeast two-hybrid assay to identify putative SUMO substrates from a bovine fetal ovary library using Ubc9 as bait. Yeast-two hybrid method have been used previously to identify and characterize SUMO substrates in various organisms and cell culture systems Müller, 1998, p01733; Giorgino, 2000, p00336; Melchior, 2000, p00351; Bhaskar, 2000, p01732\}. One of the great advantages of this technique is that it not only identifies SUMO-interacting proteins, but also can be adapted so that covalent and noncovalent interactions with SUMO can be distinguished (Hannich et al., 2005). Because Ubc9 is the only known SUMO-conjugating enzyme and can directly conjugate SUMO proteins to the target protein by recognizing and binding to the consensus SUMOylation motif $(\psi \mathrm{KXE})$ in target protein (Sampson et al., 2001), we performed yeast two-hybrid screening using Ubc9 as bait.

A total of 9 yeast clones were identified as a result of their growth in high-stringency medium (SD/-ade/-his/-leu/-trp). Plasmids were rescued from the respective yeast clones and were subjected to DNA sequence analysis. The sequence data revealed that these clones contain inserts with strong homology to five proteins (Table 2). Of the five proteins, RAN binding protein 2 (RANBP2) and E3 SUMO-protein ligase (PIAS1) were previously identified as Ubc9 interacting proteins using different approaches (Mahajan et al., 1997; Schmidt and Müller, 2002; Tatham et al., 2005), whereas the three remaining proteins have not been previously shown to interact with Ubc9. These proteins include activating transcription factor 7 interacting protein 2 (ATF7IP2), lymphocyte cytosolic protein 1 (LCP1) and exosome complex exonuclease RRP45. Further, analysis of protein sequences using SUMOsp 2.0 software program predicted high probability putative SUMO attachment sites in all the five proteins (Table 2) further supporting that they are indeed SUMO substrates. 


\section{Expression analysis of ATF7IP2}

In addition to several known targets of Ubc9, the screen identified a transcriptional regulator known as activating transcription factor 7 interacting protein 2 (ATF7IP2). The complete cDNA sequence (3229 bp) for the novel transcript was obtained by RT-PCR using fetal ovary mRNA. Sequence analysis revealed that the cDNA has an open reading frame encoding a protein of 683 amino acids. The ATF7IP2 gene is located on bovine chromosome 25 and spans approximately $52 \mathrm{~kb}$ of genomic sequence and contains about 10 exons. Analysis of tissue distribution of ATF7IP2 by quantitative real-time PCR revealed that ATF7IP2 is exclusively expressed in both female and male gonads ovarian samples with minor expression in kidney sample (Fig. 2A). Analysis of mRNA expression for ATF7IP2 in fetal ovaries of different developmental stages revealed that the transcript is detectable in fetal ovaries collected at 90 days of gestation (when primordial follicles are first observed in cows) but is highly abundant in fetal ovaries of late gestation (Fig. 2B). ATF7IP2 mRNA is expressed in germinal vesicle oocytes and surrounding follicular cells (granulosa and cumulus cells) (Fig. 2C). Furthermore, quantitative real-time PCR analysis demonstrated that expression of ATF7IP2 mRNA is abundant in germinal vesicle (GV) and metaphase II (MII) stage oocytes, as well as in early embryos, but decreases between 8-cell and blastocyst stage, suggesting that ATF7IP2 might be a maternal effect (Fig. 2D).

\section{CONCLUSION}

Collectively, our results suggest that Ubc9 is developmentally regulated in cattle and it interacts with ATF7IP2, a gonad-specific protein, which might play an important role in oocyte development and early embryonic development. 


\section{ACKNOWLEDGMENTS}

This work was supported by National Research Initiative Competitive Grant \#200835203-19094 from the USDA National Institute of Food and Agriculture (GWS), Agriculture and Food Research Initiative, Competitive Grant \#2009-65203-05706 from the USDA National Institute of Food and Agriculture (JY) and funds from the West Virginia Agricultural and Forestry Experiment Station (Hatch project No. 427). 
Table 1. List of primers used in this study

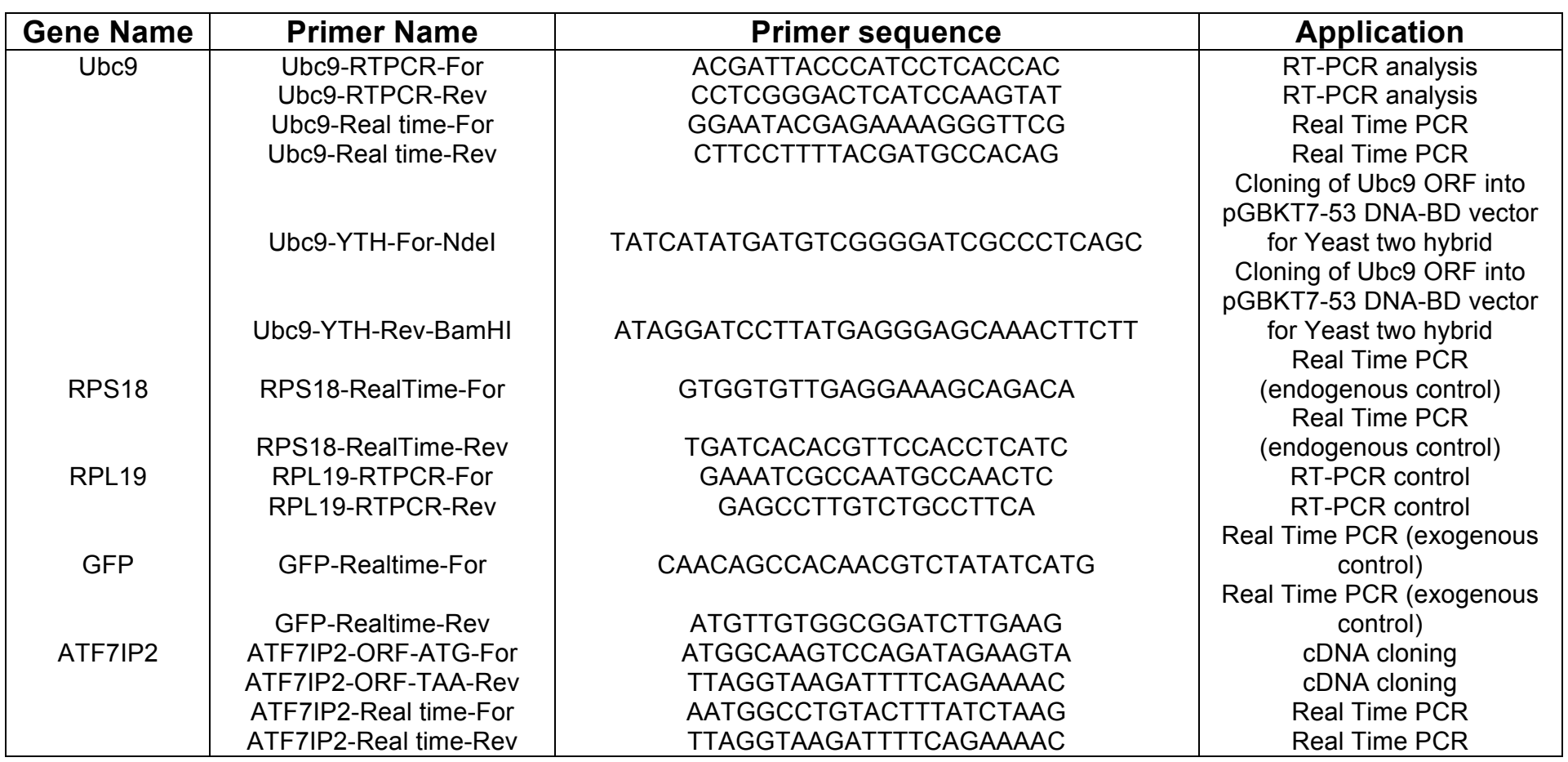


Table 2. Ubc9 interacting proteins (UIP) identified by yeast two-hybrid screening. The SUMOsp 2.0 software program was used to predict and score sumoylation sites within the interacting proteins. The consensus sumoylation site $\psi \mathrm{KXE}$ is underlined in each interacting protein

\begin{tabular}{|c|c|c|c|c|}
\hline CLONE & Gene Name & $\begin{array}{l}\text { Accession } \\
\text { Number }\end{array}$ & $\begin{array}{l}\text { No of } \\
\text { Clones }\end{array}$ & SUMO SITE ( $\underline{\Psi \mathrm{KXE}})$ \\
\hline UIP-1 & $\begin{array}{c}\text { Activating transcription factor } 7 \text { interacting } \\
\text { protein } 2 \text { (ATF7IP2) }\end{array}$ & XP_002698006.1 & 3 & DILKSEE, ET $\underline{\text { VKSET }}$ \\
\hline UIP-2 & RAN binding protein 2 (RANBP2) & DAA24795.1 & 1 & $\frac{\text { EAIKKEM, VTLKNEG, }}{\text { SSVKCEA }}$ \\
\hline UIP-3 & Lymphocyte cytosolic protein 1 (LCP1) & DAA23956.1 & 1 & DLLKTEN \\
\hline UIP-4 & E3 SUMO-protein ligase (PIAS1) & NP_001068864.1 & 3 & LGPKHEL \\
\hline UIP-5 & Exosome complex exonuclease RRP45 & NP_001030225.1 & 1 & TAFKMEK \\
\hline
\end{tabular}


A

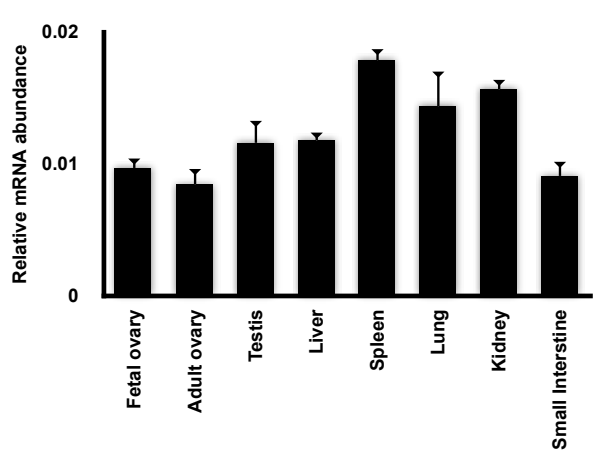

D

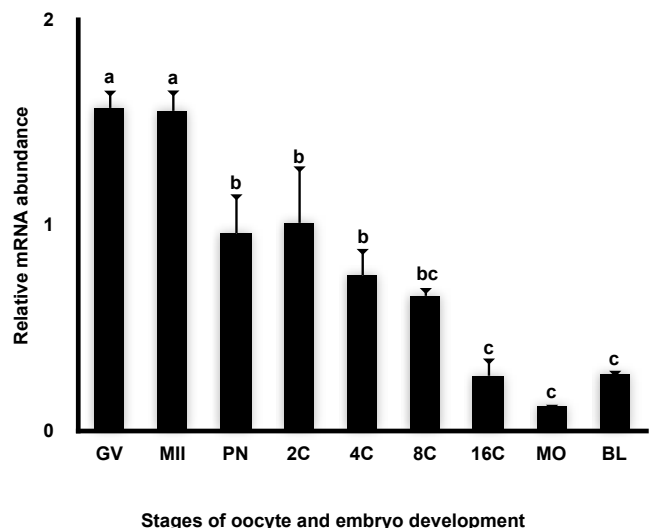

B

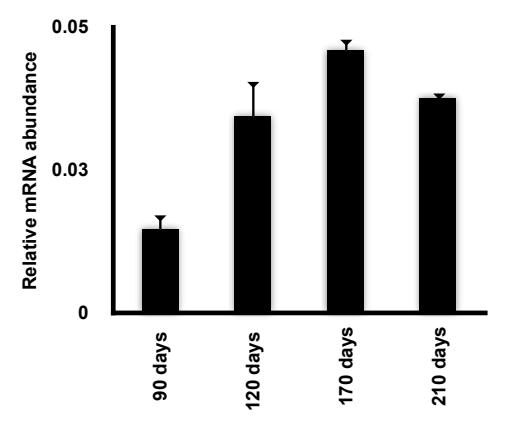

E

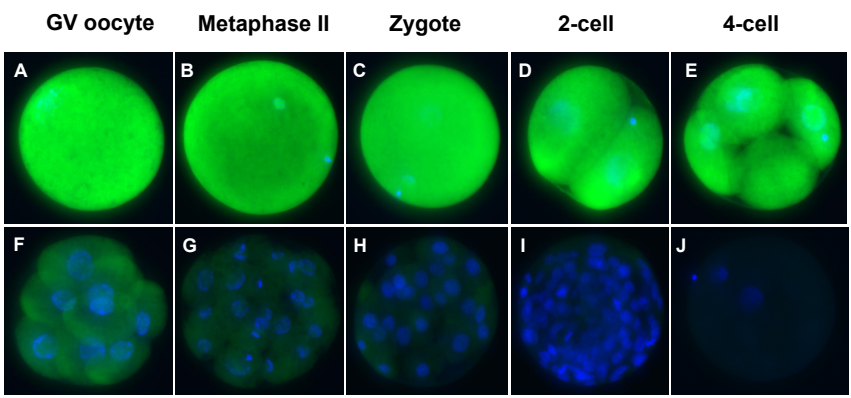

8-cell

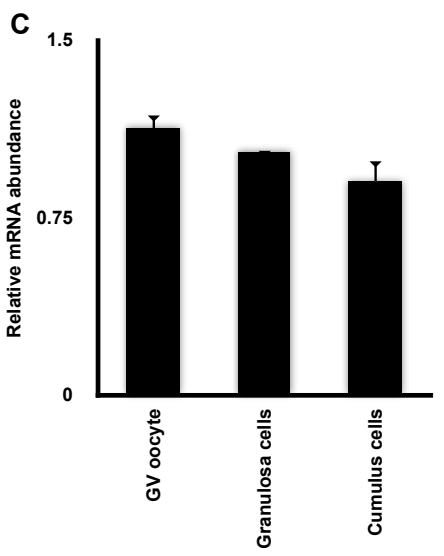

Morula

Neg control

Figure 1. Spatio-temporal expression patterns of bovine Ubc9. A) Ubc9 mRNA expression in various bovine tissues (mean $\pm \mathrm{SEM}, \mathrm{n}=3$ ) determined by quantitative real-time PCR. $B$ ) Quantitative real-time PCR analysis of Ubc9 mRNA expression in bovine fetal ovaries of different developmental stages (mean \pm SEM, $n=3$ ). C) Expression of bovine Ubc9 mRNA in granulosa cells, cumulus cells and germinal vesicle oocytes (mean \pm SEM, $n=3$ ). Bovine RPS18 was used as an endogenous control. D) Relative abundance of Ubc9 expression in bovine oocytes and in vitro produced bovine early embryos. The oocytes and embryo samples used in the experiment included GV- and Mll-stage oocytes, pronuclear (PN), two-cell (2C), four-cell $(4 \mathrm{C})$, eight-cell $(8 \mathrm{C})$, 16-cell (16C), morula (MO)-stage, and blastocyst (BL)-stage embryos. Ubc9 transcript levels were normalized relative to abundance of exogenous control (GFP) RNA and as shown as mean \pm SEM ( $n=4$ pools of 10 embryos per treatment). Different letters 
indicate statistical difference $(P<0.05)$. E) Immunoflorescent localization of Ubc9 protein during oocyte maturation and preimplantation bovine embryos. Nuclear DNA was stained with 4, 6diamidino-2-phenylindole. No staining signal was observed in the embryos incubated in the absence of Ubc9 antibody (panel J). 
A

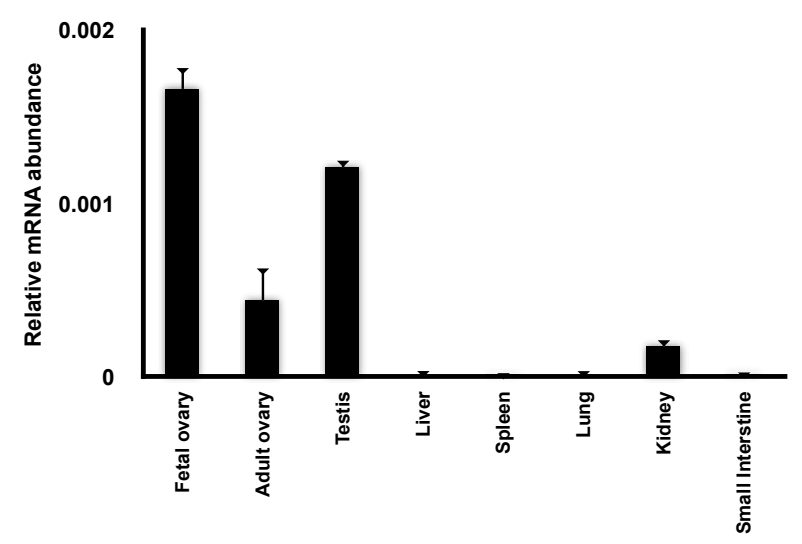

C

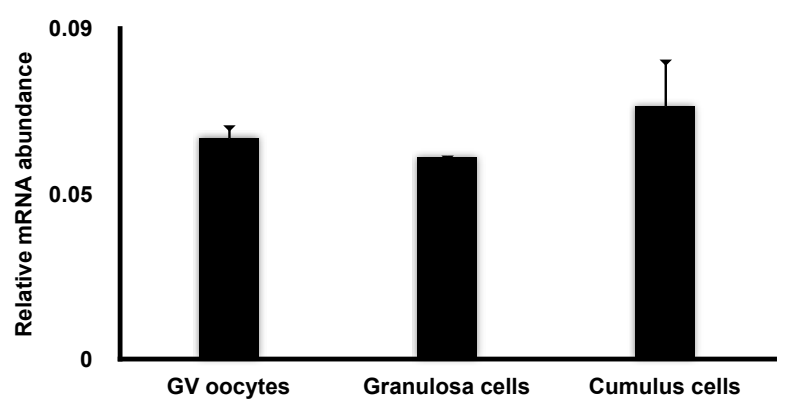

B

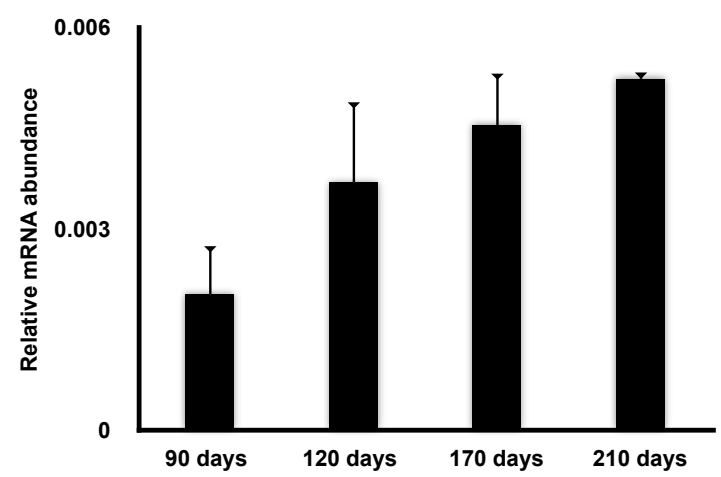

D 0.00003

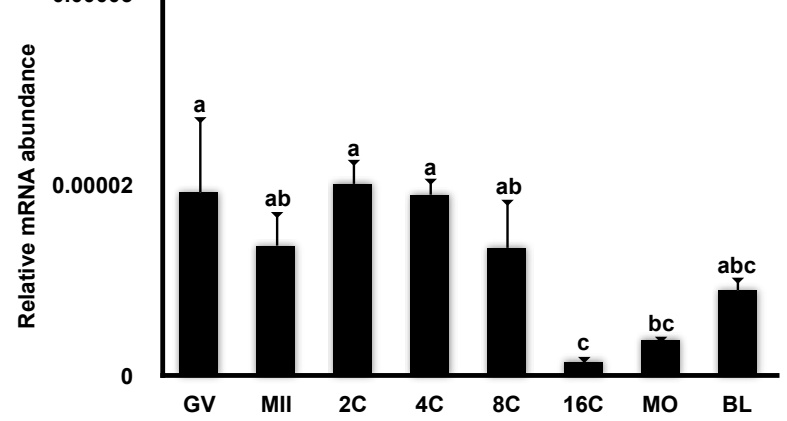

Figure 2. Expression analysis of bovine ATF7IP2. A) Quantitative real-time PCR analysis of ATF7IP2 mRNA expression in various bovine tissues (mean \pm SEM, $n=3$ ). B) ATF7IP2 mRNA expression in bovine fetal ovaries of different developmental stages (mean $\pm S E M, n=3$ ). C) Expression of bovine ATF7IP2 mRNA in granulosa cells, cumulus cells and germinal vesicle oocytes (mean \pm SEM, $n=3$ ). D) Relative abundance of ATF7IP2 expression in bovine oocytes and in vitro produced bovine early embryos. The oocytes and embryo samples used in the experiment included GV- and MII-stage oocytes, pronuclear (PN), two-cell (2C), four-cell (4C), eight-cell (8C), 16-cell (16C), morula (MO)-stage, and blastocyst (BL)-stage embryos ( $n=3$ pools of 25 embryos per treatment; mean \pm SEM). Different letters indicate statistical difference $(P<$ 0.05). Bovine RPS18 was used as an endogenous control. 


\section{REFERENCES}

Abdel-Hafiz, H., Dudevoir, M.L., Horwitz, K.B., 2009. Mechanisms underlying the control of progesterone receptor transcriptional activity by SUMOylation. J Biol Chem 284, 9099-9108.

Azuma, Y., Tan, S., Cavenagh, M., Ainsztein, A., Saitoh, H., Dasso, M., 2001. Expression and regulation of the mammalian SUMO-1 E1 enzyme. Faseb J 15, 1825-1832.

Bettegowda, A., Patel, O., Lee, K., Park, K., Salem, M., Yao, J., Ireland, J., Smith, G., 2008. Identification of novel bovine cumulus cell molecular markers predictive of oocyte competence: functional and diagnostic implications. Biology of Reproduction 79, 301-309.

Bettegowda, A., Patel, O.V., Ireland, J.J., Smith, G.W., 2006. Quantitative analysis of messenger RNA abundance for ribosomal protein L-15, cyclophilin-A, phosphoglycerokinase, beta-glucuronidase, glyceraldehyde 3-phosphate dehydrogenase, beta-actin, and histone $\mathrm{H} 2 \mathrm{~A}$ during bovine oocyte maturation and early embryogenesis in vitro. Mol Reprod Dev 73, 267278.

Bettegowda, A., Yao, J., Sen, A., Li, Q., Lee, K.-B., Kobayashi, Y., Patel, O.V., Coussens, P.M., Ireland, J.J., Smith, G.W., 2007. JY-1, an oocyte-specific gene, regulates granulosa cell function and early embryonic development in cattle. Proc Natl Acad Sci USA 104, 17602-17607.

Broday, L., Kolotuev, I., Didier, C., Bhoumik, A., Gupta, B., Sternberg, P., Podbilewicz, B., Ronai, Z., 2004. The small ubiquitin-like modifier (SUMO) is required for gonadal and uterinevulval morphogenesis Caenorhabditis elegans. Gene Dev 18, 2380-2391.

Burns, K., Viveiros, M., Ren, Y., Wang, P., DeMayo, F., Frail, D., Eppig, J., Matzuk, M., 2003. Roles of NPM2 in chromatin and nucleolar organization in oocytes and embryos. Science 300, 633-636.

Elrouby, N., Coupland, G., 2010. Proteome-wide screens for small ubiquitin-like modifier (SUMO) substrates identify Arabidopsis proteins implicated in diverse biological processes. $\mathrm{P}$ Natl Acad Sci Usa 107, 17415-17420. 
Epps, J.L., Tanda, S., 1998. The Drosophila semushi mutation blocks nuclear import of bicoid during embryogenesis. Curr Biol 8, 1277-1280.

Geiss-Friedlander, R., Melchior, F., 2007. Concepts in sumoylation: a decade on. Nat Rev Mol Cell Biol 8, 947-956.

Gibs, R., Weinstock, G., Kappes, S., Schook, L., Skow, L., Womack, J., 2006. Bovine Genomic Sequencinglnitiative.www.genome.gov/Pages/Research/Sequencing/SeqProposals/BovineSEQ .pdf, 1-12.

Golebiowski, F., Szulc, A., Sakowicz, M., Szutowicz, A., Pawelczyk, T., 2003. Expression level of Ubc9 protein in rat tissues. Acta Biochim Pol 50, 1065-1073.

Hannich, J.T., Lewis, A., Kroetz, M.B., Li, S.-J., Heide, H., Emili, A., Hochstrasser, M., 2005. Defining the SUMO-modified proteome by multiple approaches in Saccharomyces cerevisiae. J Biol Chem 280, 4102-4110.

Hay, R.T., 2005. SUMO: a history of modification. Mol Cell 18, 1-12.

Ihara, M., Stein, P., Schultz, R.M., 2008. UBE2I (UBC9), a SUMO-conjugating enzyme, localizes to nuclear speckles and stimulates transcription in mouse oocytes. Biology of Reproduction 79, 906-913.

Johnson, E.S., 2004. Protein modification by SUMO. Annu Rev Biochem 73, 355-382.

Jones, D., Crowe, E., Stevens, T.A., Candido, E.P.M., 2002. Functional and phylogenetic analysis of the ubiquitylation system in Caenorhabditis elegans: ubiquitin-conjugating enzymes, ubiquitin-activating enzymes, and ubiquitin-like proteins. Genome Biol 3, 0002.0001.

Jones, M.C., 2006. Regulation of the SUMO pathway senitizes differentiating human endometrial stromal cells to progesterone. PNAS, 1-6.

Li, T., Evdokimov, E., Shen, R.-F., Chao, C.-C., Tekle, E., Wang, T., Stadtman, E.R., Yang, D.C.H., Chock, P.B., 2004. Sumoylation of heterogeneous nuclear ribonucleoproteins, zinc finger proteins, and nuclear pore complex proteins: a proteomic analysis. P Natl Acad Sci Usa $101,8551-8556$. 
Mahajan, R., Delphin, C., Guan, T., Gerace, L., Melchior, F., 1997. A small ubiquitin-related polypeptide involved in targeting RanGAP1 to nuclear pore complex protein RanBP2. Cell 88, 97-107.

Malhi, P.S., Adams, G.P., Singh, J., 2005. Bovine model for the study of reproductive aging in women: follicular, luteal, and endocrine characteristics. Biology of Reproduction 73, 45-53.

Marongiu, M., Deiana, M., Meloni, A., Marcia, L., Puddu, A., Cao, A., Schlessinger, D., Crisponi, L., 2010. The forkhead transcription factor Foxl2 is sumoylated in both human and mouse: sumoylation affects its stability, localization, and activity. PLoS ONE 5, e9477.

Melchior, F., 2000. SUMO--nonclassical ubiquitin. Annual review of cell and developmental biology 16,591 .

Müller, S., Hoege, C., Pyrowolakis, G., Jentsch, S., 2001. SUMO, ubiquitin's mysterious cousin. Nature Reviews Molecular Cell Biology, Published online: 01 December 2007; | doi:10.1038/nrm2293 2, 202-210.

Murdoch, W.J., Dailey, R.A., Inskeep, E.K., 1981. Preovulatory changes prostaglandins E2 and F2 alpha in ovine follicles. J Anim Sci 53, 192-205.

Nacerddine, K., Lehembre, F., Bhaumik, M., Artus, J., Cohen-Tannoudji, M., Babinet, C., Pandolfi, P.P., Dejean, A., 2005. The SUMO pathway is essential for nuclear integrity and chromosome segregation in mice. Dev Cell 9, 769-779.

Nowak, M., Hammerschmidt, M., 2006. Ubc9 regulates mitosis and cell survival during zebrafish development. Mol Biol Cell 17, 5324-5336.

Panse, V.G., Hardeland, U., Werner, T., Kuster, B., Hurt, E., 2004. A proteome-wide approach identifies sumoylated substrate proteins in yeast. J Biol Chem 279, 41346-41351.

Pennetier, S., Uzbekova, S., Perreau, C., Papillier, P., Mermillod, P., Dalbiès-Tran, R., 2004. Spatio-temporal expression of the germ cell marker genes MATER, ZAR1, GDF9, BMP15,andVASA in adult bovine tissues, oocytes, and preimplantation embryos. Biology of Reproduction 71, 1359-1366. 
Richardson, C., Jones, P.C., Barnard, V., Hebert, C.N., Terlecki, S., Wijeratne, W.V., 1990. Estimation of the developmental age of the bovine fetus and newborn calf. Vet Rec 126, 279284.

Sampson, D.A., Wang, M., Matunis, M.J., 2001. The small ubiquitin-like modifier-1 (SUMO-1) consensus sequence mediates Ubc9 binding and is essential for SUMO-1 modification. J Biol Chem 276, 21664-21669.

Schmidt, D., Müller, S., 2002. Members of the PIAS family act as SUMO ligases for c-Jun and p53 and repress p53 activity. P Natl Acad Sci Usa 99, 2872-2877.

Talamillo, A., Sánchez, J., Barrio, R., 2008. Functional analysis of the SUMOylation pathway in Drosophila. Biochem Soc Trans 36, 868-873.

Tatham, M.H., Kim, S., Jaffray, E., Song, J., Chen, Y., Hay, R.T., 2005. Unique binding interactions among Ubc9, SUMO and RanBP2 reveal a mechanism for SUMO paralog selection. Nat Struct Mol Biol 12, 67-74.

Tejomurtula, J., Lee, K.-B., Tripurani, S.K., Smith, G.W., Yao, J., 2009. Role of importin alpha8, a new member of the importin alpha family of nuclear transport proteins, in early embryonic development in cattle. Biology of Reproduction 81, 333-342.

Tong, Z., Gold, L., Pfeifer, K., Dorward, H., Lee, E., Bondy, C., Dean, J., Nelson, L., 2000. Mater, a maternal effect gene required for early embryonic development in mice. Nat Genet 26, 267-268.

Tripurani, S.K., Lee, K.-B., Wang, L., Wee, G., Smith, G.W., Lee, Y.S., Latham, K.E., Yao, J., 2011. A Novel Functional Role for the Oocyte-Specific Transcription Factor Newborn Ovary Homeobox (NOBOX) during Early Embryonic Development in Cattle. Endocrinology 152, 10131023.

Vertegaal, A.C.O., Ogg, S.C., Jaffray, E., Rodriguez, M.S., Hay, R.T., Andersen, J.S., Mann, M., Lamond, A.I., 2004. A proteomic study of SUMO-2 target proteins. J Biol Chem 279, 3379133798. 
Vigneault, C., McGraw, S., Massicotte, L., Sirard, M.-A., 2004. Transcription factor expression patterns in bovine in vitro-derived embryos prior to maternal-zygotic transition. Biology of Reproduction 70, 1701-1709.

Wang, Z.-B., Ou, X.-H., Tong, J.-S., Li, S., Wei, L., Ouyang, Y.-C., Hou, Y., Schatten, H., Sun, Q.-Y., 2010. The SUMO pathway functions in mouse oocyte maturation. Cell Cycle 9.

Wohlschlegel, J.A., Johnson, E.S., Reed, S.I., Yates, J.R., 2004. Global analysis of protein sumoylation in Saccharomyces cerevisiae. J Biol Chem 279, 45662-45668.

Yasugi, T., Howley, P.M., 1996. Identification of the structural and functional human homolog of the yeast ubiquitin conjugating enzyme UBC9. Nucleic Acids Research 24, 2005-2010.

Zhang, H., Smolen, G.A., Palmer, R., Christoforou, A., van den Heuvel, S., Haber, D.A., 2004. SUMO modification is required for in vivo Hox gene regulation by the Caenorhabditis elegans Polycomb group protein SOP-2. Nat Genet 36, 507-511.

Zhao, Y., Kwon, S.W., Anselmo, A., Kaur, K., White, M.A., 2004. Broad spectrum identification of cellular small ubiquitin-related modifier (SUMO) substrate proteins. J Biol Chem 279, 2099921002. 


\title{
SWAMY K.TRIPURANI
}

\author{
2868 University Avenue, \#6 \\ Morgantown, WV 26505 \\ (304)-685-8743 \\ e-mail: s.krsna@gmail.com
}

\section{Education}

Ph.D in Genetics and Developmental Biology (Expected graduation date: March 2011)

West Virginia University, Morgantown, WV, USA

Dissertation: Functional analysis and post-transcriptional regulation of oocyte-specific transcription factors during early embryogenesis in cattle.

M.Sc. in Biotechnology, March 2003

Acharya Nagarjuna University, India

B.Sc. in Biochemistry, March 2001

Andhra University, India

\section{Work EXPERIENCE}

\section{----- West Virginia University ------}

Graduate research assistant. Completed four-year research assistantship. Gained experience as an independent researcher and communicated research data into the form of publications and conference proceedings. (Fall 2006 - May 2011).

\section{ICRISAT, Patancheru, India------}

Scientific Officer. Worked for three years at International crop research institute for the semi-arid tropics (ICRISAT), India. Responsibilities included lab management, planning and executing research in relation to the genetic engineering of groundnut for pathogen-derived resistance to virus and nutritional enhancement by over-production of $\beta$-carotenes. (October 2003 - July 2006).

\section{Specialized SkILls}

RT-PCR, PCR, Semi-quantitative PCR, Real-time PCR, plasmid DNA purification/cloning, northern-southernwestern blotting, cDNA/microRNA library construction and screening, microarray, yeast two-hybrid analysis, insitu hybridization, immunohistochemistry, immunocytochemistry, mammalian cell culture, GFP-transient assays, luciferase reporter assays, site-directed mutagenesis, mammalian embryo culture, confocal microscopy, recombinant protein production/purification, RNA\&DNA/protein and protein-protein interaction analyses. 


\section{Publications}

Swamy K. Tripurani, K B. Lee, L. Wang, G. Wee, G.W. Smith Y.S. Lee' K.E. Latham, and J. Yao. 2011. A novel functional role for the oocyte-specific transcriptional factor newborn ovary homeobox (NOBOX) during early embryonic development in cattle. Endocrinology, 152 (3): 1013-1023.

B. Lingenfelter, Swamy K. Tripurani, J. Tejomurtula, G.W. Smith, and J. Yao. 2011. Molecular cloning and expression of bovine nucleoplasmin 2 (NPM2): a maternal effect gene regulated by miR-181a. Reproductive biology and Endocrinology, (DOI: 10.1186/1477-7827-9-40).

Swamy K. Tripurani, K. Nakaminami, K B. Thompson, S V. Crowell, C L. Guy and D T. Karlson. 2011 Spatial and temporal expression of cold-responsive DEAD-box RNA helicases reveals their functional roles during embryogenesis in Arabidopsis thaliana. Plant molecular biology reporter (DOI: 10.1007/s11105-010-0282-1).

Swamy K. Tripurani, G. Wee, K B. Lee, G. W. Smith and J. Yao. MicroRNA-196a regulates bovine newborn ovary homeobox gene (NOBOX) expression during early embryonic development. (Submitted to BMC Developmental Biology).

Swamy K. Tripurani, Xiao.C, M.Salem, and J. Yao.2010. Cloning and analysis of fetal ovary- microRNAs in cattle. Animal Reproduction Science, 120: 16-22

J. Tejomurtula, K B. Lee, Swamy K. Tripurani, G. W. Smith, and J. Yao. 2009. Role of importin alpha8, a new member of the importin alpha family of nuclear transport proteins, in early embryonic development in cattle. Biology of Reproduction 81 (2): 333-342.

Swamy K. Tripurani, N S. Reddy and K R S. Sambasiva Rao. 2003. Green revolution vaccines, edible vaccines. African journal of biotechnology 2 (12): 679-683.

\section{Manuscripts in preparation}

L. Wang, Swamy K. Tripurani, W. Wanna, G.M. Weber, C.E. Rexroad III, and J. Yao. Cloning and characterization of a novel oocyte-specific gene Fbos and its interactions with proteins important for oocyte development in rainbow trout (Oncorhynchus mykiss). (Target journal Molecular Reproduction and Development).

Swamy K. Tripurani, K.B. Lee, G. Wee, G.W. Smith and J. Yao. Cloning and expression of bovine factor in the germline alpha (FIGLA) in oocytes and early embryos: a potential target of microRNA-212. (Target journal Biology of Reproduction)

Swamy K. Tripurani, K.B. Lee, L. Wang, G.W. Smith and J. Yao. The SUMO-conjugating enzyme Ubc9 is developmentally regulated and interacts with activating transcription factor 7 interacting protein 2 (ATF7IP2) in cattle. (Target journal Reproductive biology and endocrinology)

\section{Conference proceedings}


Swamy K. Tripurani, K.B. Lee, L. Wang, G.W. Smith and J. Yao. The SUMO-conjugating enzyme Ubc9 is developmentally regulated and interacts with activating transcription factor 7 interacting protein 2 (ATF7IP2) in cattle. Society for the study of reproduction (SSR) 2011 conference proceedings.

Swamy K. Tripurani, K.B. Lee, G. Wee, G.W. Smith and J. Yao. Cloning and expression of bovine factor in the germline alpha (FIGLA) in oocytes and early embryos: a potential target of microRNA-212. International Embryo Transfer Society (IETS) 2011 conference proceedings. Reproduction, fertility and development 23 (1): 109-109.

Swamy K. Tripurani, G. Wee, K.B. Lee, G.W. Smith and J. Yao. MicroRNA-196a regulates bovine newborn ovary homeobox gene (NOBOX) expression during maternal-zygotic transition. Society for the study of reproduction (SSR) 2010 conference proceedings.

Swamy K. Tripurani, K.B. Lee, L. Wang, G.W. Smith and J. Yao. Cloning and characterization of newborn ovary homeobox gene (NOBOX) in cattle. International Embryo Transfer Society 2010 conference proceedings. Reproduction, fertility and development 22 (1): 160-161.

L. Wang, Swamy K. Tripurani, W. Wanna, G.M. Weber, C.E. Rexroad III, and J. Yao. Fbos, a novel oocytespecific protein, interacts with protein important for oocyte development in rainbow trout (Oncorhynchus mykiss). Society for the study of reproduction (SSR) 2010 conference proceedings.

Kyung-Bon Lee, Swamy K. Tripurani, Jianbo Yao, James J. Ireland, and George W. Smith. Involvement of SMAD signaling in bovine early embryonic development. Society for the study of reproduction 2009 conference proceedings. Biology of Reproduction 81: 232.

Swamy K. Tripurani, Caide Xiao, Mohamed Salem, and Jianbo Yao. Cloning and expression profiling of fetal ovary-expressed microRNAs in cattle. Society for the Study of Reproduction 2009 conference proceedings. Biology of Reproduction 81: 345.

Lei Wang, Swamy K. Tripurani, Warapond Wanna, Gregory M. Weber, Caird E. Rexroad III, and Jianbo Yao. Cloning and characterization of a novel oocyte-specific gene encoding an F-box protein in rainbow trout (Oncorhynchus mykiss). Society for the Study of Reproduction 2009 conference proceedings. Biology of Reproduction 81: 349.

\section{Awards \& Recognitions}

$1^{\text {st }}$ place in student research competition at 2011 International Embryo Transfer Society (IETS) conference.

Recipient of 2010 USDA NRI CSREES merit Award.

Recipient of 2010 Larry Ewing Memorial Trainee Travel Fund.

$2^{\text {nd }}$ place in student research competition at 2010 International Embryo Transfer Society (IETS) conference.

$2^{\text {nd }}$ place in $\mathrm{PhD}$ student poster competition at Davis College Research Day, West Virginia University, 2009. 


\section{References}

1. Dr. Jianbo Yao

Associate Professor of Animal Biotechnology and Genomics

Division of Animal \& Nutritional Sciences

Davis College of Agriculture, Natural Resources and Design

West Virginia University

P.O. Box 6108

Morgantown, WV 26506-6108

(304)-293-2406 ext. 4444

jianbo.yao@mail.wvu.edu

2. Dr. George W. Smith

Professor of Animal Science and Physiology

Michigan State University

1230D Anthony Hall, East Lansing, MI 48824-1225

(517)-432-5401

smithge7@msu.edu

3. Dr. Jed. H Doelling

Associate Professor of Genetics

Division of Plant and Soil Sciences

Davis College of Agriculture, Natural Resources and Design

West Virginia University

PO Box 6108

Morgantown, WV 26506-6108

(304) 293-6023 x4347

jed.doelling@mail.wvu.edu

\section{John $\mathrm{H}$.}

